University of Rhode Island

DigitalCommons@URI

Open Access Dissertations

1982

\title{
THE INTEGRATED RELATIONSHIPS OF PROTRIPTYLINE, THYROID STATUS AND NORADRENERGIC MECHANISMS IN RAT BRAIN
}

\author{
Edward A. Kaiser \\ University of Rhode Island
}

Follow this and additional works at: https://digitalcommons.uri.edu/oa_diss

\section{Recommended Citation}

Kaiser, Edward A., "THE INTEGRATED RELATIONSHIPS OF PROTRIPTYLINE, THYROID STATUS AND NORADRENERGIC MECHANISMS IN RAT BRAIN" (1982). Open Access Dissertations. Paper 154. https://digitalcommons.uri.edu/oa_diss/154

This Dissertation is brought to you for free and open access by DigitalCommons@URI. It has been accepted for inclusion in Open Access Dissertations by an authorized administrator of DigitalCommons@URI. For more information, please contact digitalcommons-group@uri.edu. 
THE INTEGRATED RELATIONSHIPS OF PROTRIPTYLINE, THYROID STATUS AND MORADRENERGIC MECHANISMS

IN RAT BRAIN

BY

EDWARD A. KAISER

A DISSERTATION SUBMITTED IN PARTIAL FULFILLMENT OF THE REQUI: MENTS FOR THE DEGREE OF DOCTOR OF PHILOSOPHY

IN

PHARMACOLOGY

UNIVERSITY OF RHODE ISLAND 
DOCTOR OF PHILOSOPHY THESIS

OF

EDWARD A. KAISER

Approved :

Thesis Committee

Major Professor

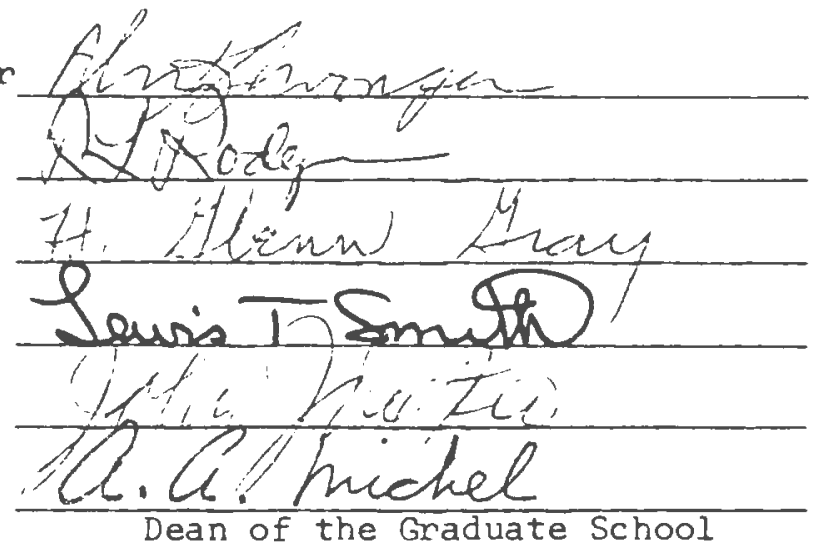

UNIVERSITY OF RHODE ISLAND 
Reasons for the observed lag-time for clinical efficacy of the tricyclic antidepressant drug, protriptyline, have been investigated. Our results demonstrate that chronic protriptyline administration resulte in several compensatory neural mechanisms: (1) changes in endogeneous cytoplasmic norepinephrine levels, (2) changes in norepinephrine turnover rate/recovery rate following the last dose in a chronlc series of test drug administrations and (3) adaptations of the pre-synaptic receptor. The time course for these adaptive changes parallel the time required for the onset of their clinical effectiveness.

We propose that acutely the action of the tricyclics on norepinephrine re-uptake is largely negated by compensatory adjustments in turnover rate of the neurotransmitter; but with chronic administration, adaptations in pre-synaptic alpha-receptors occur. This phenomena in turn reduces the extent to which the norepinephrine neurons can offset or compensate for the blockade of norepinephrine re-uptake. Specifically, pre-synaptic aloha-receptors become hyposensitive, and receptor tolerance develops; not to the direct action of the tricyclic drug on neurotransmitter re-uptake, but to the compensatory neural adjustments which offset the action of the acute tricyclic administration and delay their clinical efficacy. 
I would like to express deepest gratitude to my advisor, Dr. Alvin K. Swonger, for his unending support and encouragenent throughout the entire course of this research.

I an also grateful to Dr. Rupert Hamond for allowing we to use his facilities at Rhode Island Hospital, and also for his valuable professlonal evaluations.

I would also like to acknowledge the following individuals for their assistance in the preparation of this dissertation: Girolano A. Ortolano, Mr. Kenneth R. Hunschel, Jr. and Mr. Stephen Hallace. Lastly, a special and sincere "thank you" is extended to Dr. Milton H. Hamolsky, Chief of Medicine, at Rhode Island Hospital, who was always able to make time to "CHAT" with an overanxious graduate student.

Financial support for this Investigation was provided by the Rhode Island Hospltal fund for Basic Research. 


\section{DEDICATION}

This thesis is dedicated --

to wather ED, for his inexhaustible ambition and unyialding integrity.

to my mother, NOELA, for her endless compassion and

perpetual understanding.

AND MOST ESPECIALLY

to my wife, LAUREN, for her urrelenting support and neverending affection throughout the entire course of this arduous, time-consuring endeavor.

iv. 


\section{PREFACE}

In the last 25 years many observations have documented the suggestion that a relationship exists between centrel norepinephrine function and affective disorders. The catecholamine hypothesis of affective disorders is one theory advanced by researchers. It proposes that some, if not all depressions are assoclated with an absolute or relative deficiency of catecholamines, in particular norepinephrine (NE), at the functionally important adrenergic receptor sites in the brain. The tricyclic antidepressants (TCA), which normalize a depressed mood, block the active re-uptake of norepinephrine after release from the presynaptic nerve terwinals. Thus both the time and the concentration of norepinephine avallability is increased in the synaptic cleft for post-synaptic attachment. It is likely, however, that the ability of the tricyclics to block norepinephrine re-uptake, though the prinary mechanism of action, may not be the only mechanism involved. This is evident from the observation that re-uptake blockade of NE by the tricyclics occurs within minutes after their administration; however, clinical efficacy in patients is not obvious until these drugs have been adninistered chronically (10-20 days). This observed lag-time for clinical efficacy suggests the existence of an alternate mechanisa of action for this class of antidepressants.

My research was designed to inyestigate three possible alternate mechanisms of action for the tricyclics, which might correlate better with the requirement for chronic administration. 
our results demonstrated that tricyclic antidepressant drugs, when administered chronically, do not alter monoanine oxidase activity in viro in any of the three brain regions we examined (corpus striatun, forebrain, and hypothalamus). Similarly, we were not able to identify a noradrengeric relationship other than those that were both toxic and lethal when thyroid homone was administered with the tricyclic antidepressant drug Protriptyline. He did, however, observe that in the hyparthyroid condition norepinephrine turnover is decreased in hypothalamus when compared to control anfmals.

The results we obtained fron chronic protriptyline administration and its effects on norepinephrine levels and turnover, as well as the results we obtained when yohimbine was employed are enlightening. Chronic protriptyline administration produced decreased norepinephrine levels in hypothalamus, and decreased norepinephrine turnover, when compared to saline administered controls. The alpha-receptor antagonist (yohimbine) produced only minor effects on norepinephrine levels and turnover when experinental animals were pretreated chronically (18 days) with protriptyline.

These results suggest an adaptive response (hypo-sensitivity) of the presynaptic alpha-receptor (autoreceptor), and this phenomena also occurs at the post-synaptic alpha-receptor. These results, suggesting receptor adaptation, indicated the existence of another mechanism of action for the tricyclic antidepressants.

vi. 
Abstract

\section{CHAPTERS}

I. Introduction .................. 1

II. Monoamine Oxidase.............. 6

A. A review of history, current research and interrelationships with depressive illness. . . 6

B. Procedures and methods ........... 12

1. General experimental procedures. . . . . . 12

2. Drugs employed .............. 12

3. Assay for monoamine oxidase. . . . . . . 13

4. DNA methodology. . . . . . . . . . 14

5. Scintillation counter efficiency adfustment and DNA calculations. . . . . 15

C. Results............... 16

D. Discussion ............. . 19

III. The Thyroid Hormones .............. 21

A. Thyroid status and its interrelationship with monoamine oxidase, norepinephrine biosynthes is and the tricyclic antidepressant drugs .... . 21

B. Procedures and methods . . . . . . . . 28

1. Hyperthyroidism and hypothyroidism ... . 28

2. Assay procedure for norepinephrine determinations of pool size and turnover rate . . . . . . . . . . . . 29

3. Alumina preparation. . . . . . . . 30

4. Alpha-methyl-para-tyrosine procedure... . 31

vii. 
C. Results. . . . . . . . . . . . . 32

1. Monoamine oxidase activity in three

regions of rat brain......... . 32

2. Norepinephrine levels.......... 39

3. Norepinephrine turnover. ......... 40

D. Discussion........... 50

IV. Norepinephrine .. . . . . . . . . . 57

A. Norepinephrine and its functional relationship

with the presynaptic receptor. . . . . . . 57

1. Norepinephrine levels and turnover . . . . 57

2. Presynaptic autoreceptor modulation of noradrenergic mechanisms ........ 63

B. Methods and procedures ........... 66

C. Results. ................ 68

1. Protriptyline, norepinephrine levels and turnover . . . . . . . . . . . . 68

2. Yohimbine studies and norepinephrine turnover ............... 83

D. Discussion ............... . . 99

v. Sumnary and Conclusions. . . ..........101

VI. References ...................110

VII. Appendlx . . . . . . . . . . . 1 138 
1. Monoanine oxidase activity levels in three regions of rat brain under control conditions.

2. The effect of trilodothyronine on monoamine oxidase activity in three brain regions.

3. In vivo effects of protriptyline administration on hyperthyroid animals.

4. In vivo toxic effects of simultaneous administration of trilodothyronine and protriptyline on the rat.

5. The effect of thyroidectomy on monoamine oxidase activity in three brain reglons.

6. A comparison of slope and linear regression coefficients for saline treated animals following the administration of alpha-methyl-para-tyrosine (400 mg/kg, I.P.).

7. A comparison of slope and linear regression coefficients for protriptyline treate animals following the administration of alpia-methylpara-tyrosine $(400 \mathrm{mg} / \mathrm{kg}$, I.P.). 
1. The effect of thyroidectony or administration of trilodothyronine on norepinephrine levels in the hypothalamus.

2. Norepinephrin levels in hypothalamus following alpha-methyl-para-tyrosine administration. A dose-response curve.

3. Norepinephrine depletion in hypothalamic tissue in control animals following the administration of alpha-methyl-para-t yrosine (400 mg/kg - I.P.).

4. Turnover of norepinepherine in the hypothalamus of rats treated with triiodothyronine ( $1 \mathrm{mg} / \mathrm{kg} /$ day, 7 days, I.P.).

5. Norepinephrine depletion in hypothalamus as a measure of initial concentration, three hours after alpha-methyl-para-tyrosine administration $\left(400 \mathrm{mg} / \mathrm{kg} / \mathrm{day}, I . P_{.}\right)$.

6. Turnover of norepinephrine in the hypothalamus of thyroidectomized animals.

7. Norepinephrine levels in hypothalamic tissue following acute, subchronic and chronic protriptyline administration.

8. Norepinephrine depletion in hypothalamic tissue following acute protriptyline administration.

9. Norepinephrine depletion in hypothalamic tissue following subchronic protriptyline administration ( 6 days, $10 \mathrm{mg} / \mathrm{kg} / \mathrm{day}$, S.C.).

10. Alpha-methyl-para-tyrosine dose-response curve in animals administered protriptyline chronically. 77

11. Norepinephrine depletion in hypothalamic tissue of animals receiving chronic protriptyline administration.

12. A comparison of turnover rates in hypothalanic tissue of rats administered protriptyline or saline chronically. 


\section{EIGURE}

13. Norepinephrine depletion as a measure of \& initial concentration in the hypothalamic tissue of chronically treated protriptyline or saline animals.

14. Turnover rate/recovery rate for norepinephrine in rat hypothalamic tissue following acute, subchronic and chronic protriptyline administration.

15. Norepinephrine depletion in hypothalamic tissue following yohimbine administration.

16. Norepinephrine turnover in hypothalamus following yohimbine administration $(20.0 \mathrm{mg} / \mathrm{kg}$, I.P.) and alpha-methyl-para-tyrosine administration ( $400 \mathrm{mg} / \mathrm{kg}$, I.P.).

17. Norepinephrine levels in the hypothalamus of animals chronically administered protripytline ( $10 \mathrm{mg} / \mathrm{kg} /$ day, 18 days, S.C.) and then administered yohimbine $(20.0 \mathrm{mg} / \mathrm{kg}$, I.P.).

18. Norepinephrine depletion in hypothalamus following chronic protriptyline administration, yohimbine administration and alpha-methyl-paratyrosine administration. 
CHA P TER

I. 
INTRODUCTION:

During the past 25 years many facta have been documented regarding the antomical and biochenical phenomen which are correlated with mood. This evidence has implicated the involvenent of brain neural systens which enploy norepinephrine (NE) as their neurotransiltter (Glowinsk1 and Iversen, 1966; Kobayash1, et al., 1974; Ross and Re1s, 1974; and Malbon, 1979). Fron these studles and theories the "catecholamine hypothesis for affective disorders" has been derived (Bunney and Davis, 1965; Schildkraut and Kety, 1967; Segal, et al., 1974; Baldessarin1, 1975; Leonard, 1975; de la Funnte, 1979; and Stern, et al., 1980). This theory states that elevated mood is associated with an increased interaction of brain NE with its respective receptors; whereas, a depressed mood is associated with a decreased interaction between NE and respective receptors. In addition, it is also proposed that some, if not all, depressions are assoclated with an absolute or relative deficiency of catecholamines, in particular NE, at the functionally important adrenergic receptor sites in the brain (KcClure, 1971; McClure, 1973; and Barchas, et al., 1978). Studles in man have also shown that drugs which cause depletion and inactivation of NE centrally produce sedation and/or depression, while drugs which fncrease or potentlate brain NE levels are associated with behavioral stimulation or excitation and generally exert an antidepressant effect.

An additional building block for this theory lies in the fact that tricyclic antidepressants (TCA's), which normalize a depressed mood, 
block the active reuptake of NE after its release from the presynaptic Derre terninals (Rossi, 1976; Kant and Meyerhoff, 1977; and Sulser, et al., 1978). The reuptake process is belleved to be the primary means for terminating the post-synaptic action of $N E$, and the tricyclics are able to increase the time for released $W E$ to interact with respective target cell receptors (Hurtman, 1965; and Iversen, 1973).

Other evidence (Alpers and Hinwich, 1972: Frazer, et al., 1978; and de Montigny and Aghajanlan, 1978) suggests that the abllity of the tricyclics to block NE rouptake, though the primary mechanism of action, may not be their only mechanisis of action. Blockade of NE reuptake can be demonstrated after a single injection of a TCA drug (Callingham, 1967; Todrick and Talt, 1969; Schlldkraut, et al.. 1970; and Oswald, et al., 1972). Paradoxically, tricyclics do not exert a clinically observable antidepressant effect unless given chronically for two to three weeks. Therefore, blockade of the reuptake mechanism cannot be reconclled with the time course (lag-time) for the chronic clinical efficacy of these drugs.

As a further building block adding support to the idea that tricyclics act by another mechanism is the observation that ICA drugs inhibit monoanine oxidase (MAO) activity in vitro (Gabay and Valcourt, 1968; Halaris, et al., 1973; Roth and Gillis, 1974a; and Roth and Gillis, 1974b). MAO is a mitochondrial bound intracellular NE degrading enzyme (Johnston, 1968; Schnaitman and Greenawalt, 1968; and Greenawalt, 1972). If specific enzymatic parameters regarding NE degradation differ between noral individuals and patients prone to endogeneous depression, then 
tricyclics way exert their antidepressant influences by altering or returning to normal certain enzyme imbalances. These imbalances nay only be changed during long-tere tricyclic treatment, 1.e. MAO inhibition (Nies, et al., 1971; Youdin and Holzbauer, 1976; and Sull1van, et al., 1977).

Sixe NE avallability at post-synaptic receptor sites is one of the fundamental correlates for mood changes (depression or anxiety) it has also been suggested that cellular NE levels may decrease in individuals prone to endogeneous depression, and chronic adninistration of tricyclics reduce or prevent these changes (schildkraut, et al., 1970; Schildkraut, et al., 1971; and Leonard and Kafoe, 1976). Contrary to these findings however, Neff and Costa (1967) and Alpers and Himwich (1972) have reported that chronic TCA treatment with imipramine or protriptyline did not induce changes in cellular NE levels in rat brain.

The effect of chronic tricyclic administration on NE turnover has also been suggested as a possible mechanism or parameter which may be altered by chronically administered tricyclics (Schildkraut, et al., 1970; Schildkraut, et al., 1971; and Leonard and Kafoe, 1976); but this hypothesis is not supported by other studies (Neff and Costa, 1967 ; and Alpers and Hlmwich, 1972).

Another hypothes is this research investigated dealt with the effects and interrelationships between thyroid hormone administration and TCA drugs; and their individual and/or combined abilities to allerlate several depressive symptoms observed in clinically depressed 
pationts. Studies by Prange, et al., (1970), Wheatley, (1972) and Slusher, (1975), have reported confirming results that both patient mood and behavior improved when thyroid hormone was administered in conjunction with tricyclics, but the biochemical reasons for this improvenent in mental health remains unresolved.

It has been documented that dysfunction of the thyroid gland has long been associated with mental illness (Gibson, 1962; Prange, et al., 1969; Breese, et al., 1974; Slusher, 1975; Singhal and Rastog1, 1978; and Bain and Halfish, 1978). Consequently, symptoms of depression are frequently associated with hypothyroidism; whereas, anxiety, fatigue and irritability are assoclated with hyperthyroidism. It may be proposed that endogeneous affective disorders are linked specifically to overall thyroid status. This hypothesis has been suggested and states that in hyperthyroidism there is increased receptor sensitivity (Emlen, et al., 1972; Engstran, et al., 1974; Engstron, et al., 1975; and Strombon, et al., 1977), which induces, through compensatory mechanisms, a reduced neuronal activity and decreased NE turnover, both of which result from a negative feedback mechanism (Strambom, et al., 1977; Oppenheimer, 1979; and Sterling, 1979). Conversely, the opposite would occur in hypothyroidisw. Therefore, concurrent administration of thyrold analogs with tricyclics should hasten the biochemical mechanisms of action elicited by chronic tricyclic treatmant. This would yleld a shortar time interval for clinical efficacy for these drugs and would result in an elevated mood (Earle, 1970; Wilson, et al., 1970; and Wheatley, 1972). 
Thls aspect of this research study was designed to investigate and identify any possible central nervous systen (CNS) biochenical mechanien which might be altered following both concurrent thyroid hormone and tricyclic administration which may accelerate improvement in depressed patient.

In sumary, this study Investigated several hypotheses which were suggested as alternative mechanisms of action associated with tricyclic administration, and possibly resolve the existing controversy over the occurrence of a lag-time, between drug administration and clinical efficacy. Also, this study was designed to identify the relationship between thyrold homone administration, tricyclics and accelerated clinical improvement in depressed patients.

The several hypotheses this research atterupts to test follow:

(1) that the requirenent for chronic treatment with TCA drugs before clinical efficacy is observed is related to an action on mitochondrial MAO, and that the time course for this effect parallels the time course for clinical response.

(2) that simultaneous administration of thyroid homone potentiates the action of TCA drugs through an effect on MAO activity, NE turnover or NE cellular levels.

(3) that the time course in clinical efficacy of TCA drugs parallels the time course for development of presynaptic receptor subsensitivity (and concomitant changes in neurotransmitter turnover).

Investigations into these possible alternative mechanisns of action of the tricyclics may shed some light on clinical TCA drug treatment, and the clinical efficacy of this class of drugs. These results may ald researchers and clinicians in reconciling the urresolved time-course or lag-tine assoclated with these drugs and with their observable clinical actions. 
CHA P T R II. 
C HA P TER II.

A. MONOAMINE OXIDASE: A Review of History, Current Research and Interrelationships with Depressive Illness.

The term 'monoamine oxidase' ( $\mathrm{MHO})\left(\mathrm{O}_{2}\right.$ oxido-reductase, deaminating, E. C. 1.4.3.4) is used to designate a group of enzymes catalyzing the oxidative deamination of tyramine, tryptamine, serotonin, norepinephrine, dopamine and other monoamines. These enzymes are mainly bound to the outer mitochondrial membrase. They were first identified by Hare, (1928) as tyramine oxidases, and were further characterized by Blaschko, et al. (1937, 1954). Pugh and Quastel (1937) were the first researchers to study MAO activity in nerve tissue. MAO activity varies greatly in different regions of the brain, with highest activity being observed in the hypothalamus and basal ganglia (Collins, et al., 1970; Youdin, 1973A, Youdim, 1973B; and Hazama, et al.., 1976). The first studies on the intracellular localization of MAO were performed by Hawkins (1952) and Blaschko (1957). These independent investigators observed that in adult rat liver homogenates 70-80\% of the total Mio activity is found in the microsomal fraction of the subcellular fractionation preparation.

Evidence that $M O$ is localized in the outer mitochondrial membrane was first observed and reported by Schnaitman, et al. (1967), with additional support added by de Champlain, et al. (1969). This close association between MAO and the mitochondrial membrane has complicated the purification of the enzyme, and the study of its pure chemical nature 
and characteristic enzyuatic paraneters can only be examined using subcellulas mitochondrlal preparations employing unsolubilized partially purified enzyme preparations.

There is substantial evidence available which states that Mo exists in more than one form (Gorkin, 1966; Sandler and Youdin, 1972; Houslay and Tipton, 1973; Neff and Yang, 1974; Neff, et al.. 1974; and Youdin and Collins, 1975). Multiple forms of human brain mitochondrial MAO were first described by Collins, et al. (1970). The presence of different forms of MO in tissue howogenates, witochondrial preparation and in carefully prepared outer mitochondrial membrane preparations has been supported by the discovery of substrate selective inhibitors of MAO. The two drugs employed for the specific characterization of MAO forms ware clorgyline and deprenll (Johnston, 1968; Knoll and Magyar, 1972; Houslay and Tipton, 1974; Neff, et al., 1974; and Bakhle and Youdim, 1975).

Johnston, (1968), proposed that clorgyline allows the investigator to distinguish with in vitro and in vivo methodologies between two forms of brain MAO; termed Type A and Type B enzyme. Type A enzyme is thus very sensitive to clorgyline and preferentially deaninates 5hydroxytryptamine and norepinephrine. Type B enzyme is specifically inhibited by deprenil and is relatively insensitive to clorgyline (Knoll and Magyar, 1972). For the Type B form of MAO preferential substrates include benzylamine and phenglethylamine (Houslay and Tipton, 1974). 
Dopanine, tyranine and tryptanine are substrates for both enzyme forms (Fuller, 1972; Squires, 1972; Yang and Neff, 1973; and Neff and Yang, 1974).

There is also significant ovidence suggesting that intraneuronal MAO plays an important role in regulating the functionally active pools of NE in the nerre cell cytoplasw in the neurons of the CNS (Kopin, 1964; Bloom and Giarman, 1969; Green and Grahame-Smith, 1975; Youdim, 1975a; Youdin, 1975b; and Youdin, 1975c). The exact mechanism by which regulation for these homeostatic processes is accomplished by MO has not yet been resolved. Intraneuromal MAO may metabolize neurotransmitter monoamines before and/or after reuptake into the presynaptic nerve ending, following stimulated release.

This degradative process appears to depend solely upon the activity of the MAO enzyme present in the nerve terminals and postsynaptic structures. The reuptake process also appears to be governed or regulated by the relative concentrations of free intra- and extranouronal NE. MAO is apparently essential for keeping cytoplasmic NE in the neuron low, and within a specific steady-state equilibrium. Under conditions when MAO activity is decreased (MAO-inhibitor administration) the concentration of total cytoplasmic NE rises. It has also been suggested (Bloom, 1963; Eiduson, et al.. 1964; Kordon and Glowinski, 1970; and Gripols, 1975) that NE which is present in the presynaptic neuron cytoplasm may react with the MAO enzyme in the cytoplasm and cause a change in the steric conformational structure of the MAO enzyme. This may or may not be reversible. This steric conformational 
change in Mo results in an activity change (1.0. increasing or decreasing Mo activity in the cytoplasm) and has been further documented by Iversen, et al. (1975). This change in enzyme structure, which has been substrate induced, may alter the specific activity of MO torard a specific substrate, and paradoxically not change the affinity for this substrate (NE).

Possibilities for these conformational changes in the enzyme molecule could occur by "folding" of MnO chains, since the enzyme exists as a monomer, dimer and tetramer (Collins and Southgate, 1970; Gorkin, 1972; Southgate, 1972; and Yasunobu and 01, 1972). Each MAO chain has a molecular weight of 75,000 . Folding of these chains could result in reducing the activity of the enzyme (1.e., less accessibility of the substrate (NE) to the enzyme's active sites); or folding may initiate a self-catalytic process, or enzyme inactivation process which may or may not be reversible. Sinilarly, it has been suggested (Eiduson, et al., 1964), that the Mo degrading mechanisn consists of a three-polnt attachment to the enzyme surface by the catecholamine, which very likely involves the amine, one alpha hydrogen, and either the other alpha hydrogen or the beta-methylene, once again substantiating the complexity of this structure-activity relationship, and the possible steric varlations for inactivity that are available.

It appears there is a self-regulatory mechanisa in the nerve cell cytoplase which can increase intraneuronal NE concentrations or decrease NE levels. This process is dependent upon signals which are increased or decreased, sequentlal to neural firing rates. 
In most theorles of brain dysfunction and function, MAO is of significant importance. Ang change in the MAO activity usually alters the function of a specific CNS neurotrensmitter, and in particular NE. A physlological role for MAO has been implicated in many processes: affective disorders, agsessive behavior, psychosomatic stimulation, severe mood and behavioral changes leading to crimes of violence and suicide (Ashcroft, et al.. 1966; Shaw, et al.. 1967; Bourne, et al., 1968; and Nies, et al., 1971); drug induced seizures, sleep, environmental stress, hallicugen action (Glowinsk1, 1966; Garver, et al., 1975; Schildkraut, et al., 1976; Becker and Shaskan, 1977; Orsulak, et al., 1978; Baron, et al., 1980; Meltzer, et al., 1980); regulatory effects of adrenocortical steroids and of ovarian hormones, temperature regulation and eating (Glick and Greenberg, 1958; Avakian and Callinghan, 1968; Southgate, et al., 1968; Carpenter and Bunney, 1971; Callinghas and Della Corte, 1971; Holzbauer and Youdim, 1973; RuhmannWennhold and Nelson, 1973; Garver, et al., 1975; Otten and Thoenen, 1976; and Rastog1 and Singhal, 1978).

Since MAO exists in multiple forms (Johnston, 1968; Youdin, 1973; Houslay and Tipton, 1976; Green, et al., 1977; Jain, 1977; Student and Edwards, 1977; Trepel, et al., 1977; and Fowler and Callinghan, 1978), and because it has a central role in the degradation of biogenic amines, the therapeutic benefit of drugs which inhibit this enzyme in clinical treatments deem it imperative that MAO be examined following both acute and chronic tricyclic administration. 
Since the possibility exists that alterations in the metabolisa of central monoamines cause several mental disorders, many investigatore have studied MO activities in the CNS (Leonand, 1975; Youdin and Holzbauer, 1976; Ananth and Luchins, 1977; and Barchas, et al., 1978). Ashcroft and Shamman (1960) were the first researchers to measure the metabolites of blogenic amines in the cerebral spinal fluid (CSF) of mentally ill patients. In certain types of endogeneous depression low CSF concentrations of 5-Hydroxy Indole Acetic Acid (5-HIAA) were observed (Dencker, et al., 1966; van Praag, et al., 1970; and Sjostron, 1973). These findings also agree with the lower 5-hydroxytryptamine and 5-HIAA concentrations found in post-morten brains of patients with depressive 11lness who comitted suicide (Shaw, et al., 1967; and Bourne, et a1.. 1968).

Further support for a possible link between MAO and mental illness is documented by the beneficial effects achieved with drugs which inhibit MAO (Shaw and Hewland, 1973; Davidson, 1974; Neff, et al., 1974; Ananth and Lucins, 1977; and Campbell, et al., 1979). Since alterations in monoamine metabolism can occur during their degradation, variations in the function of MAO could ultimately result in a dysfunction of the neural pathways in which the respective monoamine (NE) plays a role as a specific transmitter substance. It is therefore important that the influence of tricyclics on MAO, when administered both acutely and chronically be examined (Roth and Gillis, 1975; Spiker and Pugh, 1976; Gabay and Achee, 1977; Honecker and Hill, 1977; Ponto, et al., 1977; Roth, 1978; and Achee and Gabay, 1978). These studies are 
imperative if we are to understand the interrelationship between tricyclics and delayed clinical efficacy.

B. PROCEDURE AND METHODS

1. General experimental procedures. Male albino rat (Charles River Laboratorles, C.D. Strain, COBS) weighing 250-400 grans were used for the determination of MO activity levels, NE pool size levels and NE turnover studies, as well as for all studies involving thyroid hormone interrelationships. All animals were housed in the animal care facility at Rhode Island Hospital and were maintained at the ambient temperature of $20-22^{\circ} \mathrm{C}$. These animals were given Purina Rat Chow and water ad libitum and were subjected to a 14-hour lighting cycle (0500-1900 hour. .

2. Drugs employed.

Radioactive substrates for monoamine oxidase included $\mathrm{c}^{14}$ -

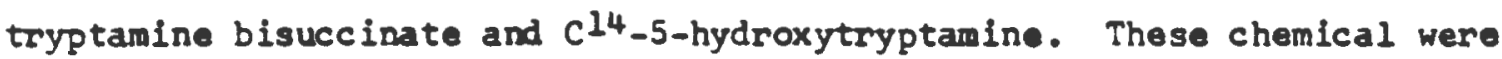
purchased from New England Nuclear, Haltham, Mass, and are listed under the following catalogue numbers: NEC 259, tryptamine; NEC 225, 5hydroxytryptanine.

The tricyclic antidepressant drug employed in these studies was protriptyline (Vivactil) manufactured by Merck Sharp \& Dohme, Pennsylvania. Protriptyline was chosen as our experimental drug since it is a secondary amine tricyclic which preferentially blocks reuptake of the catecholamine NE (Ross and Renyi, 1975a; Ross and Renyi, 1975a; Ross and Renyi, 1975b). Desipramine, desmethylchlorinipramine and nortriptyline are other similar secondary tricyclics. In contrast, 
inipramine, anitriptyline and doxepin are classifled as tertiary amines, and preferentially block the reuptake of serotonin (Ross1, 1976).

3. Assay for monoamine oxidase. MAO activity wes measured by the method of Wurtman and Axelrod (1963). Rats were decapltated and brain tissues were surgically excised. The surglcally renoved tissues were weighed by flotation in $0.5 \mathrm{M}$ potassium phosphate buffer ( $\mathrm{pH} 7.4), 15 \mathrm{ml}$ total volume. Tissues were then homogenized by a polytron cell disrupter (Model PT-10/20, with PT10, ST generator, Brinkman, Switzerland) for two winutes at high speed (dial setting 10). All preparations were kept in an ice bath during cell disruption. Following cell disruption, $100 \mathrm{ul}$ aliquots of each tissue sample was placed in assay tubes and reacted with labelled tryptamine bissuccinate or 5-hydroxytryptamine (New England Nuclear, NEC 259, and NEC 225), which were used as the substrates for the MAO enzyme.

The total assay volume was $1.2 \mathrm{ml}(0.5 \mathrm{ml}$ potassium buffer, $\mathrm{pH}$ 7.4; $0.5 \mathrm{ml}$ distilled water; $0.1 \mathrm{ml}$ tissue homogenate; and $0.1 \mathrm{ml}$ substrate solution). Assay tubes were incubated for 20 minutes in a shaker water bath at $37^{\circ} \mathrm{C}$. At the end of the incubation period, the reaction was quenched with $0.2 \mathrm{ml}$ of $2.0 \mathrm{~N} \mathrm{HCL}$. This caused denaturing of MAO and prevented further substrate degradation (deamination). The deaminated radioactive products, 5-HIA and Indole Acetic Acid (IAA), were then extracted by vigorous shaking with $6.0 \mathrm{ml}$ of a toluene/ ether solution $(1: 1)$. This procedure is a modification of the original Wurtman and Axelrod (1963) method, and allows a more efficient extraction of radioactive products (5-HIAA and IAA). Efflciency was 
increased from $62 \pm 28$ to $82 \pm 48$ and was used in all subsequent MAO determinations (Kaiser, 1975A). Following a 10 minute centrifugation, (IEC International Centrifuge, Model PR-2) of this mixture (2000 rpm, $280 \times \mathrm{g})$, a $4.0 \mathrm{ml}$ aliquot of the organic phase was transferred to a liquid scintillation counting vial containing $10.0 \mathrm{ml}$ phosphor $[0.4$ gram P-Bis-(2-5-phenyloxazolyl-benzene)] (POPOP), and 4.0 grams 2,5diphenyloxazole (PPO) per liter of toluene (Bray, 1960). These samples were then counted in a liquid scintillation counter (spectrophotometer) (Searle Analytical, Mark III) for 10 minutes. A small amount of ${ }^{14} \mathrm{C}-$ tryptamine or ${ }^{14} \mathrm{C}-5$-hydroxytryptamine (less than 0.38) (Kaiser, 1975B) was extracted by this procedure, but it creates a negligible error in the extracted radioactive samples.

4. DNA methodology. Homogenized tissue aliquots of $0.1 \mathrm{ml}$ were taken from the cell preparations previously described (assay for MAO), placed in $15.0 \mathrm{ml}$ graduated conical centrifuge tubes, and frozen until assayed. A standard DMA stock solution was prepared containing $200 \mathrm{mg}$ of deoxyribonucleic acid sodium salt (highly polymerized, grade A, Cal-Blochem, La Jolla, CA.) per $100 \mathrm{ml}$ of $1.0 \mathrm{~N}$ anmonium hydroxide $\left(\mathrm{NH}_{4} \mathrm{OH}\right)$. This solution was stored at $4^{\circ} \mathrm{C}$.

Standards of $1.0,2.0,4.0,8.0$ and 12.0 ug DNA per sample were run with each assay in order to check their reproducibility and precision. All samples were then assayed by the method of Kissane and Robins (1958), which has been slightly modified to allow the use of larger tissue samples (Wunschel, personal communication). Modifications 
involved the use of proportionately larger volumes of reagents for the extraction procedures. All sanples were assayed in triplicate and areraged.

The calculations involved in determining the DNA standard Curve, the linear regression analysis to obtain the regression coefficient, and a graphical representation of the data can be found in the Appendix section, Figure

5. Scintillation counter efficiency adjustment and DNA calculations. The calculations involved far the conversion of counts per minute (CPM) to nanomoles of IAA or 5-HIAA formed per hour per ug DNA follow:

I. For Efficiency Adjustment:

$$
\text { Disintegrations per minute (DPM) }=\frac{\text { counts per minute (CPM) }}{\begin{array}{l}
\text { counting efficiency of } \\
\text { counter }
\end{array}}
$$

II. Conversion Equation (To convert DPM's to nanomoles of (5-HIAA or IAA formed per hour per ug DNA)

$\frac{\text { DPM } \times \text { dilution factor }}{\text { counts of radioactive }} \times \frac{\text { nanomoles of radioactive }}{\text { product formed }} \times \frac{3 *}{2} \times \frac{3^{*}}{1}=$ material used (total substrated added to samples )

nanomoles of IAA or 5-HIAA $\div$ ug of DNA per 100 ul sample formed per hour per gran

= nanomoles of product formed per hour per gram per ug DNA.

*This ratio refers to the volume of organic solution extracted in the separation procedure.

*hThis ratio refers to a reaction incubation time adjustment. 
C. RESULTS

Initial experiments involving the determination of MO activity levels in brain tissue were concerned with exanining the enzymatic kinetic parameters of the enzyme. Classical velocity (V) versus time (T), and velocity (V) versus enzyme (E) concentration experiments were performed using homogenlzed tissue preparations from the three brain regions being examined (corpus striatum, forebrain and hypothalamus).

Frou these studies it was determined that a twenty minute incubation time, and a 100 ul aliquot of each homogenized tissue preparation would. produce linearity, and neither time nor enzyme concentration would be Imiting variables in future experiments.

Following these studies and enploying both a twenty minute incubation time and the 100 ul aliquot of the homogenized brain tissue preparations, further experiments were conducted to determine both $K_{m}$ and $V \max$ values for the MAO enzyme in these three brain reglons (see appendix section Figures 1-4; Tables 14-26.

After completing the enzymatic kinetic parameter studies, MAO activity levels were measured in the same three regions of rat brain in control animals. From these results it is apparent that in these brain regions there exists about 4 times more B-form MO than A-form MAO, since $C^{14}$-serotonin is selective for only the A-form of MAO, whereas $C^{14}$-tryptamine is deaminated by both the $A$ and $B$ forms of MAO. These values are reported in Table 1. When $C^{14}$-tryptamine was employed as substrate for MAO, the total moles of product formed/hr/ug DNA is signiflcantly greater $(p<0.001)$ than when $c^{14}$-serotonin was used as the 
MAO enzye substrate. Also, It is apparent that the forebrain preparetion has significantly more MAO activity $(p<0.01)$ than the other two brain reglons being examined, regardless of whether $c^{14}$-tryptanine or $C^{14}$-serotonin was employed as the MAO substrate.

\section{TABLE 1 Monoamine oxidase activity levels in three} regions of rat brain under control conditions.

$\begin{array}{lcc}\text { TISSUE } & C^{14} \text {-serotonin } & C^{14} \text {-tryptamine } \\ \text { Corpus Striatum } & 0.4462 \pm 0.032 \star(N=8) & 2.2638 \pm 0.161 \quad(N=12) \\ \text { Forebrain } & 0.5926 \pm 0.032(N=6) & 3.1692 \pm 0.139(N=8) \\ \text { Hypothalamus } & 0.3623 \pm 0.015(N=5) & 2.1469 \pm 0.061 \quad(N=8)\end{array}$

\footnotetext{
*Values represent the Mean \pm S.E.M. and are reported as nanomoles IAA or 5-HIA formed/hr/ug DNA
}

Next, an initial set of experiments was undertaken to examine the effect of protriptyline on MAO activity in vitro (appendix section, Figures 5 and 6). Corpus striatum, forebrain and hypothalanus were dissected out of whole brain and homogenized in phosphate buffer ( $\mathrm{pH} 7.4)$. Aliquots (100 ul) of these homogenized tissue preparations were then placed in reaction tubes and preincubated with varying molar concentrations of protriptyline $\left(10^{-11}\right.$ to $\left.10^{-3} \mathrm{M}\right)$ for thirty minutes at $20^{\circ} \mathrm{C}$, prior to addition of labelled substrate as described in the Methods Section. 
The results fron these experiments report that when the concentration of protriptyline in the preincubation medla approaches $10^{-6}$ N. MAO enzyme activity in the corpus striatun is inhibited when either $\mathrm{c}^{14}$-tryptamine or $\mathrm{c}^{14}$-serotonin are used as substrate. Similar results were observed in both forebrain and hypothalamus. We interpret these results to be a non-specific inhibitory effect. Numerical values and graphical illustrations are reported in the appendix section (Figures 5 and 6 ; Tables 27 and 28 ).

The next area this research investigated involved measuring the in vivo effects of protriptyline on MAO activity. Protriptyline was administered to experimental animals (male albino rats, Charles River, C.D. Strain) acutely (one daily iajection), subchronically ( 3 or 6 daily injections) and chronically ( 18 daily injections). A dose of $10 \mathrm{mg} / \mathrm{kg} /$ day protriptyline hydrochloride dissolved in physiological saline was adninistered for this regiment of infections. This dose of protriptyline was selected since it appears extensively in the literature (Schildraut, et al.. 1971; Leonard and Kafoe, 1976; Rossi, 1976). This dose of protriptyline is between 10 and 20 times the dose used in treating clinical depression (Long, 1977).

The results of these experiments are presented in the appendix section (Tables $3,4,5$ and 6 ). Our observations from these studies indicated that in vivo protriptyline administration had no consistent effect upon MAO activity in the brain tissues we examined regardless of length of administration (1, 3, 6 or 18 consecutive injections) and regardless of whether MAO activity was examined $1,3,6,12$ or 24 hours after the last drug administration. 
D. DISCUSSION

The activity of monoamine oxidase, one of the degrading enzymes In the metabolism of the neurotransmitter NE, has been measured under various experimental procedures in several regions of rat brain. This area of investigation was pursued, since the mechanism of action of the tricyclics remains controversial. Specific actions of the tricyclics on MO activity may explain why chronic treatment is required to produce clinical efficacy.

We began our studies by inftially developing and optimizing both our methodology and technique for isolating and quantitatively measuring tissue MAO. The numerical data we obtained for our enzymic kinetic parameters is supported by other investigators, and this adds support and validity to our procedures.

When examining the in vitro effects of protriptyline preincubation on MAO activity, we observed a decrease in enzyme activity at concentrations of $10^{-6} \mathrm{M}$ and higher. Similar results for the tricyclics (i.e. MAO inhibition) have been reported by other investigators (Gabay and Valcourt, 1968A; Halaris, et al.. 1973; Roth and Gillis, 1974A; Roth and Gillis, 1974B; Roth and Gillis, 1975; Roth, 1977).

Examining the effects of acute (one daily injection), subchronic (three or six daily injections) or chronic (eighteen daily injections) protriptyline administration in vivo on MAO activity, we found no consistently significant effect of protriptyline on MAO activity in the brain regions we examined. 
Having extensively researched the first hypothesis of this study, and concluding that no specific in vivo effect for protriptyline on Mo activity could be substantlated, we proceeded to test our second hypothesis, "that thyroid hormone interacts with the tricyclics and may potentiate their effect on MAO activity, NE turnover, and on cellular NE levels." 
C HA P TER III 
C H A P TER III.

A. THE THYROID HORMONES: Thyroid status and its interrelationship with monoamine oxidase, norepinephrine biosynthesis and the tricyclic antidepressant drugs.

The mechanism of action of the thyrold hormones $\left(T_{3}\right.$ and $\left.T_{4}\right)$ is of considerable interest because of the amazing diversity of their effects (Fleischmann, 1947; Fischer, et al., 1968; Prange, et al., 1971; Breese, et al., 1974; Strombon, et al., 1977; Singhal and Rastogi, 1978). These hormones exert profound effects on many enzymes and on almost all organ systems. They also play an important role in the complex biological processes involved in growth and cell differentiation (Oppenneimer, 1978). These hormones are thought to cause their actions by modulating or regulating the actions of other endogenous hormones or enzymes (Barchas, et al., 1978). This is accomplished by influencing thyroid hormone receptors associated with the nuclear chromatin (Sterling, 1979); and by altering mitochondrial function (Sterling, et al., 1978). The concept of an intracellular, nuclear receptor for thyroid hormone is based on earlier receptor models, which have been theorized for the action of steroid hormone action on respective target cells. In these models hormone action occurs via nuclear transcription (Samuels and Tsa1, 1973; De Groot and Stausser, 1974; Samuels, et al., 1974; De Groot and Torresani, 1975; Mac Lood and Baxter, 1976; Chan and O'Malloy, 1976). Other researchers (Gardner, 1975; Oppenheimer, 1975; Kurtz, et al., 1976; Surks and Oppenheiner, 1977), suggest that the 
homone penetrates the plasma membrane and is bound by a specific cytosol receptor. This homone-receptor complex enters the nucleus, and increased transcription of a genetic wessage for increased mRNA occurs. This in turn results in mRMA directing increased synthesis of specific nuclear proteins.

Ample evidence is available to support the view that an association exists between mental disturbances and altered levels of hormones such as adrenal corticoids, thyroid homones, androgens and the estrogens (Rubin and Mandell, 1966; Mandell and Mande11, 1967; Dewhurst, et al., 1969; Glass, et al., 1971; Wheatley, 1972). Only recently neuroendocrinologists have become interested in studying the effects of hormones on the functioning of the brain. Psychiatrists, however, have felt for many years that the solution to several etiological problems in psychiatry would becone manifest only after a better understanding of neuroendocrinological mechanisms becare apparent, and in particular those involving thyroid hormone mechanisms (Singhal and Rastog 1, 1978).

Since the earliest descriptions of both hyperthyroidism and hypothyroldism, it has been suggested that certain psychiatric disorders may be manfestations of thyroid dysfunction. The clinically observable symptoms of thyroid dysfunction are sometimes of such severity that they bring the patient to the attention of the psychiatrist, and occasionally demand psychiatric hospitalization.

In clinical studies conducted (Jefferys, 1972; Thonson, et al., 1972; Mc Larty, et al., 1978; Nusynowitz and Young, 1979; Cohen and 
Swigar, 1979), the prevalence of thyroid dysfunction in a psychiatric population ( 1320 patients) was 1.28 for males and 2.08 for females. It is doubtful whether these figures are significantly different from the prevalence of thyroid dysfunction in the general population (Whybrow, et al., 1969; Henschke and Pain, 1977; Tunbridge, et al., 1977). This suggests that the importance of thyroid disease and mental disturbances may not be of important clinical significance. Therefore, the value of thyroid function testing in psychiatric patients is still unclear. There are two criteria however, which must be discussed. First, thyroid dysfunction, (hypothyroidism or hyperthyroidism) may manifest itself as a psychiatric illness, and consequently some of the signs and symptoms of mental derangement mimic those observed in thyroid dysfunction (Singhal and Rastogi, 1978; de la Fuente, 1979). Thus, the diagnosis of these conditions on overt clinical parameters is sometimes very difficult. The occurrence or prevalence of thyroid dysfunction in a psychiatrically ill population is uncertain, and has been reported to be higher than the general population (Nicholson, et al., 1976; Weinberg and Katzell, 1977). It has also been reported to be the same as the general population (Bursten, 1961; Gibson, 1962; Clower, et al., 1969). It is also clear that the stress caused by various types of acute and chronic organic 1liness profoundly affect thyroid function tests (Johansson, et al., 1972; Mason, et al., 1973; Mason, 1975). Although psychiatric illness may produce similar alterations in thyroid status, the magnitude, duration, and frequency of these thyrold changes are unclear and require examination. 
It was our intent to study the interrelationships between mo activity in various brain regions following both in vitro pre-incubation with thyroid hormone ( $T_{3}$ and $T_{4}$ ) and also following in vivo subcutaneous injection of thyroid hormone for varying time periods. Also, we studied the effects of thyroidectomy on MAO activity. The thyroid homones are known to exert important influences on the central nervous system (CNS) (Fleischmann, 1947; Gibson, 1962; Harrison, 1964; Bain and Walfish, 1978; Oppenheimer, 1979; and Sterling, 1979), and in particular on both peripheral and CNS MAO activity (Novick, 1961; Fisher, et al., 1968; Breese, et al., 1974; Callingham and Lyles, 1974; Moonat, et al., 1975; Lyles and Callingham, 1976; Asaad and Clarke, 1978). It has been suggested by Novick, (1961) and Youdim and Holzbauer, (1976), that the thyroid hormones modify MAO activity, but the specific mechanisms by which these changes occur have not been resolved. There exists the possibility of modulating the blogenesis of mitochondria. This theory has been advanced by other researchers (Novick, 1961; Youdin and Holzbauer, 1976). Also, it has been suggested that the thysoid hormones can increase the synthesis of MAO itself (Fischer, et al., 1968). This theory has been documented for heart tissue (Coville and Telford, 1970; Lyles and Callingham, 1976). Also, it has been suggested that the thyroid hormones activate an inactive cytoplasmic MAO in brain tissue (Asaad and Clarke, 1976). Conversely, however, rat liver MAO activity was decreased following thyroid hormone administration (Moonat, et al., 1975). Thus, any apparent thyroid hormone Induced influences 
on MO activity still remain unclear, and also tissue specific. Similarly, emotional or mental stress may also be related to possible MO-thyroid relationships, and these relationships should be investigated.

With regard to norepinephrine levels and norepinephrine turnover following either $\mathrm{T}_{3}$ or $\mathrm{T}_{4}$ administration, once again controversies exist. Engstrom et al., $(1974,1975)$ as well as Schwark and Keesey (1975) have stated that $T_{4}$ pretreatment has no significant effect on brain concentrations of NE, dopamine or serotonin. However, Engstrom, (1974), Strombor et al., (1977) and Jacoby (1975) have reported increased turnover of brain catecholamines following $T_{4}$ pretreatment. Also, Kennedy et al., (1977) reported increased NE turnover in brown adipose tissue (BAT) pads of the rat with statistically significant increases in NE levels in this tissue with $T_{4}$ treatment. Contradictory to these studies however, Prange et al., (1970), has reported that thyroxine pretreatment caused a decrease in NE turnover and levels in the rat in both brain and heart tissue. Lastly, studies by Rastogi and Singhal (1974a, 1974b) have reported an increase in NE levels in brain and total animal body weight when $T_{3}$ was administered.

Since this controversy exists, regarding the effects of $\mathrm{I}_{3}$ and $T_{4}$ administration on NE levels and turnover, it was Imperative to Include the effects of the thyrold hormones on these NE parameters in this study.

Also, since a simllarity exists between the clinical manifestations of depression and those of hypothyroidism, the effects of thyroidectomy 
were investigated in relation to NE levels and turnover. Evidence from many clinical and animal studies indicate that a number of metabolic and psychic disturbances are comnon to both thyroid deficiency and affective 11lness (Oppenheimer, 1979; Sterling, 1979).

Biochemical studies have demonstrated that both hypothyroldisal and depression show a diminished response to infused NE (Schneckloth, et al., 1953; Prange, et al., 1967). Furthernore, psychological studies have suggested that the symptoms of myxedema, a severe form of hypothyroldism, makes an insidious appearance and is generally characterized by listlessness, lack of energy, slowness of speech, reduced sensory capacity, impaiment of memory, social withdrawal and altered sleep patterns (Eayrs, 1960; Kales, et al., 1967). Several of these psychological symptoms are coumonly observed in depressed patients; slowness of speech, roduced sensory capacity, lack of energy, social withdrawal, and altered sleep patterns (Libow and Durrell, 1965; Whybrow, et al., 1969; Davenport and Dorcey, 1972; Davenport, et al., 1976).

Even though there appears to be sufficient evidence to implicate thyroid dysfunction with associated depression, it is still impossible at present to implicate abnormal thyroid function as a result or a cause of affective disorders. In order to possibly clarify this hypothesis and gain insight into whether or not alterations in neurotransalter mechanisms (i.e. pool size and/or turnover) cause suppressed behavior and learning deficiencies, which are viewed in both depressed and hypothyroid patients, we felt that It was imperative to investigate NE parameters during hypothyroidism. 
Effective pharmacological treatments for mental illness have existed only during the last 30 years. This period has also witnessed a revolution regarding the care of psychlatric patients and has resulted in a decrease in the number of patients in both state and county mental facilities. This combination of both drug therapy and psychological and socioenvironnental treatment is responsible for the vastly improved prognosis for patients with mental illness (Barchas, et al., 1977; Berger, et al., 1977; Gold and Pottash, 1981; Spiker, 1981).

Since a high prevalence of mental dysfunction exists, and also a concomitant economic loss due to work disability and/or hospitalization, as well as the ever present danger of suicide, a persistent as well as compeling reason to search for a treatment for depression, that is both rapid, safe and convenient becomes necessary. Since treatment with thyroid hormones has been shown to enhance the pharmacological actions of several of the barbiturates (Conney and Garren, 1961; Prange, et al., 1966), and also since other clinical studies (Prange, et al., 1970A; Earle, 1970; Prange, et al., 1970B; Wheatley, 1972; Whybrow, et al., 1972; Slusher, 1975; and Schmidt, 1977) as well as some animal investigation (Prange and Lipton, 1962; Breese, et al., 1974) have documented an increase in drug efficacy, it has been theorized that the thyroid hormones may accelerate the antidepressant actions of the tricyclics or these other pharmacological agents (Cavalieri and Pitt-Rivers, 1981 ). Keeping in mind these observations we designed our experimental protocol to incorporate both protriptyline and $T_{3}$ administration. We planned to 
investigate their possible synergistic interrelationships with regard to MAO activity, NE levels and NE turnover in three tissues of the rat brain.

The occurrence of psychiatric symptoms in patients suffering from hypothyroidism is well established (Asher, 1979; Rubin and Mandel1, 1966; Oppenheimer, 1979; Sterling, 1979). Also, the similarity between the manifestations of anxiety states and hyperthyroidism is also well established (Dewhurst, et al., 1969; Singhal and Rastogi, 1978; Youdin and Holzbauer, 1976). Therefore, whether as a cause or an effect, there is evidence which implicates thyroid dysfunction with psychlatric illness.

Since this strong implication exists, between thyrold status and mental illness, it becomes more critical that effective, fast-acting pharmacological treatments for mental illness become avallable. These treatments will become available only after sufficient animal research has been conducted and only then will there be immense benefits for both patients and the general population. B. PROCEDURES AND METHODS

1. General experimental procedures. Pharmacological hyperthyroidism was induced by dafly subcutaneous injection of L-thyroxine (either $T_{3}$ or $\left.T_{4}\right), 1.0 \mathrm{mg} / \mathrm{kg} / \mathrm{day},(10 \mathrm{mg} / \mathrm{cc}$ in nomal saline with 2 drops of $1.0 \mathrm{~N} \mathrm{NaOH}$ ) for seven consecutive days (Barker, et al., 1949; Engstrom, et al., 1975; Kennedy, et al., 1977), and these animals were then sacrificed on the 8 th day by decapitation. This dose of thyroxine was sufficient to maintain significantly elevated protein bound iodine (PBI) levels (Hammond, 1968; Engstrom, et al., 1975; Kennedy, et al., 1977). 
Hypothyroidism was induced by surgical thyroidectomy at 7 weaks of age (approximately 175 grams body weight), a time at which thyroid function has stabilized to the adult level (Hammond, 1968; Kennedy, et al., 1977; Hamolsky, personal communication). Studies based on measurements of protein bound lodine (PBI) levels and basal metabolic rate have revealed that significant hypothyroidism does not develop in the rat until 7 to 8 weeks post-thyroidectomy (Hammond, 1968; Kennedy, et al., 1977). Therefore, no measurements other than body weight recordings were made until after this time period had passed. Also, it is appropriate to note that an age difference existed among the experimental groups being examined, and this partially accounts for the observed differences in total body weight. The thyroidectomized rats were approximately 18 weeks of age when sacrificed, whereas, thyroxine treated animals were 12 weeks of age. In each instance corresponding euthyroid animals of equivalent age served as paired controls for each experimental group. Also, to adjust for varying total body weights and animal age differences, DNA determinations were conducted on all brain tissue fractions used in MAO activity level measurements.

2. Assay methodology for norepinephrine levels and turnover. Norepinephrine (NE) in brain tissue was assayed by being extracted into $0.4 \mathrm{~N}$ perchloric acid (PCA) with subsequent purification over alumina columns. The NE was oxidized to its trihydroxyindole derivative and assayed fluorometrically on a spectrophotofluorometer (Aminco-Bownan) by the method of Lund (1950). 
The method for NE determinations is as follows: brain tissue samples were homogenized in 0.4 N PCA (total volume, $10 \mathrm{al}$ ) on a Brinkman polytron, high speed for 30 seconds. Following hemogenization another $25 \mathrm{ml}$ of $0.4 \mathrm{~N}$ PCA was added to the bomogenate (total volume $35 \mathrm{ml})$. The homogenate was allowed to stand for one hour at $4^{\circ} \mathrm{C}$, and shaken vigorously every 15 minutes until the hour had elapsed. The homogenate was then centrifuged (IEC-International Centrifuge, PR-2, $2000 \mathrm{rpn}, 280 \times \mathrm{g}$ ) for 20 minutes, and the supernatant was decanted. The $\mathrm{pH}$ of the supernatant was adjust between 8.3 to 8.5 with $0.5 \mathrm{~N}$ $\mathrm{NH}_{4} \mathrm{OH}$ and $5.0 \mathrm{~N} \mathrm{NH}_{4} \mathrm{OH}$ and then poured on alumina columns. The alunina had been prepared by the method of Crout, (1961), (see 3. Alumina Preparation), and the NE was adsorbed onto the alumina beads. The NE was then eluded off these alumina beads with $0.3 \underline{\mathrm{N}}$ acetic acid $(2.0$ ml). The eluded NE fraction was axidized with potassiun ferricyanide (258) and fluroescence was read on the spectrophotofluorometer with the excitation wavelength at 400 nmeters and emission wavelenght at 510 nmeters. An external standard with NE as well as an internal standard ( $H^{3}-D L-n o r e p i n e p h r i n e$, New England Nuclear) was simultaneously assayed and recovery was $84.4 \pm 58$ ( $N=1834$ determinations). All values were corrected for parcentage recovery, (See Appendix Section, Figures 24 and 25 .

3. Alumina preparation.

Powdered alumina (Elsher Scientific, chromatographic grade) is used for NE adsorption following the acidic activation of this alumina. For alumina activation 200-300 grams of neurtral alumina are boiled in 
one liter of $2 \mathrm{~N}$ HCL for 30 minutes in a reflux apparatus. After boiling the cloudy supernatant is discarded, and one liter of distilled water is added to the acidified alumina while still in the reflux apparatus, and stirred briefly. After allowing the alumina to settle, the clear supernatant is decarded. These distilled water washings are repeated 12-15 times until the $\mathrm{pH}$ of the discarded supernatant attains a $\mathrm{pH}$ between $4.0-5.0$. The alumina is then collected in a large suction funnel, and allowed to dry overnight at room temperature $\left(20-22^{\circ} \mathrm{C}\right)$. The alumina is then heated in an oren at $100^{\circ} \mathrm{C}$ for 2 hours. The alumina is now activated and can be used for $N E$ adsorption.

4. Alpha-methyl-para-tyrosine procedure. Alpha-methyl-para-tyrosine (methyl ester, Sigma Chemical Co.) was used to measure NE turnover. This agent competitively inhibits tyrosine hydroxylase, the rate-limiting enzyme in the synthetic pathway for NE biosynthesis. At zero time, $400 \mathrm{mg} / \mathrm{kg}$ alpha-methylpara-tyrosine (Brodie, et al., 1966) is injected interperitoneally (IP) into both experimental and control animals, and these animals are sacrificed by decapitation at varying time intervals after alphamethyl-para-tyrosine administration. Depletion rates for all groups of animals were determined from 0 to 9 hours after alpha-methyl-para-tyrosine injection.

The validity of this method rests on several assumptions. First, NE is assumed to be maintained at a steady state level, existing in a single depletable compartment within the nerve ending. In this situation only, can efflux rate be said to be equal to synthesis rate. 
Second, that tyrosine hydroxylase is and remains totally inhibited over the entire course of the turnover measurement. Third, that alphamethyl-para-tyrosine acts only by blocking $N E$ synthes1s, does not interfere with tysosine uptake (or required cofactors). Also, that the mechanisas for release or re-uptake of neurotransmitters are not altered. Fourth, that the neuronal pools of both DOPA and dopamine are very small, and thus cannot serve as a reservolr for NE synthesis after tyrosine hydroxylase has been inhibited. The fifth, and last criteria, is that alpha-methyl-para-tyrosine does not interfer with the experimental drug which is being studied. Similarly, the experimental drug cannot affect the enzyme inhibiting characteristics of alpha-methyl-paratyrosine on tyrosine hydroxylase activity.

In addition, an alpha-methyl-para-tyrosine dose-response curve for tyrosine hydroxylase was performed, resulting in a dose for alphamethyl-para-tyrosine which no longer produced an increase in the slope of the depletion curve for NE. It was at this dose $(400 \mathrm{mg} / \mathrm{kg})$ that all synthesis of NE by tyrosine hydroxylase had been inhibited (Figure 2),(Nagatsu, et al., 1964; Spector, et al., 1965; Volicer and Reid, 1969; Costa, 1971; Ostman-Smith, 1979).

C. RESULTS

1. Monoamine oxidase activity in three brain regions.

The effects of preincubation with tissue homogenate with triiodothyronine ( $\left.T_{3}\right)$ on MAO activity in three rat brain regions (corpus strlatun, forebrain and hypothalamus) has been measured using 
in vitro techniques and employing either $c^{14}$-tryptamine or $c^{14}$ serotonin as substrate. In these studies concentrations of $T_{3}$ of $10^{-9} \mathrm{M}$ and highar significantly reduced MAO activity in all brain regions studied. MAO activity was reduced by $20-40 \%$, regardless of length of preincubation time with $T_{3}(0,15,30$ or 60 ninutes) (Appendix section, Figure 7 and Tables 29-34). In the hypothalamic preparation at least 30 minutes of preincubation with $T_{3}$ was required for Mo inhibition. Similar results were obtained when preincubation times were 0 , 15 or 30 minutes; and whether using $C^{14}$-tryptamine or $C^{14}$-serotonin as substrate.

At the $t$ ime of sacrifice $T_{3}$ and $T_{4}$ administered animals were found to have a decreased body weight ( $24 \pm 5$ grams), whereas saline administered animals gained $54 \pm 11$ grams

One to eight days of S.C. administra,ion of $T_{3}(1 \mathrm{mg} / \mathrm{kg} /$ day $)$ resulted in no consistent changes in MAO activity when the animals were sacrificed 24 hours after the last $T_{3}$ injection, when $C^{14}$-serotonin was used as substrate (Table 2). Similar results were obtained when $C^{14}$-tryptanine was used as substrate and when thyroxine $\left(T_{4}\right)$ was employed instead of $\mathrm{T}_{3}$ (Appendix section, Tables 35, 36, and 37 ).

At the conclusion of these in vivo $\mathrm{T}_{3}$ and $\mathrm{T}_{4}$ studies, we investigated the interactions of $T_{3}$ administration and subsequent protriptyline administration on MAO activity in corpus striatum, forebrain and hypothalamus. We chose to use only $T_{3}$ in these studies since it is the more active form of the thyroid hormones and is more potent, faster acting and more rapidly metabolized (Tata, 1964; Prange, et al., 1970; 
TABLE 2 The effect of triiodothyronine on monoamine oxidase activity in three brain regions.

\begin{tabular}{|c|c|c|c|c|c|c|c|}
\hline \multirow{2}{*}{\multicolumn{2}{|c|}{$\begin{array}{l}\text { Days of } \\
\text { Injection }\end{array}$}} & \multicolumn{2}{|c|}{ Corpus Striatum } & \multicolumn{2}{|c|}{ Forebrain } & \multicolumn{2}{|c|}{ Hypothalamus } \\
\hline & & Saline & $\mathrm{T}_{3}$ & Saline & $\mathrm{T}_{3}$ & Saline & $T_{3}$ \\
\hline No & Injection & $\cdots---0.460$ & $0.03-\ldots$ & ----0.476 & $0.04 \ldots \ldots$ & ----0.256 & $0.02 \ldots$ \\
\hline & 1 & $0.543 \pm .05^{1,2}$ & $0.410 \pm .06$ & $0.729 \pm .16$ & $0.580 \pm .10$ & $0.254 \pm .03$ & $0.183 \pm .02$ \\
\hline & 2 & $0.468 \pm .03$ & $0.509 \pm .06$ & $0.499 \pm .05$ & $0.493 \pm .03$ & $0.264 \pm .04$ & $0.271 \pm .03$ \\
\hline & 3 & $0.666 \pm .05$ & $0.622 \pm .11$ & $0.761 \pm .13$ & $0.768 \pm .13$ & $0.385 \pm .05$ & $0.310 \pm .04$ \\
\hline & 4 & $0.570 \pm .03$ & $0.520 \pm .06$ & $0.601 \pm .05$ & $0.565 \pm .03$ & $0.295 \pm .02$ & $0.258 \pm .02$ \\
\hline & 5 & $0.563 \pm .03$ & $0.425 \pm .03$ & $0.670 \pm .07$ & $0.575 \pm .09$ & $0.273 \pm .03$ & $0.228 \pm .02$ \\
\hline & 6 & $0.465 \pm .03$ & $0.568 \pm .12$ & $0.640 \pm .06$ & $0.582 \pm .04$ & $0.279 \pm .03$ & $0.301 \pm .03$ \\
\hline & 7 & $0.603 \pm .04$ & $0.598 \pm .08$ & $0.683 \pm .07$ & $0.680 \pm .09$ & $0.299 \pm .02$ & $0.358 \pm .03$ \\
\hline & 8 & $0.521 \pm .04$ & $0.529 \pm .10$ & $0.719 \pm .09$ & $0.838 \pm .12$ & $0.315+.03$ & $0.249+.03$ \\
\hline
\end{tabular}

$N=6$ for each determination

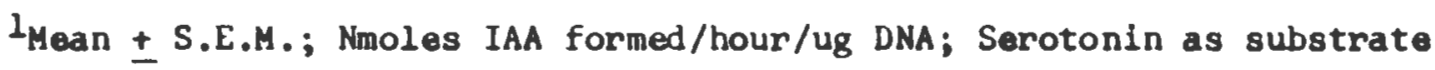

${ }^{2}$ No statistical significance was observed between any of the time pts. examined 
Oppenheimer, 1975; Oppenheimer, 1979). No further data involving $\mathrm{T}_{4}$ administration are presented.

The $T_{3}$ and protriptyline studies were performed since previous investigators (Prange, et al., 1969; Hilson, et al., 1970; Earle, 1970; Whybrow, et al., 1972) have documented that thysoid hormone, when administered with tricyclics, produces a quicker clinical improvement in depressed patients. In these studies animals were made hyperthyroid by seren consecutive S.C. injections of $\mathrm{T}_{3}(1 \mathrm{mg} / \mathrm{kg} / \mathrm{day})$, a regiment previously shown to produce physiological changes analogous to hyperthyroidism (Hammond, 1968; Kennedy, et al., 1977). On the seventh day following their last $\mathrm{T}_{3}$ infection, animals received one injection of protriptyline (10 mg/kg - S.C.); three hours after receiving protriptyline all animals had perished; convulsing prior to death (Table 3 ).

The next group of experiments involved simultaneous administration of $T_{3}(1 \mathrm{mg} / \mathrm{kg}-\mathrm{S.C.})$ and protriptyline $(10 \mathrm{mg} / \mathrm{kg}-\mathrm{S.C.})$. Six hours after the second simultaneous injection of $\mathrm{T}_{3}$ and protriptyline all animals perished, convulsing prior to death (Table 4).

These results (Tables 3 and 4 ) agree with those of other investigators, and suggest that $T_{3}$ pretreatment enhances the toxicity of many centrally acting drugs (Carrier and Buday, 1961; Conney and Garren, 1961; Prange and Lipton, 1962; Coville and Telford, 1970; Park, et al., 1972; Breese, et al., 1974).

Animals surviving sinultaneous administration of protriptyline ( 5 and $1 \mathrm{mg} / \mathrm{kg}$ ) and $T_{3}(0.1 \mathrm{mg} / \mathrm{kg})$, resulted in MAO activity levels which 
TABLE 3 In vivo effects of protriptyline administration on hyperthyrold animals. I

Protriptyline dosage

$10.0 \mathrm{mg} / \mathrm{kg}$

$5.0 \mathrm{mg} / \mathrm{kg}$

$1.0 \mathrm{mg} / \mathrm{kg}$
Results ${ }^{2}$

death within 3 hours

death within 3 hours

death within 6 hours

${ }^{1}$ Hyperthyroid animals had received 7 consecutive injections of $T_{3}(1 \mathrm{mg} / \mathrm{kg} /$ day $)$ for 7 days, prior to protriptyline administration

${ }^{2} \mathrm{~N}=5$ for each group 
TABLE 4 In vivo toxic effects of simultaneous adninistration of trilodothyronine and protriptyline on the rat.

\begin{tabular}{|c|c|c|c|}
\hline \multicolumn{2}{|c|}{ Protriptyline dosage } & $\begin{array}{c}T_{3} \text { dosage } \\
(\mathrm{mg} / \mathrm{kg} / \mathrm{day}-\mathrm{s.c.})\end{array}$ & Results ${ }^{I}$ \\
\hline Group 1 & 10.0 & 1.0 & $\begin{array}{l}\text { death, 2nd day within } \\
6 \text { hours of infections }\end{array}$ \\
\hline Group 2 & 5.0 & 1.0 & $\begin{array}{l}\text { death, 2nd day within } \\
6 \text { hours of injections }\end{array}$ \\
\hline Group 3 & 1.0 & 1.0 & $\begin{array}{l}\text { death, 3rd day within } \\
6 \text { hours of injections }\end{array}$ \\
\hline Group 4 & 10.0 & 0.5 & $\begin{array}{l}\text { death, 3rd day within } \\
6 \text { hours of injections }\end{array}$ \\
\hline Group $5^{2}$ & 5.0 & 0.5 & $\begin{array}{l}\text { death in } 3 \text { of } 5 \text { animals } \\
\text { within } 6 \text { hours after } \\
\text { last injections }\end{array}$ \\
\hline Group $6^{2}$ & 1.0 & 0.5 & $\begin{array}{l}\text { death in } 2 \text { of } 5 \text { animals } \\
\text { within } 6 \text { hours after } \\
\text { last injections }\end{array}$ \\
\hline Group $7^{2}$ & 10.0 & 0.1 & $\begin{array}{l}\text { death in } 4 \text { of } 5 \text { animals } \\
\text { within } 6 \text { hours after } \\
\text { last injections }\end{array}$ \\
\hline Group $8^{3}$ & 5.0 & 0.1 & $\begin{array}{l}\text { all animals survived } 7 \\
\text { simultaneous injections }\end{array}$ \\
\hline Group $9^{3}$ & 1.0 & 0.1 & $\begin{array}{l}\text { all animals survived } 7 \\
\text { simultaneous injections }\end{array}$ \\
\hline & $\begin{array}{l}1_{N}=5 \\
{ }^{2} \text { Group } \\
\text { errat } \\
{ }^{3} \text { Group } \\
\text { and } i\end{array}$ & $\begin{array}{l}\text { each group of anin } \\
6 \text { and } 7 \text { MAO activi } \\
\text { hen measured in the } \\
\text { and } 9 \text { MAO activity } \\
\text { sistent }\end{array}$ & $\begin{array}{l}\text { Levels were extremely } \\
\text { spective brain regions } \\
\text { els were again erratic }\end{array}$ \\
\hline
\end{tabular}


were not reproducible, between animals of the same group, and were inconsistent when one group was compared to another group.

Our thyroidectomized $(T x)$ and sham-operated animals underwent surgery at seven weeks of age and eight weeks prior to sacrifice. During the efght week time interval, total body weight recordings of animal growth were maintained. During this interval ix animals gained approximately $30 \pm 8$ grams; paired controls (sham-operated) gained 150 to 200 grams. This observation, that Tx animals exhibit deficient growth patterns, has been previously documented (Fleischmann, 1947; Barker, 1949; Eayrs and Taylor, 1951).

The data obtained for MAO activity levels in the three brain regions we examined are presented in Table 5. As illustrated in Table 5 the Tx group clearly exhibits a significant reduction in MAO activity levels regardless of substrate employed or brain region examined, when these values are compared to age-matched sham-operated controls.

Since Tx decreased MAO activity in the brain regions we examined, our next group of experiments investigated possible changes in MAO activity in both $\mathrm{Ix}$ and sham-operated aninals following protriptyline administration (10 mg/kg/day-S.C.). Animals were administered protriptyline acutely (one injection) and subchronically (3 or 6 consecutive daily injections, S.C.). Animals were sacrificed at varying time intervals following the last administration of protriptyline. These results are presented in the Appendix section (Tables 11,12 and 13). 
TABLE 5 The effect of thyroidectony on MAO activity in three brain regions

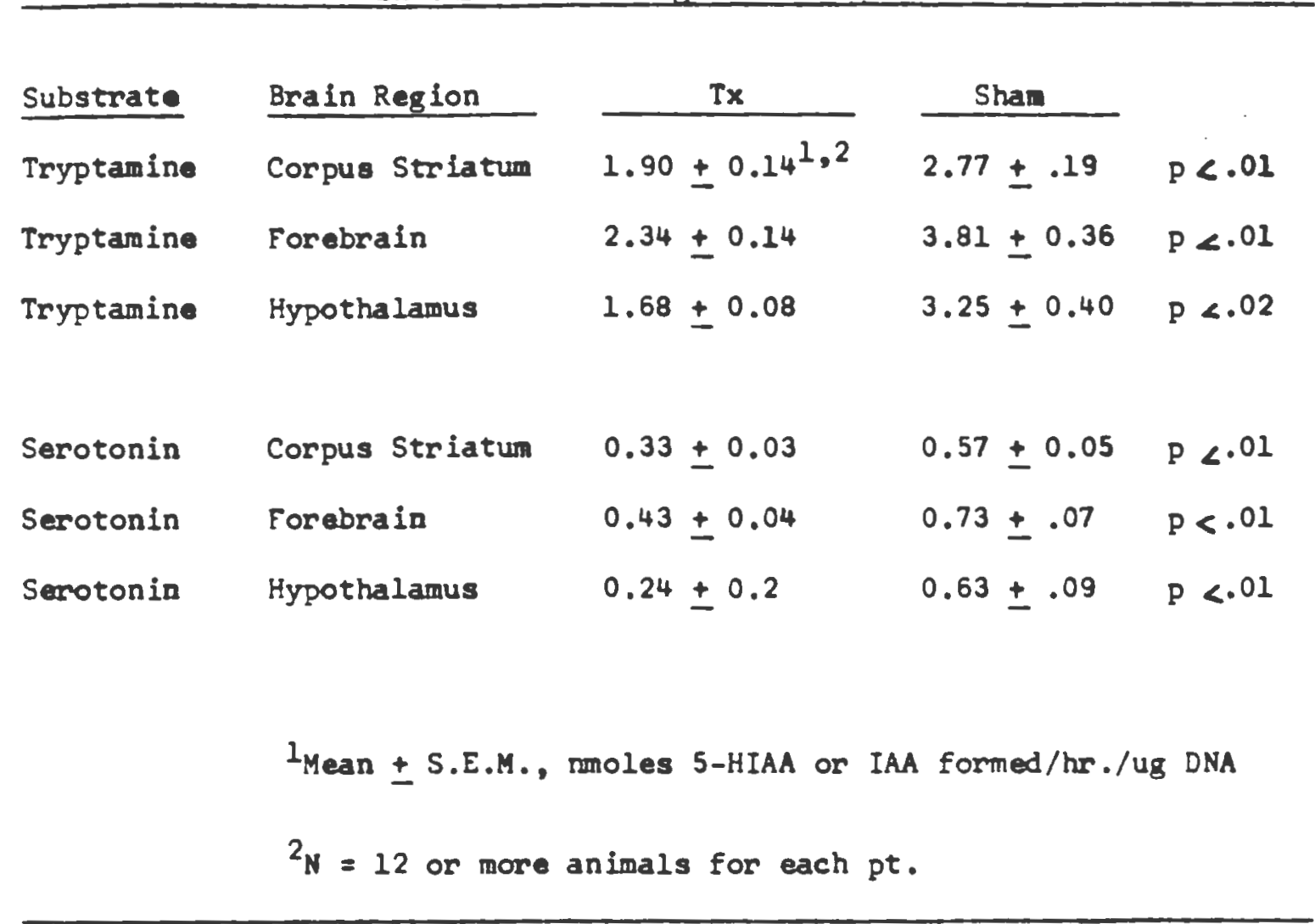

Statistically significant differences between groups have been indicated; however, MAO activity levels are inconsistent, and no pattern for these changes in MAO activities exist.

2. Norepinephrine levels.

Prior to determining tissue levels of NE, NE concentrations were determined in known standard samples using fluorometric techniques. A standard curve was established and has been illustrated in the Append Lx section (Figure 24). Following the determination of the NE external standard curve, labelled NE (DI-H ${ }^{3}$-norepinephrine) was added to 
experimental samples to serve as an internal standard for our alumina colum recovery. These data have been presented in the Appendix section (Figure 25).

Norepinephrine levels have been quantitatively determined in the hypothalamus of $T_{3}$ pretreated animals, $\mathrm{TX}$ and sham-operated controls. These values are illustrated in Figure 1. Seven days of S.C. T3 administration ( $1 \mathrm{mg} / \mathrm{kg} / \mathrm{dag}$ ) significantly reduced the $\mathrm{NE}$ levels in hypothalamus $(p<0.01)$. On the other hand, neither Tx nor sham-operated control animals displayed significantly altered NE levels in hypothalamus. Numerical values for these data as well as for corpus striatum and forebrain are presented in the Appendix section (Table 38 ).

3. Norepinephrine turnover.

The rate and extent of depletion of $N E$ after administration of alpha-methyl-para-tyrosine (MT) (Spector, et al., 1965; Brodie, et al., 1966; Spector, et al., 1967; Weiner, 1974; Ostman-Smith, 1979), has been studied as a measure for assessing NE turnover in control animals (saline administered), $\mathrm{T}_{3}$ injected ( $1 \mathrm{mg} / \mathrm{kg} /$ day-7 days), Tx (7 weeks of age, 8 weeks prior to sacrifice), and in sham-operated Tx controls.

Prior to assessing NE turnover with MT a dose-response curve for tyrosine hydroxylase inhibition was conducted. Literature values (Brodie, et al., 1966; Spector, et al., 1967) for effective tyrosine hydroxylase (TH) inhibition indicate that $200 \mathrm{mg} / \mathrm{kg}$ MT (IP), is necessary with an additional booster administration every two hours to maintain inhibition. However, a single $400 \mathrm{mg} / \mathrm{kg}$ injection of MT will inhibit TH for 3.5 hours. The results of our dose-response curve are represented 


\section{FIGURE 1}

TITLE: The effect of thyroidectomy and of administration of triladothyronine on norepinephrine levels in the hypothalamus

\section{LEGEND}

Norepinephrine concentration per gram of tissue wet weight was measured in the hypothalamus in animals made hyperthyroid by 7 days of administration of triiodothyronine ( $1 \mathrm{mg} / \mathrm{kg}$ seven daily injections, S.C.), in animals thyroidectomized at 7 weeks of age, 8 weeks prior to measurement, and in sham operated controls, in comparison to saline injected controls. The cross-hatched band illustrates the mean \pm S.E. for saline injected controls $(n=70)$. Vertical bars indicated the mean, S.E. and number of animals in each experimental group. The result for the $T_{3}$ treated group (*) is significantly less than control ( $\mathrm{p}<.01$, $t$-test). 


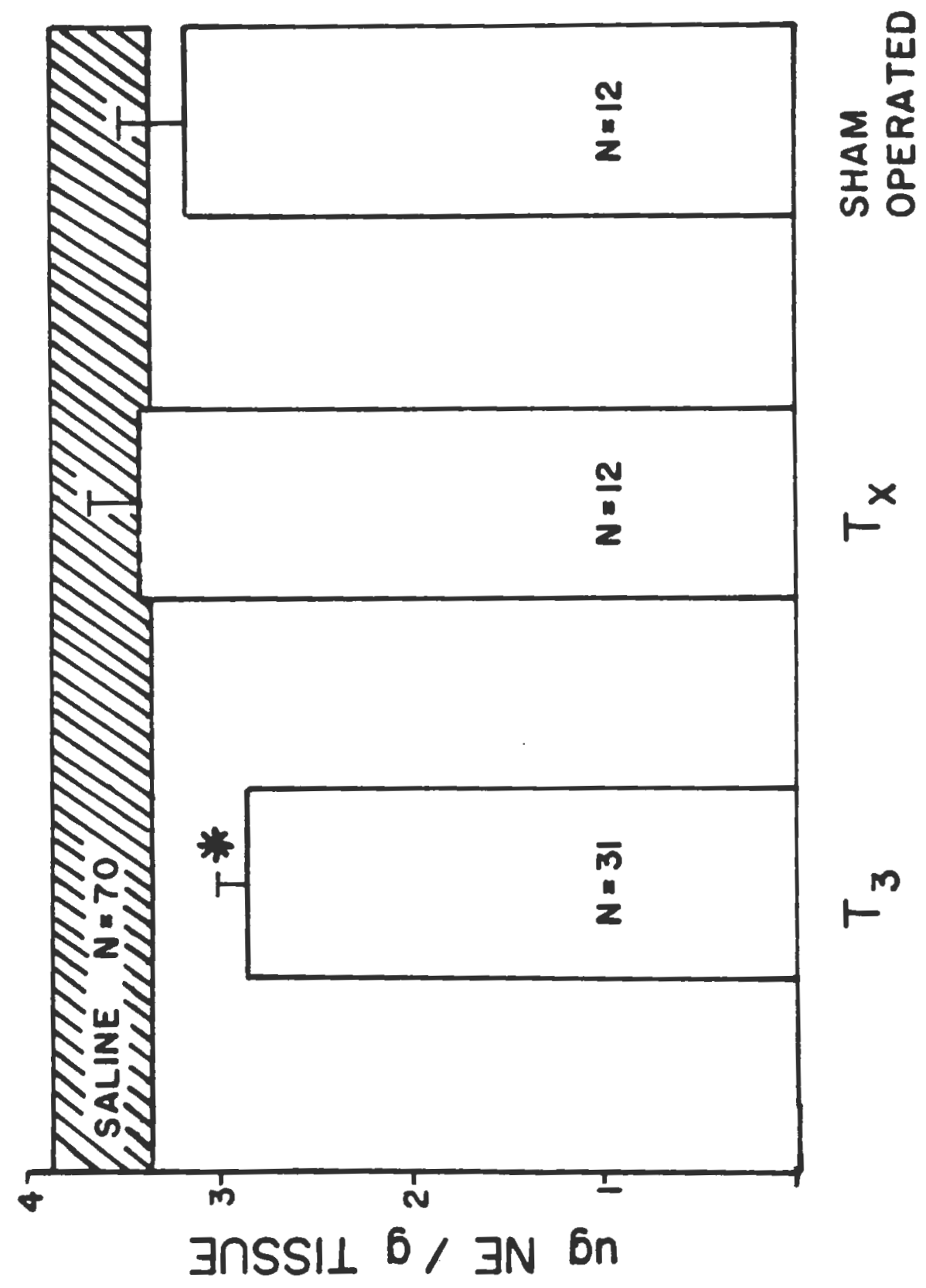


in Figure 2. The numerical values for this plot can be found in the Appendix section (Table 39). Figure 2 illustrates NE levels in the hypothalamus 3 hours after a MT administration of 200,400,600 and 800 $\mathrm{mg} / \mathrm{kg}$ - I.P.. We chose to use the $400 \mathrm{mg} / \mathrm{kg}$ dose in NE turnover studies. A similar MT dose-response curve was performed for $T_{3}$ administered aninals ( $1 \mathrm{mg} / \mathrm{kg} /$ day -7 days). Trilodothyronine administration increases tyrosine hydroxylase activity (Jacoby, 1975; Strombom, et al., 1977 ; Kennedy, et al., 1977), and this study was conducted to insure complete tyrosine hydroxylase inhibition at the $400 \mathrm{mg} / \mathrm{kg}$ dose. All data are presented in the Appendix section (Table 40) for corpus striatum, forebrain and hypothalamus. This dose was found to be effective, fully inhibiting tyrosine hydroxylase in pretreated hyperthyroid animals. No MT dose-response curve was performed for Tx animals.

Figure 3 reports NE depletion, when $400 \mathrm{mg} / \mathrm{kg}$ MT was administered to control animals that were sacrificed at varying time points after MT administration. The numerical data for each point, slope and regression coefficient in this plot, as well as for corpus striatum and forebrain (which are not presented graphically) can be found in the Appendix section (Table 41).

Figure 4 reports the results obtained for NE levels in hypothalamus after MT has been administered to hyperthyrold animals ( $1 \mathrm{mg}$ ) $\mathrm{kg} /$ day -7 consecutive days). Numerical values for each point in this plot, as well as for corpus striatum and forebrain are listed in the appendix section (Table 42 ). 


\section{FIGURE 2}

TITLE: NE levels in hypothalamus following MT administration: A dose-response curve.

LEGEND

NE levels were determined in hypothalamic tissue of the rat three hours after the administration of various doses of MT $(200,400,600$ and $800 \mathrm{mg} / \mathrm{kg}$ - I.P.). Each point represents the MEAN $\pm S . E$. for three or more determinations. There was no statistically significant difference in NE levels in hypothalamic tissue following the administration of 400,600 or $800 \mathrm{mg} / \mathrm{kg} \mathrm{MT}$. 


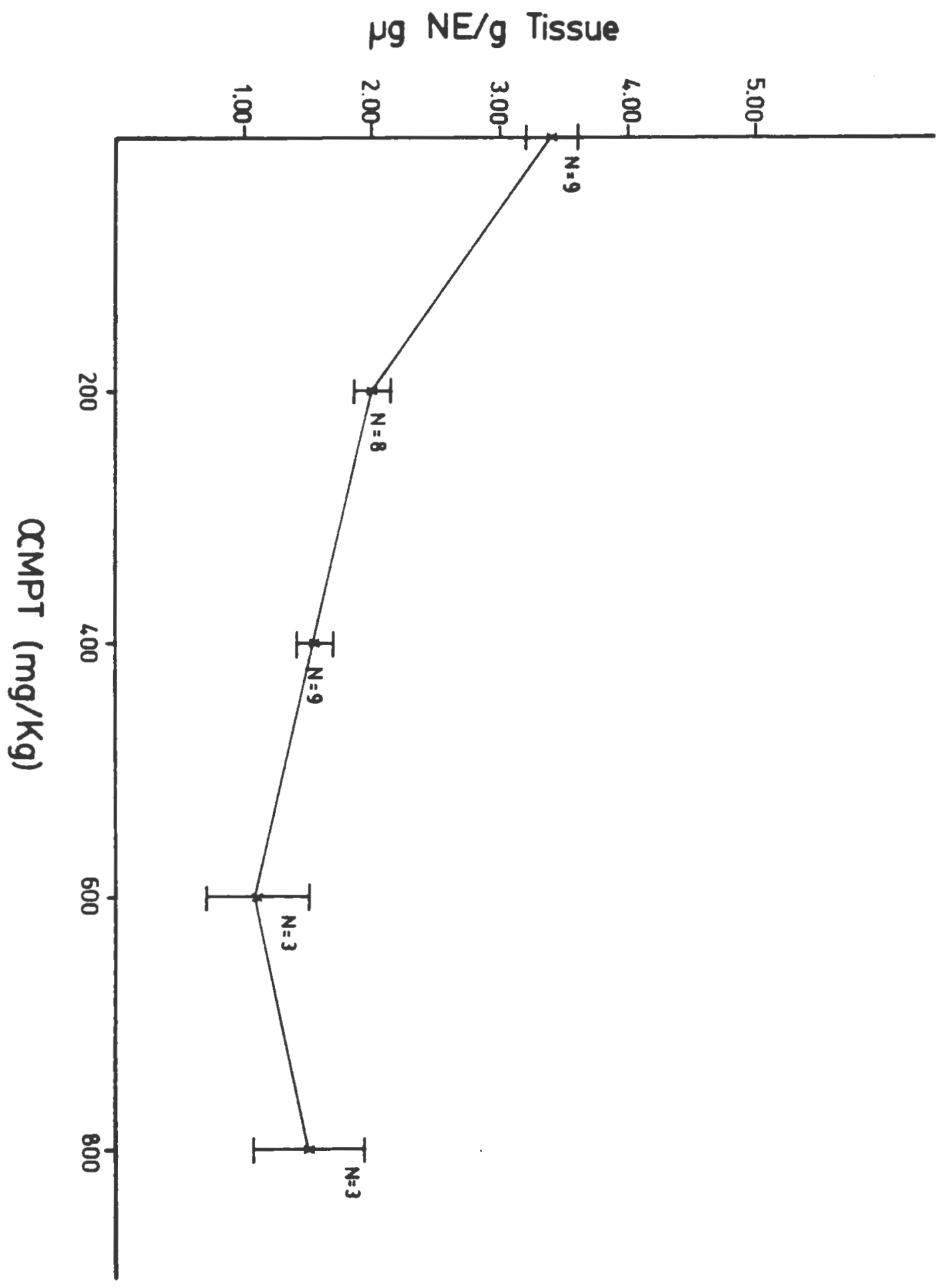


FIGURE 3

TITLE: NE depletion in hypothalamic tissue in control animals following administration of MT (400 mg/kg - I.P.).

LEGEND

NE levels have been determined in control animals at different time intervals following the administration of MT $(400 \mathrm{mg} / \mathrm{kg}$ I.P.). Each point represents the MEAN \pm S.E. for five or more determinations. NE has been maximally depleted 4.5 hours after MT administration at the dosage of MT. 


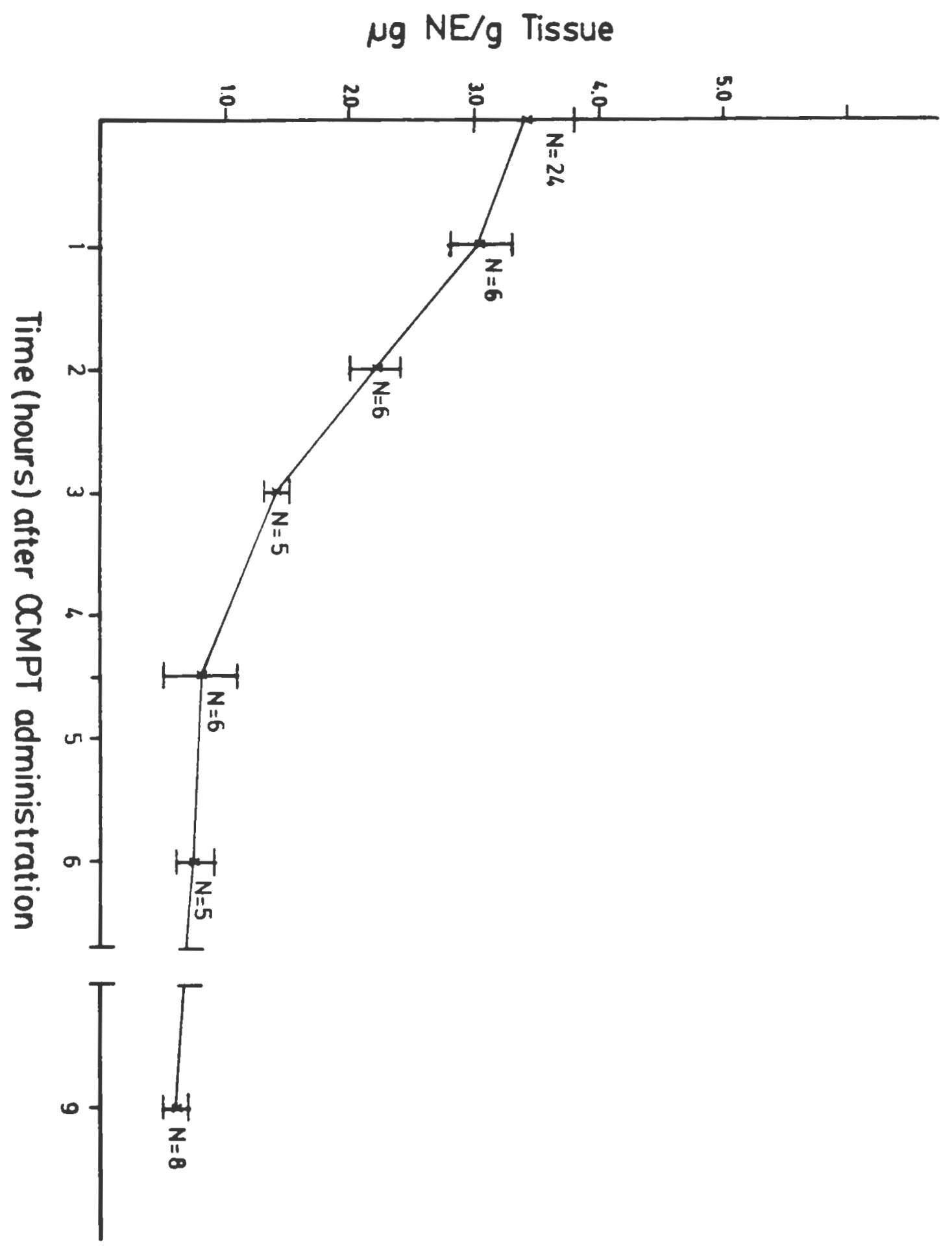




\section{FIGURE 4}

TITLE: Turnover of norepinephrine in the hypothalamus of rats treated with triiodothyronine.

\section{LEGEND}

Animals were sacrificed $0,1,2,3,4,5$. or 6 hours after administration of a-MT ( $400 \mathrm{mg} / \mathrm{kg}$, I.P.) and norepinephrine levels were measured in the hypothalamus. Each point represents the mean and standard emror for a group of five animals except the zero time point which is derived from a group of 30 animals. Triiodothyronine-treated animals $(-x-)$ were injected daily for seven days ( $1 \mathrm{mg} / \mathrm{kg}$, S.C.). 


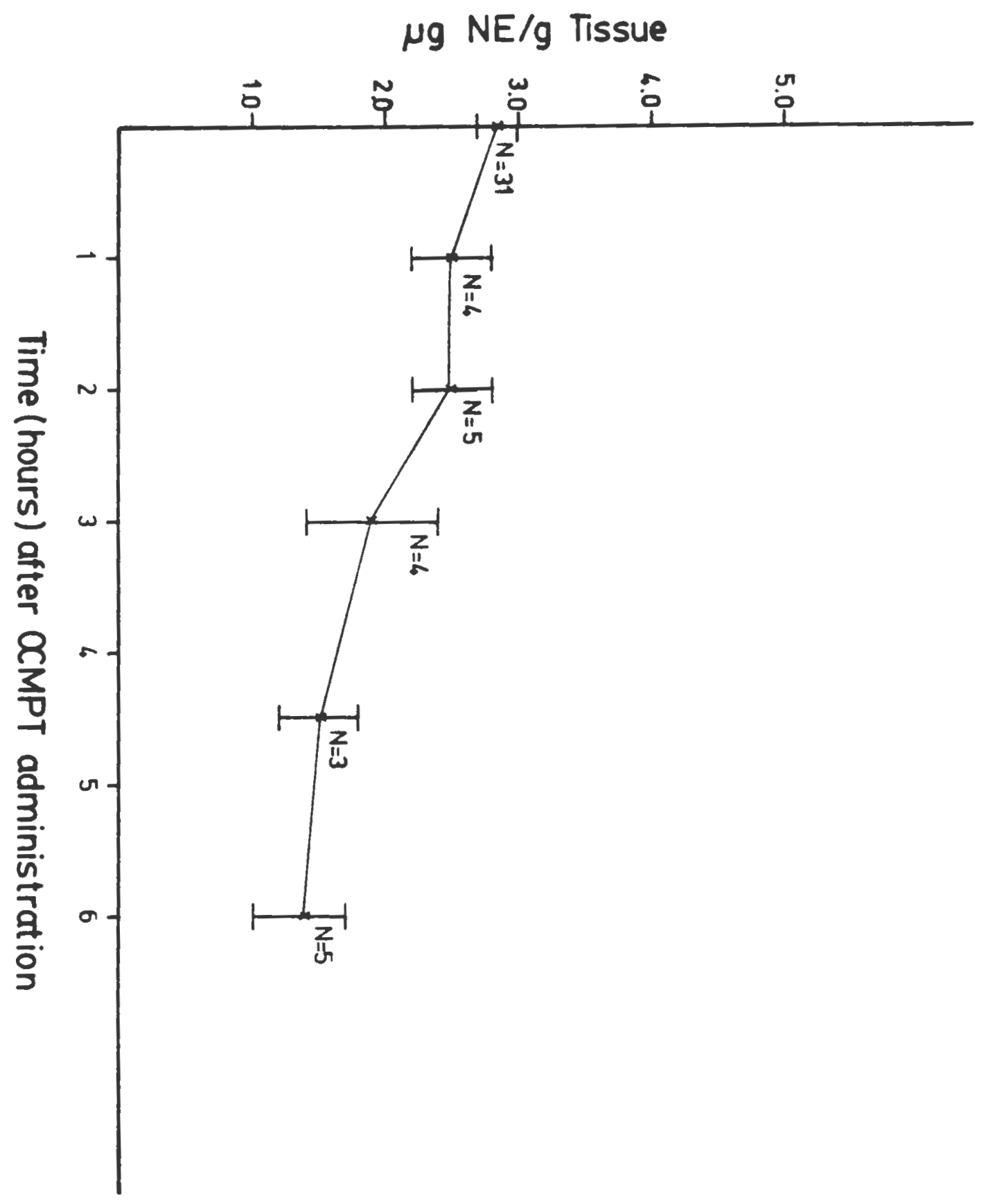


Figure 5 depicts the data from Figures 3 and 4 when these values are plotted as initial concentration of NE.

The results of NE depletion following administration of MT $(400 \mathrm{mg} / \mathrm{kg}$ - I.P.) in thyroidectomized (TX) animals and age-matched, sham-operated controls are illustrated in Figure 6. Eight weeks after TX, NE turnover is increased; however, repletion has also occurred more quickly. Numerical data for these points, as well as for corpus striatum and forebrain are listed in the Appendix section (Tables 43 and 44 ).

D. DISCUSSION

Our second hypothesis was that simultaneous administration of thyroid hormone potentiates the action of TCA drugs through an effect on MAO activity, NE turnover and/or NE cellular levels. Our data indicate that $\mathrm{T}_{3}$ administration ( $1 \mathrm{mg} / \mathrm{kg} / \mathrm{day}-7$ days) produces no inhibition of MAO activity in vivo, although MAO inhibition was observed in vitro in these brain tissues. Similar results have been reported by other investigators for rat heart and kidney (Callingham and Lyles, 1974; Lyles and Callingham, 1976; Asaad and Clark, 1978). Trilodothyronine administration produced a significant decrease $(p<0.01$ ) in NE levels and NE depletion (turnover) in these brain regions when compared to saline administered animals.

Thyroidectomy, on the other hand, was associated with a decrease in MAO activity in these tissues. NE levels in these tissues were unchanged, however, an increase in both depletion and repletion rates was observed following MT administration. 
FIGURE 5

TITLE: NE depletion in hypothalamus as a measure of initial concentration three hours after MT administration (400 mg/kg - I.P.).

LEGEND

In control aninals (-0-) NE has been depleted 588 three hours after MT administration. In hyperthyroid animals $(-x-)$ NE has been depleted 358 three hours after MT administration (a 238 difference in NE turnover rate). A t-test for depletion rate resulted in a statistically significant difference between these two slopes $(p<0.01)$. 


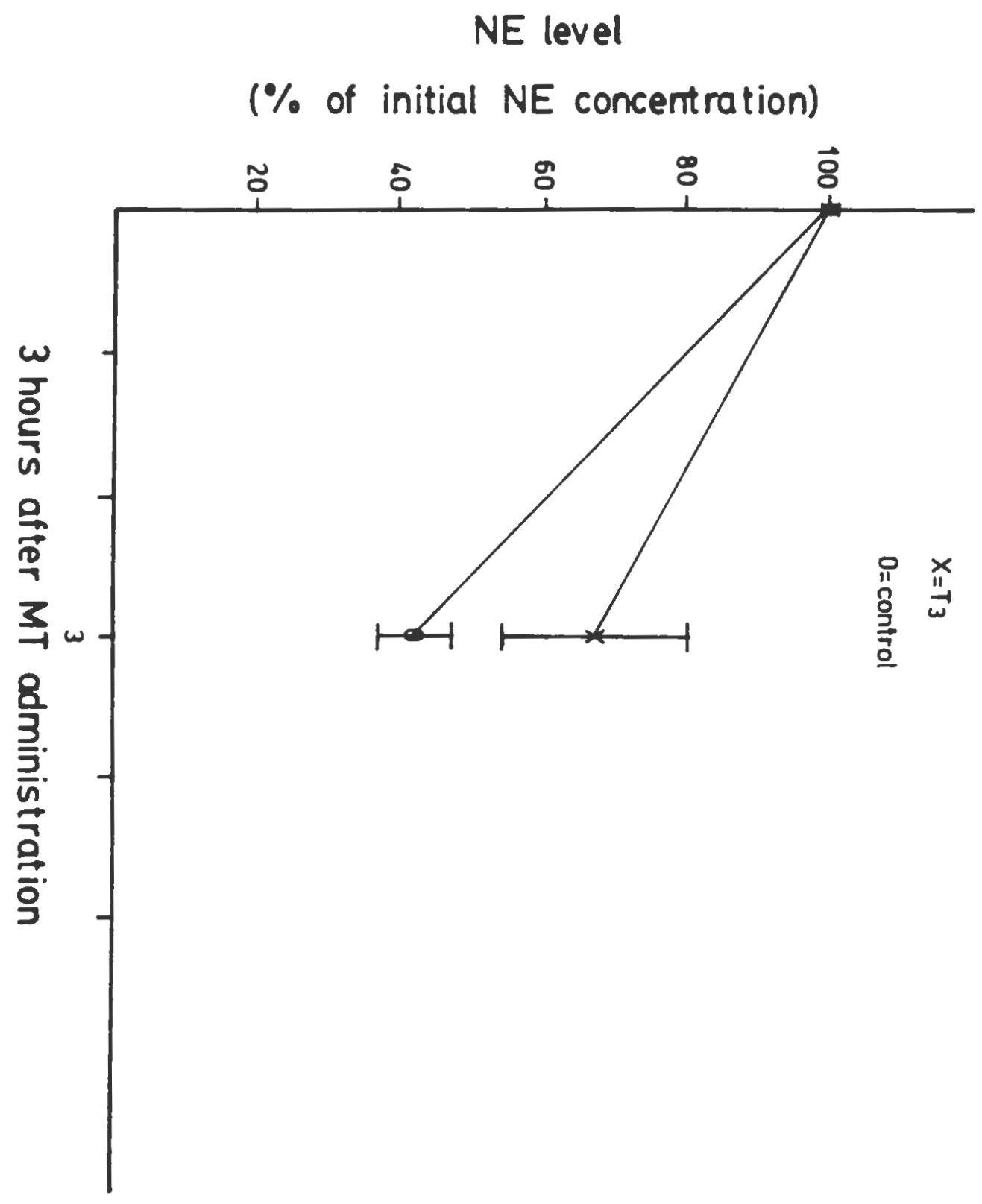




\section{FIGURE 6}

TITLE: Turnover of norepinephrine in the hypothalanus of thyroidectomized rats.

LEGEND

Animals were sacrificed $0,1,2,3,4,5,6$ or 9 hours after administration of a-MT (400 mg/kg, I.P.) and norepinephrine levels were measured in the hypothalamus. Thyroidectomized animals $\left(-x_{-}\right)$and sham operated controls $\left(-_{-}\right)$were compared. Each point represents the mean and standard error for a group of $s$ ix animals. The values for the thyroidectomized groups at $2,4,5$ and 6 hours differ significantly from controls ( $p<.05$ t-test). Regression analysis ( $t$-test) of the slopes between 0 and 2 hours indicated a significant difference $(p<.05)$. 


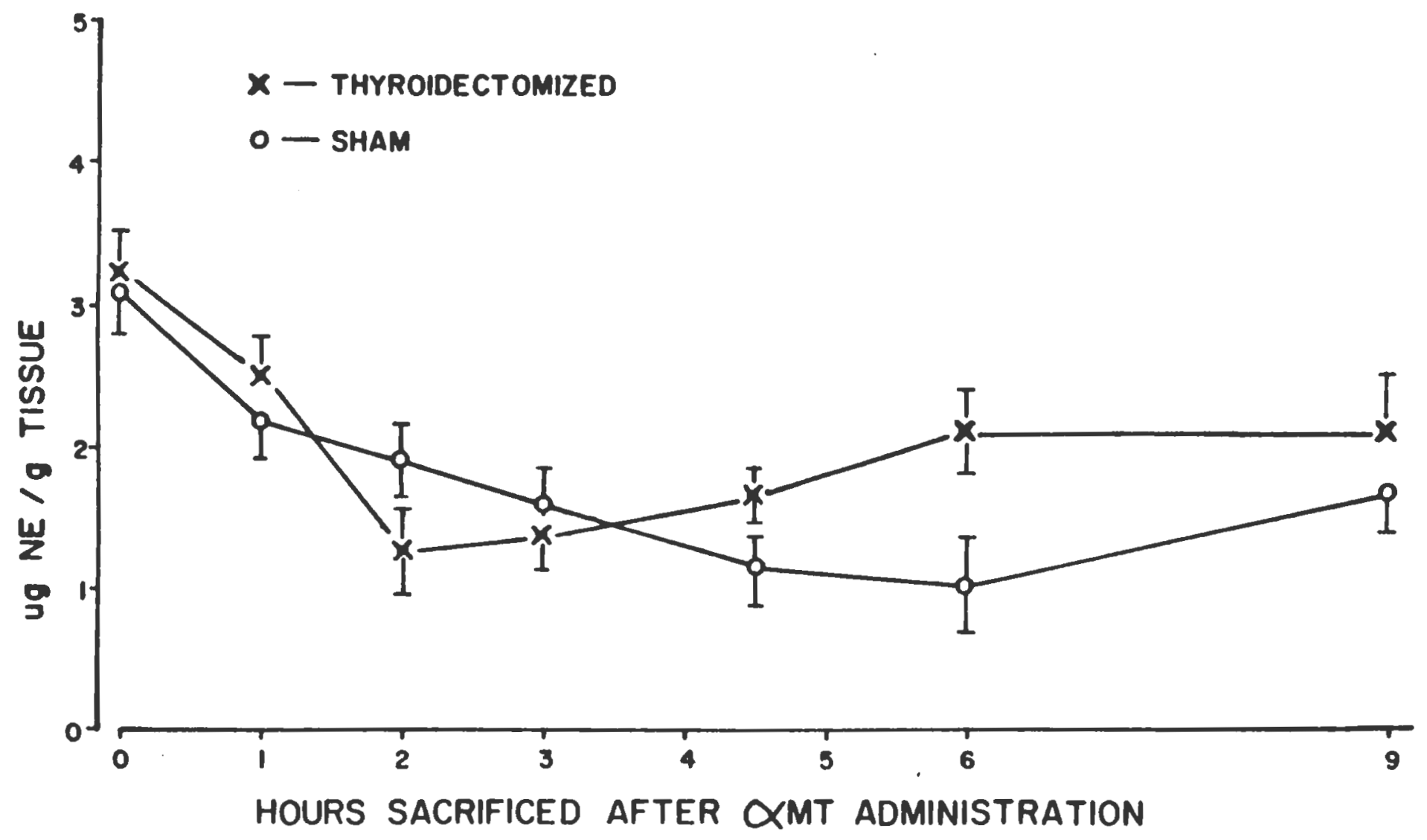


Also it was observed that when rats are made hyperthyroid by $\mathrm{T}_{3}$ administration and are then administered a single injection of protriptyline, the animals begin to convulse and die within six hours. Similar toxic results have been viewed by other researchers when employing imipramine (Prange and Lipton, 1962; Breese, et al., 1974). This observation remains unresolved. A possible suggestion for increased toxicity may be due to an increased interaction between $T_{3}$ and increased receptor sensitivity in heart tissue to catecholamines (Bax, et al., 1980; Chang and Kunos, 1981), thus accounting for the observed convulsions prior to death.

Reviewing our results, any interaction between thyroid hormone $\left(T_{3}\right)$ and MAO activity in these brain regions is inconclusive, except for significantly decreased MAO levels following thyroidectomy. Zile, (1960), has reported that $T_{3}$ administration does not effect whole brain MAO activity; we are in agreement with these results. MAO activity in peripheral tissues (heart, liver and kidney) following $\mathrm{T}_{3}$ administration however, has been shown to increase (Callingham and Lyles, 1974; Lyles and Callingham, 1974; Asaad and Clark, 1978), indicating organ specificity.

We feel our results indicate that $T_{3}$ does not effect brain MAO activity, and any alterations in MAO activity are non-specific. Thus, any interaction between the tricyclics and thyroid hormone is not related to MAO.

NE levels and turnover following $T_{3}$ administration or after thyroidectomy indicate a decrease in turnover in hyperthyroid rats 
in the brain regions we examined. These results are In agreement with Prange, et al., (1970). He observed decreased NE levels in the brain areas of hyperthyroid animals and these results are in agreenent with Engstron (1974). Landsberg and Axelrod (1968) presented data in heart tissue which is in agreenent with our data for brain tissue, that following thyroidectomy there is increased NE turnover. From these results it appears that our observations define situations in which adjustments in the parameters of functional norepinephrine activity occur contrary to what would be predicted by the NE hypothesis for affective disorders. He view these contrary changes in neurotransmitter parameters as adjustments that are compensatory in nature. Possibly a fundamental interaction occurs between thyroid hormone and brain NE mechanisms, which leads to an enhanced noradrenergic tone, predicted by the NE hypothesis for affective disorders; and that as a result of this yet-to-be-identified interaction, a compensatory decrease in NE turnover and NE levels result. Conversely, in thyroidectomized animals, the absence of this thyroid-hormone-induced facilltation of NE activity likewise triggers compensatory adjustments, i.e., decreased MAO activity and increased turnover. 
C H A P TER IV. 
C H A P T E R IV.

A. NOREPINEPHRINE: Norepinephrine and its functional relationship with the presynaptic receptor.

1. Norepinephrine levels and turnover.

The catecholanines (norepinephrine, epinephrine and dopamine)

are low molecular weight substances that contain a catechol nucleus and an amine group. Norepinephrine (NE), one of these catecholamines, is synthesized and secreted by mamalian nerve tissue and serves an important function both in neural and endocrine integration.

The amino acid tyrosine (the substrate precursor to $\mathrm{NE}$ ) is normally present in the circulation in levels between $10-15 \mathrm{mg} / 1$ (Spector, et al., 1963). Tyrosine is taken up from the bloodstream and concentrated within the brain and other neural tissues via an active transport mechanism (Chirigos, et al., 1960). Once inside the nerve cell ending or chromaffin cell, tyrosine undergoes a series of biochemical enzymatic transformations that ultinately lead to NE synthesis.

Norepinephrine is known by several different names: noradrenaline, levarternol and DL-arterenol all of which are trivial names for 3, 4dihydroxy-phenyl-ethanolamine (Himms-Hagen, 1967).

Knowledge of catecholamine synthesis began in the late 1930's with the discovery by Holtz (1939) of decarboxylase and by Blaschko's (1939) hypothetical but correct, biosynthetic scheme starting from the dietary substrate tyrosine.

Norepinephrine is primarily stored in a bound form in nerve cells within chronaffin granules or dense-core vesicles (Xirshner, 1974). 
This bound catecholamine further interacts with adenosine triphosphate (ATP) and forms a totracatecholamine-ATP complex. This salt is further bound to soluble proteins, the chromgranins, which are located within the storage particle. The inability of labelled exosenuous catecholamines to enter these storage granules suggests that the endogenous ATPamine complexes are still further combined with macromolecular components within the granules and form a still further stable complex (Weiner, 1970).

Results also suggest that NE is not located in a single pool, but that only a small percentage of neuronal $\sqrt{ } E$ is necessary for normal neural function (Glowinski, et al., 1966; Sulser and Sanders-Bush, 1970). NE thus exists in a large 'storage pool' and a much smaller 'functional pool' both of which are located within the nerve cell axoplasm.

Currently it is suggested that the functional pool contains newly synthesized NE, while the storage pool contains catecholamine which has been in the nerve cell for longer periods of time. This assumption is based upon the observation that newly synthesized NE is preferentially released during enhanced neural firing. Kopin, et al. (1968) has demonstrated that newly synthesized NE is preferentially released during stimulation of isolated cat spleen. In vivo studies have reported that utilization of newly synthesized NE is increased in response to certain stressful conditions; whereas, utilization of NE stored for longer time intervals was not affected (Thierry, et al. 1971; Glowinsk1, et al., 1972). 
Evidence also exists to suggest that in addition to containing newly synthesized NE, the functional pool also contalns NE which has been accumulated via the re-uptake process. Therefore, both newly synthesized NE as well as conserved NE are preferentially utilized through release in response to immediate stressful conditions (Potter, et al., 1962 ; Chidsey and Harrison, 1963).

The localization of $N E$ in cell bodles, axons, and axon terminals is not randon, but regulated by a specific set of chemical laws, which are still porrly understood. NE is present mainly in vesicles in nerve tissue. These vesicles are distributed along the axon and at the nerve endings. NE in these vesicles is in a state of equilibrium with unbound NE in the cellular fluids of the cytoplasm. Cytoplasmic NE is available for destruction by MAO and for linited leakage or diffusion out of the cell.

$N E$ released presynaptically by stimulation is primarily transported back into the presymaptic neuron $(80 \%)$ and is then once again bound in these presynaptic vesicles. This prevents degradation by MAO and preserves intracellular NE (Kopin, 1966; Titus and Dengler, 1966). The re-uptake of NE by active transport and binding into the presynaptic vesicles protects NE from depletion and destruction by MAO. MAO, therefore plays an important role in the regulation of the "free" intracellular levels of NE. Very small quanta of the presynaptically released NE reaches the post-synaptic target tissue. Synaptic NE may be 0-methylated and excreted, or can be excreted "free" or conjugated as glucuronides or sulfonates (Kopin, 1964; Axelrod, 1966). 
Norepinephrine which has leaked from storage vesicles into the axoplasa is rapidly metabolized to physiologically inactive producta (Kopin, 1964; Axelrod, 1966). Enzymatic destruction of NE by MAO appears to serve primarily as a means for the degradation of NE within the cell, thus limiting the concentration of free NE in the inactive cytoplasmic compartment and also controlling NE synthesis and the level of bound NE. Complete intraneuronal deamination of NE and other catecholamines by MAO readily occurs if uptake and storage into synaptic vesicles is blocked (i.e. reserpine, or cocaine administration) (Burn and Rand, 1968; Helner, 1970).

Catechol-0-methyl-transferase (COMT), another enzyme responsible for the degradation of catecholamines, is apparently unimportant in the metabolization of intraneuronal NE. COMT is significantly involved in the catabolism of circulating catecholamines, which occurs chiefly in the Liver and kidney.

The third hypothesis this research attempts to investigate relates changes in cellular NE levels and turnover to acute subchronic and chronic tricyclic administration, and these changes parallel their delayed clinical efficacy. As stated earlier the "catecholamine hypothesis for affective disorders" proposes that some, if not all depressions are associated with an absolute or relative deficiency of catecholamines, particularly NE, at the functionally important adrenergic receptor sites in the brain. Consequently, studies have shown that drugs which cause depletion and inactivation of NE in brain produce sedation or depression, whereas, drugs which increase or potentiate brain NE are 
associated with behavioral stimulation or excitation and generally produce or exert an antidepressant effect in man.

Because a lag-time is evident between tricyclic administration and clinical efficacy (Schildkraut, et al., 1970; Schildkraut, et al., 1971; Sulser and Sanders-Bush, 1971; Leonard, 1975; Leonard and Kafoe, 1976; and Berger, 1978), this aspect of this study will examine possible changes in intracellular $\mathrm{NE}$ and also turnover rates and attempts to observe if these changes parallel the time course for clinical efficacy for this class of antidepressant agents.

Because brain NE levels are maintained constant in the face of conditions which alter nerve firing rate, It has been suggested that $N E$ which is utilized during enhanced neuronal firing is replaced by an increase in NE synthesis (Weiner, 1970; Costa and Meek, 1974; Bjorklund, et al., 1976; and Ostman-Smith, 1979). This compensatory mechanism has been termed "the theory of steady-state kinetics."

The mechanism by which increased noradrenergic nerve activity results in the stimulation of increased NE synthes is is not known. The most concrete explanation however, is that nerve stimulation releases $\mathrm{NE}$ from a nerve teminal, which consequently results in decreased intraneuronal $N E$ concentrations. Since $N E$ competetively inhibits its own synthesis by interfering with the pteridine cofactor required by tyrosine hydroxylase (Udenfriend, et al., 1965; Gordon, et al., 1966; Kennedy, et al., 1977), nerve stimulation would result in a decrease in negative feedback Inhibltion of tyrosine hydroxylase. The converse also applies 
(Spector, et al., 1965; Spector, 1966; Spector, et al., 1967; and Weiner, 1970). It is therefore approprlate for one to conclude that NE synthesis is controlled by a small, chemically undetectable pool of intraneuronal cytoplasmic NE.

The term "turnover" refers to a process of renewal of a substance in an organ. The concept of turnover implies that the substance being renewed exists at some steady-state level, which is balanced by identical rates of influx and efflux. In the case of brain $\mathrm{NE}$ the rate of $\mathrm{NE}$ influx equals the rate of $\mathrm{NE}$ syntehsis, since endogenous $\mathrm{NE}$ cannot enter the brain via the circulation due to the blood-brain barrier (Dobbing, 1961; Guroff and Udenfriend, 1962; Bertler, et al., 1966; and Oldendorf, 1974). The rate of efflux is determined by release of NE into the circulation and resultant metabolic destruction by MAO or COMT. Assuming that $N E$ levels are maintained at some steady-state value, the $N E$ influx rate (synthesis rate) would equal the NE efflux rate. Then this rate, which may be estimated by any method which can measure NE turnover, would give the investigator an indication of the rate at which brain NE is synthesized and utilized, which then, may be used as an indicator of central noradrenergic activity.

Many methods for measuring NE turnover exist and have been reviewed extensively by others (Costa and Neff, 1968; Costa, 1970; Costa and Neff, 1970; and Weiner, 1974). The method employed here is a measurenent of the rate of decline of endogenous brain NE after inhibition of tyrosine hydroxylase by alpha-methyl-para-tyrosine. This method was first described by Brodie, et al., (1966). 
Synthesis inhibition is accomplished by employing alpha-methylpara-tyrosine, (MT), an in vivo reversible inhibitor of tyrosine hydroxylase (TH), the rate-limiting step in NE synthesis (Spector, et al., 1965; and Spector, 1968). After blockade of NE synthesis, brain NE levels decline in a monoexponential fashion (Brodie, et al., 1966), 1.e. the concentration of NE declines at a rate that is proportional to the NE concentration remaining in the neuronal cytoplasm at any given time. This phenomena may be viewed as "the rate of NE utilization," and at the steady-state, "the rate of synthesis," which is proportional to cytoplasmic NE concentrations.

Therefore it was imperative that we investigate the noradrenergic effects caused by tricyclic administration during acute, subchronic and chronic treatment schedules, and thus possibly identify biochemical changes in NE levels and turnover rates. These data may then add support in identifying noradrenergic mechanisms necessary for latent clinical efficacy.

2. Presynaptic autoreceptor modulation of noradrenergic mechanisms. Before introducing the concept "presynaptic alpha-receptors" (Norberg and Hamerger, 1964; Langer, 1974; Berthelsen and Pettinger, 1977; Malbon, 1979; U'Prichard and Synder, 1979), it is first necessary to examine the processes involved in NE release from presynaptic noradrenergic nerve terminals. NE is synthesized from the amino acid tyrosine, and is stored in vesicles in the neuroplasm. These vesicles in turn migrate to the nerve cell membrane, and release transmitter when an action potentlal arrives. It has also been demonstrated that an 
influx of calcium into the neuroplast causes these $\mathrm{NE}$ containing vesiclea to migrate to the neuronal membrane (Rubin, 1970; Blaustein, et al., 1972; Phillis, 1974). The nechanisw involved in this migration is still unclear. At the membrane, fusion occurs, and these vesicles discharge their contents into the synaptic cleft. These vesicles then re-form after discharge and are again filled with transmitter from the neuroplasm.

Brown and Gillespie (1957) first suggested that this release may be modulated by another mechanism, in addition to the arrival of an action potential. They also noted that the alpha-blocking agent phenoxybenzamine increased the overflow of $\mathrm{NE}$ in cat spleen caused by repeated nerve stimulation.

Other studles conducted by Starke, et al., (1971); and Enero, et al., (1972) using other alpha-receptor blocking agents also caused an increase in overflow of transmitter following repeated nerve stimulation. These observations led to the hypothesis that alpha-receptors are present in the outer surface of adr- nembranes of neurons and are involved in the regulation of NE reidase via a negative feedback mechanism. Thus, as NE is released into the synaptic cleft, it tends to limit its own release, by stimulating a presynaptic inhibitory alphareceptor (Kirpekar and Puig, 1971; Starke, 1972; Starke and Schumann, 1972; Rochette, et al., 1976; Lorenz, et al., 1979). This phenomenon occurs in peripheral tissues as well as in the CNS (Bunney and Aghajanian, 1975; Carlsson, 1975; Roth, et al., 1975; Strombon, 1975; Langer and Dubocovich, 1977; Baraban and Aghajanian, 1980). When presynaptic alphareceptors are stinulated by an approprlate agonist or blocked by an 
appropriate antagonist (oxymetazoline, phenoxybenzamine, or phentolamine) (Kapur and Mottram, 1978; Kalsner and Chan, 1979; Wener, et al., 1979; Baraban and Aghajanian, 1980) the negative feedback mechanism inhibiting or facilitating NE release is altered. The sequential release of $N E$ resulting in transmitter overflow thus occurs "or" is prevented. It also appears that the presynaptic alpha-receptors modulate the release of $\mathrm{NE}$ by controlling the influx of calcium into the presynaptic nerve ending (Langer, et al., 1975). In summary, the presynaptic alphareceptor mediates $\mathrm{NE}$ release, which is dependent upon synaptic neurotransmitter concentrations, and a functionally operative negative feedback mechanism. Activation of presynaptic alpha-receptors (autoreceptors) leads to a decrease in transmitter release, while blockade of these alpha-receptors results in an increase of $N E$ release following nerve stimulation (overflow) (Langer, 1974; Langer, 1977; Starke, et al., 1977).

The physiological and biochemical events reulting from the activation or inactivation of alpha-receptors in the CNS remains unclear. Some evidence (Segal, et al., 1975; Greengard, et al., 1976; Skolnick and Daly, 1977; Kanof and Greengard, 1978; Hall and Ogren, 1981) in tucn activates cyclic-AMP generating systems. Other studies (Glaubiger and Lefkowitz, 1977; Hilliams and Lefkowitz, 1977) indicate that the number of CNS alpha-receptors can be altered in a variety of brain areas by chronic treatment with specific drugs and hormones, which in turn results in altered CNS mechanisms. Still other studies suggest that drugs and hormones may sensitize or desensitize these pre- and post- 
synaptic alpha-receptors (Comsa, 1950; Thibault, 1956; Pottar, et al., 1962; Haggendal and Lindqvist, 1964; Lee, et al., 1967; Lipton, et al., 1968; Prange, et al., 1970).

It was our intent in this study to examine the effects of the alpha-receptor antagonist (yohimbine) on NE levels and turnover following chronic tricyclic administration.

Several studies have indicated that chronic administration of tricyclics cause changes in NE levels and NE turnover in brain and other tissues (Schildkraut, et al., 1970; Schildkraut, et al., 1971; RofflerTarlov, et al., 1973; Leonard and Kafoe, 1976; Anden and Grabowska, 1977; Frazier, et al., 1978; Svensson and Usdin, 1978). Since chronic tricyclic treatment is necessary. for therapeutic results, it has been suggested that a slow developing adaptive process at the level of the autoreceptor may be occurring (Vetulani, et al., 1976; Crews and Smith, 1978; Sulser, et al., 1978; Bergstrom and Kellar, 1979; Collis and Shepherd, 1980).

We felt that if receptor adaptation occurs with chronic tricyclic treatment, employing yohimbine would allow us the opportunity to observe these changes in both NE levels and turnover rate. These results would then allow us to specifically test whether adaptive changes in presynaptic receptors might be an important component of the mechanism of chronic tricyclic action.

\section{B. METHODS AND PROCEDURES}

Initial experiments involving NE levels and turnover were performed in three areas of rat brain (corpus striatum, forebrain, and hypothalamus) 
in control animals (saline injected), protriptyline administered (10 $\mathrm{mg} / \mathrm{kg} /$ day for $1,3,6$, and 18 days) and in thyroidectomized animals which also received protriptyline acutely, subchronically and chronically.

With the conclusion of these studies, the examination of both corpus striatum and forebrain was discontinued, since the primary neurotransmitter in the corpus striatum is dopamine (Hillarp, et al., 1966; Snyder and Coyle, 1969; Iversen, 1973; Hornyklewicz, 1973; Harris and Baldessarini, 1973), and 5-hydroxytryptamine (serotonin) for forebrain (Schwark and Keesey, 1975; Saavedra, et al., 1976; Bjorklund, et al., 1976). It was felt that further examination of these tissues would be unnecessary, and unrelated to the effects of chronic protriptyline administration on norepinephrine turnover. All studies involving yohimbine are performed only with hypothalamic tissue preparations. He chose to examine only the hypothalamus in our receptor-interaction studies because we considered the hypothalamus an important target tissue for the actions of protriptyline. This area of the brain is responsible for many neuroendocrine transwitter interactions (Stokes, et al., 1981) as well as regulating or modulating both physiological and emotional responses (Kordon and Glowinski, 1970; Dewhurst, et al., 1968; Kobayashi, et al., 1974, de la Fuente, 1979).

Yohimbine our presynaptic autoreceptor antagonist was obtained from Sigma Chemical Company, St. Louls, Missouri.

Our experimental protocol for drug administration involving our norepinephrine turnover studies is complicated and has been diagrammed 
below for better understanding. This procedure allowed us to examine norepinephrine turnover when protriptyline and or our test drug, yohimbine, were at maximal plasma levels and optimally effective.

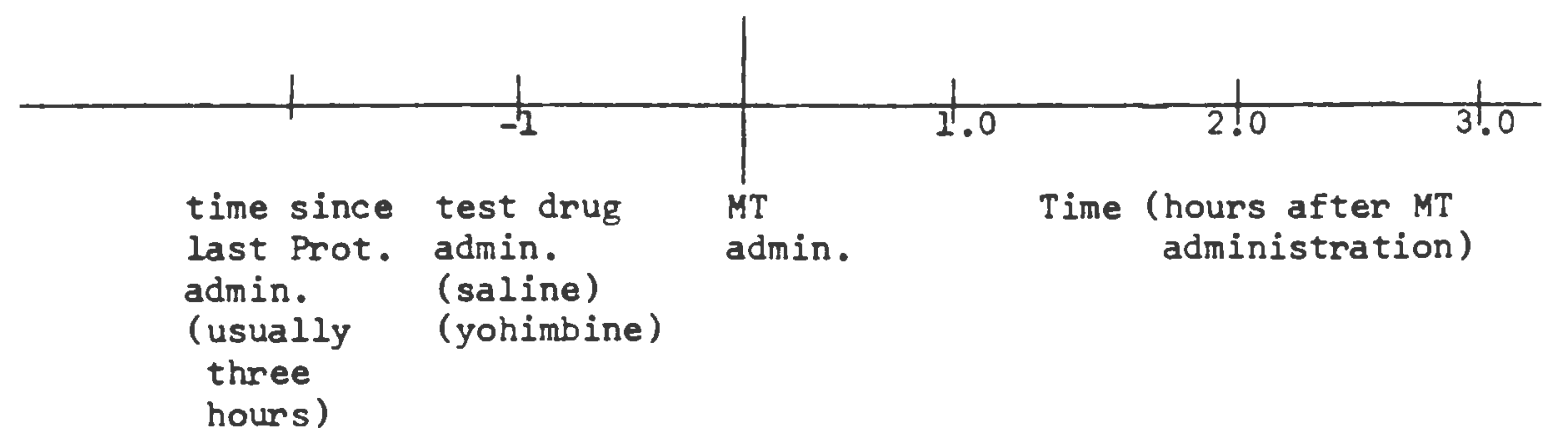

C. RESULTS

1. Protriptyline, NE levels and turnover.

NE levels were determined in corpus striatum, forebrain and hypothalamus following $1,3,6$ and 18 days of protriptyline administration (10 mg/kg/day - S.C.). The data obtained for these determinations are presented in Figure 7. The numerical values for NE determinations for corpus striatum and forebrain are presented in the appendix section (Tables 45 and 46). A statistically significant difference from control animals was recorded in NE levels in the hypothalamus when protriptyline treated animals were sacrificed 3 hours after the last test drug injection in both the acute and chronically administered protriptyline animals $(p<0.01)$. Chronic protriptyline administration also resulted in a statistically significant difference in NE levels in corpus striatum $(p<0.01)$. In the hypothalamus a 268 decrease in NE levels was recorded following acute drug administration and a corresponding 308 decrease in 
TITLE: Norepinephrine levels in hypothalamic tissue following acute, subchronic and chronic protriptyline administration

LEGEND

Animals were administered protriptyline 1, 3, 6 and 18 consecutive days (10 mg/kg/day - S.C.). All animals were sacrificed 3 hours after their final drug administration. Acute and chronic protriptyline administration caused a statistically significant decrease in NE levels in hypothalamic tissue $(p<0.01)$ when compared to saline administered controls. 


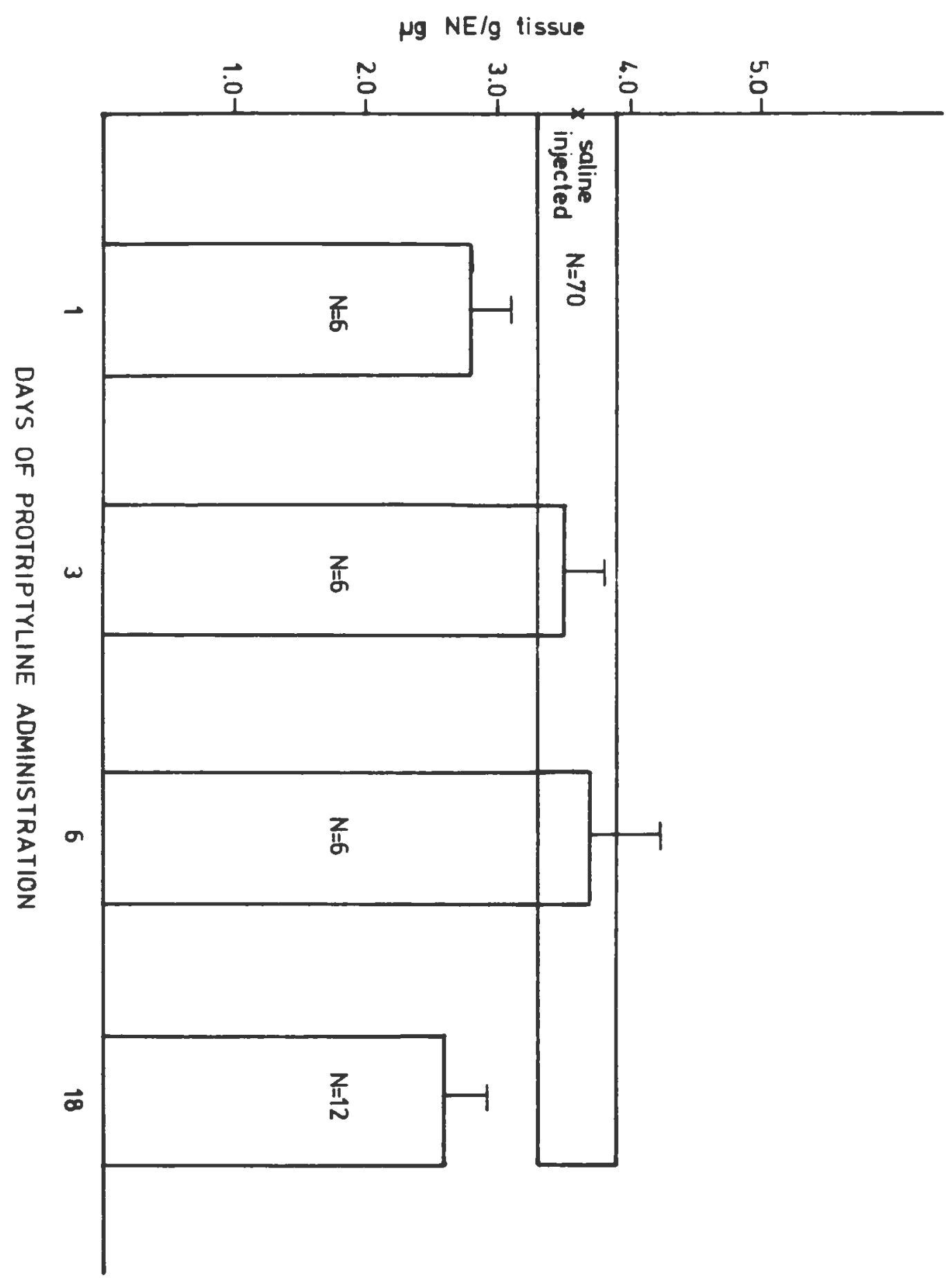


NE levels was observed following chronic administration. Similar results have been reported by others examining whole brain preparations (Schildkraut, et al., 1970; Schildkraut, et al., 1971; Roffler-Tarlov, et al., 1973).

Figure 8 presents data for NE depletion in hypothalamic tissue following acute protriptyline administration (10 mg/kg - S.C.), and followed by MT administration ( $400 \mathrm{mg} / \mathrm{kg}$ - I.P.). MT was administered three hours after protriptyline. These animals were sacrificed at various times after MT administration. A t-test for comparison of depletion rates between saline administered (Figure 3 ) and acute protriptyline administration resulted in a statistically significant difference in turnover rate $(p<0.005)$. This result is consistent with Leonard and Kafoe (1976). Numerical values for these data are listed in the appendix section (Table 47 ).

Figure 9 presents data for NE depletion in hypothalamic tissue following subchronic ( 6 consecutive daily injections) protriptyline administration ( $10 \mathrm{mg} / \mathrm{kg} /$ day - S.C.). MT was administered 6 hours after the last protriptyline injection. Animals were sacrificed at various times after MT administration. A $t$-test for the comparison of depletion rates between saline administered and protriptyline administered animals resulted in a statistically significant difference in depletion rate between groups $(p<0.01)$. Numerical values for each time point are listed in the appendix section (Table 48). 


\section{FIGURE 8}

TITLE: Norepinephrine depletion in hypothalamic tissue following acute protriptyline administration

LEGEND

Animals were administered MT three hours after an acute administration of protriptyline. Animals were sacrificed $0,1,2,3,4.5$, and 6 hours after subsequent MT administration. Each point represents the MEAN \pm S.E. for 3 or more experiments. 
73

g NE/g Tissue

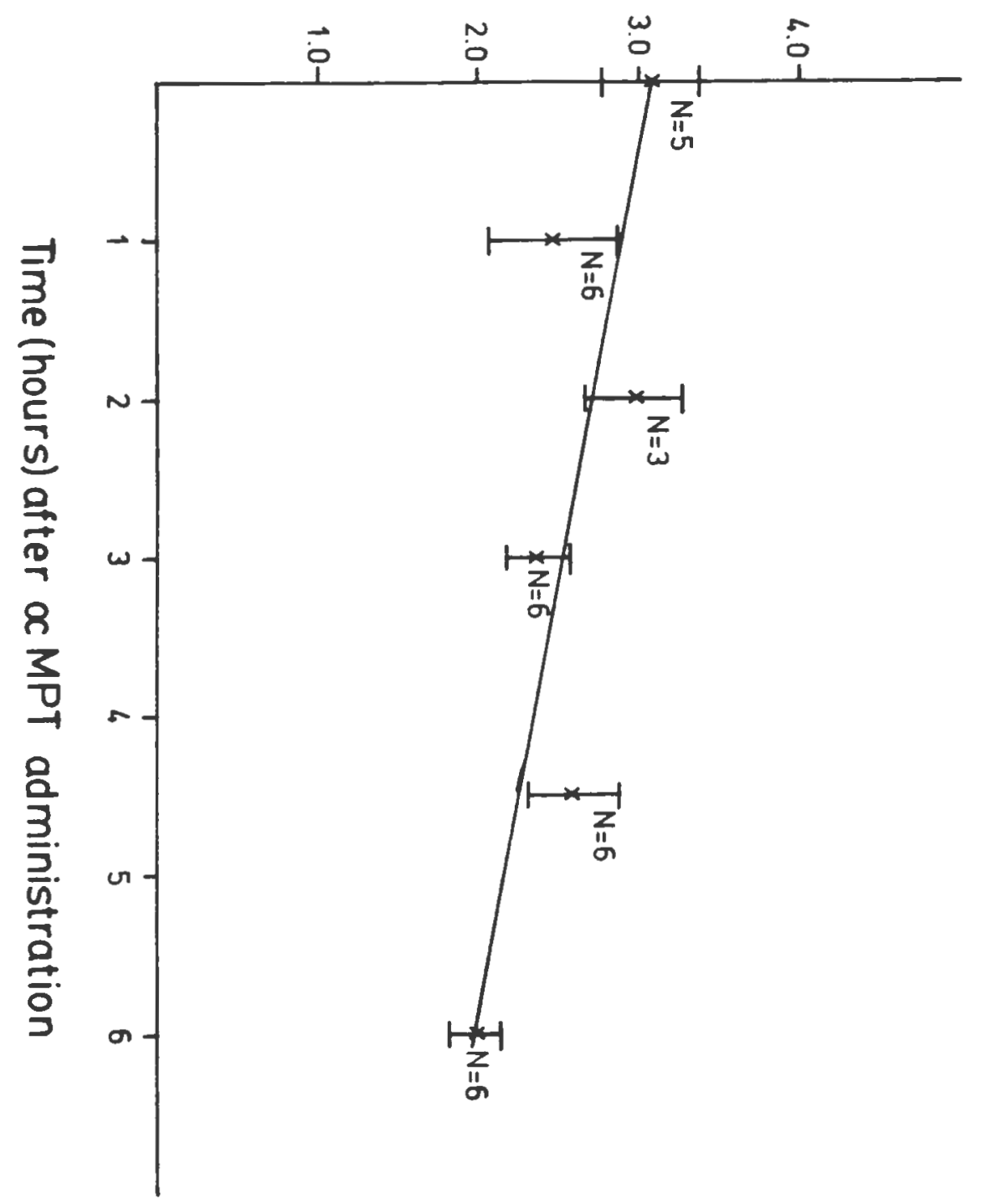




\section{FIGURE 9}

TITLE: Norepinephrine depletion in hypothalamic tissue following subchronic protriptyline administration

\section{LEGEND}

Animals received six consecutive injections of protriptyline (10 mg/kg/day - S.C.). MT was administered six hours after the final protriptyline injection. Animals were sacrificed $0,1,2$ and 3 hours after MT administration. All points represent the MEAN $\pm S . E$. of at least 3 or more experiments. 


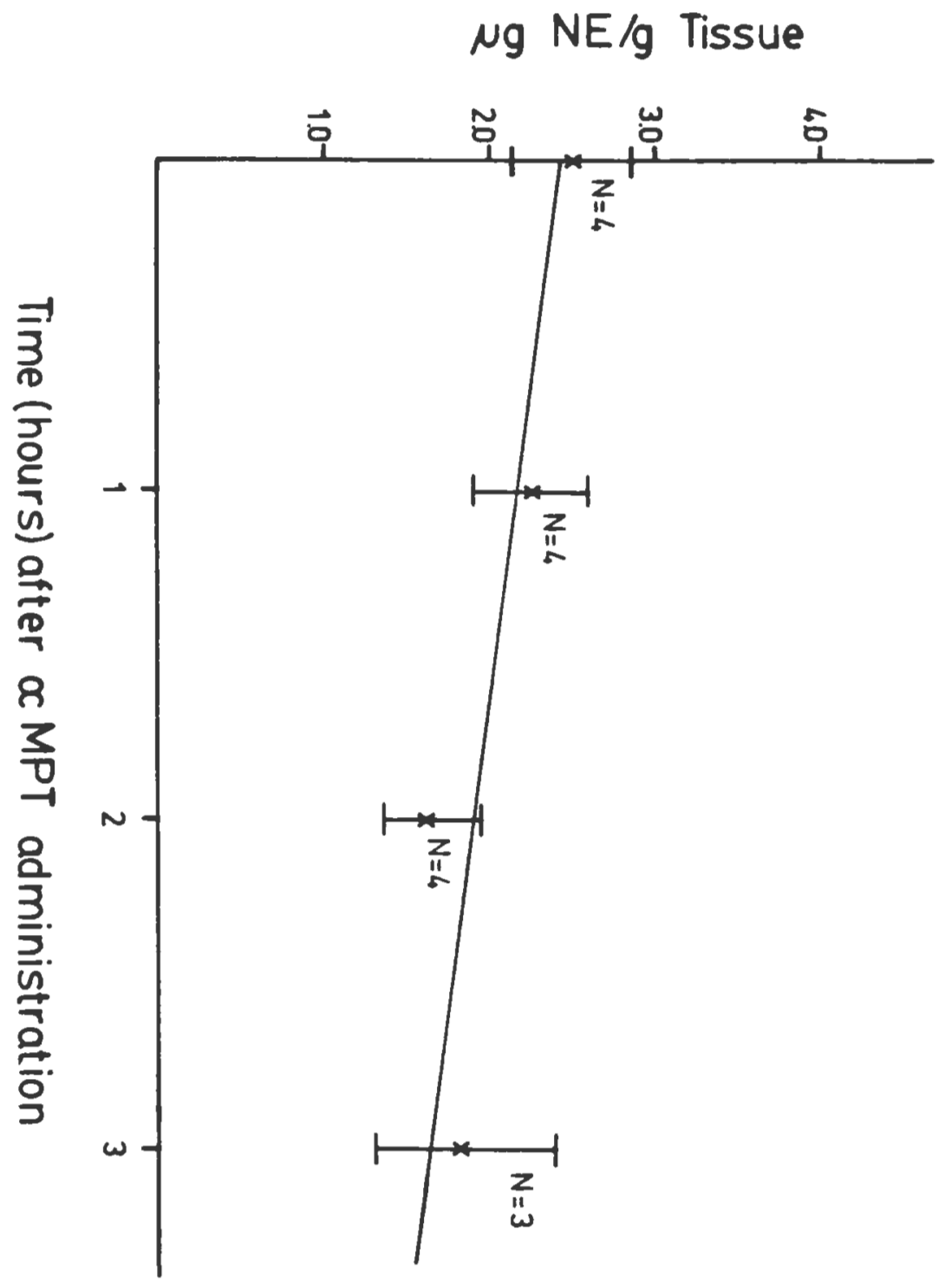


A MT dose-response curve was conducted on chronically treated protriptyline animals prior to examining NE turnover. Figure 10 presents our results for NE depletion in chronically treated protriptyline animals following the administration of various doses of MT (200, $400,600$ and $800 \mathrm{mg} / \mathrm{kg})$. Numerical values for each data point in this figure are presented in the appendix section (Table 51). These data suggest that tyrosine hydroxylase (TH) is completely inhibited three hours after MT administration at any of the above doses. Thus, the $400 \mathrm{mg} / \mathrm{kg}$ dose was employed for our turnover studies in chronically administered animals.

Figure 11 represents NE depletion in hypothalamic tissue following 18 days of chronic protriptyline treatment. Numerical data for each time point are listed in the appendix section (Table 52).

Figure 12 is a composite of the data recorded in Figures 3 and 11. The decrease in NE depletion following chronic protriptyline administration becomes more evident. A t-test on the comparison of turnover rates between these two conditions between zero time after MT administration and three hours after MT administration indicate that a statistically significant difference exists between these two groups $(p<0.01)$. After the three hour time point values were not included in the depletion rate calculations.

When the data in Figure 12 are plotted as "percent of initial concentration of NE" (Figure 13), MT administration causes a $58 \%$ depletion in NE in saline administered animals when these animals are sacrificed three hours after MT administration. A 228 decrease in NE 
FIGURE 10

TITLE: MT dose-response curve in animals administered protriptyline chronically

LEGEND

Animals received protriptyline chronically ( $10 \mathrm{mg} / \mathrm{kg} /$ day, 18 days) and were then administered various doses of MT three hours after the final protriptyline injection. Animals were sacrificed three hours after receiving MT $(200,400,600$ or $800 \mathrm{mg} / \mathrm{kg}$ - I.P.). Each data point represents the MEAN $\pm S . E$. of at least 4 experimental determinations. No statistically significant difference in NE depletion was observed between any of the MT doses examined. 


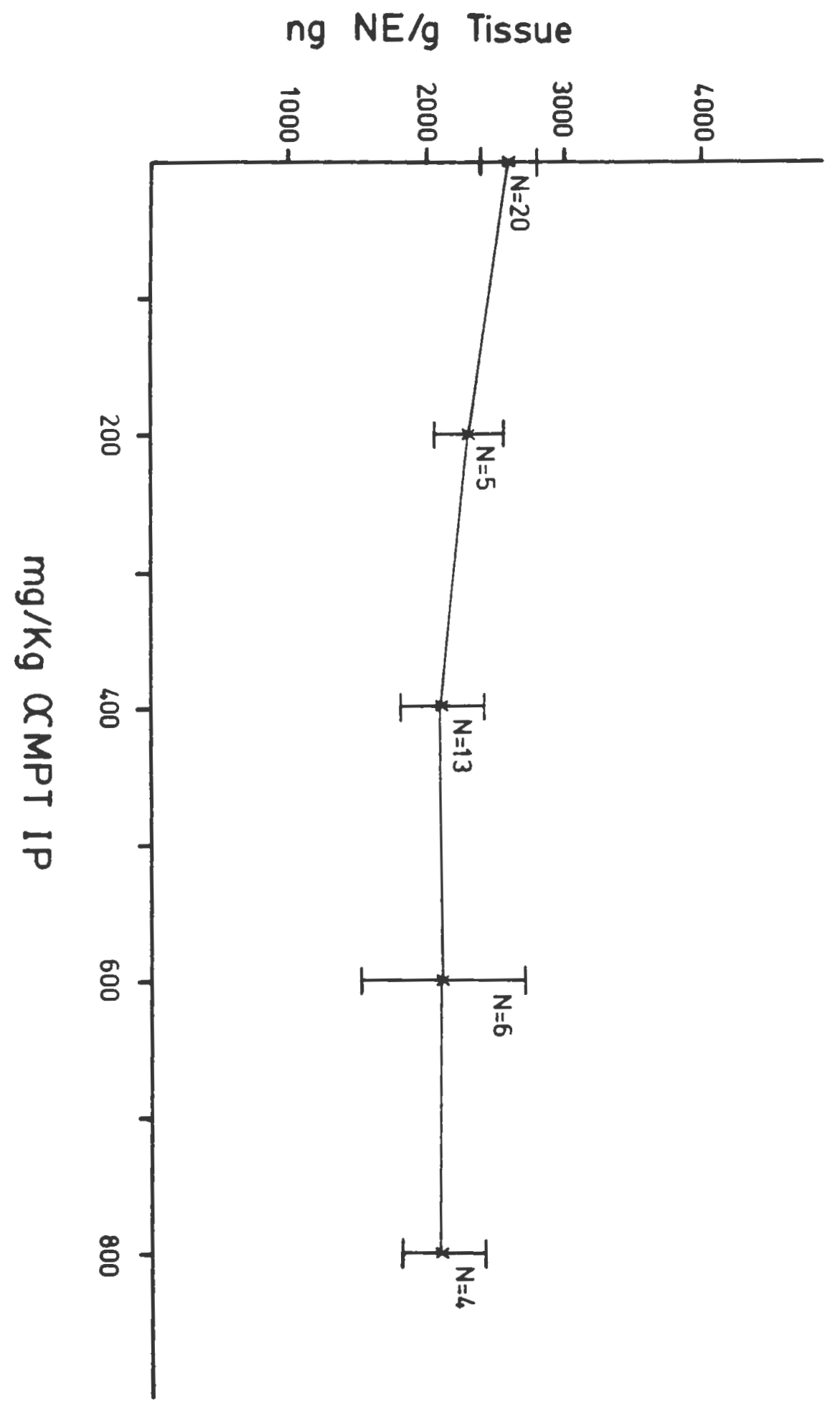


FIGURE 11

TITLE: Norepinephrine depletion in hypothalamic tissue of animals receiving chronic protriptyline administration

LEGEND

Animals received protriptyline chronically $(10 \mathrm{mg} / \mathrm{kg} /$ day, 18 days $)$ and 3 hours after the final protriptyline injection, they were administered MT (400 mg/kg - I.P.). Animals were sacrificed at various times after MT administration $(0,1,2,3,4.5,6$ and 9 hours). Each point represents the MEAN $\pm S . E$. for at least 4 experimental determinations. 


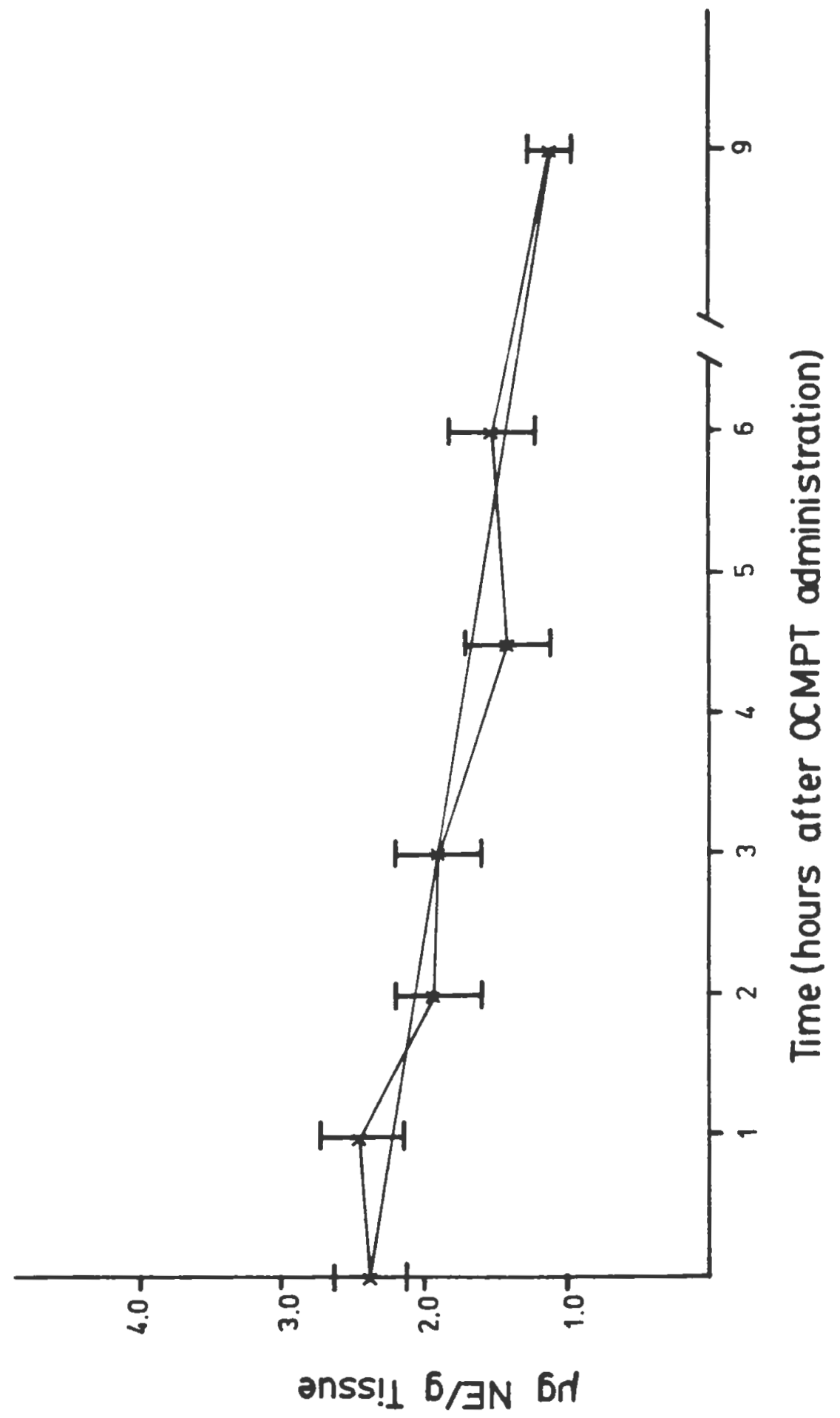


FIGURE 12

TITLE: A comparison of turnover rates in hypothalamic tissue in rats administered protriptyline or saline chronically

LEGEND

Animals were administered protriptyline (10 mg/kg/day, 18 days) $(-x-)$ or saline $\left(-0_{-}\right)$. Three hours after the final injection of protriptyline or saline, animals were administered MT $(400 \mathrm{mg} / \mathrm{kg}$ I.P.). Animals were sacrificed at various times after MT administra$\operatorname{tion}(0,1,2,3,4.5,6$ and 9 hours). All values represent the MEAN $\pm S . E$. for at least 3 experimental determinations. A t-test for comparison of depletion rates between 0 and 3 hours after MT administration indicates taht a statistically significant difference existed in depletion rate between these two groups $(p<0.01)$. 


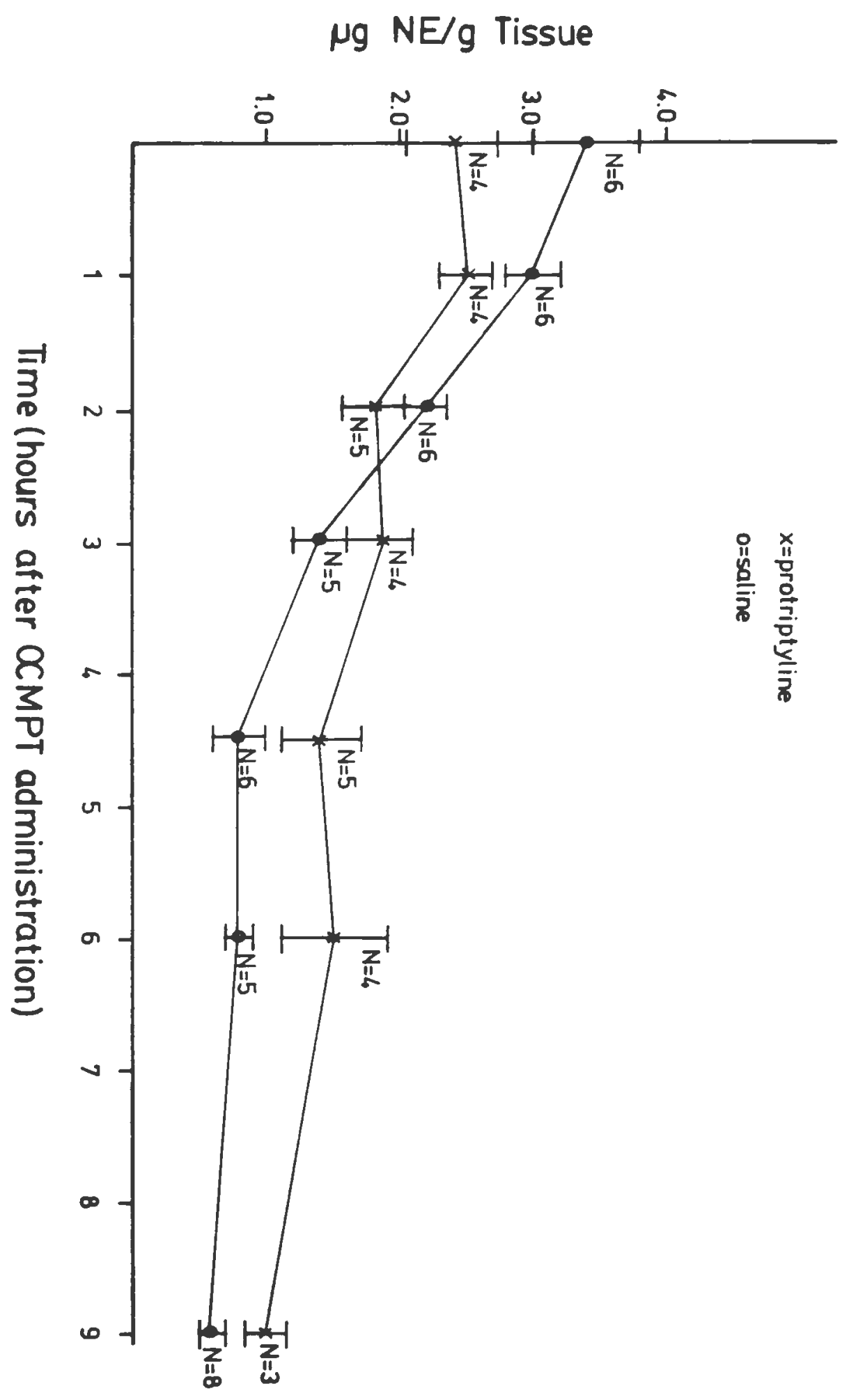


is observed in the hypothalamus when chronically treated protriptyline animals are sacrificed three hours after MT administration. A $36 q$ difference in NE depletion is recorded between these treatment conditions.

Tables 6 and 7 list both the slope and regression coefficient for saline and protriptyline treated animals. Table 57 in the appendix section presents the statistical results when NE depletion was compared between these two groups.

Figure 14 is a turnover rate/recovery rate plot for the data presented in Tables 6 and 7 . These data suggest that adaptations in NE turnover rate/recovery rate have resulted from chronic protriptyline administration.

A t-test for the comparison of turnover rate/recovery rate indicated that acute turnover rate/recovery rate is significantly different when compared to either subchronic or chronic turnover rate/ recovery rate $(p<0.001)$. No statistically significant difference was observed when subchronic administration was compared to chronic administration for turnover rate/recovery rate.

2. Yohimbine studies and norepinephrine turnover. Studies determining $\mathrm{NE}$ levels and turnover following yohimbine, protriptyline and MT administration were conducted. The first plot (Figure 15) employing yohimbine illustrates the effects of a single injection of yohimbine on NE levels in the hypothalamus of control animals. In Figure 15 yohimbine, using either a $2.0 \mathrm{mg} / \mathrm{kg}$ and $20.0 \mathrm{mg} / \mathrm{kg}$ dose, depletes hypothalamic tissue levels of NE. The $20.0 \mathrm{mg} / \mathrm{kg}$ dose, however, depletes NE for a longer time interval. In Figure 15 a $56 \%$ 
FIGURE 13

TITLE: NE depletion as a measure of initial concentration in the hypothalamic tissue of chronically treated protriptyline or saline animals

LEGEND

Animals received protriptyline ( $10 \mathrm{mg} / \mathrm{kg} / \mathrm{day}, 18$ days) or saline, and were then administered MT 3 hours after the final protriptyline or saline injection. Animals were sacrificed three hours after MT administration. NE levels in protriptyline treated animals $(-x-)$ was depleted 228 and in saline administered animals (-0-) a 588 depletion in NE level was recorded. 
NE level

(\% of initial NE concentration)

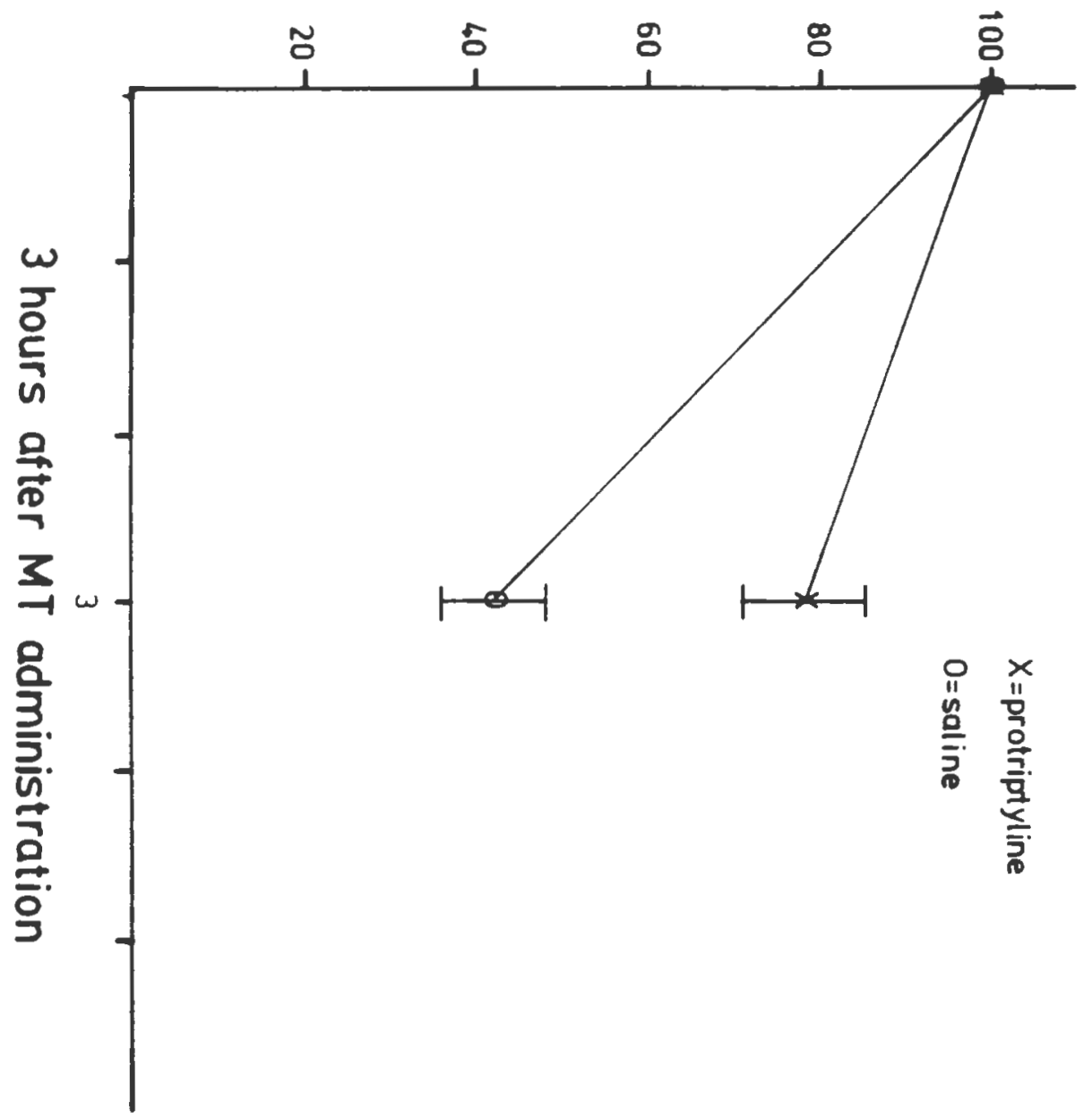


TABLE 6 A comparison of slope and linear regression coefficients for saline treated animals following administration of $\mathrm{MT}$ ( $400 \mathrm{mg} / \mathrm{kg}-$ I.P.)

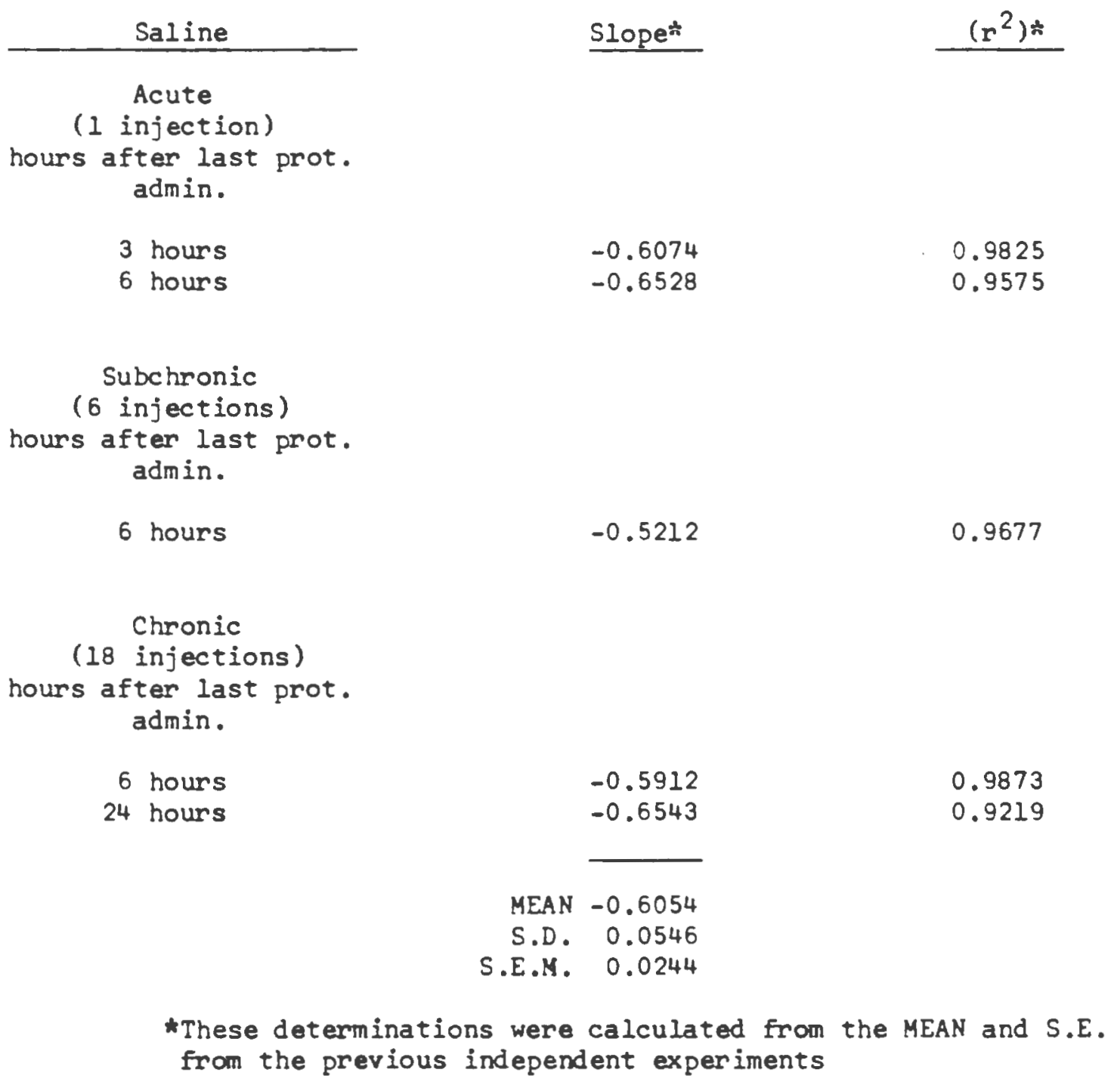


TABLE 7 A comparison of slope and linear regression coefficients for protriptyline treated animals following administration of MT ( $400 \mathrm{mg} / \mathrm{kg}$ - I.P.)

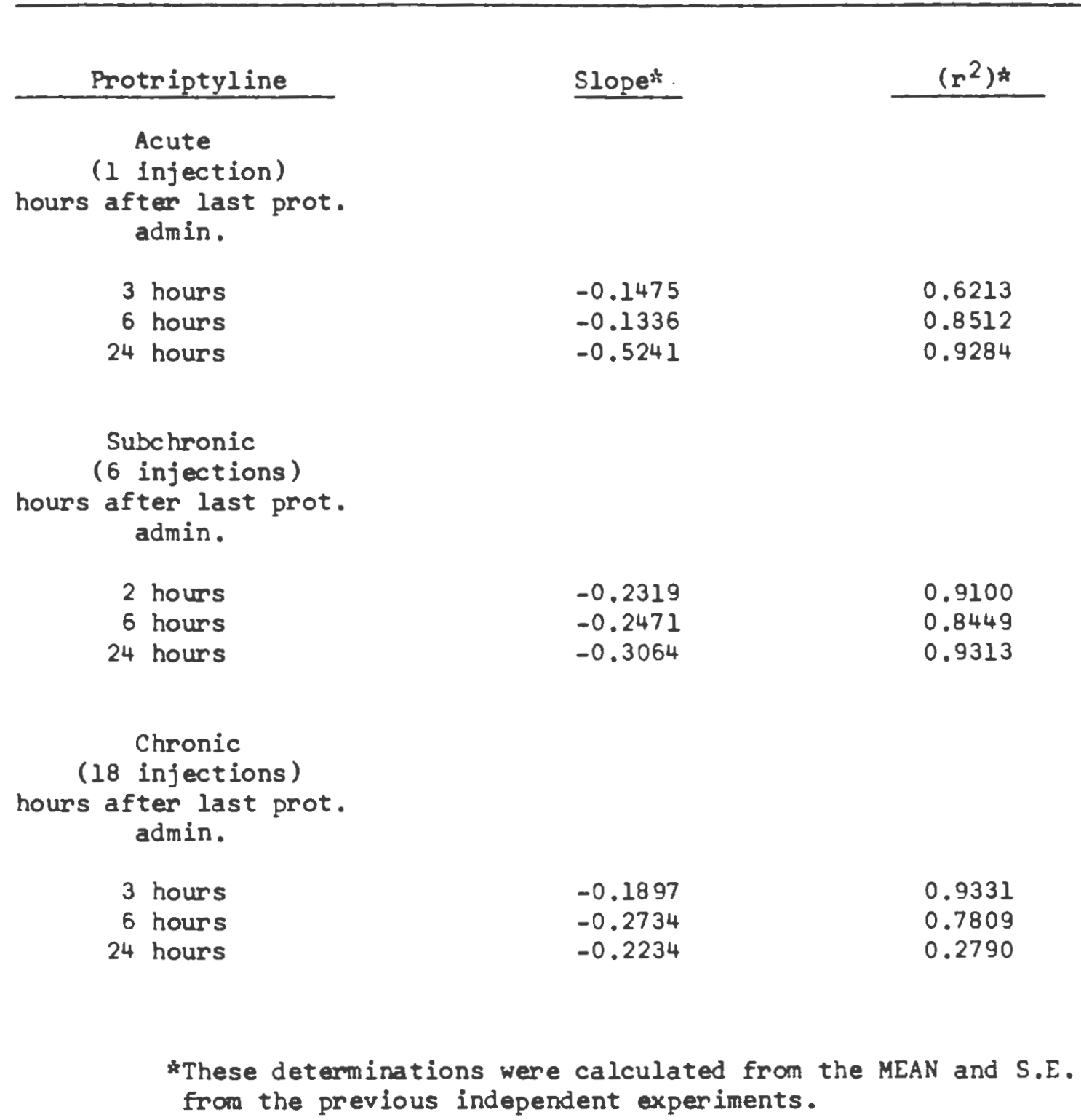




\section{FIGURE 14}

TITLE: Turnover rate/recovery rate for NE in rat hypothalamic tissue following acute, subchronic and chronic protriptyline administration

\section{LEGEND}

The turnover rate/recovery rate for $N E$ in rat hypothalamic tissue following acute, subchronic and chronic protriptyline administration has been plotted and the slope for these 3 injection schedules has been determined. The acute turnover rate/recovery rate slope (-ø-) is significantly different $(p<0.001)$ from either subchronic turnover rate/recovery rate $\left(-x_{-}\right)$or chronic turnover rate/recovery rate $(-0-)$. 


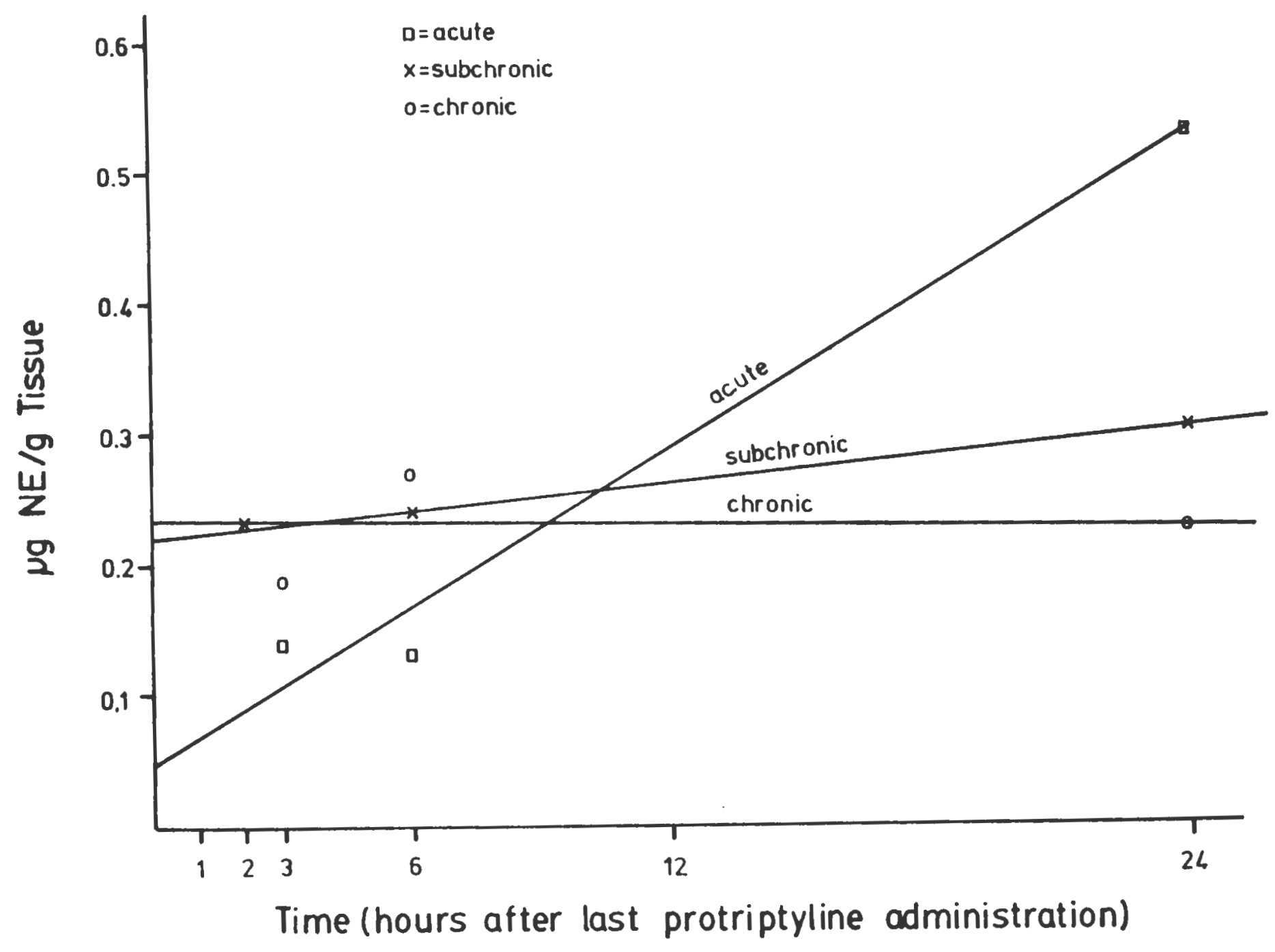


FIGURE 15

TITLE: Norepinephrine depletion in hypothalamic tissue following yohimbine administration

LEGEND

Animals were administered yohimbine $(2.0 \mathrm{mg} / \mathrm{kg}$ or $20.0 \mathrm{mg} / \mathrm{kg})$ and were sacrificed $0,1,2.5$ and 5 hours after this administration. All points represent the MEAN $\pm S . E$. for at least 4 experimental determinations. 


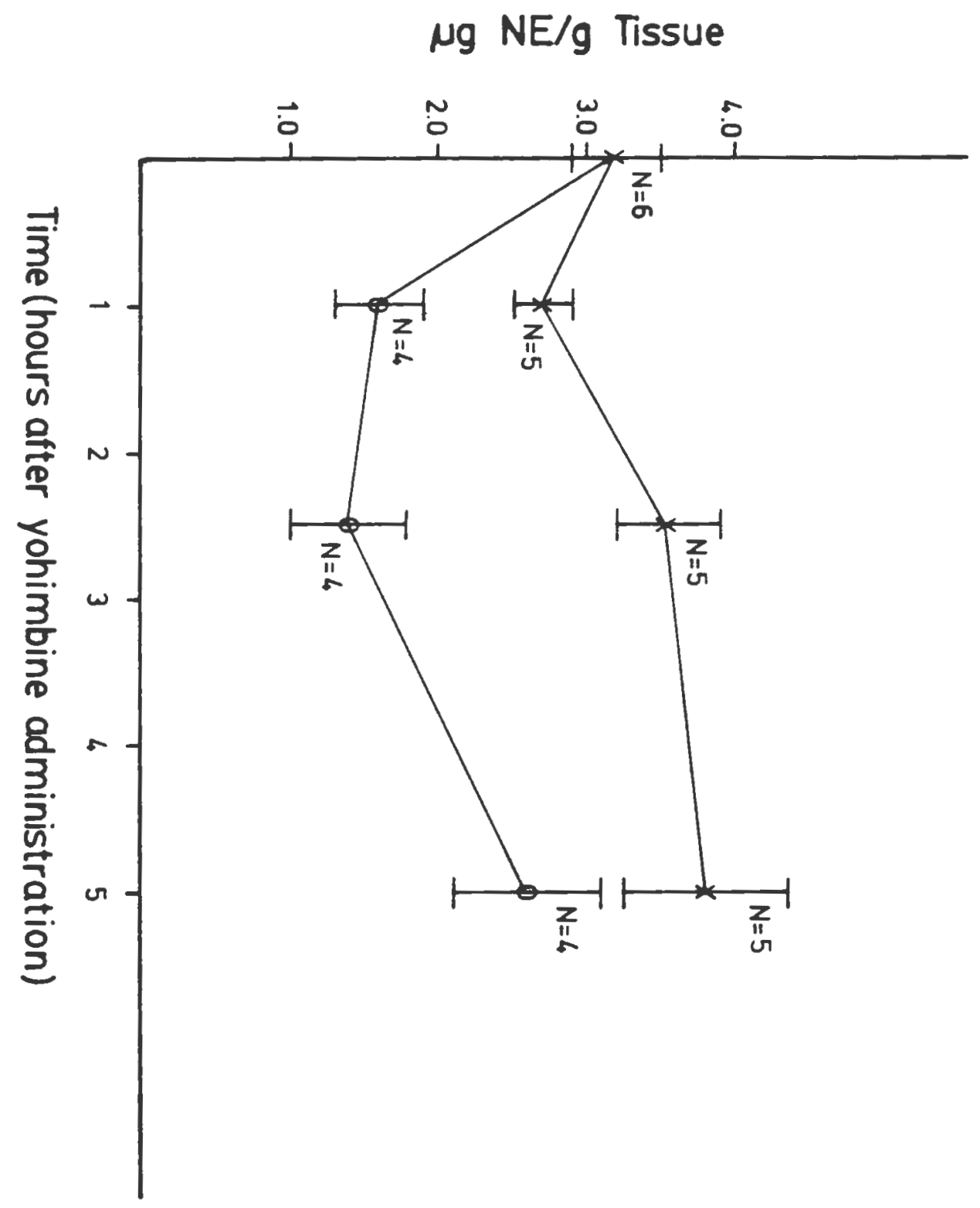


decrease in $N E$ is reported following a single administration of yohimbine at $20.0 \mathrm{mg} / \mathrm{kg}$. Similar results have been reported by Papeschi and Theiss (1975) in whole brain preparations. A $20.0 \mathrm{mg} / \mathrm{kg}$ dose was employed for our future studies, since it allowed a longer time interval for the measurement of turnover following MT administration. Numerical values for each time point are presented in the appendix section (Table 53).

Figure 16 illustrates the effects of yohimbine and MT administration on NE levels in control animals. NE levels in the hypothalamus are maximally depleted one hour after MT administration, and two hours after yohimbine administration. The 658 depletion in NE levels is not recorded in saline administered animals which received MT. Numerical values for these data are presented in the appendix section (Table 54 ).

Figure 17 reports the effects of a single administration of yohimbine $(20.0 \mathrm{mg} / \mathrm{kg})$ on animals which have been chronically administered protriptyline ( $10 \mathrm{mg} / \mathrm{kg} /$ day, 18 days). Animals were administered yohimbine three hours after the final protriptyline injection. This plot illustrates that three hours after yohimbine administration NE levels do not deplete in the hypothalamus. This result contrasts with our observation in Figure 15. In Figure 15, yohimbine administration resulted in a 568 decrease in NE levels. The numerical values for Figure 17 are presented in the appendix section (Table 55). Figure 18 presents data illustrating the effects of both yohimbine and MT administration on NE levels following chronic 


\section{FIGURE 16}

TITLE: NE turnover in hypothalamus of animals which have received yohimbine and sequentially MT

\section{LEGEND}

Animals were administered yohimbine $(20 \mathrm{mg} / \mathrm{kg}-$ I.P.) and one hour later MT (400 mg/kg - I.P.). Animals were then sacrificed 0 , 1, 2, 3, 4.5 and 6 hours after MT administration. Each data point represents the MEAN $\pm S . E$. for at least 4 experimental determinations. 


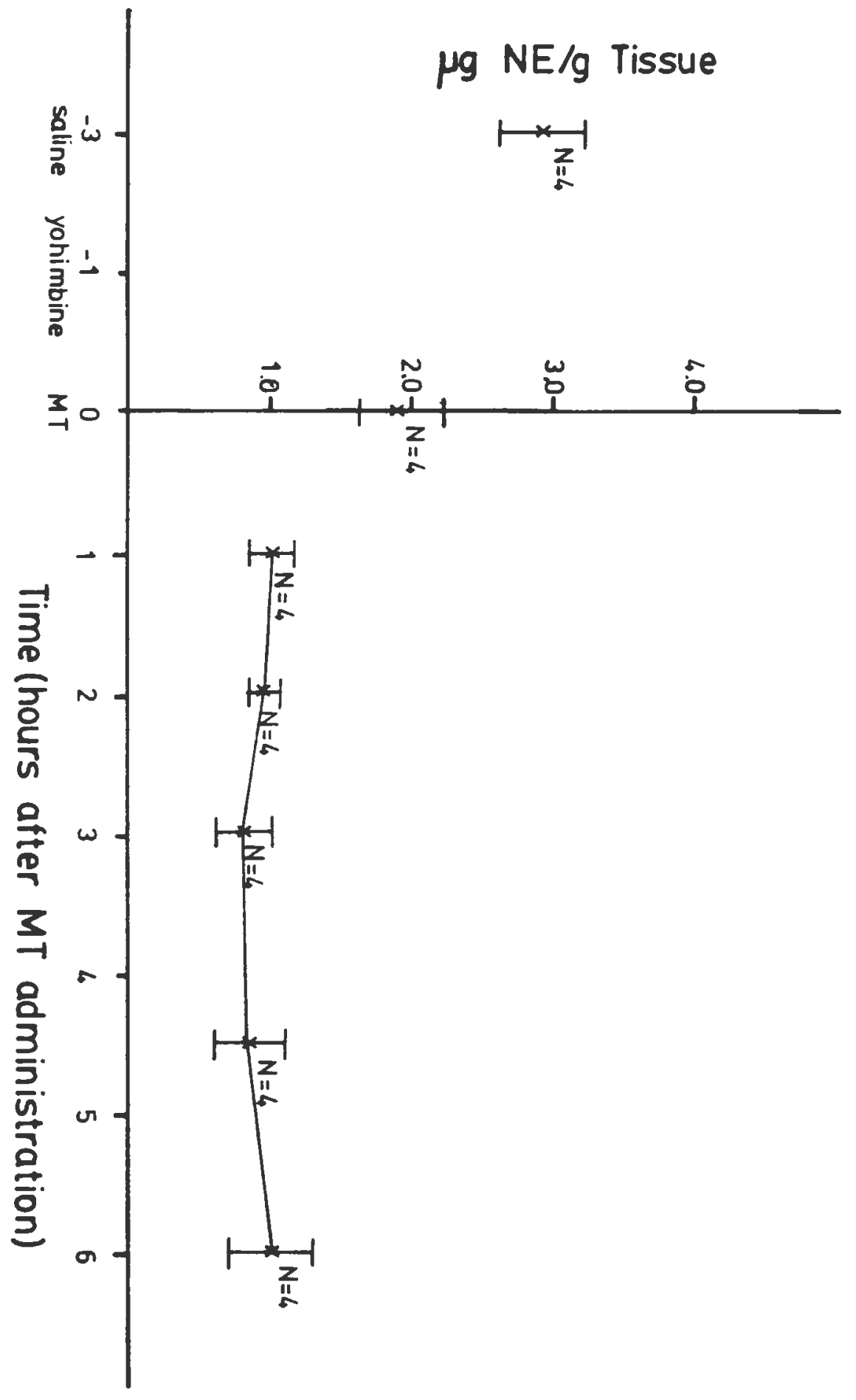




\section{FIGURE 17}

TITLE: NE depletion in the hypothalamus of animals receiving chronic protriptyline treatment and then administered yohimbine

LEGEND

Animals received protriptyline ( $10 \mathrm{mb} / \mathrm{kg} /$ day - 18 days S.C.) and three hours after their final protriptyline injection they received yohimbine $(20 \mathrm{mg} / \mathrm{kg}$, I.P.). These animals wore sacrificed 0,1 , and 3 hours after yohimbine. Each data point represents the MEAN $\pm S . E$. for at least 4 experimental determinations. 
96

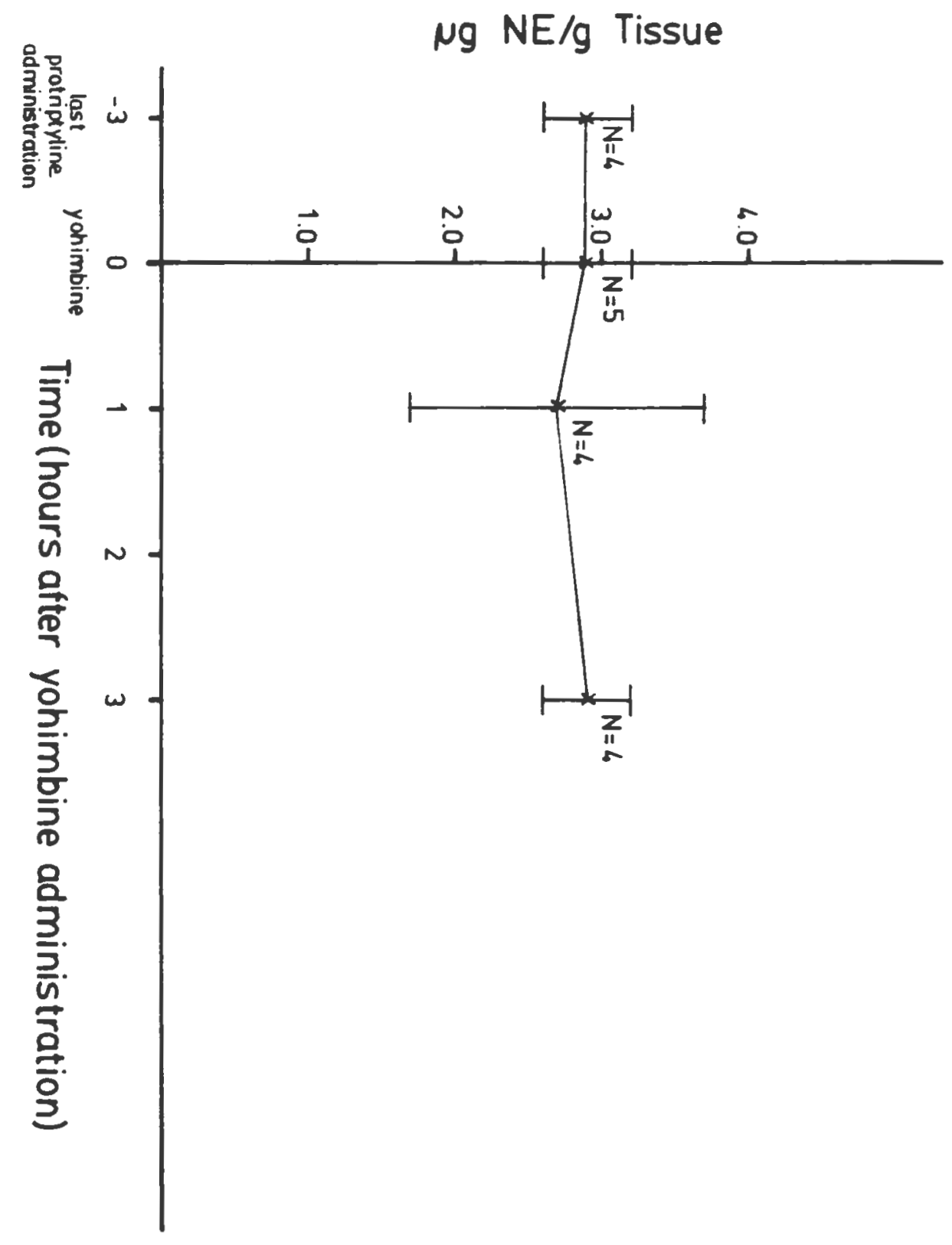


FIGURE 18

TITLE: NE depletion in hypothalamus following chronic protriptyline administration, yohimbine administration and MT administration

LEGEND

Animals were administered protriptyline chronically $(10 \mathrm{mg} / \mathrm{kg} / \mathrm{day}$, 18 days - S.C.). Three hours after the final protriptyline administration animals were administered yohimbine (20 mg/kg) I.P.. One hour after yohimbine administration animals were administered MT $(400 \mathrm{mg} / \mathrm{kg}$ - I.P.). Animals were then sacrificed 0 , 1, 2, and 3 hours after MT administration. Each data point represents the MEAN $\pm S . E$. for at least 4 experimental determinations. 


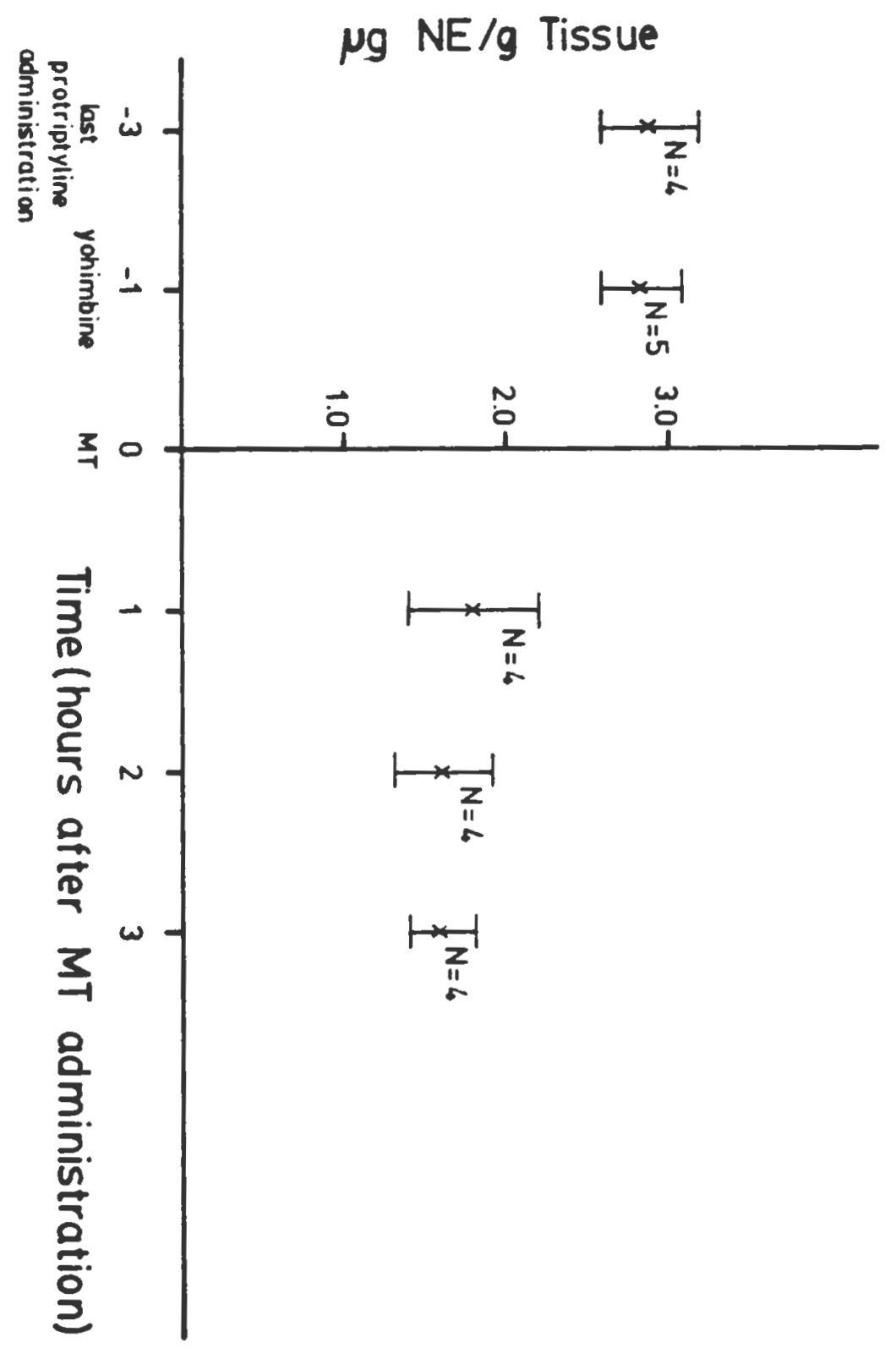


protriptyline administration ( $10 \mathrm{mg} / \mathrm{kg} /$ day, S.C. - 18 days). Three hours following MT administration, NE levels were not statistically different from the NE levels reported following chronic protriptyline administration and subsequent MT administration (see Figure 11 ). This study indicates that the effects of yohimbine appear nullified when protriptyline has been administered chronically. In control studies, it should be recalled that NE was depleted 568 and 708 three hours after yohimbine administration (Figures 15 and 16). Numerical values for each time point are listed in the appendix section (Table 56).

D. DISCUSSION

To test our third hypothesis "that chronic protriptyline administration may induce changes in specific NE parameters and the presynaptic autoreceptor" studies were designed to evaluate changes in $\mathrm{NE}$ levels and turnover, employing the alpha-receptor antagonist yohimbine after chronic protriptyline administration. The results of these studies strongly suggest that chronic administration of protriptyline alters presynaptic alpha-receptors. Chronic protriptyline administration decreases NE levels in the hypothalamus; a finding which at first seems contradictory to the "catecholamine hypothesis of affective disorders", which suggests that increased NE at post-synaptic receptor sites is required to alleviate depression. Increased neurotransmitter levels would indicate increased release following an action potential, and decreased NE levels would indicate decreased neurotransmitter release. 
Secondly, chronically administered protriptyline decreases NE turnover when compared to control animals, and exhibits increased turnover when compared to acute protriptyline administration. This result also seems contrary to the "catecholamine hypothesis of affective disorders" since one would predict that increases in turnover (i.e. synthetic rate) are necessary (to alleviate depression) to maintain the constant efflux of NE to the post-synaptic receptor.

Thirdly, yohimbine administration (which in control animals illicited NE depletion), to chronically administered protriptyline animals has no effect or minimal effects on NE depletion (Figure 17). This suggests that chronic protriptyline administration may produce subsensitivity of alpha-2-(presynaptic)-receptors, which in turn modify NE release to the synapse.

These results suggest the existence of presynaptic alpha-2receptors are undergoing adaptation when protriptyline is administered chronically to experimental animals. The implications of these adaptive mechanisms and their relationships to the catecholamine hypothesis of affective disorders will be discussed in Chapter $V$. 
C H A P T E R V 


\section{A. SUMMARY AND CONCLUSIONS}

Our studies attempted to identify possible alternate mechanisms of action in the CNS when the tricyclic, protriptyline, was administered chronically to rats. These studies also examined the effects of both protriptyline and thyroid hormone administration on monoamine oxidase (MAO) activity. The following results were observed:

(1) In vitro preincubation with protriptyline inhibits MAO activity in all three brain regions examined.

(2) In vivo administration of protriptyline has varying and inconsistant effects on MAO activity.

(3) Monoamine oxidase activity is inhibited in vitro by preincubation with triiodothyronine.

(4) Triiodothyronine administration has no in vivo effect on MAO activity in the three brain regions examined.

(5) Thyroidectany decreases MAO activity in all three brain regions examined.

(6) The simultaneous administration of protriptyline and triiodothyronine have toxic lethal effects on animals when administered at the dose ranges we examined, and in those animals which survived simultaneous administration, monoamine oxidase data was inconsistent and inconclusive.

(7) Protriptyline administration to thyroidectomized animals results in variable and inconsistent effects on MAO activity.

Several of these observations $(1,3,4)$ have been documented by others (Gabay and Valcourt, 1968A; Roth and Gillis, 1974A; Roth, 1977). In addition, other animal studies have documented toxic effects of concurrent triiodothyronine administration with the tricyclic imipramine, or with other pharmacological agents (Carrier and Buday, 
1961; Conney and Garren, 1961; Prange and Lipton, 1962; Coville and Telford, 1970; Breese, et al., 1974). No documentation could be found identifying toxic interactions when protriptyline was administered with triiodothyronine.

At the completion of these studies it was concluded that any interaction between protriptyline and MAO activity was non-specific and our first hypothesis "that the requirement for chronic treatment with tricyclics before clinical efficacy is observed is related to an action on mitochondrial $\mathrm{MAO}$, and that the time course for this effect parallels the time course for clinical response" was incorrect. Similarly, the toxic interactions of simultaneous triodothyronine and protriptyline administration, though of interest, also remain unresolved.

Continuing, we next examined the effects of thyroidectomy and both triiodothysonine $\left(T_{3}\right)$ and protriptyline administration on $N E$ levels and turnover. He observed the following results:

(1) That seven days of triiodothyronine administration ( $1 \mathrm{mg} / \mathrm{kg} /$ day) results in decreased NE pool size in the brain areas examined.

(2) That thyroidectomy induces no change in NE pool size in these same brain regions.

(3) That both acute and chronic protriptyline administration (10 mg/kg/day) result in decreased NE pool size.

(4) That NE turnover is decreased in trilodothyronine treated animals when compared to saline administered control animals.

(5) That NE turnover in thyroidectomized animals is increased when compared to Sham-operated control animals. 
(6) That NE turnover in the hypothalamus of both acutely and chronically administered protriptyline rats is decreased when compared to saline administered control animals.

The possible physiological significance of alterations in brain ME levels and turnover after triiodothyronine administration, and following acute and chronic protriptyline administration may be postulated to be related to compensatory and adaptive mechanisms, resulting from changes in noradrenergic alpha-receptor sensitivity. Decreases in both NE levels and turnover were observed after seven days of $T_{3}$ administration. Our observation of both a decrease in $\mathrm{NE}$ level and decreased turnover would be explicable if $\mathrm{T}_{3}$ induces increased receptor sensitivity to $\mathrm{NE}$. Increased receptor sensitivity would allow a decrease in the amount of $\mathrm{NE}$ released into the synapsis and still illicite a target cell response. Increased receptor sensitivity induced by $I_{3}$ has been documented (Engstrom, et a1., 1974; Engstrom, et al., 1975; Strombom, et al., 1977).

Increased receptor sensitivity may also be responsible for the toxic side effects of protriptyline. Long (1977) has reported animal results in which heart palpitations and arrhythmias have occurred when $\mathrm{T}_{3}$ was administered with other pharmacological agents. Possibly $\mathrm{T}_{3}$ increases receptor sensitivity and sequential protriptyline administration results in an increase in toxic effects.

Both acute and chronic protriptyline administration induced changes in NE levels and turnover in hypothalamus. The acute effects of the tricyclics on brain noradrenergic parameters have been documented by many investigators (Schildkraut, et al., 1970; Schildkraut, et al., 
Roffler-Tarlov, et al., 1973; Leonard and Kafoe, 1976). Decreases in NE levels have been postulated to result from the negative feedback inhibition by $\mathrm{NE}$ on tyrosine hydroxylase (TH) activity, via the pteridine cofactor site. Decreased turnover also results from negative feedback inhibition. Alternations in both of these noradrenergic parameters result from the tricyclics primary mechanism of action (re-uptake blockage) and may be viewed as compensatory noradrenergic neural adfustments.

In our chronic protriptyline studies we observed decreased hypothalamic tissue levels of $N E$ and also a decrease in NE turnover rate compared to chronic saline administered controls. These results suggest a decrease in $\mathrm{NE}$ synthetic rate. Other investigators have also demonstrated changes in other noradrenergic parameters which also suggest decreased synthetic rate. Mandel, et al., (1973) demonstrated that chronic imipramine treatment decreases midbrain tyrosine hydroxylase (TH) activity. Schildkraut (1965) and Schildkraut, et al., (1972, 1975) demonstrated that chronic treatment with amitriptyline or imipramine decreased the excretion rate of norepinephrine metabolites in the CSF. We postulate that the observed decrease in NE levels and turnover rate is an adaptive response resulting from increased efficiency of transmission as a consequence of re-uptake blockade.

Our studies suggest that adaptations in the presynaptic alphareceptor in the hypothalamus have occurred following chronic protriptyline administration. In our final studies we employed yohimbine in an attempt 
to further examine whether alpha-receptor adaptations have occurred and whether such changes correlate with the lag-time observed for clinical efficacy.

The following results were obtained when yohimbine was employed:

(1) Yohimbine administration ( $20.0 \mathrm{mg} / \mathrm{kg}$, I.P.) produced a $56 \%$ decrease in total cytoplasmic NE levels in control animals three hours after test drug administration.

(2) Yohimbine administration $(20.0 \mathrm{mg} / \mathrm{kg}$, I.P.) to chronically treated protriptyline ( $10 \mathrm{mg} / \mathrm{kg}, 18$ days, S.C.) animals produced NO decrease in total cytoplasmic NE levels three hours after test drug administration.

(3) Yohimbine administration ( $20.0 \mathrm{mg} / \mathrm{kg}$, I.P.) followed by alpha-methyl-para-tyrosine (MT) administration (400 mg/ $\mathrm{kg}$, I.P.) to control animals resulted in a 728 decrease in total cytoplasmic NE levels three hours after MT administration.

(4) Yohimbine administration ( $20.0 \mathrm{mg} / \mathrm{kg}$, I.P.) followed by MT administration ( $400 \mathrm{mg} / \mathrm{kg}$, I.P.) to chronically treated protriptyline animals ( $10 \mathrm{mg} / \mathrm{kg}, 18$ days, S.C.) produced a $40 \%$ decrease in total cytoplasmic NE levels three hours after MT administration.

These results can be explained in the following manner. Yohimbine, a pre-synaptic alpha-receptor antagonist, suppresses feedback inhibition of NE release. This phenomena results in depletion of cytoplasmic presynaptic NE levels. In chronically treated protriptyline animals constant exposure to $N E$ in the synapse results in the evolution of a state of subsensitivity of both pre-and post-synaptic receptors. In other words, receptor tolerance develops as a result of constant NE exposure. Constant exposure to elevated synaptic concentrations of NE produces receptor subsensitivity in a time course which parallels the observed lag-time for clinical efficacy for this class of antidepressant 
agents. Post-synaptic receptor subsensitivity has already been documented in peripheral systems (Langer and Luchelli-Fortis, 1977).

\section{B. SUMMARY}

We have documented several compensatory neural mechanisms which occur during the chronic treatment period with tricyclics: (1) changes in endogeneous cytoplasmic total NE levels, (2) changes in NE turnover rate/recovery rate following the last dose in a chronic series of test drug administrations, and (3) adaptations in the pre-synaptic receptor.

1. Adaptations in total $\mathrm{NE}$ tissue levels.

Decreases in cytoplasmic NE levels following chronic protriptyline treatment (Figure 7) suggest a more efficient utilization of NE (less neurotransmitter is required to maintain normal physiologic function). Clinical studies support this postulate and report increases in $\mathrm{H}^{3}-\mathrm{NMN}$ (a COMT metabolite) and decreases in $\mathrm{H}^{3}$-DCM (MAO metabolies, 3, 4 dihydroxymandelic acid and 3, 4-dihydroxy-phenyl-glycol) following chronic tricyclic administration. These data indicate that more neurotransmitter is available to symaptic receptors (and COMT), despite ar. observed reduction in total endogeneous cytoplasmic NE levels.

2. Adaptations in NE turnover. Acute protriptyline administration results in a decreased slope for NE turnover, three and six hours after tricyclic administration, when compared to saline treated animals. Twenty-four hours after protriptyline administration the slope for NE turnover has returned to control values (Tables 6 and 7). This observation has been observed by others when 
measuring $H^{3}$-metabolites $\left(H^{3}-N M N\right)$ following $H^{3}-N E$ infusion, and employing acutely imipramine or DMI pretreatment. Since re-uptake blockade by tricyclics results in an accumulation of NE in the synapse, this accumulation would stimulate pre-synaptic alpha-receptors and in turn a negative feedback mechanism would become operative; thus resulting in a decrease in the release of pre-synaptic NE. This mechanism is responsible for the decrease in NE turnover following acute protriptyline administration.

With subchronic ( 6 day) protriptyline treatmert, the slope for NE turnover appears to be elevated at both the three and six hour time points after the last protriptyline injection, when these slopes for turnover rate are compared to the turnover rates for acute protriptyline administration. Similarly, the slopes for turnover rate for chronically administered animals also suggest an increase in NE turnover rate, when compared to acute protriptyline administration. These data suggest the development of receptor adaptations following a chronic tricyclic treatment schedule.

Figure 18, a turnover rate/recovery rate plot, depicts this comparison of turnover slopes for acute, subchronic and chronic treatment groups. This figure explicitly demonstrates the modifications in neurotransmitter turnover rate/recovery rate in the three treatment schedules.

3. Adaptations in pre-synaptic receptor sensitivity. Pre-synaptic alpha-receptor adaptation (hyposensitivity) following chronic protriptyline administration is suggested by our data. Since 
yohimbine prevents pre-synaptic alpha-receptor stimulation, and allows NE overflow to the adrenergic synapse to occur, chronic protriptyline administration modifies this mechanism. Control of $\mathrm{NE}$ release by these receptors (which is dependent upon synaptic NE concentration) is altered, thus the negative feedback mechanism for facilitating or suppressing the controlled release of NE to the synapse becomes modified.

When animals were administered protriptyline chronically and subsequently administered yohimbine, a decrease in endogeneous NE levels was not observed in our studies (Figure 17). These results are contrary to carlier studies involving yohimbine administration to control animals (Figure 15). This observation suggests that chronic protriptyline administration induces pre-synaptic hyposensitiivity.

\section{CONCLUSIONS}

It appears that chronic protriptyline administration results in adaptive changes in central noradrenergic mechanisms. The time course for these adaptive changes parallel the time required for the onset of their clinical effectiveness. We propose that acutely the action of tricyclics on norepinephrine re-uptake is (largely) negated by compensatory adjustments in turnover rate of the neurotransmitter; but with chronic administration, adaptations in pre-synaptic alpha-receptors occur. This in turn reduces the extent to which the norepinephrine Deurons can offset or compengate for the blockade of norepinephrine reuptake. Specifically, pre-synaptic alpha-receptors become hyposensitive, and tolerance develops, not to the direct action of the tricyclic drug 
on neurotransmitter re-uptake, but to the compensatory neural adjustments which offset the action of the acute tricyclic administration and delay their clinical efficacy. 
C $\begin{array}{llllll}\text { A P } & \text { T E R } & \text { VI }\end{array}$

(References) 
Achee, F.M. and Gabay, S.: Studies of monoamine oxidases: Inhibition of bovine brain MAO in intact mitochondria by tricyclic antidepressant drugs. Biochem. Pharmacol. 28: 1197-1203, 1979.

Aghajanian, G.K., Cedarbaum, J.M., and Wang, R.Y.: Evidence for norepinephrine-mediated collateral inhibition of locus coeruleus neurons. Brain Res. 136: 570-577, 1977.

Alpers, H.S. and Himwich, H.E.: The effects of chronic imipramine administration on rat brain levels of serotonin, 5-hydroxyindole acetic acid, norepinephrine and dopamine. J. Pharmacol. Exp. Ther. 180: 531-538, 1972.

Ananth, J. and Luchins, D.: A review of combined tricyclic and MAOI therapy. Comprehensive Psychiatry 18: 221-230, 1977.

Anden, N., Grabowska, M.: FLA 136=selective agonist at central alphaadrenoceptors mediating changes in the turnover of noradrenaline. Naunyn-Schmiedeberg's Arch. Pharmacol. 298: 239-243, 1977.

Antelman, S.M., Chiodo, L.A.: Repeated antidepressant treatments induce a long-lasting dopamine autoreceptor subsensitivity: Is daily treatment necessary for clinical efficacy. Psychopharmacology Bull. 17: 92-94, 1981 .

Asaad, M.M., Clarke, D.E.: Thyroid mediated activiation of monoamine oxidase (MAO). Fed. Proc. 35: 267, 1976.

Asaad, M.M., Clarke, D.E.: Modulation in vitro of monoamine oxidase activity by thyroid hormones. Biochem. Pharmacol. 27: 751-756, 1978.

Ashcroft, G.H., Crawford, T.B.B., Eccleston, D., Sharman, D.F., MacDougall, E., Stanton, J.B., and Binns, J.K.: 5-hydroxyindole compounds in the cerebrospinal fluid of patients with psychiatric or neurological diseases. Lancet 2: 1049-1052, 1966.

Ashcroft, G.W., Sharman, D.F.: 5-hydroxyindoles in human cerebrospinal fluids. Nature (London) 186: 303-305, 1960.

Asher, R.: Myxoedenatous madness. Brit. Med. J. 2: 555-562, 1949.

Avakian, V.M., Callingham, B.A.: An effect of adrenalectomy upon catecholamine metabolism. Brit. J. Pharmacol. Chemother. 33: 211-212P, 1968.

Axelrod, J.: Methylation reactions in the formation and metabolism of catecholamines and other biogenic amines. Pharmacol. Rev. 18: $95-113,1966$. 
Axelrod, J.: Regulation of the neurotransmitter norepinephrine. In The Neurosciences, Third Study Program, ed. by F.O. Schmitt, F.G. Worden, Pp. 863-876, MIT Press, Cambridge, 1974.

Bain, J., Walfish, P.G.: The assessment of thyroid function and structure. Symposium on Advances in Otolaryngologic Diagnosis. 11: $419-443,1978$.

Bakhle, Y.S., Youdim, M.B.H.: Inactivation of phenylethylamine and 5hydroxytryptamine in rat isolated lungs: Evidence for monoamine oxidase A and B in lung. J. Physiol. (London) 248: 23-25P, 1975.

Baldessarini, Ross J.: The basis for amine hypotheses in affective disorders. Arch. Gen. Psychiat. 32: 1087-1093, 1975.

Baraban, J.M. and Aghajanian, G.K.: Suppression of firing activity of 5$H T$ neurons in the dorsal raphe by alpha-adrenergic antagonists. Neuropharmacology 19: 355-363, 1980.

Barchas, J.D., Akil, H., Elliott, G.R., Holman, R.B., Watson, S.J.: Behavioral neurochemistry: Neuroregulators and behavioral states. Science 200: 964-973, 1978.

Barchas, J., Berger, P., Ciaranello, R., Elliott, G.: Promise and limits of psychopharmacology. In Psychopharmacology: from Theory to Practice, ed. by J.D. Barchas, P.A. Berger, R.D. Ciaranello, G.R. Elliott, PP. 527-538, Oxford Press, New York, 1977.

Barker, S.B., Kiely, C.E., Lipner, H.J.: Metabolic effects of thyroxine injected into normal thiouracil-treated and thyroidectomited rats. Endo. 45: 624-627, 1949 .

Baron, M., Perlman, R., Levitt, M.: Paranoid schizophrenia and platelet MAO activity. Am. J. Psychiat. 137: 1465-1466, 1980.

Bax, N.D.S, Lennard, M.S., Tucker, G.T.: Effect of beta-blockers on thyroid homone. Brit. Med. J. 281: 1283, 1980.

Becker, R.E., Shaskan, E.G.: Platelet monoamine oxidase activity in schizophrenic patients. Am J. Psychiat. 134: 512-517, 1977.

Berger, P.A.: Medical treatment of mental illness. Science 200: $974-$ 981,1978 .

Berger, P.A., Hamburg, B., Hamburg, D.A.: Mental health: Progress and problems. Daedalus 106: 261-276, 1977.

Bergstrom, D.A., Kellar, K.J.: Adrenergic and serotonergic receptor binding in rat brain after chronic desmethylimipramine treatment. J. Pharmacol. Exp. Ther. 209: 256-261, 1979. 
Berthelsen, S., Pettinger, W.A.: A functional basis for classification of L-adrenergic receptors. Life Sci. 21: 595-606, 1977.

Bertler, A., Folck, B., Owman, C., Rosengreun, E.: The localization of monoaminergic blood-brain barrier mechanisms. Pharmacol. Rev. 18: $369-385,1966$.

Bjorklund, A., Axelsson, S., Falck, B.: Intraneuronal indolamines in the central nervous system. Adv. in Biochem. Psychopharmacol. 15: $87-94,1976$.

Blaschko, H.: The specification of L-dopa decarboxylase. J. Physiol. 96: 50P-5lP, 1939.

Blaschko, H.: Amine oxidase and amine metabolism. Pharmacol. Rev. 6: $23-28,1954$.

Blaschko, $H_{.}:$Physiological significance of monoamine oxidases. Farmaco, Pavia 12: 220-31, 1957.

Blaschko, H., Richter, D., Schlossmann, H.: The inactivation of adrenaline. J. Physiol. (London) 90: 1-17, 1937.

Blaustein, M.P., Johnson, E.M., Needleman, P.: Calcium-dependent norepinephrine release from pre-synaptic nerve endings in vitro. Proc. Nat. Acad. Sci. 69: 2237-2240, 1972.

Bloom, B.M.: Some structural considerations regarding compounds that influence monoamine metabolism. Annals N.Y. Academy Sciences 107: 840-890, 1963.

Bloom, F.E., Giarman, N.J.: Physiologic and pharmacologic consideration of biogenic amines in the nervous system. Ann. Rev. Pharmacol. 8: 229-247, 1969.

Bourne, H.R., Bunney, H.E., Colburn, R.W., Davis, J.M., Davis, J.N., Shaw, D.M., Coppen, A.J.: Noradrenaline, 5-hydroxythyptamine, and 5-hydroxyindole acetic acid in hind brains of suicidal patients. Lancet II, P.805, 1968 .

Bray, G.A.: A simple efficient liquid scintillator for counting aqueous solutions in a liquid scintilation counter. Analytical Biochem. 1: 279-285, 1960 .

Breese, G.R., Cooper, B.R., Prange, A.J., Cott, J.M., Lipton, M.A.: Interacting of thyrotropin-releasing hormone with centrally acting drugs. In The Thyroid Axis, Drugs, and Behavior, ed. by A.J. Prange, pp. 115-127, Raven Press, New York, 1974. 
Breese, G.R., Prange, A.J., Lipton, M.A.: Pharmacological studies of thyroid-imipramine interactions in animals. In The Thyroid Axis, Drugs and Behavior, ed. by A.J. Prange, Jr., Pp. 29-62, Raven Press, New York, 1974.

Brodie, B.B., Costa, E., Dlabac, A., Neff, N.H., and Smookler, H.H.: Application of steady state kinetics to the estimation of synthesis rate and turnover time of tissue catecholamines. J. Pharmacol. Exp. Ther. 154: 493-498, 1966.

Brown, G.L. and Gillespie, J.S.: The output of sympathetic transmitter from the spleen of the cat. J. Physiol. (London) 138: 81-102, 1957.

Bunney, B.S., Aghajanian, G.K.: Evidence for drug action on both preand post-synaptic catecholamine receptors in the CNS. In Preand Post-synaptic Receptors, ed. by E. Usdin and W.E. Bunney, pp. 89-120, Marcel Dekker, Inc., New York, 1975.

Bunney, W.E., Jr., and Davis, J.M.: Norepinephrine in depressive reactions. Arch. Gen. Psychiat. 13: 483-494, 1975.

Burn, J.H., Rand, M.J.: The action of sympathomimetic amines in animals treated with reserpine. J. Physiol. 144: 314-336, 1958.

Bursten, B.: Psychoses associated with thyrotoxicosis. Arch. Gen. Psychiat. 4: 267-273, 1961.

Callingham, B.A.: The effects of imipramine and related compounds on the uptake of noradrenaline into sympathetic nerve endings. Excerpta Medica International Congress Series, No. 122, pp. 35$43,1967$.

Callingham, B.A., Della Corte, L.: Effect of adrenalectomy upon some rat heart enzymes. Brit. J. Pharmacol. 41: 392P, 1971.

Callingham, B.A., Lyles, G.A.: An effect of thyroid hormones upon monoamine oxidase activity. Brit. J. Pharmacol. 51: 113P-114P, 1974.

Campbell, I.C., Robinson, D.S., Lovenberg, W., Murphy, D.L.: The effects of chronic regiments of clorgyline and pargyline on monoamine metabolism in the rat brain. J. Neurochemistry 32: 49-55, 1979.

Carlsson, A.: Receptor-mediated control of dopamine metabolism. In Pre and Post-synaptic Receptors, ed. by E. Usdin and W.E. Bunney, Pp. 49-63, Marcel Dekker, Inc., New York, 1975.

Carpenter, W.T., Bunney, W.E.: Adrenal cortical activity in depressive illness. Am J. Psychiat. 128: 63-72, 1971. 
Carrier, R.N. and Buday, P.V.: Augmentation of toxicity of monoamine oxidase inhibitor by thyroid feeding. Nature (London) 191: 1197,1961 .

Cavalieri, R.R. and Pitt-Rivers, R.: The effects of drugs on the distribution and metabolism of thyroid hormones. Pharmacol. Rev. 33: 55-80, 1981 .

Cedarbaum, J.M. and Aghajanian, G.K.: Boradrenergic neurons of the locus coeruleus: Inhibition by epinephrine and activation by the alpha-antagonist piperoxane. Brain Res. 112: 413-417, 1976.

Chan, L., O'Malley, B.W.: Mechanism of action of the sex steroid hormones. N. Eng. J. Med. 294: 1322-1328, 1372-1381, 1430-1437, 1976.

Chang, H.Y. and Kunos, G.: Short term effects of triiodothyronine on rat heart adrenoceptors. Biochem. Biophysical Res. Commun. 100: $313-320,1981$.

Chidsey, C.A., Harrison, D.C.: Studies on the distribution of exogenous norepinephrine in the sympathetic neurotransmitter store. J. Pharmacol. Exp. Ther. 140: 217-223, 1963.

Chirigos, M.A., Greengard, P., Udenfriend, S.: Uptake of tyrosine by rat brain in vivo. J. Biol. Chem. 235: 2075-2079, 1960.

Clower, C.G., Young, A.:., Kepas, D.: Psychotic states reulting from disorders of thyroid function. John Hopkins Med. J. 124: 305$310,1969$.

Cohen, K.L., Swigar, M.E.: Thyroid function screening in psychiatric patients. J.A.M.A. 242: 254-257, 1979.

Collins, G.G.S.: Properties of monoamine oxidase and some related enzymes. Adv. Biochem. Psychopharmacology 5: 129-132, 1972.

Collins, G.G.S., Sandler, M., Williams, E.D., Youdim, M.B.H.: Multiple forms of human brain mitochondrial monoamine oxidase. Nature (London) 225: 817-820, 1970.

Collins, G.G.S. and Southgate, J.: The effect of progesterone and oestradiol on rat uterine monoamine oxidase activity. Biochem. J. 117 : 38P, 1970.

Collis, M.G., Shepherd, J.T.: Antidepressant drug action and presynaptic L-receptors. Mayo Clinic Proc. 55: 567-572, 1980.

Comsa, J.: Adrenaline-thyroxine interaction in guinea pigs. Am. J. Physiol. 161: $550-553,1950$. 
Conney, A.H., Garren, L.: Contrasting effects of thyrozine on zoxazolamine and hexobarbital metabolism. Biochem. Pharmacol. 6: 257-262, 1961 .

Costa, E.: Methods for measuring indolealklamine and catecholamine turnover rate in vivo. Adv. Exp. Med. Biol. 13: 157-174, 1971.

Costa, E.: Simple neuronal models to estimate turnover rate of noradrenergic transmitters in vivo. In Biochemistry of Simple Neuronal Models, ed. by E. Costa and E. Giacubini, Pp. 169-204, Adv. Biochem. Psychopharmacol. Vol. 2, Raven Press, New York, 1970.

Costa, E., Iverson, L.L., Paoletti, R. (editors): Studies of neurotransmitters at the synaptic level. In Advances in Biochemical Psychopharmacology, Raven Press, New York, Vol, 6, 1972.

Costa, E., Meek, J.L.: Regulation of biosynthesis of catecholamines and serotonin in the CNS. Annual Rev. Pharmacol. 14: 491-511, 1974.

Costa, E., Neff, N.H.: Principle of steady-state kinetics as applied to the evaluation of drug effects on adrenergic neurons. In The Importance of Fundamental Principles in Drug Evaluation, ed. by D.H. Tedeschi, R.E. Tedeschi, Pp. 185-202, Raven Press, New York, 1968.

Costa, E. and Neff, N.H.: Estimation of turnover rates to study the metabolic regulation of the steady-state level of neuronal monoamines. In The Handbook of Neurochemistry Vol. IV, ed. by A. Lajtha, Pp. 45-90, Plenum Press, New York, 1970.

Coville, P.F., Telford, J.M.: Influence of thyroid hormones on the sensitivity of cardiac and smooth muscle, biogenic amines and other drugs. Brit. J. Pharmacol. 39: 49-68, 1970.

Coville, P.F. and Telford, J.M.: The effect of thyroid hormones on the action of some centrally acting drugs. Brit. J. Pharmacol. 40: $747-758,1970$.

Crawley, J.N., Hattox, S.E., Maas, J.W. and Roth, R.H.: 3-methoxy4-hydroxyphenylethyleneglycol increases in plasma after stimulation of the locus coeruleus. Brain Res. 14l: $380-385,1978$.

Crews, F.T., Smith, C.B.: Presynaptic alpha-receptor subsensitivity after long-term antidepressant treatment. Science 202: 322-324, 1978.

Crowt, R.J.: Catecholamines in urine. In Standard Methods of Clinical Chemistry, ed. by D. Seligson, pp. 62-80, Academic Press, New York, Vol. 3, 1961. 
Dahlstrom, A. and Fuxe, K.: Evidence for the existence of monoamine neurons in the central nervous system. ACTA Physiologica Scandinavica, Vol. 64, Supplementum 247, pp. 7-34, 1965.

Daiman, W.: Multiple measures of compensatory adaptation in catecholamine biosynthesis. In New Concepts in Neurotransmitter Regulation, ed. by A.J. Mandell, pp. 1-20, Plenum Press, New York, 1973.

Dairman, W., Gordon, R., Spector, S., Sjoerdsma, A., Udenfriend S.: Increased synthesis of catecholamines in the intact rat following administration of L-adrenergic blocking agents. Mole. Pharmacol. 4: 457-464, 1968 .

Davenport, J.W. and Dorcey, T.P.: Hypothyroidism: Learning deficit induced in rats by early exposure to thiouracil. Horm. and Behav. 3: 97-112, 1972 .

Davenport, J.W., Gonzalez, L.M., Hennies, R.S., Hagquist, W.M.: Severity and timing of early thyroid deficiency as factors in the induction of learning disorders in rats. Horm. and Behav. 7: 139-157, 1976 .

Davidson, J.: The management of resistant depression. Brit. J. Psychiat. 124: 219-220, 1974 .

deChamplain, J., Muller, A., Axelrod, J.: Subcellular localization of monoamine oxidase in rat tissues. J. Pharmacol. Exp. Ther. 166: 339-344, 1969.

de La Fuente, J.R.: Endocrine changes in depressive illness. Psychiatric Annals 9: $37-50,1979$.

deGroot, L.J., Stausser, J.L.: Binding of $\mathrm{T}_{3}$ in rat liver nuclei. Endo. 95: 74-83, 1974 .

deGroot, L.J., Torresani, J.: Triiodothyronine binding to isolated liver cell nuclei. Endo. 96: 357-369, 1975.

deMontigny, C. and Aghajanian, G.K.: Tricyclic antidepressants: Longterm treatment increases responsivity of rat forebrain neurons to serotonin. Science 202: 1303-1306, 1978.

Dencker, S.J., Malm, U., Roos, B.E., Werdinius, B.: Acid monoamine metabolites of cerebrospinal fluid in mental depression and mania. J. Neurochem. 13: 1545-1548, 1966.

Dewhurst, K.E., elKabir, D.J., Harris, G.K.: Observations on the blood concentration of thyrotrophic hormone (TSH) in schizophrenia and the affective states. Brit. J. Psychiat. 115: 1003-1011, 1969. 
Dewhurst, K.E., elKabir, D.J., Harris, G.W., Mandelbrote, B.M.: A review of the effect of stress on the activity of the central nervous-pituitary-thyroid axis in animals and man. Confin. Neurol. 30: 161-196, 1968.

Dobbing, J.: The blood brain barrier. Physiol. Rev. 41: 130-188, 1961.

Dunn, J.T.: The effects of thyroid hormone or protein synthesis in the central nervous system of developing mammals. Adv. in Exptl. Med. and Biol. 30: 367-383, 1972 .

Earle, B.V.: Thyroid hormone and tricyclic antidepressants in resistant depressions. Am. J. Psychiat. 126: 143-145, 1970.

Eayrs, J.T.: Influence of the thyroid on the central nervous system. Brit. Med. Bulletin 16: 122-127, 1960.

Eayrs, J.T. and Taylor, S.H.: The effect of thyroid deficiency induced by methyl thiourocil on the maturation of the central nervous system. J. of Anatomy 85: 350-358, 1951 .

Eiduson, S., Geller, E., Yuwiler, A., Eiduson, B.T. (editors): Biochemistry and Behavior, pp. 352-355, D. Van Nostrand Company, Inc., Princeton, N.J., 1964.

Emlen, W., Segal, D.S., Mandell, A.J.: Thyroid state: Effects on preand postsynaptic central noradrenergic mechanisms. Science 175: $79-82,1972$.

Enero, M.A., Langer, S.Z., Rothlin, R.P., Stefano, F.J.E.: Role of the L-adrenoceptor in regulating noradrenaline overflow by nerve stimulation. Brit. J. Pharmacol. 44: 672-688, 1972.

Engstrom, G., Svensson, T.H., Waldeck, B.: Thyroxine and brain catecholamines: Increased transmitter synthesis and increased receptor sensitivity. Brain Res. 77: 471-483, 1974.

Engstrom, G., Strombom, U., Svensson, T.H., Waldeck, B.: Brain monoamine synthesis and receptor sensitivity after a single or repeated administration of thyroxine. J. of Neural Transmission $37: 1-10,1975$.

Enna, S.J., Mann, E., Kendall, D., Stancel, G.M.: Effect of chronic antidepressant administration on brain neurotransmitter receptor binding. In Antidepressants: Neurochemical, Behavioral, and Clinical Perspectives, ed. by S.J. Enna, J.B. Malick, E. Richelson, pp. 91-105, Raven Press, New York, 1981.

Fisher, A.G., Schulz, A.R., Oliner, L.: Thyroidal biosynthesis of iodothyronines. II. General characteristics and purification of mitochondrial monoamine oxidase. Biochimica Et Biophysica ACTA 159: 460-471, 1968 . 
Fleischmann, W.: Comparative physiology of the thyroid hormone. Quant. Rev. Biol. 22: 119-140, 1947.

Fowler, C.J., Callingham, B.A.: Monoamine oxidase A and B: A useful concept? Biochem. Pharmacol. 27: 97-101, 1978 .

Fowler, C.J. and Oreland, L.: Substrate-selective interaction between monoamine oxidase and oxygen. In Monoamine Oxidase: Structure, Function, and Altered Functions, ed. by T.P. Singer, R.W. Von Korff, D.L. Murphy, pp. 145-151, Academic Press, New York, 1979.

Frazer, A., Hess, M.E., Mendels, J., Gable, B., Kunkel, E. and Bender, A.: Influence of acute and chronic treatment with desmethylimipramine on catecholamine effects in the rat. J. Pharmacol. Exp. Ther. 206: 311-319, 1978 .

Fuller, R.W.: Selective inhibition of monoamine oxidase. Adv. Biochem. Psychopharmacology 5: 339-354, 1972.

Fuller, R.W.: Enhancement of monoaminergic neurotransmission by antidepressant drugs. In Antidepressants: Neurochemical, Behavioral, and Clinical Perspectives, ed. by S.J. Enna, J.B. Malick, E. Richelson, pp. 1-12, Raven Press, New York, 1981.

Gabay, S., Achee, F.M.: Psychoactive drug effects and substratespecificity in intact mitochondrial monoamine oxidase from brain. Psychopharmacology Bulletin 13: 45-47, 1977.

Gabay, S. and Valcourt, A.J.: Studies of monoamine oxidase. I. Purification and properties of the rabbit liver mitochondrial enzyme. Biochim. Biophys. ACTA 159: 440-450, 1968A.

Gabay, S. and Valcourt, A.J.: Biochemical determinants in the evaluation of monoamine oxidase inhibitors. Rec. Adv. Biol. Psychiat. 10: $29-41,1968 \mathrm{~B}$.

Gardner, R.S.: Nuclear thyroid hormone receptors: Evidence for association with nucleolar chromatin. Biochem. Biophys. Res. Commun. 67: 625$633,1975$.

Garver, D.L., Pandey, G.N., Dekirmenjian, H., Deleon-Jones, F.: Growth hormone and catecholamines in affective disease. Am J. Psychiat. 132: 1149-1154, 1975.

Gibson, J.G.: Emotions and the thyroid gland: A critical appraisal. J. Psychosomatic Research 6: 93-116, 1962.

Glass, G.S., Heninger, G.R., Lansky, M.: Psychiatric emergency related to the menstrual cycle. Am J. Psychiat. 128: 705-711, 1971. 
Glaubiger, G., Lefkowitz, R.J.: Elevated B-adrenergic receptor number after chronic propranolol treatment. Biochem. Biophys. Res. Commun. 78: 720-727, 1977 .

Glick, D., Greenberg, L.J.: The quantitative histological distribution of the succinic dehydrogenase system in the rat adrenal and the influence of hypophysectomy on ACTH and cortisone. Endocrinology $63: 778-784,1958$.

Glowinski, J.: Metabolism of Norepinephrine in the central nervous system. Pharmacol. Rev. 18: 1201-1238, 1966.

Glowinski, J. and Axelrod, J.: Inhibition of uptake of tritiatednoradrenaline in the intact rat brain by imipramine and structurally related compounds. Nature (London) 204: 1318-1319, 1964 .

Glowinski, J., Besson, M.J., Cheramy, A. and Thierry, A.M.: Disposition and role of newly synthesized amines in central catecholaminergic neurons. Adv. in Biochem. Psychopharmacology 6: 93-109, 1972.

Glowinski, J. and Iversen, L.: Regional studies of catecholamines in the rat brain--III: Subcellular distribution of endogenous and exogenous catecholamines in various brain regions. Biochem. Pharmacol. 15: 977-987, 1966.

Glowinski, J., Iversen, L.L., Axelrod, J.: Storage and sunthesis of norepinephrine in the reserpine-treated rat brain. J. Pharmacol. Exp. Ther. 151: 385-399, 1966.

Gold, M.S., Pottash, A.C.: Depression: Diagnosis and treatment with tricyclic antidepressants. Postgrad. Med. 69: 104-107, 110-117, 1981 .

Goldstein, D.J., Fischer-Ferraro, C.L., Mahmod, V.E., Finkielman, S.: Angiotensin $I$ in renal and extra-renal tissues. Medicina (Buenos Aires) $30: 81-83,1970$.

Gordon, A., Surks, M.I., Oppenheimer, J.H.: Thyroxine stimulation of amino acid incorporation into mitochondrial protein: Differences between in vivo and in vitro effects. ACTA Endocrinologia 72: $684-696,1973$.

Gordon, R., Spector, S., Sjoerdsma, A., Udenfriend, S.: Increased synthesis of norepinephrine and ephedrine in the intact rat during exercise and exposure to cold. J. Pharmacol. Exp. Ther. 153: $440-447,1966$.

Gorkin, V.Z.: Monoamine oxidases. Pharmac. Rev. 18: 115-120, 1966. 
Gorkin, V.2.: Qualitative alterations in enzymatic properties of amine oxidases. Adv. Biochem. Psychopharmacology 5: 55-65, 1972.

Green, A.R., Grahame-Smith, D.G.: 5-hydroxyindoleamine and other indoles in the central nervous system. In Handbook of Psychopharmacology Vol. 3, ed. by L.L. Iversen, S. Iversen, S. Snyder, pp. 169-245, Plenum Press, New York, 1975.

Green, A.R., Mitchell, B.D., Tordoff, A.F.C., Youdim, M.B.H.: Evidence for dopamine deamination by both type $A$ and type $B$ monoamine oxidase in rat brain in vivo, and for the degree of inhibition of enzyme necessary for increased functional activity of dopamine and 5-hydroxytryptamine. Br. J. Pharmacol. 60: 343-349, 1977.

Greenawalt, J.W.: Localizations of Monoamine oxidase in rat liver mitochondria. Adv. in Biochemical Psychopharmacology 5: 207-226, 1972.

Greengard, D.A., U'Prichard, D.C., Snyder, S.H.: Alpha-noradrenergic receptor binding in mammalian brain: Differential labeling of agonist and antagonist states. Life Sci. 19: 69-82, 1976.

Gripois, D.: Developmental characteristics of monoamine oxidase. Comp. Biochem. Physiol. 51C: 143-151, 1975.

Guroff, G., Udenfriend, S.: Studies on aromatic amino acid uptake by rat brain in vivo. J. Biol. Chem. 237: 803-806, 1962.

Haggendal, J., Lindquist, M.: Brain monoamine levels and behavior during long-term adminstration of reserpine. Int. J. Neuropharmacol. 3: 59-64, 1964 .

Halaris, A.E., Lovell, R.A. and Freedman, D.X.: Effect of Chlorimepramine on the metabolism of 5-hydroxythyptamine in the rat brain. Biochem. Pharmacol. 22: 2200-2202, 1973.

Hall, H. and Ogren, S.O.: Effects of antidepressant drugs in different receptors in the brain. European J. of Pharmacol. 70: 393-407, 1981.

Hamlet, M.A., Rorie, D.K., Tyce, G.M.: Release of endogenous catecholamines from slices of hypothalamus of rats. Brain Res. 217: 315325,1981 .

Hammond, R.P.: Thyroid-catecholamine interrelationships: Effects on lipolysis in isolated brown fat cells. Brown Univ. Division of Biological and Medical Sciences (Ph.D. Thesis) 1968.

Hamolsky, M.W.: Chief of Medicine, Rhode Island Hospital, Providence, RI.

Hansen, J.M., Siersbaek-Nielsen, K.: Cerebrospinal fluid thyroxine. J. Clin. Endocrinol. 29: 1023-1026, 1969. 
Hare, M.L.C.: Tyramine oxidase. Biochem. Journal 22: 968-979, 1928.

Harris, J.E., Baldessarini, R.J.: The uptake of $\mathrm{H}^{3}$-dopamine by homogenates of rat corupus striatum: Effects of cations. Life Sci. 13: 303$312,1973$.

Harrison, T.S.: Adrenal medullary and thyroid relationships. Physiological Rev. 44: 161-185, 1964.

Hawkins, J.: The localization of amine oxidase in the liver cell. Biochem. J. 50: 577-581, 1952.

Hazama, H., Ito, M., Hirano, M., Uchimura, H.: Monoamine oxidase activities in neuronal and glial fractions from regional areas of rat brain. J. of Neurochern. 26: 417-419, 1976.

Henschke, P.J., Pain, R.W.: Thyroid disease in a psychogeriatric population. Age and Ageing 6: 151-156, 1977.

Hillarp, N.A., Fuxe, K., Dahlstrom, A.: Demonstration and mapping of central neurons containing dopamine, noradrenaline, and 5-hydroxythyptamine and their reactions to psychopharmaca. Pharmacol. Rev. 18: 727-741, 1966.

Himms-Hagen, J.: Sympathetic regulation of metabolism. Pharmacol. Rev. 46: $67-101,1967$.

Holtz, P.: Anwendung der bestimmung der aktivitat decarboxydase. Naturiwissensch 27: 724-731, 1939 .

Holzbauer, M., Youdim, M.B.H.: The oestrous and monoamine oxidase activity. Brit. J. Phamacol. 48: 600-608, 1973.

Honecker, H., Hill, R.: Does long term treatment with amitriptyline alter the monoamine oxidase of rat brain. Pharmakopsychiat. 10: $32-35,1977$.

Hornykiewicz, 0.: Dopamine in the basal ganglia. Brit. Med. Bull. 29: $172-178,1973$.

Howslay, M.D., Tipton, K.F.: The nature of the electrophorectically separable multiple forms of rat liver monoamine oxidase. Biochem. J. 135: 173-186, 1973.

Howslay, M.D., Tipton, K.F.: A kinetic evaluation of monoamine oxidase activity in rat liver mitochondrial outer membrane. Biochem. $J$. 139: 645-652, 1974 .

Howslay, M.D., Tipton, K.F.: Multiple forms of monoamine oxidase: Fact and artefact. Life Sci. 19: 467-478, 1976. 
Iversen, L.L.: Catecholamine uptake processes. Brit. Med. Bull. 29: $130-135,1973$.

Iversen, L., Iversen, S., Snyder, S. (editors): Enzymes involved in catabolism of catecholamines. In Handbood of Psychopharmacologv, Vol. 3, pp. 20-25, 179-182, Plenum Press, New York, 1975.

Jacoby, J.H., Mueller, G., Wurtman, R.J.: Thyroid state and brain metabolism. Endo. 97: 1332-1335, 1975.

Jain, M.: Monoamine oxidase: Examination of multiple forms. Life Sci. 20: $1925-1933,1977$.

Jarrott, B., Louis, W.J., Summers, R.J.: The effect of a series of clonidine analogues on $\left(\mathrm{H}^{3}\right)$ - clonidine binding in rat cerebral cortex. Biochem. Pharmacol. 27: 141-144, 1979.

Jefferys, P.M.: The prevalence of thyroid disease in patients admitted to a geriatric department. Age and Ageing 1: 33-37, 1972.

Johnston, J.P.: Some observations upon a new inhibitor of monoamine oxidase in brain tissue. Biochem. Pharmacol. 17: 1285-1297, 1968.

Kaiser, E.A.: Effects of cold acclimation on content and activity of monoamine oxidase in brown adipose tissue of rats. (M. Sc. Thesis) Univ. of R.I., Kingston, R.I., USA, $1975 \mathrm{~A}$.

Kaiser, E.A., Gray, H.G., Hammond, R.P.: Effect of estrous cycle and castration on MAO activity. J. Animal Sci. Vol. 4l: p. 439, $1975 \mathrm{~B}$.

Kales, A., Heuser, G., Jacobson, A., Kales, J.D., Hanley, J., Zweizig, J.R, Paulson, M.J.: All night sleep studies in hypothyroid patients, before and after treatment. J. Clin. Endocrinol. Metab. 27: 1593-1599, Nov. 1967.

Kalsner, S., Chan, C.: Adrenergic antagonists and the presynaptic receptor hypothesis in vascular tissue. J. Phamacol. Exp. Ther. 211: 257-264, 1979.

Kanof, P.D. and Greengard, P.: Brain histamine receptors as targets for antidepressant drugs. Nature 272: 329-332, 1978.

Kant, G.J., Meyerhoff, J.L.: Release of endogenous norepinephrine from rat hypothalamus in vitro. Life Sci. 20: 149-154, 1977.

Kapur, H., Mottram, D.R.: A comparative study on the pre- and postsynaptic alpha blocking activity of a series of benzodioxanes. Biochem. Pharmacol. 27: 1879-1880, 1978. 
Kennedy, D.R., Hammond, R.P., Hamolsky, M.W.: Thyroid, cold-acclimation influences on norepinephrine metabolism in brown fat. Am. J. Physiol. 232: E565-E569, 1977.

Kirpekar, S.M. and Puig, M.: Effect of flow stop on noradrenaline release from normal spleen and spleens treated with cocaine, phentolamine, or phenoxybenzamine. Brit. J. Pharmacol. 43: 359-369, 1971 .

Kirshner, N.: Function and organization of chromaffin vesicles. Life Sci. 14: 1153-1167, 1974 .

Kissane, J.M. and Robins, E.: The fluorometric measurement of deoxyribonucleic acid in animal tissues with special reference to the central nervous system. J. Biol. Chem. 233: 184-188, 1958.

Kobayashi, R.M., Palkovits, M., Kopin, I.J. and Jacobowitz, D.M.: Biochemical mapping of noradrenergic nerves arising from the rat locus coeruleus. Brain Res. 77: 269-279, 1974.

Knoll, J., Magyar, K.: Some puzzling pharmacological effects of monoamine oxidase inhibitors. Adv. Biochem. Psychopharmacology 5: $393-408,1972$.

Kopin, I.J.: Storage and metabolism of catecholamines. The role of monoamine oxidase. Pharmacol. Rev. 16: 179-191, 1964.

Kopin, I.J.: Biochemical aspects of release of norepinephrine and other amines from sympathetic nerve endings. Pharmacol. Rev. 18: $513-523,1966$.

Kopin, I.J., Breese, G.R., Krauss, K.R., Weise, V.K.: Selective release of newly synthesized norepinephrine from the cat spleen during sympathetic nerve stimulation. J. Pharmacol. Exp. Ther. 161: $271-278,1968$.

Kordon, C. and Glowinski, J.: Role of brain catecholamines in the control of anterior pituitary functions. In Neurochemical Aspects of Hypothalamic Function, ed. by L. Martini, J. Meites, pp. 85100, Academic Press, New York, 1970.

Kurtz, D.T., Sippel, A., Feigelson, P.: Effect of thyroid hormones on the level of the hepatic mRNA for $\mathrm{L} 2$ globulin. Biochem. 15: $1031-1036,1976$.

Lambert, G.A., Lang, W.J., Friedman, E., Meller, E., Gershon, S.: Pharmacological and biochemical properties of isomertic yohimbine alkaloids. European J. Pharmacol. 49: 39-48, 1978.

Landsberg, L. and Axelrod, J.: Reduced accumulation of $H^{3}$-norepinephrine in the rat heart following hypophysectomy. Endo. 82: 175-178, 1968. 
Lang, W.J., Lambert, G.A., Rush, M.L.: The role of the central nervous system in the cardiovascular responses to yohimbine. Arch. Int. Pharmacodyn. 217: 57-67, 1975.

Langer, S.Z.: Presynaptic regulation of catecholamine release. Biochem. Pharmacol. 23: 1793-, 1974.

Langer, S.Z.: Presynaptic receptors and their role in the regulation of transmitter release. Brit. J. Pharmacol. 60: 481-497, 1977.

Langer, S.Z., Adler, E., Enero, M.A. and Stefano, F.J.E.: The role of the L-receptor in regulating noradrenaline overflow by nerve stimulation. XXVth International Congress of Physiological Sciences, Munich, p. 335, $\overline{1971 .}$

Langer, S.Z., Dubocovich, M.L.: Subsensitivity of presynaptic Ladrenoceptors after exposure to noradrenaline. European $\mathrm{J}$. Pharmacol. 4l: 87-88, 1977 .

Langer, S.Z., Dubocovich, M.L., Celuch, S.M.: Prejunctional regulatory mechanisms for noradrenaline release by nerve stimulation. In Chemical Tools in Catecholamine Research Vol. 2, ed. by C. Almgren, A. Carlsson, J. Engel, pp. 183-19l, Elsevier NorthHolland Publishing Co., Amsterdam, 1975.

Lapin, I.P.: Adrenergic nonspecific potentiation of yohimbine toxicity in mice by antidepressants and related drugs and antiyohimbine action of antiadrenergic and serotonergic drugs. Psychopharmacology 70: $179-185,1980$.

Lee, F.L., Weiner, N., Trendelenburg, U.: The uptake of tyramine and formation of octopamine in normal and tachyphylactic rat atria. J. Pharmacol. Exp. Ther. 155: 211-222, 1967.

Leonard, B.E.: Neurochemical and neuropharmacological aspects of depression. Int. Rev. Neurobiology 18: 357-387, 1975.

Leonard, B.E. and Kafoe, W.F.: A comparison of the acute and chronic effects of four antidepressant drugs on the turnover of serotonin, dopamine and noradrenaline in the rat brain. Biochem. Pharmacol. 25: 1939-1942, 1976.

Lewander, T., Joh, T.H. and Reis, D.J.: Tyrosine hydroxylase: Delayed activation in central noradrenergic neurons and induction in adrenal medulla elicited by stimulation of central cholinergic receptors. J. Pharmacol. Exp. Ther. 200: 523-528, 1977.

Libow, L.S., Durrell, J.: Clinical studies on the relationship between psychosis activity. II Psychotic symptoms and thyroid regulation in a case of post-thyroidectomy depressive psychosis. Psychosm. Med. 27: 377-382, 1965. 
Lipton, M.A., Prange, A.J., Daiman, W., Udenfriend, S.: Increased rate of norephinephrine biosynthesis in hypothyroid rats. Fed. Proc. 27 : 399, 1968.

Long, J.W.: Drug profiles. In The Essential Guide to Prescription Drugs, ed. by C.L. Dingler, PP. 564-567, Harper and Row Publishers, New York, 1977.

Lorenz, R.R., Vanhoutte, P.M., Shepherd, J.T.: Interaction between neuronal amine uptake and prejunctional alpha-adrenergic receptor activation in smooth muscle from canine blood vessels and spleen. Blood Vessels 16: 113-125, 1979.

Lyles, G.A. and Callingham, B.A.: The effects of thyroid hormones on monoamine oxidase in the rat heart. J. Pharm. Pharmacol. 26: $921-930,1976$.

Lund, A.: Simultaneous fluorometric determinations of adrenalin and noradrenalin in blood. Acta Pharmacol. Toxicol. 6: 137-146, 1950.

Maas, J.W., Fawcett, J.A., Dekimenjian, H.: Catecholamine metabolism, depressive illness and drug response. Arch. Gen. Psychiat. 26: 252-262, 1972 .

MacLeod, K.M., Baxter, J.D.: Chromatin receptors for thyroid hormones: Interactions of the solubilized proteins with DNA. J. Biol. Chem. 251: $7380-7387,1976$.

Malbon, C.C.: Avenues of adrenergic research. J. Laboratory and Clinical Medicine 94: $381-386,1979$.

Malick, J.B.: Yohimbine potentiation as a predictor of antidepressant action. In Antidepressants: Neurochemical, Behavioral, and Clinical Perspectives, ed. by S.J. Enna, J.B. Malick, E. Richelson, pp. 141-155, Raven Press, New York, 1981.

Mandell, A.J., Mandell, M.P.: Suicide and the menstrual cycle. J. Am. Med. Assoc. 200: 792-793, 1967.

Mandel, A.J., Segal, D.S., Kuczenski, R.T., Knapp, S.: Amphetamineinduced changes in the receptor functions in the brain. In Pharmacology and the Future of Man, 5th Int. Congr. Pharmacol. 1972, Vol. 1, pp. 95-105, Karger, Basel, $19 \overline{73}$.

Mason, J.W.: Emotion as reflected in patterns of endocrine integration. In "Emotions-Their Parameters and Measurement", ed. by L. Levi, pp. 143-181, Raven Press, New York, 1975.

Mason, J.H., Hartley, L.H., Kotchen, T.A.: Plasma thyroid-stimulating hormone response in anticipation of muscular exercise in the human. J. Clin. Endocrinol. Metab. 37: 403-406, 1973. 
McClure, D.J.: Biochemistry of depression. Can. Psychiat. Assoc. J. 16: $247-252,1971$.

McClure, D.J.: The role of dopamine in depression. Can. Psychiat. Assoc. J. 18: 309-312, 1973.

McLarty, D.G., Ratcliffe, W.A., Ratcliffe, J.G., Shimmins, J.G., Goldberg, A.: A study of thyroid function in psychiatric inpatients. Brit. J. Psychiat. 133: 211-218, 1978.

Meltzer, H.Y., Arora, R.C., Jackman, H., Pscheidt, G., Smith, M.D.: Platelet monoamine oxidase and plasma amine oxidase in psychiatric patients. Schizophrenia Bulletin 6: 213-219, 1980.

Moonat, L.B.S., Assad, M.M., Clarke, D.E.: L-thyroxine and monoamine oxidase activity in the kidney and some other organs of the rat. Res. Conmun. Chem. Pathol. Pharmacol. 12: 765-779, 1975.

Nagatsu, T., Levitt, M., Udenfriend, S.: Tyrosine hydroxylase, the initial step in norepinephrine biosynthesis. J. Biol. Chem. 238: 2910-2917, 1964 .

Neff, N.H. and Costa, E.: Effect of tricyclic antidepressants and chlorpromazine on brain catecholamine synthesis. In Antioepressant Drugs, ed. by S. Garattin, M.N.G. Dukes, pp. 28-34, International Congress Series No. 122, Excerpta Medica Foundation, Amsterdam, 1967.

Neff, N.H., Yang, H.Y.T.: Another look at the monoamine oxidases and the monoamine oxidase inhibitor drugs. Life Sci. 14: 2061$2074,1974$.

Neff, N.H., Yang, H.Y., Fuentes, J.A.: The use of selective monoamine oxidase inhibitor drugs to modify amine metabolism in brain. Adv. Biochem. Psychopharmacology 12: 49-58, 1974.

Nicholson, G., Liebling, L.I., Hall, R.A.: Thysoid dysfunction in female psychiatric patients. Brit. J. Psychiat. 129: 236-238, 1976.

Nies, A., Robinson, D.S., Ravaris, C.L., Davis, J.M.: Amines and monoamine oxidase in relation to ageing and depression in man. Psychosomatic Medicine 33: 470, 1971.

Norberg, K.A. and Hamberger, B.: The sympathetic adrenergic neuron. Acta Physiologica Scandinavica, Vol. 63, Supplementum 238, PP. 5-42, 1964.

Novick, W.J.: The effect of age and thyroid hormones on the monoamine oxidase of rat heart. Endo. 69: 55-59, 1961. 
Nusynowitz, M.L., Young, R.L.: Thyroid dysfunction in the ailing, aging, and aberrant. JAMA 242: 275-276, 1979.

Oldendorf, W.H.: Blood-brain barrier permeability to drugs. Ann. Rev. Pharmacol. 14: 239-248, 1974.

Oppenheimer, J.H.: Initiation of thyroid-hormone action. N. Eng. J. Med. 292: 1063-1068, 1975.

Oppenheimer, J.H.: Thyroid hormone action at the cellular level. Sci. 203: 971-979, 1979.

Orsulak, P.J., Schildkraut, J.J., Schatzberg, A.F., Herzog, J.M.: Differences in platelet monoamine oxidase activity in subgroups of schizophrenic and depressive disorders. Biol. Psychiatry 13: $637-647,1978$.

Ostman-Smith, I.: Studies on the turnover of noradrenaline in brain and heart based on synthesis inhibition by L-methyltyrosine. Acta Physiologica Scandinavica Supplementum 477 Chapter 5, pp. 62-71, 1979.

Oswald, I., Brezinova, V. and Dunleavy, D.L.F.: On the slowness of action of tricyclic antidepressant drugs. Brit. J. Psychiat. 120: 673$677,1972$.

Otten, U. and Thoenen, $H_{.}$: Selective induction of tyrosine hydroxylase and dopamine B-hydroxylase in sympathetic ganglia in organ culture: Role of glucocorticoids as modulators. Molecular Pharmacol. 12 : 353-361, 1976.

Papeschi, R. and Theiss, P.: The effect of yohimbine on the turnover of brain catecholamines and serotonin. Europ. J. Pharmacol. 33: $1-12,1975$.

Park, S., Happy, J.M., Prange, A.J.: Thyroid action on behavioralphysiological effects and disposition of phenothiazines. Europ. J. Pharmacol. 19: 257-265, 1972.

Peroutka, S.J., Snyder, S.H.: Interactions of antidepressants with neurotransmitter receptor sites. In Antidepressants: Neurochemical, Behavioral and Clinical Perspectives, ed. by S.J. Enna, J.B. Malick, E. Richelson, Pp. 75-90, Raven Press, New York, 1981.

Phillis, J.W.: The role of calcium in the central effects of biogenic amines. Life Sci. 14: 1189-1201, 1974.

Ponto, L.B., Perry, P.J., Liskow, B.I., Seaba, H.H.: Tricyclic antidepressants and monoamine oxidase inhibitor combination therapy. Drug Therapy Reviews 68: 283-289, 1977.

Potter, L.T., Axelrod, J., Kopin, I.J.: Differential binding and release of norepinephrine and tachyphylaxis. Biochem. Pharmacol. 11: 254$256,1962$. 
Prange, A.J., Lipton, M.A.: Enhancement of imipramine mortality in hyperthyroid mice. Nature 196: 588-589, 1962.

Prange, A.J. Lipton, M.A., Shearin, R.B., Love, G.N.: The influence of thyroid states on the effects and metabolism of pentobarbital and thiopental. Biochem. Pharmacol. 15: 237-248, 1966.

Prange, A.J., McCurdy, R.L., Cochrane, C.M.: The systolic blood pressure resonse of depressed patients to infused norepinephrine. J. Psychiat. Res. 5: 1-13, 1967.

Prange, A.J., Meek, J.L., Lipton, M.A.: Catecholamines: Diminished rate of synthesis in rat brain and heart after thyroxine pretreatment. Life Sci. 9: 901-907, 1970.

Prange, A.J., Wilson, I.C., Knox, A., McClane, T.K., Lipton, M.A.: Enhancement of imipramine by thyroid stimulating hormone: Clinical and theoretical implications. Am. J. Psychiat. 127: $191-198,1970$.

Prange, A.J., Wilson, I.C., Rabon, A.M., Lipton, M.A.: Enhancement of imipramine antidepressant activity by thyroid hormone. Am. J. Psychiatry 126: 457-469, 1969.

Pugh, C.E.M., Quastel, J.M.: Oxidation of aliphatic amines by brain and other tissues. Biochem. J. 31: 286-291, 1937.

Ramon, Juan de la Fuente: Endocrine changes in depressive illness. Psychiatric Annais 9: 196-204, 1979.

Rastogi, R.B. and Singhal, R.L.: Thyroid hormone control of 5-hydroxytryptamine metabolism in developing rat brain. J. Pharmacol. Exp. Ther. 191: 72-81, 1974A.

Rastogi, R.B. and Singhal, R.L.: Alterations in brain norepinephrine and tyrosine hydroxylase activity during experimental hypothyroidism in rats. Brain Res. 81: 253-266, 1974 .

Rastogi, R.B. and Singhal, R.L.: Evidence for the role of adrenocortical hormones in the regulation of noradrenaline and dopamine metabolism in certain brain areas. Brit. J. Pharmacol. 62: 131-136, 1978.

Reinstein, D.K., Isaacson, R.L.: Clonidine sensitivity in the developing rat. Brain Res. 135: 378-382, 1977.

Rochette, L., Beley, A., Bralet, J.: Effect of the activiation of alpha-adenoreceptors on the synthesis and release of noradrenaline by peripheral adrenergic nerves in vivo. J. Neural Transmission 39: $21-32,1976$. 
Roffler-Tarlov, S., Schildkraut, J.J., Draskorzy, P.R.: Effects of acute and chronic administration of desmethylimipramine on the content of norepinephrine and other monoamines in the rat brain. Biochem. Pharmacol. 22: 2923-2926, 1973.

Ross, R.A. and Reis, D.J.: Effects of lesions of locus coeruleus on regional distribution of dopamine-B-hydroxylase activity in rat brain. Brain Res. 73: 161-166, 1974.

Ross, S.B. and Renyi, A.L.: Tricyclic antidepressant agents. II. Effect of oral administration on the uptake of $\mathrm{H}^{3}$-noradrenaline and $\mathrm{Cl}^{14}$ 5-hydroxytryptamine in slices of the midbrain-hypothalamus region of the rat. Acta. Pharmacol, et Toxicol. 36: 395-408, 1975A.

Ross, S.B. and Renyi, L.: Tricyclic antidepressant agents. I. Com-

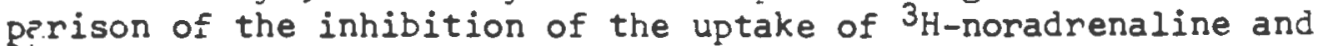
${ }^{14} \mathrm{C}$-hydroxytryptamine in slices and crude synaptosome preparations of the midbrain bypothalamus region of the rat brain. Acta Pharmacol. Toxicol. 36: 382-394, 1975B.

Rossi, G.V.: Pharmacology of tricyclic antidepressants. Am. J. Pharmacy 148: 37-45, March-April, 1976.

Roth, J.A.: Inhibition of human type B monoamine oxidase by tricyclic psychoactive drugs. Molecular Pharmacol. 14: 164-171, 1978.

Roth, J.A. and Gillis, C.N.: Deamination of B-phenylethylamine by monoamine oxidase-inhibition by imipramine. Biochem. Pharmacol. 23: $2537-2545,1974$ A.

Roth, J.A. and Gillis, C.N.: Inhibition of lung, liver and brain monoamine oxidase by emepramine and desipramine. Biochem. Pharmacol. 23: 1138-1140, 1974B.

Roth, J.A., Gillis, C.N.: Some structural requirements for inhibition of type $A$ and $B$ forms of rabbit monoamine oxidase by tricyclic psychoactive drugs. Molecular Pharmacol. 11: 28-35, 1975.

Roth, R.H., Walters, J.R., Murrin, L.C., Morgenroth, V.H.: Dopamine neurons: Role of impulse flow and presynaptic receptors in the regulation of tyrosine hydroxylase. In Pre and Post-synaptic Receptors, ed. by E. Usdin and W.E. Bunney, pp. 5-46, Marcel Dekker, Inc., New York, 1975.

Rubin, R.P.: The role of calcium in the release of neurotransmitter substances and hormones. Pharmacol. Rev. 22: 389-428, 1970.

Rubin, R.T., Mandell, A.J.: Adrenal cortical activity in pathological emotional states: A review. Am. J. Psychiat. 123: 387-400, 1966.

Ruhmann-Wennhold, A. and Nelson, D.H.: Corticosteroidogenesis and its relation to ACTH dependence of mitochondrial components. Endocrinology 93: 977-982, 1973. 
Saavedra, J.M., Grobecker, H., Zivin, J.: Catecholamines in the raphe of the rat. Brain Res. 114: 339-345, 1976.

Samuels, H.H., Tsai, J.S.: Thyroid hormone action in cell culture: Demonstration of nuclear receptors in intact cells and isolated nuclei. Proc. Natl. Acad. Sci. 70: 3488-3492, 1973.

Samuels, H.H., Tsai, J.S., Casanova, J.: Thyroid hormone action: In vitro characterization of solubilized nuclear receptors from rat liver and cultured GH cells. J. Clin. Invest. 54: 853-865, 1974.

Sandler, M. and Youdim, M.B.H.: Multiple forms of monoamine oxidase: Functional significance. Pharmacol. Rev. 24: 331-348, 1972.

Schildkraut, J.J., Herzog, S.M., Orsulak, P.J., Edelman, J.E., Shein, H.M., Frazier, S.H.: Reduced platelet monamine oxidase activity in a subgroup of schizophrenic patients. Am. J. Psychiatry 133: $438-440,1976$.

Schildkraut, J.J. and Kety, S.S.: Biogenic amines and emotion. Sci. 156: $21-30,1967$.

Schildkraut, J.J., Winokur, A., Applegate, C.W.: Norepinephrine turnover and metabolism in rat brain after long term administration of imipramine. Sci. 168: 867-869, 1970.

Schildkraut, J.J., Winokur, A., Draskolzy, P.R., Hensle, J.H.: Changes in norepinephrine turnover in rat brain during chronic administration of imipramine and protriptyline: A possible explanation for the delay in onset of clinical antidepressant effects. Am J. Psychiatry 127: 1032-1039, 1971.

Schmidt, J.: Treatment of endogenous depressions with thyrotropinreleasing hormone (TRH) under oral administration. Acta Psychiat. Scand. 55: 142-146, 1977.

Schnaitman, L., Erwin, V.G., Greenawalt, J.W.: The submitochondrial localization of monoamine oxidase. J. Cell. Biol. 32: 719-735, 1967.

Schnaitman, C., Greenawalt, J.W.: Enzymatic properties of the inner and outer membranes of rat liver mitochondria. J. Cell Biology 38: $158-175,1968$.

Schneckloth, R.E., Kurland, G.S., Freedberg, A.S.: Effect of variation in thyroid function on pressor response to norepinephrine in man. Metab. Clin. Exp. 2: 546-555, 1953.

Schwark, W.S., Keesey, R.R.: Thyroid hormone control of serotonin in developing rat brain. Res. Communications Chemical Pathology and Pharmacol. 10: 37-50, 1975. 
Segal, D.S., Kuczenski, R. and Mandell, A.J.: Theoretical implications of drug-induced adaptive regulation for a biogenic amine hypothesis of affective disorder. Biol. Psychiat. 9: 147-159, 1974.

Segal, D., Geyer, M.A., Weiner, B.E.: Strain differences during intraventricular infusion of norepinephrine: A possible role of receptor sensitivity. Sci. 189: 301-306, 1975.

Shaw, D.M., Camps, F.E., Eccleston, E.G.: 5-hydroxytryptamine in the hind brain of depressive suicides. Brit. J. Psychiat. 113: 1407$1411,1967$.

Shaw, D.M., Hewland, R.: The management of resistant depression. Brit. J. Psychiat. 123: 489-492, 1973.

Singhal, R.L. and Rastogi, R.B.: Neurotransmitter mechanisms during mental illness induced by alterations in thyroid function. Adv. Pharmacol. Chemother. 15: 203-262, 1978.

Sjostrom, R.: 5-hydroxyindole acetic acid and homovanillic acid in cerebrospinal fluid in manic depressive psychosis and the effect of probenecid treatment. Europ. J. Clin. Pharmacol. 6: 75-80, 1973.

Skobba, T. and Miya, T.S.: Hyperthermic responses and toxicity of chlorpromazine in L-thyroxine sodium treated rats. Toxicology and Applied Pharmacol. 14: 176-181, 1969.

Skolnick, P., Daly, J.W.: Regulations of cyclic amp formation in brain tissue by putative neurotransmitters. In Cyclic Nucleotides: Mechanisms of Action, ed. by H. Cramer, J. Schultz, pp. 289302, J. Wiley and Sons, Baltimore, 1977.

Skolnick, P., Daly, J.W., Segal, D.S.: Neurochemical and behavioral effects of clonidine and related imidazolines: Interaction with L-adrenoceptors. Eur. J. Pharmacol. 47: 451-455, 1978.

Slusher, N.: Thyroid hormone in the treatment of depression. Southern Med. J. 68: 1035-1036, 1975.

Southgate, J.: Endometrial monoamine oxidase: The effect of sex steroids. Adv. Biochem. Psychopharmacology 5: 263-269, 1972.

Southgate, J., Grant, E.C.G., Pollard, W., Pryse-Davis, J., Sandler, M.: Cyclic variation in endometrial monoamine oxidase: Correlation of histochemical and quantitative biochemical assays. Biochem. Pharmacol. 17: 721-726, 1968.

Spector, S.: Inhibitors of endogenous catecholamine biosynthesis. Pharmacol. Rev. 18: 599-609, 1966. 
Spector, S.: Regulation of NE synthesis. In Psychopharmacology, A Review of Progress, 1957-1967, ed. by D.H. Efron, PP. 13-16, Public Health Service Publication No. 1836, 1968.

Spector, S., Gordon, R., Sjoerdsma, A., Udenfriend, S.: End-product inhibition of tyrosine hydroxylase as a possible mechanism for the regulation of norepinephrine synthesis. Molecular Pharmacol. 3: $549-555,1967$.

Spector, S., Sjoerdsma, A., Udenfriend, S.: Blockage of endogenous norepinephrine synthesis by L-methyl-tyrosine, an inhibitor of tyrosine hydroxylase. J. Pharmacol. Exp. Ther. 147: 86-95, 1965.

Spector, S., Sjoerdsma, A., Zaltzman-Nirenberg, P., Levitt, M., Udenfriend, S.: Norepinephrine synthesis from tyrosine-cl4 in isolated perfused guinea pig heart. Sc1. 139: 1299-1301, 1963.

Spiker, D.G.: The pharmacological treatwent of schizoaffective disorderdepressed: A review of the literature. Psychopharmacology Bull. 17: 75-78, 1981 .

Spiker, D.G., Pugh, D.D.: Combining tricyclic and monoanine oxidase inhibitor antidepressants. Arch. Gen. Psychiat. 33: 838-830, 1976.

Squires, R.F.: Multiple forms of monoamine oxidase in intact mitochondria as characterized by selective Inhibitors and thermal stability: A comparison of eight mammalian species. Adv. Biochem. Psychopharamacol. 5: 355-370, 1972.

Srimal, R.C., Gulati, K., Dhawan, B.K.: On the mechanism of central hypotensive action of clonidine. Canad. J. Physiol. Pharmacol. 55: $1007-1014,1977$.

Starke, K.: Alpha sympathomimetic inhibition of adrenergic and cholinorgic transmission in the rabbit heart. Naunyn-Schmiedeb Arch. Pharmacul. 274: 18-45, 1972 .

Starke, K., Borowski, E., Endo, T.: Preferential blockade of preynaptic L-adrenoceptors by yohimbine. Eur. J. Pharmacol. 34: $385-388,1975$.

Starke, K., Montel, H., Schumann, H.J.: Influence of cocaine and phenoxybenzamine on noradrenaline uptake and release. Naunyn Schmiedebargs Arch. Pharmacol. 270: 210-214, 1971.

Starke, K., Schumann, H.J.: Interaction of angiotensin phenoxybenzaine and propanolol on noradrenaline release during symathetic nerve stimulation. Eur. J. Pharmacol. 18: 27-30, 1972.

Starke, K., Taube, H.D., Borowsk1, E.: Presynaptic receptor eystems in catecholaminergic transmission. Biochem. Pharnacol. 26: 259-268, 1977. 
Starling, K.: Thyroid hormone action at the cell level. N. Eng. J. Hed. 300: 117-123, 173-177, 1979.

Starling, K., Lazarus, J.H., Milch, P.O., Sakurada, T., Brenner, H.A.: Mitochoodrial thyroid hormone receptor: Localization and physiological significance. Sc1. 201: 1126-1129, 1978 .

Stern, S.L., Rush, A.J. and Mendels, J.: Toward a rational pharmacotherapy of depression. Am. J. Psychiat. 137: 545-552, 1980.

Stokes, P.E., Frazer, A., Casper, R.: Unexpected neuroendocrinetransmitter relationships. Psychopharmacol. Bull. 17 : 72-75, 1981.

Strombon, U.: On the functlonal role of pre- and post-synaptic catecholamine receptors in the brain. Acta Physiologica Scandinavica Supplementum 431: 1-43, 1975.

Strombon, U.: Catecholamine receptor agonists. Naunyn-Schmiedeberg's Arch. Pharmacol. 292: 167-176, 1976.

Strombor, U., Svensson, T.H., Jackson, D.M., Engstrom, G.: Hyperthyroidian: Specifically increased response to central NA(L-) receptor stimulation and generally increased monoamine turnover in brain. J. Neural Transm. 41: 73-92, 1977.

Student, A.K., Edwands, D.J.: Subcellular localization of types A and $B$ monoamine oxidase in rat brain. Biochem. Pharmacol. 26: 2337-2342, 1977 .

Sugrue, M.F.: Chronic antidepressant administration and adaptive changes in central monoaminergic systems. In Antidepressants: Neurochemical, Behavioral, and Clinical Perspectives, ed. by S.J. Enna, J.B. Malick, E. Richelson, PP. 13-51, Raven Press, New York, 1981.

Sullivan, J.L., Dackis, C., Stanfield, C.: In vivo inhibition of platelet MO activity by tricyclic antidepressants. Am. J. Psychiat. 134: 188-190, 1977.

Sulser, F., Sanders-Bush, E.: Biochenical and metabolic considerations concerning the wechanism of action of amphetamine and related compounds. In Psychotomimetic Drugs, ed. by D.H. Efron, PP. 83-94, Ravan Press, New York, 1970.

Sulser, F. and Sanders-Bush, E.: Effect of drugs on amines in the CNS. Ann. Rev. Pharmacol. 11: 209-230, 1971.

Sulser, F., Vetulani, J. and Mobley, P.L.: Mode of action of antidepressant drugs. Blochen. Pharnacol. 27: 257-261, 1978. 
Surks, M.I., Oppenheiver, J.H.: Concentration of L-thyroxine and Ltrilodothyronine specifically bound to nuclear receptors in rat Iiver and kidney: Quantitative evidence favoring a major role of $\mathrm{T}_{3}$ in thyroid homone action. J. Clin. Invest. 60: 555-562, 1977.

Suzuki, O., Katsumata, Y., Oya, M.: Characterieation of some biogenic monoamines as substrates for type A and type B monoamine oxidase. In Honoamine Oxidase: Structure, Function, and Altered Function, ed. by T.P. Singer, R.H. Von Korff, D.L. Murphy, PP. 197-204, Academic Press, New York, 1979.

Svensson, T.H., Usdin, T.: Feedback Inhibition of brain noradrenaline neurons by tricyclic antidepressants: L-receptor mediation. Sclence 202: 1089-1091, 1978.

Snyder, S.H. and Coyle, J.T.: Regional differences in $H^{3}$-norepinephrine and $\mathrm{H}^{3}$-dopamine uptake into rat brain homogenates. J. Pharmacol. Exp. Ther. 165: 78-86, 1969.

Tata, J.R.: Blological action of thyroid hormones at the cellular and molecular levels. In Actlons of Hormones on Molecular Processes, ed. by G. Litwack, D. Kritchersky, Pp. 111-148, John Wlley Sons, New York, 1964.

Thibault, $0 .:$ Action de l'acide truodothyroacetique sur le metabolisme de base tu rat ethyroide. Ann. Endocrinol. 17:35-42, 1956.

Thlerry, A.M., Blanc, G., Glowinskl, J.: Effect of stress on the disposition of catecholamines localized in various intraneuronal storage forms in the brain stem of the rat. J. Neurochem. 18: $449-461,1971$.

Thonson, J.A., Andrews, G.R., Caird, F.I., Hilson, R.: Serum proteinbound and plasma inorganic lodine in the elderly at home. Age and Ageing 1: 158-151, 1972.

Timemans, P.B.M.W.M. and Van Zwieten, P.A.: Central and peripheral Ladrenergic effects of sone imidazolidines. Eur. J. Pharmacol. 45: 229-236, 1977.

Tipton, K.F.: Sowe properties of mononine oxidase. Adv. Biochem. Peychopharmacology 5: 11-24, 1972.

Titus, E. and Dengler, H.J.: The mechanism of uptake of norepinephrine. Pharmacol. Rev. 18: 525-535, 1966.

Todrick, S. and Talt, A.C.: The inhibition of human platelet 5hydroxytryptamine uptake by tricyclic antidepressant drugs. The relation between structure and potency. J. Pharmacy and Pharmacol, 21: 751-762, 1969. 
Trepel, J.B., Wyatt, R.J. and Neff, H.H.: Differential distribution of type $A$ and $B$ monoamine oxidase in neuronal tissues. Eur. J. Pharmacol. 43: 373-375, 1977.

Tunbridge, H.M.G., Evered, D.C., Hall, R., Appleton, D., Brewis, M., Clark, F., Evans, J.G., Young, E., Bind, T., Smith, P.A.: The spectrum of thyroid disease in a community: The Whickham survey. Cinical Endocrinology 7 : 481-493, 1977.

Udenfriend, S., Zaltman-Nirenberg, P., Kagatsu, T.: Inhibitors of purified beef adrenal tyrosine hydroxylase. Biochem. Pharmacol. 14: 837845, 1965.

U'Prichard, D.C., Snyder, S.H.: Distinct L-noradrenergic receptors differentiated by binding and physiological relationships. Life Sc1. 24: 79-88, 1979.

Van Praag, H.M., Kork, J., Puite, J.: 5-hydroxyindoleacetlc acid levels in the cerebrospinal fluid of depressive patients treated with probenecid. Nature (London) 225: 1259-1260, 1970.

Vetulani, J., Stawarz, R.J., Sulsen, F.: Adaptative mechanisms of the noradrenergic cyclic amp generating system in the limbic forebrain of the rat: Adaptation to persistant changes in the a vailability of norepinephrine. J. Neurochem. 27: 661-666, 1976.

Volicer, L. and Reid, H.D.: Effect of drugs on turnover rate of heart norepinephrine. Int. J. Neuropharmacol. 8: 1-7, 1969.

Weinberg, A.D., Katzell, T.D.: Thyroid and adrenal function among psychiatric patients. Lancet 1: 1204-1105, 1977.

Weiner, N.: Regulation of norepinephrine biosynthesis. Ann. Rev. Phamacol. 10: 273-290, 1970 .

Weiner, N.: A critical assessment of methods for the determination of monoamine synthesis turnover rates in vivo. In Neuropsychopharmacology of monoamines and their regulatory enzymes, ed. by E. Usdin, Pp. 143-159, Raven Press, New York, 1974.

Wewer, J., Van der Lugt, J.C., De Langen, C.D.J., Mulder, A.H.: On the capacity of presynaptic alpha receptors to modulate norepinephrine release from silces of rat neocortex and the affinity of some agonists and antagonists for these receptors. J. Pharmacol. Exp. Ther. 211: 445-451, 1979.

Wheatley, D.: Potentiation of amitriptyline by thyroid hormone. Arch. Gen. Psychiat. 26: 229-233, 1972 .

Whybrow, P.C., Coppen, A., Prange, A.J., Noguera, R., Bailey, J.E.: Thyroid function and the response to liothyronine in depression. Arch. Gan. Psychiat. 26: 242-245, 1972. 
Whybrow, P.C., Prange, A.J., Treadway, C.R.: Mental changes accompanging thyroid gland dysfunction. A reappraisal using objective psychological measurement. Arch. Gen. Psychiat. 20: 48-63, 1969.

HIIlams, L.T., Lefkowitz, R.J.: Regulation of rabbit myonetrial alpha adrenergic receptor by estrogen and progesterone. J. Clin. Invest. 60: 815-822, 1977 .

Wilson, I.C., Prange, A.J., Lara, P.P.: L-triiodothyronine alone and with emipramine in the treatwent of depressed wowen. In The Thyrold Axis, Drugs and Behavior, ed. by A.J. Prange, pp. 4963, Raven Press, New York, 1974.

WIlson, I.C., Prange, A.J., McClane, T.K., Rabon, Hif., Lipton, M.A.: Thyroid-hormone enchancement of imipranine in nonretarded depressions. N. Eng. J. Med. 282: 1063-1067, 1970.

Hunschel, K.R., Jr.: Supervisor, Endocrinology Research, R.I. Hospital, Providence, RI.

Hurtman, R.J.: Catecholamines. N. Eng. J. Med. 273: 548-559, 693-700, $746-753,1965$.

Hurtman, R.J. and Axelrod, J.: A sensitive and specific assay for the estimation of monoamine oxidase. Biochem. Pharmacol. 12: 14391441, 1963.

Wurtman, R.J., Larin, F., Mostofapour, S., Fernstrom, J.D.: Brain catechol synthesis: Control by brain tyrosine concentration. Sclence 185: $183-184,1974$.

Yang, H.Y.T. and Neff, N.H.: Beta-phenylethylamine: A specific substrate for type B monoamine axidase of brain. J. Pharmacol. Exp. Ther. 187: 365-371, 1973.

Yasunobu, K.T. and S.O.: Mechanistic aspects of the Bovine hepatic monoamine oxidase reaction. Adv. Blochen. Psychopharmacol. 5: 91-105, 1972.

Youdin, M.B.H.: Heterogenelty of rat brain and liver mitochondrial monoamine cxidase: subcellular fractionation. Blochem. Soc. Trans. 1: 1126-1127, 1973.

Youdin, M.B.H.: Multiple forms of mitochondrial monoamine oxidase. Brit. Med. Bull. 29: 120-122, 1973.

Youdin, M.B.H.: Assay and purification of brain monoamine exidase. In Mothods in Neurochemistry, ed. by N. Marks, R. Rodnight, Pp. 48-71, Plenum Press, Now York, 1975. 
Youdim, M.B.H.: Monoanine deaminating systen in mamalian tissues. In MTP International Review of Science (Biochenlstry series, Vol. 12), ed. by H.X.F. Blaschko, Pp. 169-211, London: Buttemorths, 1975.

Youdin, M.B.H.: Monoamine oxidase: its inhibition. In Modern Problens of Pharmaco-psychiatry: Genetics and Paychopharmacology, od. by J. Mendlewicz, pp. 65-89, Basel:Karger, 1975.

Youdin, M.B.H., Collins, G.G.S.: Properties and physiological significance of multiple forms of mitochondrial monoamine oxidase (MAO). In Isozymes. II. Physiological Function, d. by C.L. Market, pp. 619-637, Academic Press, New York, 1975.

Youdin, M.B.H. and Holzbauer, M.: Physiological and pathological changes in tissue monoamine oxidase activity. J. Neural Trans. 38: 193-229, 1976 . 
C H A P T E R VII

(Appendix Section) 
TABLE 1 Kinetic parameters for monoamine oxidase activity in three brain regions

\begin{tabular}{|c|c|c|c|c|c|c|}
\hline \multirow[b]{2}{*}{ TISSUE } & \multirow[b]{2}{*}{$5-\mathrm{HT}$} & \multicolumn{3}{|c|}{$\mathrm{Km}\left(\times 10^{-6} \underline{\mathrm{M}}\right)$} & \multicolumn{2}{|c|}{$\begin{array}{l}\text { Vmax (nmoles of 5-HIAA or } \\
\text { IAA formed/hr.ug DNA) }\end{array}$} \\
\hline & & $\left(r^{2}\right)$ & tryptamine & $\left(r^{2}\right)$ & $5-\mathrm{HT}$ & tryptamine \\
\hline Corpus Striatum & 28.0 & 0.9961 & 9.0 & 0.9988 & 0.2389 & 1.1362 \\
\hline Forebrain & 45.0 & 0.9988 & 12.0 & 0.9994 & 0.7759 & 3.0816 \\
\hline Hypothalamus & 27.0 & 0.9975 & 9.0 & 0.9989 & 0.3467 & 1.5766 \\
\hline
\end{tabular}


TABLE 3.0 The effect of acute protriptyline administration (one, infection) on MAO activity in three rat brain regions ${ }^{1}$

\begin{tabular}{|c|c|c|c|}
\hline$c^{14}$-truptanine (IAA) & $\begin{array}{l}\text { Time sacrificed } \\
\text { after drug } \\
\text { administration } \\
\quad \text { (hours) }\end{array}$ & Protriptyline Group & Saline group ${ }^{2}$ \\
\hline \multirow[t]{5}{*}{ Corpus Striatum } & 1 & $2.103+0.366^{3}$ & $1.969+0.345$ \\
\hline & 3 & $2.657 \mp 0.276$ & $2.702+0.624$ \\
\hline & 6 & $2.800 \mp 0.454$ & $2.888 \pm 0.201$ \\
\hline & 12 & $2.569 \pm 0.147$ & $2.262 \pm 0.126$ \\
\hline & 24 & $2.275 \mp 0.165$ & $2.428 \mp 0.145$ \\
\hline \multirow[t]{5}{*}{ Forebrain } & 1 & $3.002 \mp 0.184$ & $2.425 \mp 0.370$ \\
\hline & 3 & $2.657 \pm 0.276$ & $2.702 \mp 0.624$ \\
\hline & 6 & $4.166 \pm 0.670$ & $4.862 \pm 0.831$ \\
\hline & 12 & $3.151 \pm 0.246$ & $2.837 \pm 0.109$ \\
\hline & 24 & $3.365 \mp 0.566$ & $2.436 \mp 0.110$ \\
\hline \multirow[t]{5}{*}{ Hypotha lamus } & 1 & $2.029 \mp 0.201$ & $1.950 \mp 0.331$ \\
\hline & 3 & $2.238 \mp 0.309$ & $2.330 \mp 0.173$ \\
\hline & 6 & $2.196 \mp 0.266$ & $2.059 \mp 0.268$ \\
\hline & 12 & $2.181 \mp 0.189$ & $1.927 \mp 0.168$ \\
\hline & 24 & $1.401 \pm 0.205$ & $1.678 \pm 0.152$ \\
\hline \multicolumn{4}{|c|}{$c^{14}-$ serotonin $(5-$ HIAA $)$} \\
\hline \multirow[t]{5}{*}{ Corpus Striatum } & 1 & $0.287+0.041$ & $0.273+0.046$ \\
\hline & 3 & $0.539 \pm 0.058$ & $0.443+0.068$ \\
\hline & 6 & $0.426 \pm 0.052$ & $0.465 \pm 0.055$ \\
\hline & 12 & $0.370 \mp 0.017$ & $0.325 \pm 0.027$ \\
\hline & 24 & $0.452 \pm 0.041$ & $0.455 \pm 0.032$ \\
\hline \multirow[t]{4}{*}{ Forebrain } & 1 & $0.416 \pm 0.029$ & $0.409 \pm 0.052$ \\
\hline & 3 & $0.535 \pm 0.046$ & $0.547 \pm 0.058$ \\
\hline & 6 & $0.665 \mp 0.135$ & $0.850 \mp 0.014$ \\
\hline & 12 & $0.459 \mp 0.048$ & $0.408 \pm 0.014$ \\
\hline & 24 & $0.664 \pm 0.098$ & $0.457 \pm 0.036$ \\
\hline \multirow[t]{5}{*}{ Hypothalamus } & 1 & $0.224 \mp 0.040$ & $0.228 \pm 0.028$ \\
\hline & 3 & $0.423 \mp 0.088$ & $0.398 \pm 0.063$ \\
\hline & 6 & $0.308 \mp 0.030$ & $0.284 \pm 0.025$ \\
\hline & 12 & $0.264 \mp 0.031$ & $0.217 \pm 0.021$ \\
\hline & 24 & $0.245 \mp 0.026$ & $0.306 \mp 0.059$ \\
\hline
\end{tabular}

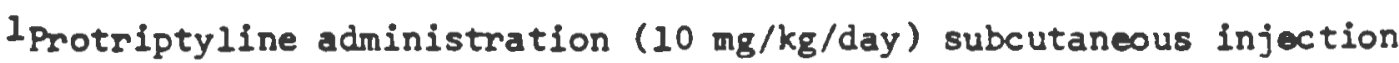

${ }^{2}$ Equal volumes of saline were administered to controls

${ }^{3} \mathrm{~N}=6$ for all groups, values represent the Mean + S.E.M. for MAO activity and are reported as nanomoles of 5-HIAA or IAA formed/hr./ ug DNA 
TABLE 4.0 The effect of subchronic protriptyline administration (three consecutive injections) on MAO activity in three rat brain ragions 1

\begin{tabular}{|c|c|c|c|}
\hline$c^{14}$-tryotamine & $\begin{array}{l}\text { Time sacrificed } \\
\text { after last drug } \\
\text { administration } \\
\text { (hours) }\end{array}$ & $\begin{array}{l}\text { Protriptyline } \\
\text { Group }\end{array}$ & Saline Group ${ }^{2}$ \\
\hline \multirow[t]{4}{*}{ Corpus Striatum } & 3 & $2.429+0.235^{3}$ & $2.352+0.112$ \\
\hline & 6 & $1.775 \mp 0.150$ & $1.711 \mp 0.190$ \\
\hline & 12 & $1.861 \div 0.196$ & $2.262 \mp 0.146$ \\
\hline & 24 & $2.327 \pm 0.227$ & $2.027 \pm 0.205$ \\
\hline \multirow[t]{4}{*}{ Forebra in } & 3 & $2.841 \pm 0.209$ & $2.647 \pm 0.094$ \\
\hline & 6 & $2.824 \mp 0.204$ & $2.662 \mp 0.151$ \\
\hline & 12 & $3.111 \mp 0.203$ & $3.337 \mp 0.237$ \\
\hline & 24 & $3.261 \mp 0.150$ & $2.893 \mp 0.283$ \\
\hline \multirow[t]{4}{*}{ Hypothalamus } & 3 & $2.487+0.198$ & $2.102+0.298$ \\
\hline & 6 & $1.880 \mp 0.125$ & $1.493 \mp 0.345$ \\
\hline & 12 & $2.025 \mp 0.308$ & $2.078 \mp 0.348$ \\
\hline & 24 & $2.358 \mp 0.182$ & $1.937 \mp 0.101$ \\
\hline \multicolumn{4}{|l|}{$c^{24}$-serotonin } \\
\hline \multirow[t]{4}{*}{ Corpus Striatum } & 3 & $0.568+0.035$ & $0.512+0.027$ \\
\hline & 6 & $0.402 \mp 0.026$ & $0.385 \mp 0.043$ \\
\hline & 12 & $0.402 \mp 0.045$ & $0.437 \mp 0.021$ \\
\hline & 24 & $0.502 \mp 0.031$ & $0.495 \mp 0.032$ \\
\hline \multirow[t]{4}{*}{ Forebrain } & 3 & $0.618+0.053$ & $0.507+0.016$ \\
\hline & 6 & $0.622 \mp 0.050$ & $0.610 \mp 0.027$ \\
\hline & 12 & $0.600 \mp 0.033$ & $0.674 \mp 0.059$ \\
\hline & 24 & $0.681 \mp 0.036$ & $0.669 \mp 0.058$ \\
\hline \multirow[t]{4}{*}{ Hypothalamus } & 3 & $0.598 \pm 0.053$ & $0.424+0.038 *$ \\
\hline & 6 & $0.428 \mp 0.036$ & $0.355 \mp 0.060$ \\
\hline & 12 & $0.359 \mp 0.047$ & $0.573 \mp 0.079 \%$ \\
\hline & 24 & $0.453 \mp 0.022$ & $0.442 \mp 0.018$ \\
\hline
\end{tabular}

lProtriptyline administration $(10 \mathrm{mg} / \mathrm{kg}$ ) subcutaneous injection

${ }^{2}$ Equal volumes of saline were administered to controls

${ }^{3} \mathbf{N}=6$ for all groups, values represent the Mean + S.E.M. for MAO activity and are reported as nanomoles of 5-HIAA or IAA formed/hr.l ug DNA

$*_{P}<0.05$ from protriptyline group 
TABLE 5.0 The effect of subchronic protriptyline administration (six consecutive injections) on MAO activity in three rat brain regionsl

\begin{tabular}{|c|c|c|c|}
\hline م14 antaming & $\begin{array}{l}\text { Time sacrificed } \\
\text { after last drug } \\
\text { administration } \\
\text { (hours) }\end{array}$ & $\begin{array}{l}\text { Protriptyline } \\
\text { Group }\end{array}$ & Saline Group ${ }^{2}$ \\
\hline \multirow{4}{*}{ Corpus Striatum } & 3 & $2.359+0.175^{3}$ & $2.327+0.240$ \\
\hline & 6 & $2.326+0.170$ & $2.173+0.153$ \\
\hline & 12 & $1.995 \mp 0.093$ & $2.697 \mp 0.218 *$ \\
\hline & 24 & $2.132 \mp 0.262$ & $2.616 \pm 0.288$ \\
\hline \multirow[t]{4}{*}{ Forebrain } & 3 & $3.304+0.407$ & $3.431+0.264$ \\
\hline & 6 & $3.505 \mp 0.261$ & $2.923 \mp 0.219$ \\
\hline & 12 & $4.808 \mp 0.446$ & $3.106 \mp 0.147 \%$ \\
\hline & 24 & $2.411 \mp 0.191$ & $3.922 \mp 0.743$ \\
\hline \multirow[t]{4}{*}{ Hypotha lamus } & 3 & $1.791+0.032$ & $2.101+0.145$ \\
\hline & 6 & $1.659 \mp 0.101$ & $1.839 \mp 0.180$ \\
\hline & 12 & $2.798 \mp 0.164$ & $2.067 \mp 0.256$ \\
\hline & 24 & $1.903 \mp 0.177$ & $2.127 \pm 0.211$ \\
\hline \multicolumn{4}{|l|}{$c^{14}$-serotonin } \\
\hline \multirow[t]{4}{*}{ Corpus Striatum } & 3 & $0.519+0.059$ & $0.512+0.055$ \\
\hline & 6 & $0.589 \mp 0.049$ & $0.461 \mp 0.049$ \\
\hline & 12 & $0.388 \mp 0.029$ & $0.426 \mp 0.050 *$ \\
\hline & 24 & $0.238 \mp 0.039$ & $0.374 \mp 0.033 \%$ \\
\hline \multirow[t]{4}{*}{ Forebrain } & 3 & $0.669+0.061$ & $0.669+0.048$ \\
\hline & 6 & $0.815 \mp 0.073$ & $0.599 \mp 0.052$ \\
\hline & 12 & $0.938 \mp 0.080$ & $0.672 \mp 0.037 \%$ \\
\hline & 24 & $0.292 \pm 0.036$ & $0.619 \mp 0.108 *$ \\
\hline \multirow[t]{4}{*}{ Hypotha lamus } & 3 & $0.395+0.017$ & $0.433+0.026$ \\
\hline & 6 & $0.394 \mp 0.025$ & $0.429 \mp 0.073$ \\
\hline & 12 & $0.478 \mp 0.033$ & $0.454 \mp 0.059 \%$ \\
\hline & 24 & $0.207 \pm 0.030$ & $0.259 \mp 0.040$ \\
\hline
\end{tabular}

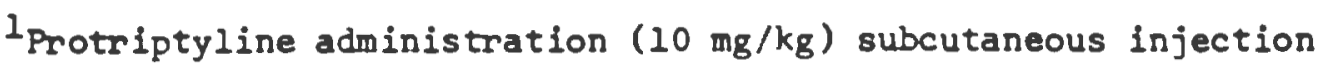

${ }^{2}$ Equal volumes of saline were administered to controls

$3_{\mathrm{N}}=6$ or more animals for all groups examined; values represent the MEAN \pm S.E.M. for MAO activity and are reported as nanomoles of 5-HIAĀ or IAA formed/hr./ug DNA

$\star P<0.05$ fran protriptyline group 
TABLE 6.0 The effect of chronic protriptyline administration ( 18 consecutive injections) on MAO activity in three rat brain regions ${ }^{1}$

\begin{tabular}{|c|c|c|c|}
\hline c14_trumtamino & $\begin{array}{l}\text { Time sacrificed } \\
\text { after last drug } \\
\text { administration } \\
\text { (hours) }\end{array}$ & $\begin{array}{l}\text { Protriptyline } \\
\text { Group }\end{array}$ & Saline Group ${ }^{2}$ \\
\hline \multirow{4}{*}{ Corpus Striatum } & 3 & $3.792+0.330^{3}$ & $2.553+0.262^{\star}$ \\
\hline & 6 & $2.965 \mp 0.778$ & $1.861+0.094$ \\
\hline & 12 & $2.576 \mp 0.212$ & $2.743 \mp 0.275$ \\
\hline & 24 & $1.792 \pm 0.147$ & $1.939 \pm 0.131$ \\
\hline \multirow[t]{4}{*}{ Forebrain } & 3 & $3.338+0.183$ & $3.256+0.167$ \\
\hline & 6 & $3.254 \mp 0.174$ & $3.373 \mp 0.137$ \\
\hline & 12 & $3.339 \mp 0.305$ & $3.261 \mp 0.181$ \\
\hline & 24 & $3.273 \mp 0.226$ & $2.894 \pm 0.057$ \\
\hline \multirow[t]{4}{*}{ Hypothalamus } & 3 & $2.704 \pm 0.390$ & $2.452 \pm 0.197$ \\
\hline & 6 & $2.441 \mp 0.327$ & $2.069 \mp 0.154$ \\
\hline & 12 & $2.376 \mp 0.118$ & $2.319 \mp 0.090$ \\
\hline & 24 & $2.183 \mp 0.130$ & $2.279 \pm 0.142$ \\
\hline \multicolumn{4}{|l|}{$c^{14}$-serotonin } \\
\hline \multirow[t]{4}{*}{ Corpus Striatum } & 3 & $0.752 \pm 0.077$ & $0.512 \pm 0.047 *$ \\
\hline & 6 & $0.688 \mp 0.192$ & $0.447 \mp 0.056$ \\
\hline & 12 & $0.631 \mp 0.038$ & $0.685 \mp 0.045$ \\
\hline & 24 & $0.423 \pm 0.044$ & $0.453 \mp 0.020$ \\
\hline \multirow[t]{4}{*}{ Forebrain } & 3 & $0.739+0.042$ & $0.826+0.088$ \\
\hline & 6 & $0.709 \mp 0.045$ & $0.686 \mp 0.037$ \\
\hline & 12 & $0.975 \mp 0.074$ & $0.851 \mp 0.065$ \\
\hline & 24 & $0.720 \mp 0.031$ & $0.676 \pm 0.028$ \\
\hline \multirow[t]{4}{*}{ Hypothalamus } & 3 & $0.495+0.084$ & $0.513+0.058$ \\
\hline & 6 & $0.456 \mp 0.054$ & $0.416 \mp 0.032$ \\
\hline & 12 & $0.551 \pm 0.023$ & $0.545 \mp 0.030$ \\
\hline & 24 & $0.454 \pm 0.047$ & $0.355 \pm 0.036$ \\
\hline
\end{tabular}

${ }^{1}$ Protriptyline administration $(10 \mathrm{mg} / \mathrm{kg})$ subcutaneous injection

${ }^{2}$ Equal volumes of saline were administered to saline rats to serve as controls

${ }^{3} \mathrm{~N}=6$ for all determinations; values represent the Mean + S.E.M. for MAO activity and are reported as nanomoles of 5-HIAA or IAA formed/hr./ug DNA

$\star_{p}<0.05$ from protriptyline group 


\section{FIGURE 1}

TITLE: Velocity versus substrate concentration for MAO activity in the corpus striatum

LEGEND

Monoamine oxidase activity in the corpus striatum has been evaluated using Michalis-Menton kinetics and employing $C^{14}$-tryptamine as substrate. MAO enzyme activity begins to plateau at $20.0 \times 10^{-6} \mathrm{M}$ substrate concentration. Each point represents the MEAN of 6 experimental determinations. Similar results were obtained when forebrain or hypothalamus were examined and $c^{14}$-tryptamine was employed as substrate. Numerical values for all enzyme velocity versus substrate concentration are listed in the appendix section (Tables 19-26). 
144

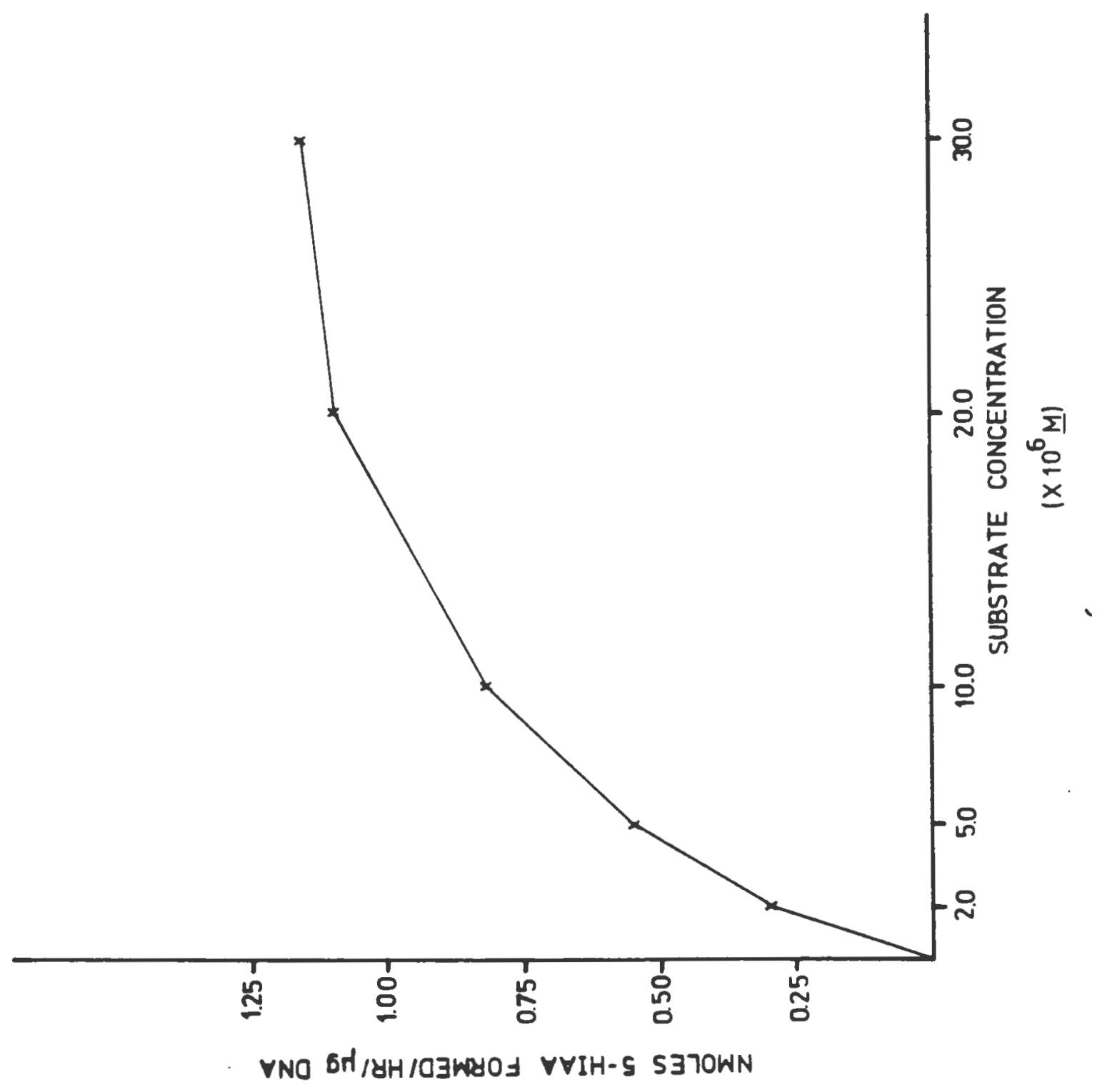




\section{FIGURE 2}

TITLE: Reciprocal plot for MAO enzyme velocity versus substrate concentration (Lineweaver-Burke)

LEGEND

This graph represents a reciprocal plot of the data obtained in

Figure 1. The $\mathrm{Km}$ value for $M A O$ is $9.0 \times 10^{-6} \mathrm{M}$, which agrees

with the values reported by Collins, (1972) and Tipton, (1972)

in pig brain, rat liver and beef adrenal medulla. Similarly,

the Vmax value obtained is 1.1362 moles of IAA formed/hr/ug DNA.

The linear regression coefficient $\left(r^{2}\right)$ is 0.9988 . 


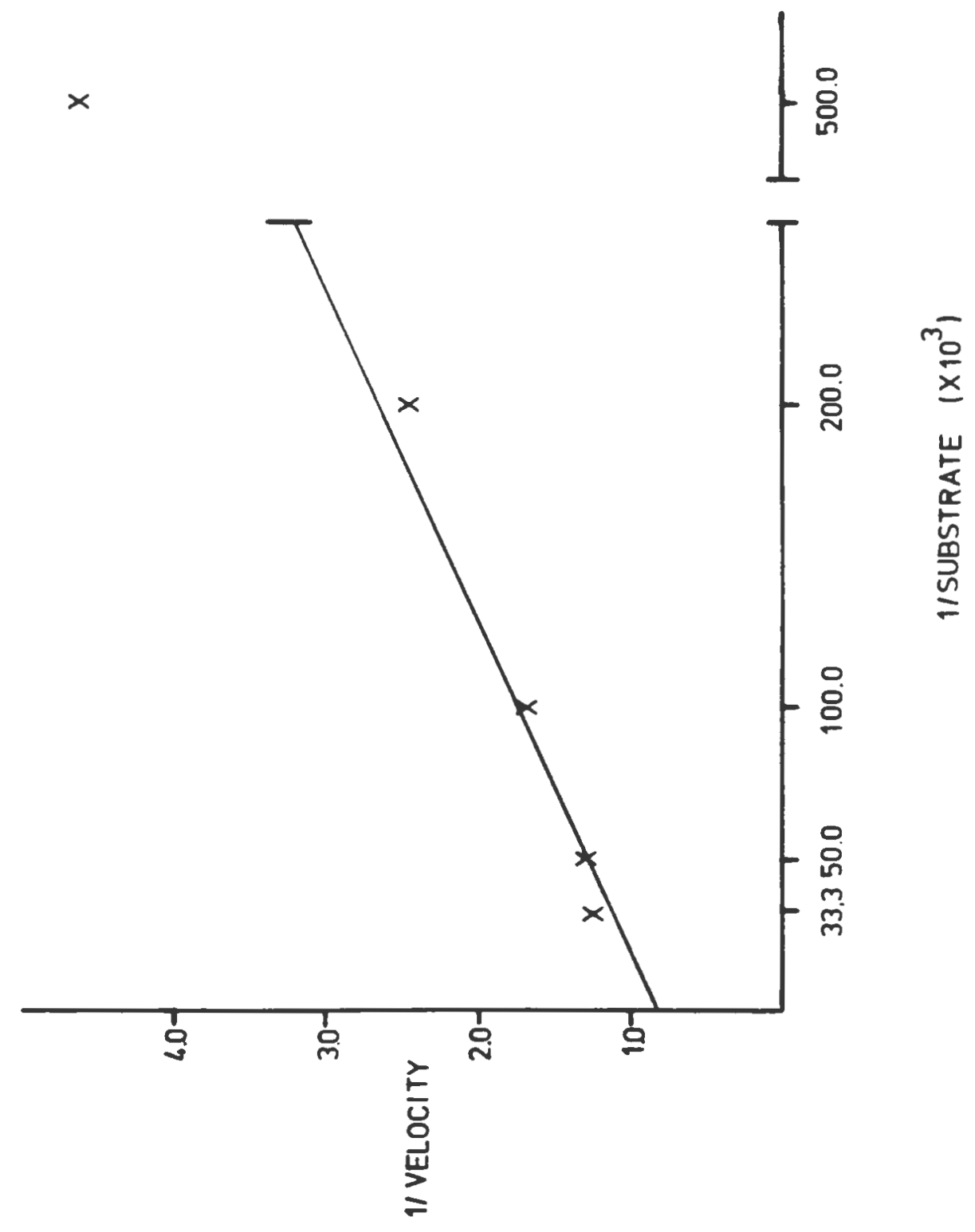


FIGURE 3

TITLE: Velocity versus substrate concentration for MAO activity in corpus striatum.

LEGEND

Monoamine oxidase activity in the corpus striatum has been evaluated using Michalis-Menton kinetics and employing $\mathrm{C}^{14}$ serotonin as substrate. MAO enzyme activity begins to plateau at $20.0 \times 10^{-6} M$ substrate concentration. Each point represents the MEAN of 6 experimental determinations. Similar results were obtained when forebrain or hypothalamus were examined and $\mathrm{C}^{14}$-serotonin was employed as substrate. Numerical values for all enzyme versus substrate concentration are listed in the appendix section (Tables 19-26). 


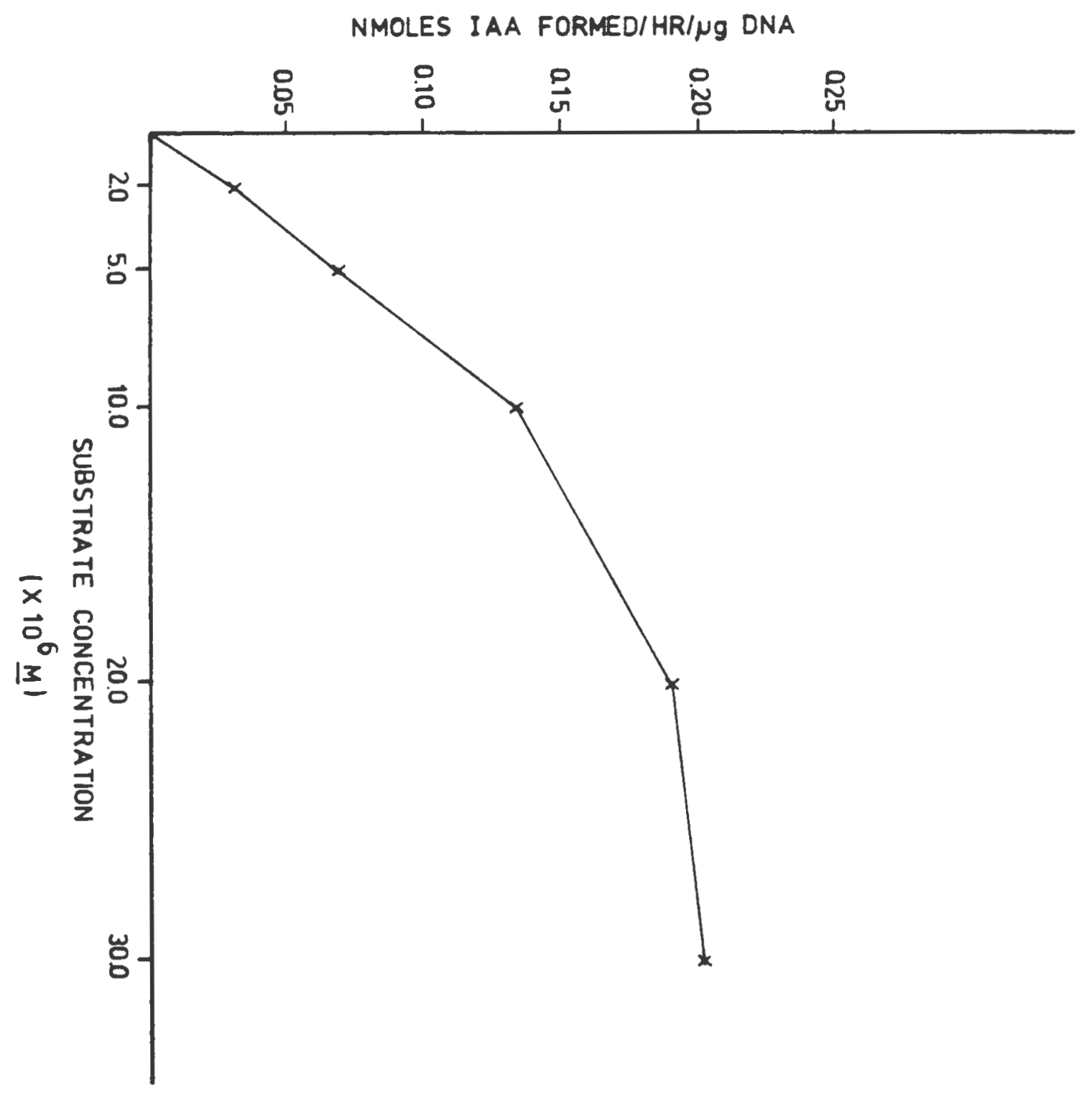


FIGURE 4

TITLE: Reciprocal plot for MAO enzyme velocity versus substrate concentration (Lineweaver-Burke)

\section{LEGEND}

This graph represents a reciprocal plot of the data obtained in Figure 3. The $\mathrm{Km}$ value for $\mathrm{MAO}$, when $\mathrm{C}^{14}$-serotonin has been employed as substrate, is $28.0 \times 10^{-6} \mathrm{M}$. This value is in agreement with other investigators (Collins, 1972; Tipton, 1972; Fowler and Oreland, 1979; Suzuki, 1979). Similarly, the Vmax value obtained is 0.2389 moles of 5 -HIAA formed/hr/ ug DNA. The linear regression coefficient $\left(r^{2}\right)$ is 0.9961 . 


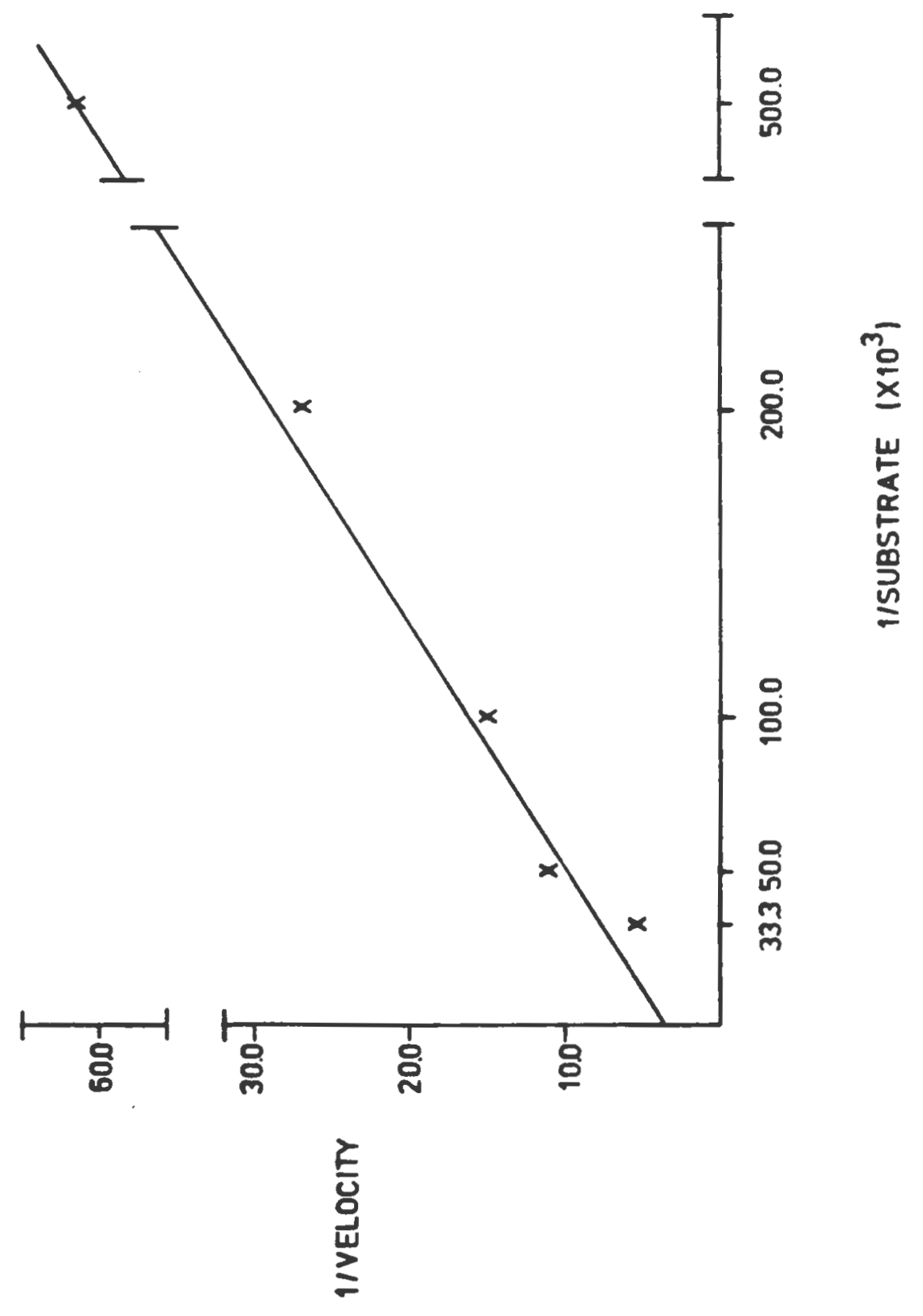


FIGURE 5

TITLE: Monoamine oxidase activity in corpus striatum following in vitro preincubation with varying molar concentrations of protriptyline.

\section{LEGEND}

MAO activity has been evaluated in the corpus striatum following preincubation with protriptyline. $c^{14}$-tryptamine has been used as the substrate. Each data point represents the MEAN \pm S.E.M. for 6 experimental determinations. Inhibition of MAO activity begins at a molar concentration of protriptyline at $10^{-5} \mathrm{M}$. 


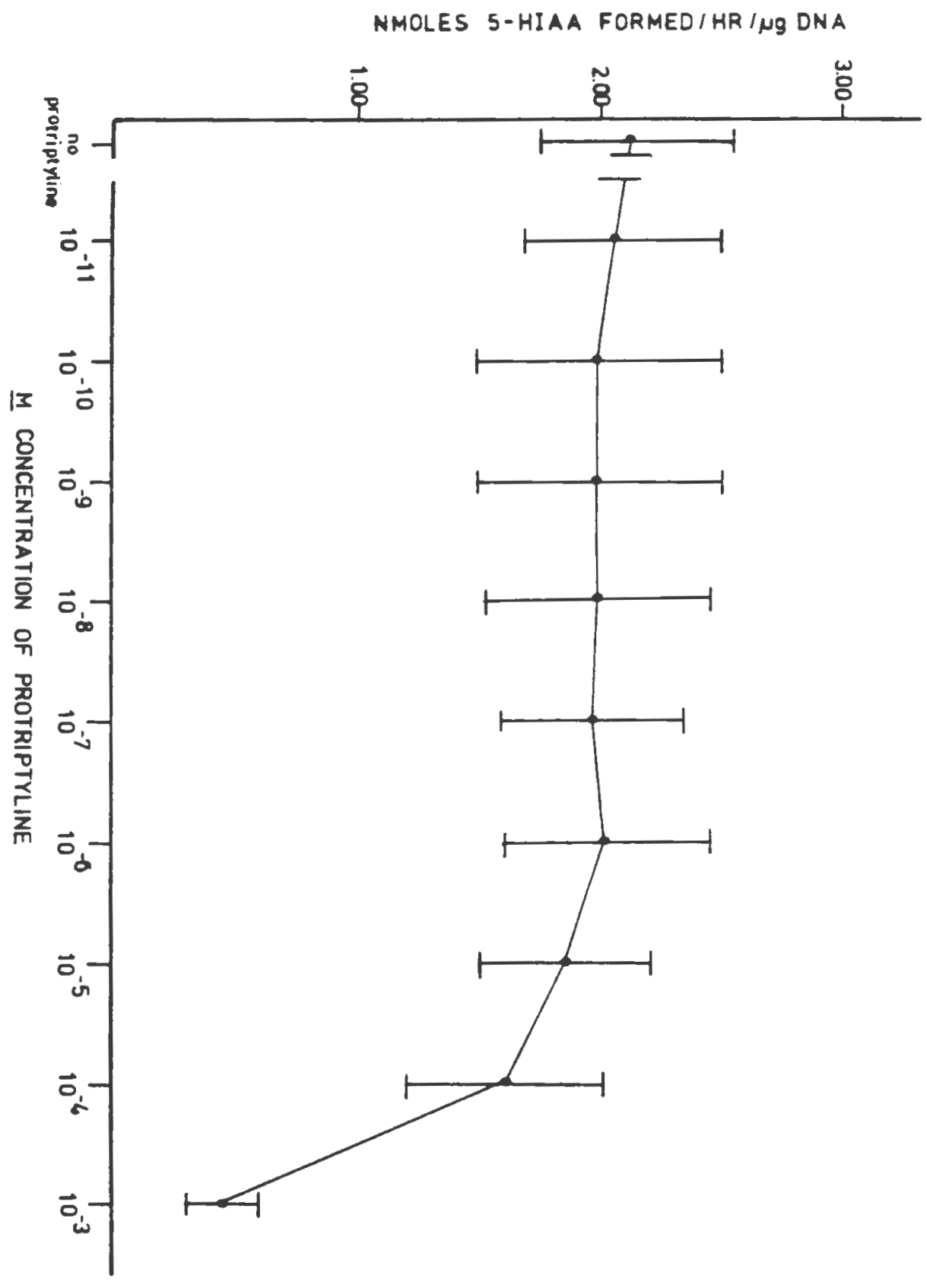


FIGURE 6

TITLE: Monoamine oxidase activity in corpus striatum following in vitro preincubation with varying molar concentrations of protriptyline.

LEGEND

MAO activity has been evaluated in the corpus striatum following preincubation with protriptyline. $\mathrm{C}^{14}$-serotonin has been used as the substrate. Each data point represents the MEAN \pm S.E.M. for 6 experimental determinations. Inhibition of MAO activity begins at a molar concentration of protriptyline at $10^{-5} \mathrm{M}$. 
$\stackrel{4}{\dddot{n}}$

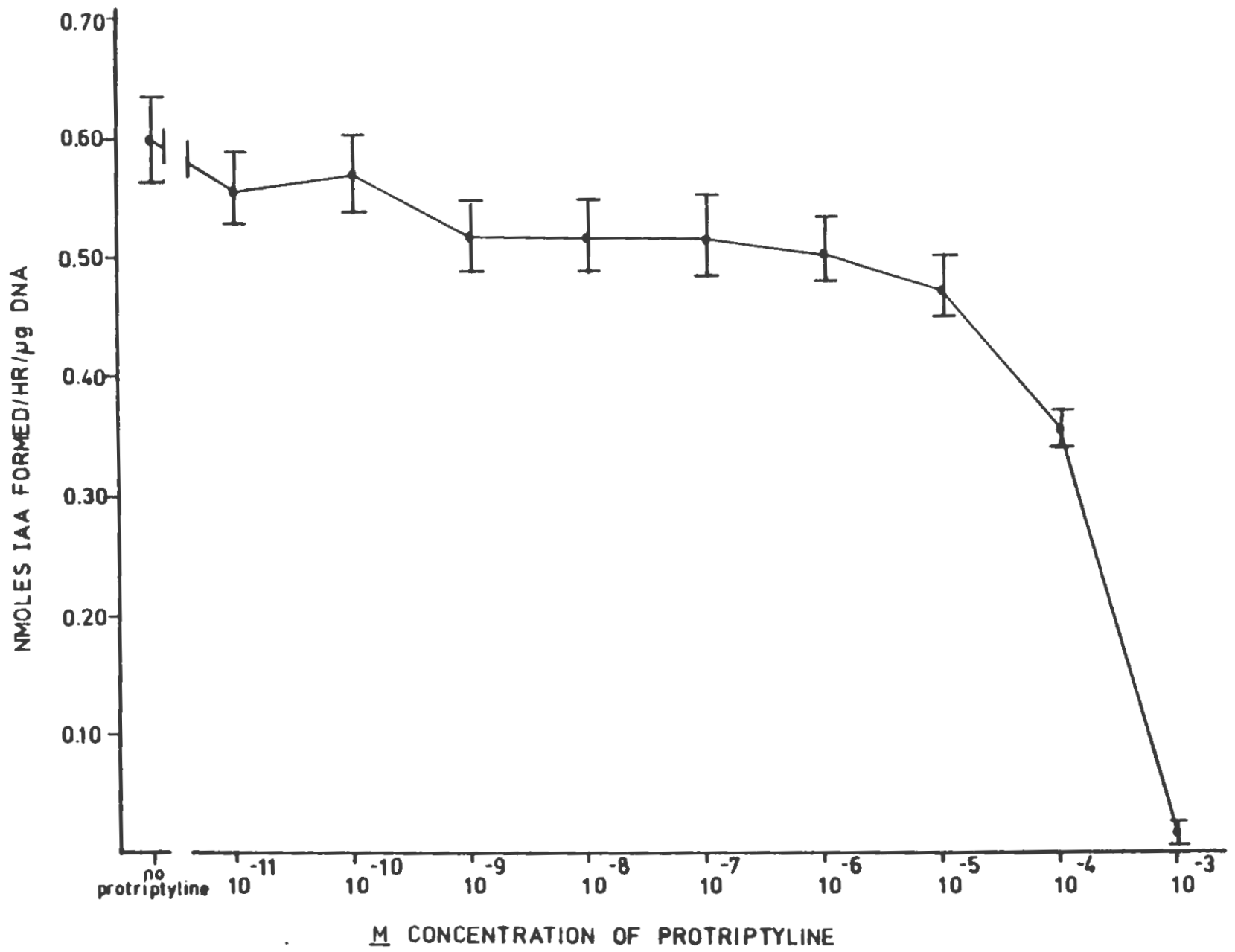


TABLE 11 The effect of thyroidectomy and acute protriptyline on MAO activity in three brain reglons.

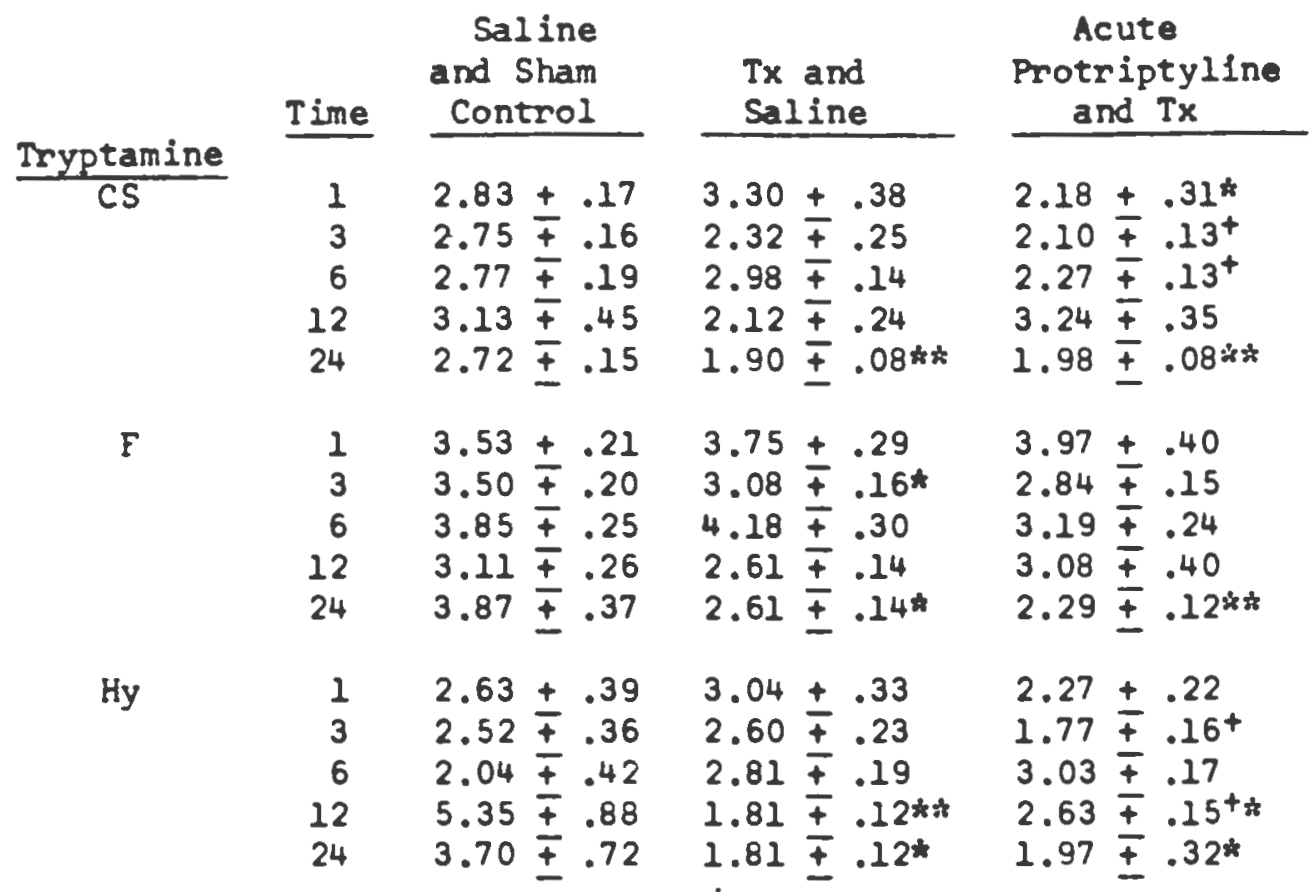

Serotonin

CS

$\begin{array}{rl}1 & 0.67 \pm .05 \\ 3 & 0.64 \pm .05 \\ 6 & 0.81 \pm .09 \\ 12 & 0.83 \pm .11 \\ 24 & 0.51 \pm .03\end{array}$

$0.76 \pm .11$

$0.61 \pm .04$

$0.50 \mp .05$

$0.69 \mp .03$

$0.40 \mp .03 * *$

$0.48 \div .03$

$0.56 \pm .02^{++t}$

$0.32 \pm .03 * t$

$0.62 \mp .08+\pi$

$0.34 \mp .02 * \%$

F

$\begin{array}{rl}1 & 0.76 \pm .05 \\ 3 & 0.75 \pm .05 \\ 6 & 0.83 \pm .04 \\ 12 & 0.75 \pm .07 \\ 24 & 0.71 \pm .07\end{array}$

$0.78+.08$

$0.62 \mp .04 *$

$0.91+.10$

$0.82 \mp .03$

$0.53 \mp .02 \%$

$0.53 \mp .02$

$0.60 \mp .04$

$0.70 \mp .05$

$0.59 \mp .09$

$0.41 \pm .03+k \hbar$

Hy

$\begin{array}{rl}1 & 0.65 \pm .06 \\ 3 & 0.61 \pm .05 \\ 6 & 0.50 \pm .09 \\ 12 & 1.17 \pm .12 \\ 24 & 0.69 \pm .15\end{array}$

$0.64+.08$

$0.48 \mp .03$

$0.56 \mp .04$

$0.27 \mp .02 \pi *$

$0.27 \mp .02 \%$

$0.53+.05$

$0.46 \mp .02 \%$

$0.69 \mp .04$

$0.43 \mp .03^{+\star \star *}$

$0.27 \mp .04 \%$

$N=6$ per group

* Significantly different than control $p<.05$

* Signiflcantly different than control $p<.01$

+ Significantly different than $T x$ and Saline $p<.05$

+ t+ Significantly different than $T x$ and Sallne $p<.01$ 
TABLE 12 The effect of thyroidectomy and three days protriptyline on MAO activity in three brain regions.

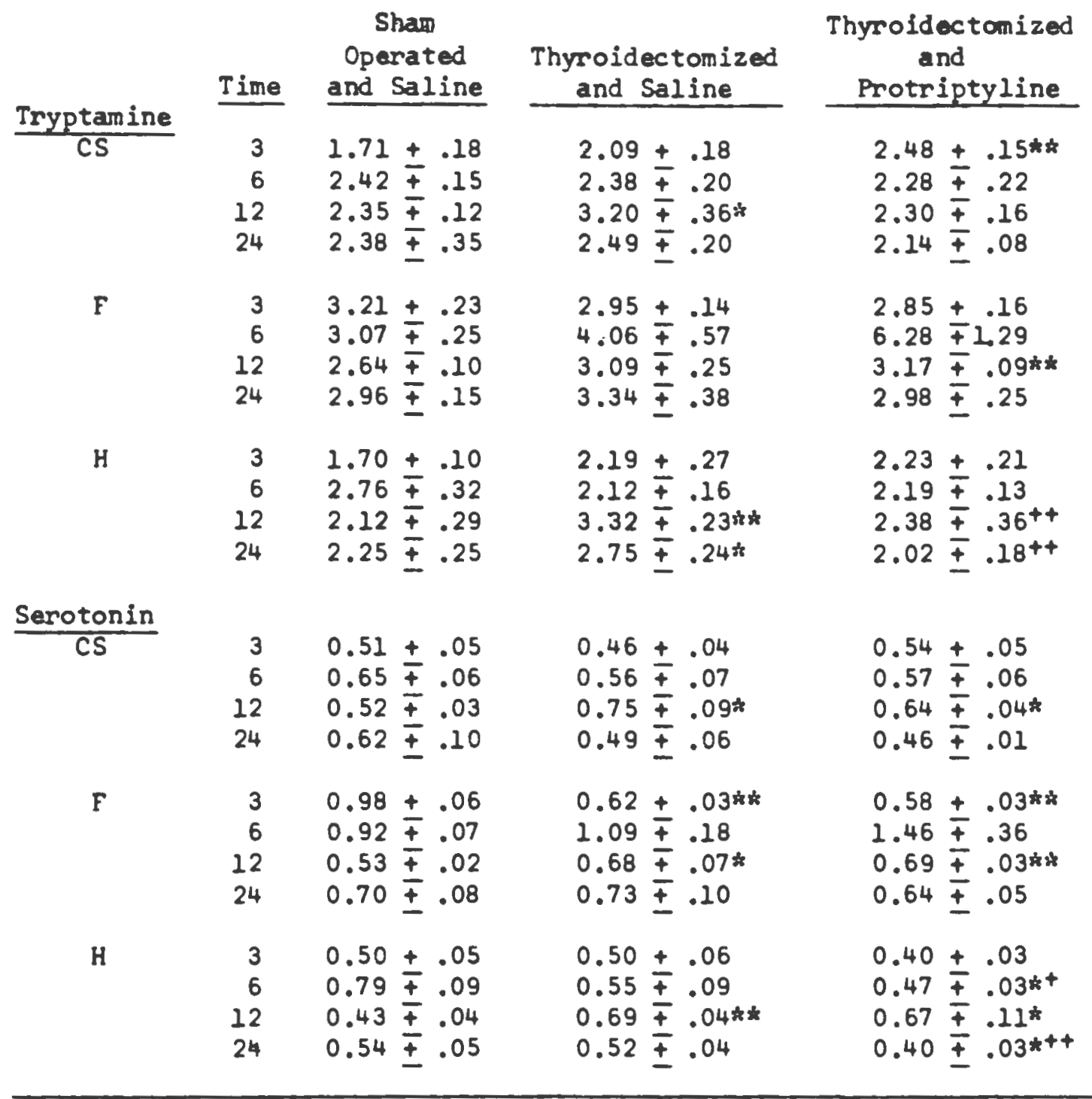

$N=6$ per group

* Significantly different than control $p<.05$

* Significantly different than control $\mathrm{p}<.01$

+ Significantly different than thyroidectomized-saline $p<.05$

+t Significantly different than thyroidectomized-saline $\mathrm{P}<.01$ 
TABLE 13 The effect of thyroidectomy and six days protriptyline on MAO activity in three brain regions.

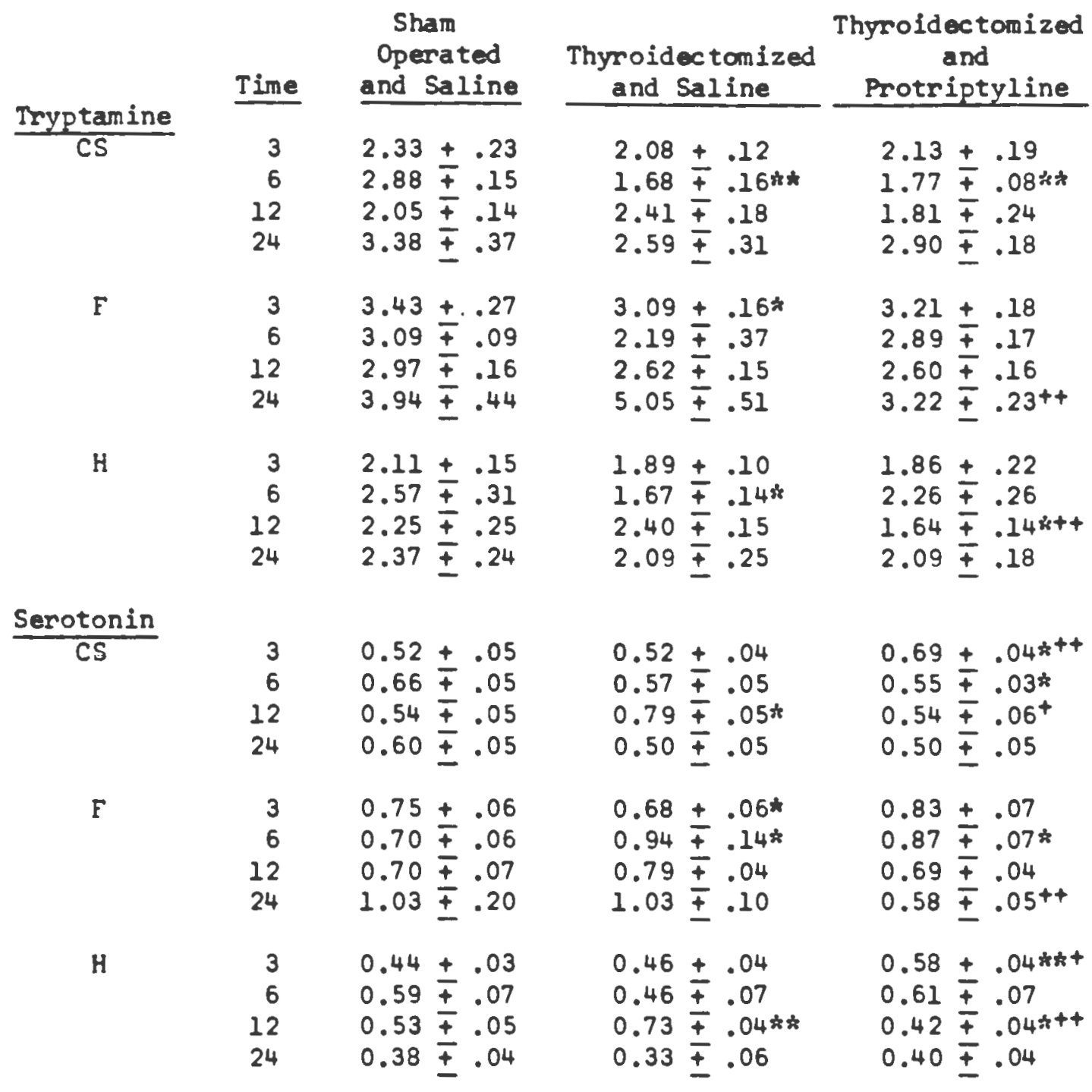

$N=6$ per group

* Significantly different than control p $<.05$

t* Significantly different than control $\mathrm{p} z .01$

+ Significantly different than thyroidectomized-saline $p<.05$

+ Significantly different than thysoidectomized-saline $\mathrm{p}<.01$ 
TABLE 14 Klnetic Parameters for Monoanine Oxidase Activity in Three Brain Regions

Corpus Striatum: using $\mathrm{c}^{14}$-tryptamine as Substrate

$$
\begin{array}{rlrl}
1 / V_{\max } & =0.880116 & 1 / \mathrm{Km} & =1.15749 \times 10^{5} \\
V_{\max }=1.136213 & \mathrm{Km} & =9.0 \times 10^{-6} \mathrm{M} \\
R^{2} & =0.9988 & \text { slope } & =0.000008 \\
R_{\text {using }} C^{14} \text {-serotonin as substrate } & \\
1 / V_{\max }=4.18507 & 1 \mathrm{Km} & =3.607329 \times 10^{4} \\
V_{\max }=0.23895 & \mathrm{Km} & =28.0 \times 10^{-6} \mathrm{M} \\
R^{2} & =0.9961 & \text { slope } & =0.000116
\end{array}
$$

Forabrain: using $c^{14}$-tryptamine as Substrate

$$
\begin{array}{lll}
I / V_{\max }=0.324503 & I / K_{m}=8.18113 \times 10^{4} \\
V_{\max }=3.08164 & \mathrm{Km} & =12.0 \times 10^{-6} \mathrm{M} \\
R^{2} & =0.9994 & \text { slope }=0.000004
\end{array}
$$

: using $\mathrm{C}^{14}$-serotonin as Substrate

$$
\begin{array}{lll}
1 / V_{\max }=1.2887 & 1 / \mathrm{Km}_{\mathrm{m}}=2.2044 \times 10^{4} \\
V_{\max }=0.7759 & \mathrm{Km} & =24.0 \times 10^{-6} \mathrm{M} \\
\mathrm{R}^{2} & =0.9988 & \text { slope }=0.0001
\end{array}
$$

Hypothalanus: using $c^{14}$-tryptamine as Substrate

$$
\begin{array}{rlrl}
1 / V_{\max } & =0.63429 & 1 / \mathrm{Km} & =1.1684 \times 10^{5} \\
V_{\max } & =1.576561 & \mathrm{Km} & =9.0 \times 10^{-6} \mathrm{M} \\
\mathrm{R}^{2} & =0.99897 & \text { slope } & =0.00005 \\
r_{\text {using }} C^{14} \text {-serotonin as Substrate } & \\
1 / V_{\max } & =2.88438 & 1 / \mathrm{Km} & =3.6383 \times 10^{4} \\
V_{\max } & =0.346695 & \mathrm{Km} & =27.0 \times 10^{-6} \mathrm{M} \\
\mathrm{R}^{2} & =0.99753 & \text { slope } & =0.000079
\end{array}
$$

$N=6$ for all determinations using linear regression analysis 
TABLE 15 Michalls-Menton Data for Corpus Striatum using Cl4-tryptamine as Substrate ( $V$ va $S$ )

$\underline{2.0} \quad \underline{5.0} \quad \underline{10.0} \quad 20.0 \quad 30.0 \quad \begin{aligned} & \text { Substrate Conc. }\left(10^{-6} \mathrm{M}\right) \\ & \mathrm{C}^{14} \text {-tryptamine }\end{aligned}$

MEAN $\quad 0.290 \quad 0.543 \quad 0.811 \quad 1.124 \quad 1.163$

S.E.M. $\quad \begin{array}{lllll}0.07 & 0.12 & 0.17 & 0.23 & 0.24\end{array}$

$M=6$ Values represent the Mean \pm S.E.M. for noles of 5-HIMA formed/hr./ug DNA

TABLE 16 Lineweaver-Burke Data for Corpus Striatun using $C^{14}$-tryptamine as Substrate $(1 / v$ vs $1 / S)$

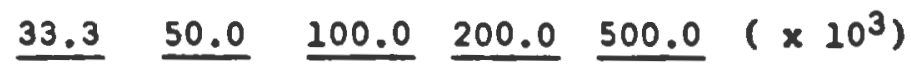

MEAN $\quad 4.677 \quad 2.411 \quad 1.674 \quad 1.275 \quad 1.180$

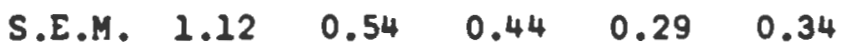

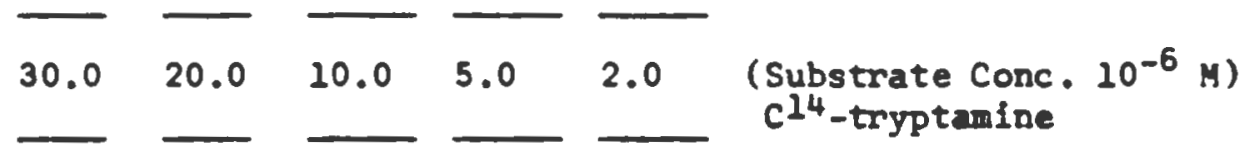

$M=6$ Values represent the Mean \pm S.E.M. for namomoles of 5-HIAA forwed/hry ug DNA 
TABLE 17 Michalls-Menton Data for Corpus Striatum using $C^{14}$-serotonin as Substrate ( $V$ vs $S$ )

$2.0 \quad \underline{5.0} \quad \underline{10.0} \quad \underline{20.0} \quad \underline{30.0} \begin{aligned} & \text { Substrate Conc. }\left(10^{-6} \mathrm{M}\right) \\ & \text { Cl4 }^{14} \text {-serotonin }\end{aligned}$

$\begin{array}{llllll}\text { MEAN } & 0.033 & 0.069 & 0.129 & 0.283 & 0.205\end{array}$

$\begin{array}{llllll}\text { S.E.H. } & 0.01 & 0.02 & 0.04 & 0.07 & 0.10\end{array}$

$N=6$ Values represent the Mean \pm S.E.M. for nmoles of IAA formed/hr./ug DNA

TABLE 18 Lineweaver-Burke Data for Corpus Striatum using $C^{14}$-serotonin as Substrate $(1 / V$ vs $1 / S)$

$33.3 \quad 50.0 \quad 100.0 \quad 200.0 \quad 500.0\left(\times 10^{3}\right)$

MEAN $\quad 61.957 \quad 28.267 \quad 14.761 \quad 11.895 \quad 6.521$

S.E.H. $\quad 24.06 \quad 10.65 \quad 5.08 \quad 5.27 \quad 2.50$

-

$N=6$ Values represent the Mean \pm S.E.H. for moles of IAA forwed/hr./ug DNA 
TABLE 19 Michalis-Menton Data for Forebrain using $C^{14}$-tryptamine as Substrate ( $V$ vs $S$ )

$2.0 \quad 5.0 \quad 10.0 \quad 20.0 \quad 30.0 \quad \begin{aligned} & \text { Substrate Conc. }\left(10^{-6} \mathrm{M}\right) \\ & \mathrm{C}^{14} \text {-tryptamine }\end{aligned}$

MEAN $\quad 0.466 \quad 0.936 \quad 1.417 \quad 2.057 \quad 2.333$

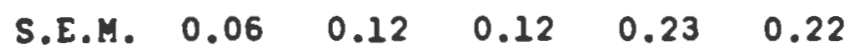

$N=6$ Values represent the Mean \pm S.E.M. for nmoles of 5-HIAA formed/hr./ug DNA

TABLE 20 Lineweaver-Burked Data for Forebrain using $C_{14}$-tryptamine as Substrate ( $1 / \mathrm{V}$ vs $\left.1 / \mathrm{S}\right)$

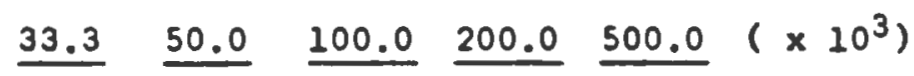

MEAN $\quad 2.297 \quad 1.148 \quad 0.726 \quad 0.510 \quad 0.445$

$\begin{array}{llllll}\text { S.E.M. } & 0.25 & 0.13 & 0.05 & 0.05 & 0.04\end{array}$

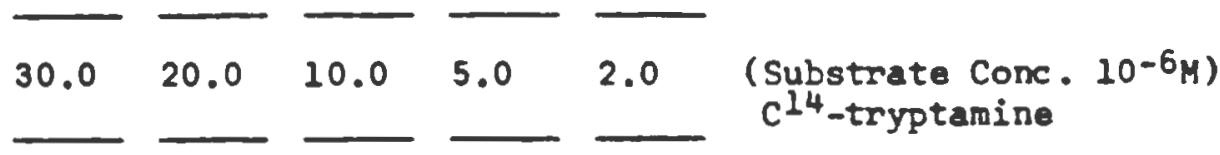

$N=6$ Values represent the Mean \pm for nanomoles of 5-HIAA formed/hr./ug DNA 
TABLE 21 Michalis-Menton Data for Forebrain using $C^{14}$-serotonin as Substrate ( $V$ vs $S$ )

$2.0 \quad \underline{5.0} \quad \underline{10.0} \quad 20.0 \quad 30.0 \quad \begin{aligned} & \text { Substrate Conc. } \\ & \mathrm{C}^{14} \text {-serotonin }\end{aligned}$

$\begin{array}{llllll}\text { MEAN } & 0.445 & 0.109 & 0.189 & 0.288 & 0.365\end{array}$

S.E.H. $\quad 0.01 \quad 0.02 \quad 0.04 \quad 0.04 \quad 0.04$

$N=6$ Values represent the Mean \pm S.E.M. for moles of IAA formed/hr./ug DNA

TABLE 22 Lineweaver-Burke Data for Forebrain using $\mathrm{C}^{14}$-serotonin as Substrate ( $1 / \mathrm{V}$ vs $\left.1 / \mathrm{S}\right)$

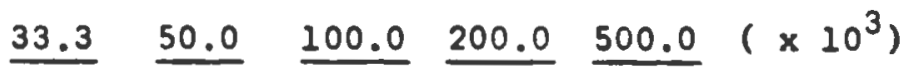

MEAN $\quad 30.327 \quad 13.367 \quad 7.572 \quad 4.000 \quad 2.817$

S.E.H. $\quad \begin{array}{lllll}4.34 & 1.46 & 0.91 & 0.39 & 0.25\end{array}$

$=\left[\begin{array}{lllll}30.0 & 20.0 & 10.0 & 5.0 & 2.0 \quad \begin{array}{c}\text { (Substrate Conc. 10-6 M) } \\ \text { C }^{14} \text {-serotonin }\end{array}\end{array}\right.$

$N=6$ Values represent the Mean \pm S.E.M. for nanowoles of IAA formed/hr. ug DNA 
TABLE 23 Mfchalis-Menton Data for Hypothalamus using Michalis-Menton Data for Hypothalamus
$C^{14}$-tryptamine as Substrate ( $V$ v $S$ )

$\underline{2.0} \quad \underline{5.0} \quad \underline{10.0} \quad \underline{20.0} \quad \underline{30.0} \begin{aligned} & \text { Substrate Conc. } \\ & \mathrm{C}^{14} \text {-tryptamine }\end{aligned}$

MEAN $\quad 0.334 \quad 0.617 \quad 0.951 \quad 1.299 \quad 1.511$

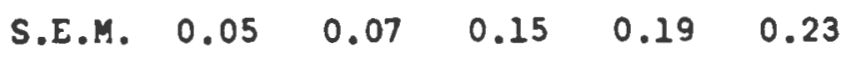

$N=6$ Values represent the Mean \pm S.E.M. for nanomoles of 5-HIAA formed/hr./ug DNA

TABLE 24 Lineweaver-Burke Data for Hypothalamus using $\mathrm{C}^{14}$-tryptamine as Substrate ( $1 / \mathrm{V}$ vs $\left.1 / \mathrm{S}\right)$

$33.3 \quad 50.0 \quad 100.0 \quad 200.0 \quad 500.0 \quad\left(\times 10^{3}\right)$

$\begin{array}{llllll}\text { MEAN } & 3.329 & 1.770 & 1.196 & 0.878 & 0.793\end{array}$

$\begin{array}{llllll}\text { S.E.M. } & 0.45 & 0.25 & 0.19 & 0.16 & 0.18\end{array}$

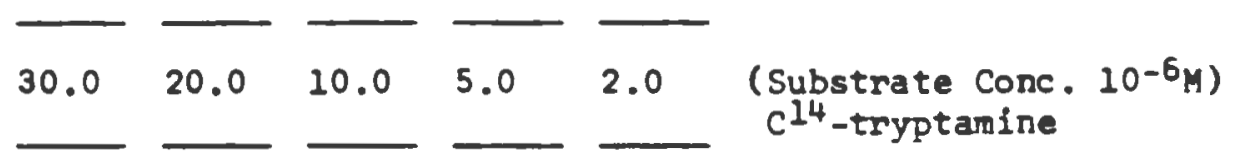

$N=6$ Values represent the Mean \pm S.E.M. for nmoles of 5-HIAA formed/hr./ug DNA 
TABLE 25 Michalis-Menton Data for Hypothalamus using $C^{14}$-serotonin as Substrate ( $V$ VB $\left.S\right)$

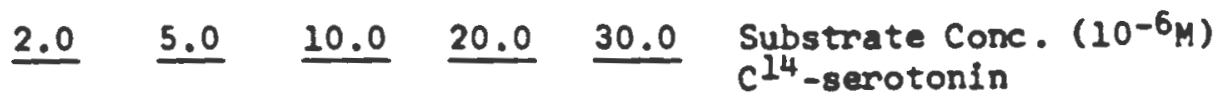

MEAN $\quad 0.027 \quad 0.060 \quad 0.107 \quad 0.171 \quad 0.185$

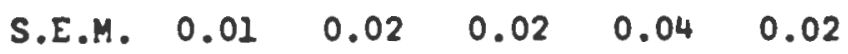

$N=6$ Values represent the Hean \pm S.E.M. for moles of IAA formed/hr./ug DNA

TABLE 26 Lineweaver-Burke Data for Hypothalamus using $C^{14}$-serotonin as Substrate ( $1 / V$ vs $\left.1 / 5\right)$

$$
33.3 \quad 50.0 \quad 100.0 \quad 200.0 \quad 500.0 \quad\left(\times 10^{3}\right)
$$

$\begin{array}{llllll}\text { MEAN } \quad 42.068 \quad 19.947 & 11.061 & 6.535 & 4.838\end{array}$

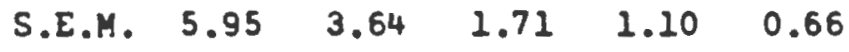

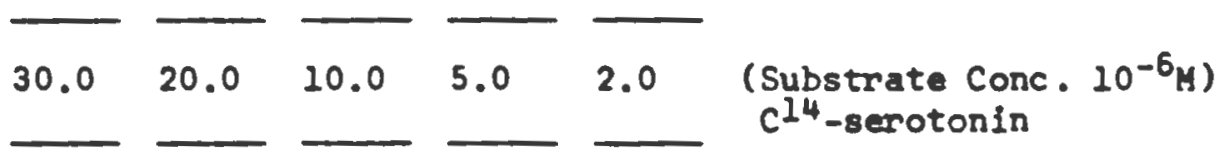

$N=6$ Values represent the Mean \pm S.E.M. for nanomoles of IAA formed/hr./ug DNA 
TABLE 27 In Vitro Monoanine Oxidase Activity following Preincubation with varying molar concentrations of Protriptyline (Preincubation - 30 minutes at $40 \mathrm{C}$ )

\begin{tabular}{|c|c|c|c|c|c|c|c|c|c|c|}
\hline Corpus Striatur & $\begin{array}{l}\text { No } \\
\text { Protriptyline }\end{array}$ & $10-11$ & $10-10$ & $10-9$ & $10^{-8}$ & $10^{-7}$ & $10^{-6}$ & $10^{-5}$ & $10^{-4}$ & $10^{-3}$ \\
\hline MEAN & 2.135 & 2.085 & 2.024 & 2.020 & 2.000 & 1.977 & 2.009 & 1.825 & 1.591 & 0.447 \\
\hline S.D. & 1.067 & 1.063 & 1.120 & 1.127 & 1.149 & 0.996 & 1.032 & 0.933 & 0.978 & 0.323 \\
\hline S.E.H. & 0.435 & 0.434 & 0.457 & 0.460 & 0.469 & 0.398 & 0.421 & 0.381 & 0.399 & 0.132 \\
\hline
\end{tabular}

\section{Forabrain}

$\begin{array}{lllllllllll}\text { MEAN } & 13.005 & 11.955 & 11.902 & 11.412 & 11.478 & 11.548 & 11.281 & 11.026 & 10.370 & 3.423 \\ \text { S.D. } & 2.931 & 2.538 & 2.563 & 2.395 & 2.184 & 2.245 & 2.139 & 2.211 & 2.120 & 0.704 \\ \text { S.E.H. } & 1.197 & 1.032 & 1.046 & 0.978 & 0.891 & 0.917 & 0.874 & 0.903 & 0.866 & 0.288\end{array}$

\section{Hypothelamus}

$\begin{array}{lllllllllll}\text { MEAN } & 1.678 & 1.599 & 1.536 & 1.476 & 1.578 & 1.523 & 1.506 & 1.379 & 1.162 & 0.278 \\ \text { S.D. } & 0.681 & 0.649 & 0.590 & 0.598 & 0.678 & 0.635 & 0.668 & 0.579 & 0.492 & 0.166 \\ \text { S.E.H. } & 0.278 & 0.265 & 0.241 & 0.244 & 0.277 & 0.259 & 0.273 & 0.236 & 0.201 & 0.068\end{array}$

N=6 for each determination

Values represent the nanomoles of 5-HIAA formed/hr./ug DNA

Monoamine Oxidase substrate used in this experiment was $c^{14}$-tryptamine 
TABLE 28 In VItro Monoamine Oxidase Activity following Preincubation with varying molar concentrations of Protriptyline (Preincubation - 30 minutes at $4^{\circ} \mathrm{C}$ )

\begin{tabular}{|c|c|c|c|c|c|c|c|c|c|c|}
\hline Corpus Striatum & $\begin{array}{l}\text { No } \\
\text { Protriptyline }\end{array}$ & $10-11$ & $10-10$ & $10-9$ & $10-8$ & $10-7$ & $10-6$ & $10^{-5}$ & $10^{-4}$ & $10^{-3}$ \\
\hline MEAK & 0.591 & 0.556 & 0.562 & 0.514 & 0.516 & 0.518 & 0.503 & 0.478 & 0.352 & 0.017 \\
\hline S.D. & 0.392 & 0.385 & 0.359 & 0.344 & 0.365 & 0.392 & 0.335 & 0.347 & 0.234 & 0.022 \\
\hline S.E.M. & 0.160 & 0.157 & 0.146 & 0.141 & 0.149 & 0.160 & 0.137 & 0.142 & 0.095 & 0.009 \\
\hline
\end{tabular}

\section{Forobrain}

$\begin{array}{lllllllllll}\text { MEAN } & 3.530 & 3.291 & 3.291 & 3.289 & 3.230 & 3.280 & 3.200 & 2.943 & 2.214 & 0.221 \\ \text { S.D. } & 0.813 & 0.631 & 0.716 & 0.671 & 0.736 & 0.746 & 0.803 & 0.874 & 0.440 & 0.052 \\ \text { S.E.M. } & 0.332 & 0.258 & 0.292 & 0.274 & 0.300 & 0.304 & 0.328 & 0.357 & 0.180 & 0.021\end{array}$

\section{Hypothalamus}

$\begin{array}{lllllllllll}\text { MEAN } & 0.434 & 0.390 & 0.371 & 0.400 & 0.411 & 0.382 & 0.367 & 0.347 & 0.210 & 0.009 \\ \text { S.D. } & 0.213 & 0.192 & 0.161 & 0.181 & 0.211 & 0.195 & 0.203 & 0.183 & 0.109 & 0.010 \\ \text { S.E.M. } & 0.087 & 0.978 & 0.066 & 0.974 & 0.086 & 0.080 & 0.083 & 0.075 & 0.045 & 0.004\end{array}$

N=6 for each determination

Values represent the nanomoles of IM formed/hr./ug DNA

Monoamine Oxidase substrate used in this experiment was $\mathrm{C}^{14}$-serotonin 
TABLE 29 Mo Activity following preincubation with varlous molar concentrations of $T_{3}$ and for various preincubation time intervals

Corpus Striatum

Prelncubation Times (Minutes)

$\begin{array}{llllr}\begin{array}{l}\text { Molar Concentration } \\ \text { of } T_{3}\end{array} & \text { No Preincubation } & 15 \text { minutes } & 30 \text { minutes } & 60 \text { minutes } \\ \text { No } T_{3} & 0.480 \pm 0.07 & 0.359 \pm 0.04 & 0.403 \pm 0.03 & 0.427 \pm 0.04 \\ 10^{-9} M & 0.320 \pm 0.07 & 0.292 \pm 0.07 & 0.302 \pm 0.05 & 0.266 \pm 0.07 \\ 10^{-7}- & 0.334 \pm 0.07 & 0.334 \pm 0.13 & 0.322 \pm 0.09 & 0.259 \pm 0.09 \\ 10^{-5} \underline{M} & 0.263 \pm 0.05 & 0.317 \pm 0.12 & 0.324 \pm 0.06 & 0.288 \pm 0.09 \\ 10^{-4}- & 0.194 \pm 0.03 & 0.218 \pm 0.03 & 0.167 \pm 0.02 & 0.184 \pm 0.03 \\ 10^{-3} \mathrm{M} & 0.084 \pm 0.02 & 0.100 \pm 0.02 & 0.069 \pm 0.03 & 0.065 \pm 0.01\end{array}$

$N=3$ for each determination

Values represent the Mean \pm S.E.M., and are reported as nanomoles IAA formed/hr./ug DNA

Substrate employed was $\mathrm{c}^{14}$-serotonin 
TABLE $30 \quad$ Mo Activity following preincubation with varlous molar concentrations of $T_{3}$ and for various preincubation time intervals

\section{Forebrain}

Preincubation Tínes (Minutes)

\begin{tabular}{|c|c|c|c|c|}
\hline $\begin{array}{l}\text { Molar Concentration } \\
\text { of } T_{3}\end{array}$ & No Preincubation & 15 minutes & 30 minutes & 60 minutes \\
\hline No $\mathrm{T}_{3}$ & $0.546 \pm 0.05$ & $0.551 \pm 0.02$ & $0.539 \pm 0.03$ & $0.523 \pm 0.01$ \\
\hline $10^{-9} \underline{H}$ & $0.399 \pm 0.01$ & $0.397 \pm 0.05$ & $0.397 \pm 0.05$ & $0.384 \pm 0.06$ \\
\hline $10^{-7} \underline{M}$ & $0.408 \pm 0.02$ & $0.419 \pm 0.07$ & $0.424 \pm 0.07$ & $0.405 \pm 0.06$ \\
\hline $10^{-5} \underline{M}$ & $0.352 \pm 0.04$ & $0.404 \pm 0.05$ & $0.435 \pm 0.04$ & $0.376 \pm 0.04$ \\
\hline $10^{-4} \underline{M}$ & $0.278 \pm 0.01$ & $0.302 \pm 0.05$ & $0.291 \pm 0.03$ & $0.254 \pm 0.01$ \\
\hline $10^{-3} \underline{m}$ & $0.177 \pm 0.04$ & $0.145 \pm 0.03$ & $0.142 \pm 0.03$ & $0.125 \pm 0.03$ \\
\hline
\end{tabular}

$N=3$ for each determination

Values represent the Mean \pm S.E.M., and are reported as nanomoles IAA formed/hr./ug DNA Substrate eaployed was $\mathrm{C}^{14}$-8erotonin 
TABLE 31 MO Activity following preincubation with various molar concentrations of $T_{3}$ and for various preincubation time intervals

\section{Hypothalamus}

Proincubation Times (Minutes)

$\begin{array}{llllr}\begin{array}{l}\text { Molar Concentration } \\ \text { of } \mathrm{T}_{3}\end{array} & \text { No Preincubation } & 15 \text { minutes } & 30 \text { minutes } & 60 \text { minutes } \\ & 0.224 \pm 0.02 & 0.207 \pm 0.04 & 0.203 \pm 0.03 & 0.192 \pm 0.04 \\ \text { No } T_{3} & 0.257 \pm 0.02 & 0.201 \pm 0.09 & 0.156 \pm 0.02 & 0.142 \pm 0.07 \\ 10^{-9} \underline{M} & 0.194 \pm 0.05 & 0.215 \pm 0.07 & 0.215 \pm 0.08 & 0.151 \pm 0.07 \\ 10^{-7} \underline{M} & 0.149 \pm 0.03 & 0.204 \pm 0.08 & 0.183 \pm 0.06 & 0.112 \pm 0.07 \\ 10^{-5} \underline{M} & 0.068 \pm 0.02 & 0.094 \pm 0.05 & 0.095 \pm 0.03 & 0.047 \pm 0.02 \\ 10^{-4} \underline{M} & 0.029 \pm 0.01 & 0.044 \pm 0.03 & 0.032 \pm 0.02 & 0.009 \pm 0.01 \\ 10^{-3} \underline{M} & & & \end{array}$

$N=3$ for each determination

Values represent the MEAN \pm S.E.M., and are reported as nanomoles IAA formed/hr./Ug DNA

Substrate employed was $\mathrm{C}^{14}$-serotonin 
TABLE 32 MAO Activity following preincubation with various molar concentrations of $T_{3}$ and for various preincubation time intervals.

\section{Corpus Striatum}

Preincubation Times (Minutes)

\begin{tabular}{|c|c|c|c|c|}
\hline $\begin{array}{l}\text { Molar Concentration } \\
\text { of } \mathrm{T}_{3}\end{array}$ & No Preincubation & 15 minutes & 30 minutes & 60 minutes \\
\hline No $T_{3}$ & $1.121 \pm 0.18$ & $1.243 \pm 0.18$ & $1.384 \pm 0.19$ & $1.313 \pm 0.19$ \\
\hline $10^{-9_{M}}$ & $1.208 \pm 0.18$ & $1.318 \pm 0.19$ & $1.398 \pm 0.19$ & $1.450 \pm 0.12$ \\
\hline $10^{-7} \underline{M}$ & $1.281 \pm 0.17$ & $1.463 \pm 0.27$ & $1.441 \pm 0.26$ & $1.377 \pm 0.17$ \\
\hline $10^{-5} \underline{M}$ & $1.274 \pm 0.18$ & $1.347 \pm 0.16$ & $1.253 \pm 0.16$ & $1.318 \pm 0.18$ \\
\hline $10^{-4} \underline{M}$ & $1.005 \pm 0.17$ & $0.932 \pm 0.11$ & $0.977 \pm 0.15$ & $1.019 \pm 0.31$ \\
\hline $10^{-3} \underline{M}$ & $0.466 \pm 0.08$ & $0.489 \pm 0.06$ & $0.426 \pm 0.06$ & $0.622 \pm 0.17$ \\
\hline
\end{tabular}

$N=3$ for each determination

Values ropresent the MEAN \pm S.E.M., and are reported as nanomoles 5-HIAA formed/hr./Ug DNA

Substrate enployed was $C^{14}$-tryptanine 
TABLE 33 Mo Activity following preincubation with various molar concentrations of $\mathrm{T}_{3}$ and for various preincubation time intervals

Forebrain

Preincubation TImes (Minutes)

$\begin{array}{lllll}\begin{array}{l}\text { Molar Concentration } \\ \text { of } T_{3}\end{array} & \text { No Proincubation } & 15 \text { minutes } & 30 \text { minutes } & 60 \text { minutes } \\ \text { No } T_{3} & 3.220 \pm 0.53 & 3.653 \pm 0.59 & 3.617 \pm 0.45 & 3.641 \pm 0.38 \\ 10^{-9} & 3.609 \pm 0.36 & 3.758 \pm 0.47 & 3.945 \pm 0.45 & 3.886 \pm 0.37 \\ 10^{-7} \underline{M} & 3.616 \pm 0.36 & 3.701 \pm 0.51 & 3.819 \pm 0.54 & 3.813 \pm 0.42 \\ 10^{-5} \underline{M} & 3.331 \pm 0.34 & 3.532 \pm 0.42 & 3.506 \pm 0.43 & 3.547 \pm 0.39 \\ 10^{-4} \underline{M} & 2.906 \pm 0.31 & 2.803 \pm 0.49 & 2.994 \pm 0.43 & 3.174 \pm 0.38 \\ 10^{-3} \underline{M} & 1.779 \pm 0.24 & 1.847 \pm 0.22 & 1.724 \pm 0.20 & 2.314 \pm 0.49\end{array}$

$N=3$ for each determination

Values represent the MEAN \pm S.E.M., and are reported as nanomoles 5-HIAA formed/hr./ug DNA

Substrate employed was $\mathrm{c}^{14}$-tryptamine 
TABLE 34 Mo Activity following proincubation with various molar concentrations of $T_{3}$ and for various preincubation time intervals

\section{Hypothalamus}

Preincubation TImes (Minutes)

\begin{tabular}{|c|c|c|c|c|}
\hline $\begin{array}{l}\text { Molar Concentration } \\
\text { of } T_{3}\end{array}$ & No Preincubation & 15 minutes & 30 minutes & 60 minutes \\
\hline No $T_{3}$ & $1.156 \pm 0.26$ & $1.605 \pm 0.33$ & $1.727 \pm 0.25$ & $1.615 \pm 0.37$ \\
\hline $10^{-9} \underline{M}$ & $1.229 \pm 0.26$ & $1.653 \pm 0.31$ & $1.737 \pm 0.34$ & $1.559 \pm 0.25$ \\
\hline $10^{-7} \underline{M}$ & $1.235 \pm 0.26$ & $1.815 \pm 0.40$ & $1.767 \pm 0.39$ & $1.554 \pm 0.28$ \\
\hline $10^{-5} \underline{\underline{M}}$ & $1.257 \pm 0.23$ & $1.488 \pm 0.30$ & $1.581 \pm 0.29$ & $1.555 \pm 0.23$ \\
\hline $10^{-4} \underline{H}$ & $0.931 \pm 0.19$ & $1.122 \pm 0.22$ & $1.114 \pm 0.22$ & $1.173 \pm 0.21$ \\
\hline $10^{-3} \underline{\underline{H}}$ & $0.473 \pm 0.13$ & $0.534 \pm 0.11$ & $0.497 \pm 0.10$ & $0.701 \pm 0.24$ \\
\hline
\end{tabular}

$N=3$ for each determination

Values represent the MEAN + S.E.M., and are reported as nanonoles 5-HIAA formed/hr./ug DNA

Substrate employed was $\mathrm{c}^{14}$-tryptamine 


\section{FIGURE 7}

TITLE: The in vitro effect of various molar concentrations of $\mathrm{T}_{3}$ on activity of monoamine oxidase from three brain regions

\section{LEGEND}

Brain homogenates were preincubated with concentrations of triiodothyronine $\left(T_{3}\right)$ from $10^{-3}$ to $10^{-9} \mathrm{M}$, or without $T_{3}$, for 60 minutes (similar results, not depicted here, were obtained when the preincubation period was 0,15 or 30 minutes). Monoamine oxidase activity was determined by measurement of concentrations of indole acetic acid (IAA) formed per hour per microgram of tissue DNA following addition of ${ }^{14} \mathrm{C}$-serotonin to the homogenates. Each point illustrated is the mean of three determinations with the standard error depicted. 


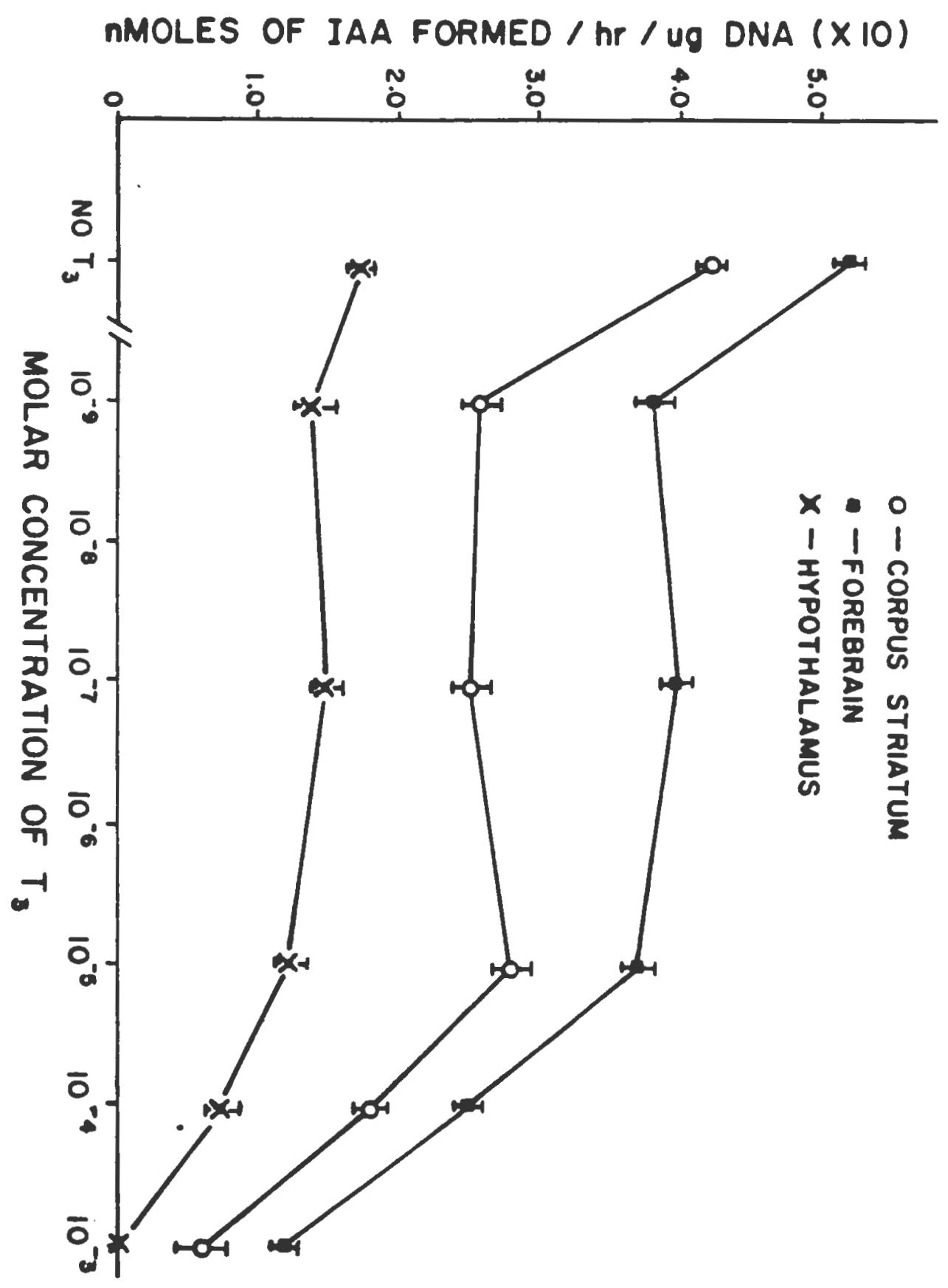


TABLE 35 Effect of Trllodothyronine on MAO Activity in Three Brain Reglons

\section{Corpus Striatum}

Saline

$T_{3}$

Saline

$\mathrm{T}_{\mathbf{3}}$

Days of

Infection

No Infection

$2.151 \pm 0.26$

$2.968 \pm 0.18$

$2.147 \pm 0.18$
1

2

4

5

6

7

B

$\begin{array}{llllll}3.313 \pm 0.21 & 2.647 \pm 0.29 & 3.741 \pm 0.56 & 3.716 \pm 0.71 & 1.810 \pm 0.15 & 1.711 \pm 0.05 \\ 2.782 \pm 0.16 & 3.317 \pm 0.33 & 3.077 \pm 0.25 & 3.259 \pm 0.29 & 1.952 \pm 0.21 & 1.981 \pm 0.18 \\ 3.669 \pm 0.37 & 4.339 \pm 0.61 & 4.217+0.68 & 4.843 \pm 0.54 & 2.795 \pm 0.20 & 2.607 \pm 0.43 \\ 3.808 \pm 0.23 & 3.296 \pm 0.42 & 3.932 \pm 0.53 & 3.510 \pm 0.29 & 2.703 \pm 0.27 & 2.111 \pm 0.31 \\ 3.550 \pm 0.27 & 3.255 \pm 0.17 & 4.093 \pm 0.49 & 3.353 \pm 0.36 & 2.590 \pm 0.29 & 2.276 \pm 0.13 \\ 2.835 \pm 0.16 & 3.702 \pm 0.55 & 3.593 \pm 0.30 & 3.817 \pm 0.15 & 2.092 \pm 0.13 & 2.697 \pm 0.17 \\ 3.406 \pm 0.24 & 3.425 \pm 0.40 & 4.050 \pm 0.45 & 3.884 \pm 0.44 & 2.640 \pm 0.29 & 2.422 \pm 0.14 \\ 3.012 \pm 0.22 & 2.709 \pm 0.47 & 4.888 \pm 0.82 & 4.750 \pm 0.69 & 2.038 \pm 0.21 & 21109 \pm 0.27\end{array}$

$N=6$ for each determination no statistical significance was observed

Values represent the MEAN \pm S.E.M., and are reported as nanomoles 5-HIAA formed/hr./ug DNA Substrate employed was $\mathrm{C}^{14}$-tryptamine

All animals were sacrificed 24 hours after the last T3 infection 
TABLE 36 Effect of Thyroxine $\left(\mathrm{T}_{4}\right)$ on MAO Activity in Three Brain Regions

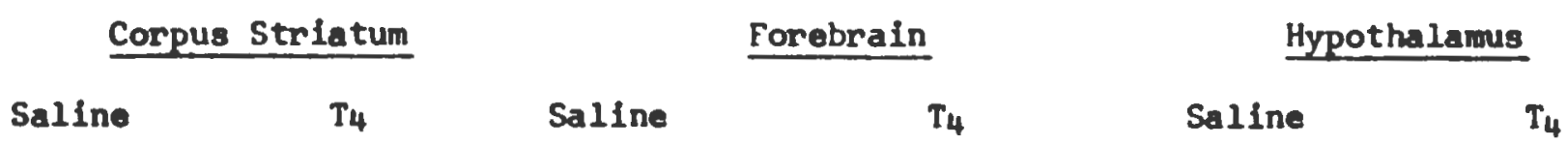

\begin{abstract}
Days of
Injection
\end{abstract}

No Infection

$$
0.345 \pm 0.05
$$$$
2.968 \pm 0.18
$$

$$
2.147 \pm 0.18
$$

1

$0.933 \pm 0.210 .969+0.29$

$0.871 \pm 0.14$

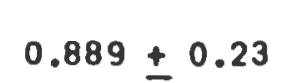

$N=6$ for each determination

Mean \pm S.E.M.; Nmoles IAA formed/hr./ug DNA; serotonin as substrate

All aninals ware sacrificed 24 hours after the last $T_{4}$ infection

No statistical significance was observed 
TABLE 37 Effect of Thyroxine $\left(T_{4}\right)$ on MAO Activity in Three Brain Regions

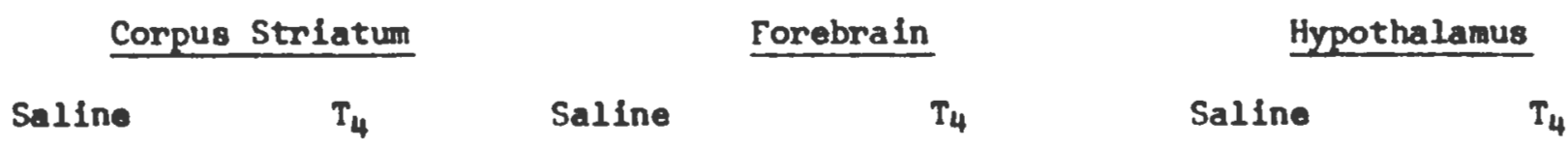

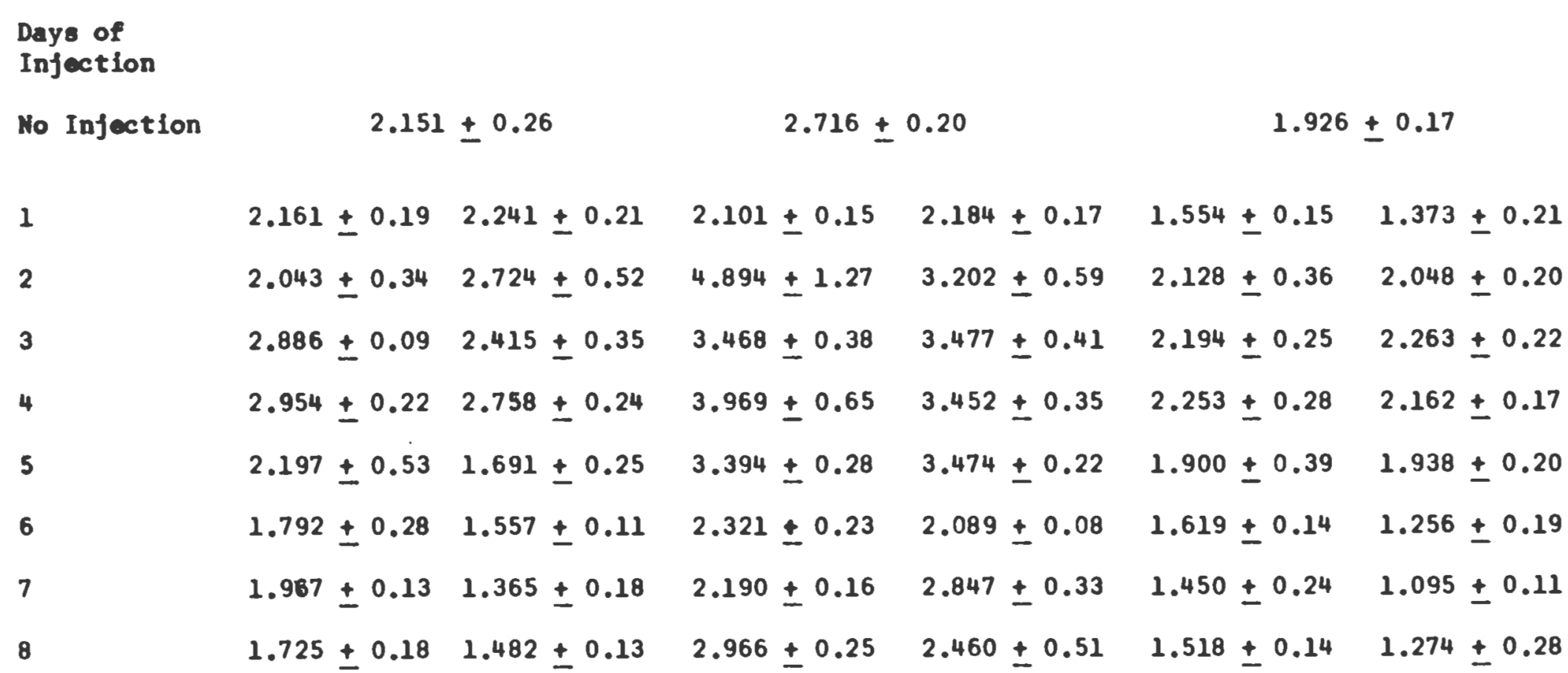

$N=6$ for each determination

MEAN \pm S.E.M.; Nmoles 5-HIAM formed/hr./ug DNA; $\mathrm{C}^{14}$-tryptamine as substrate

All animals were sacrificed 24 hours after the last $T_{4}$ infection

No statistical significance was observed 


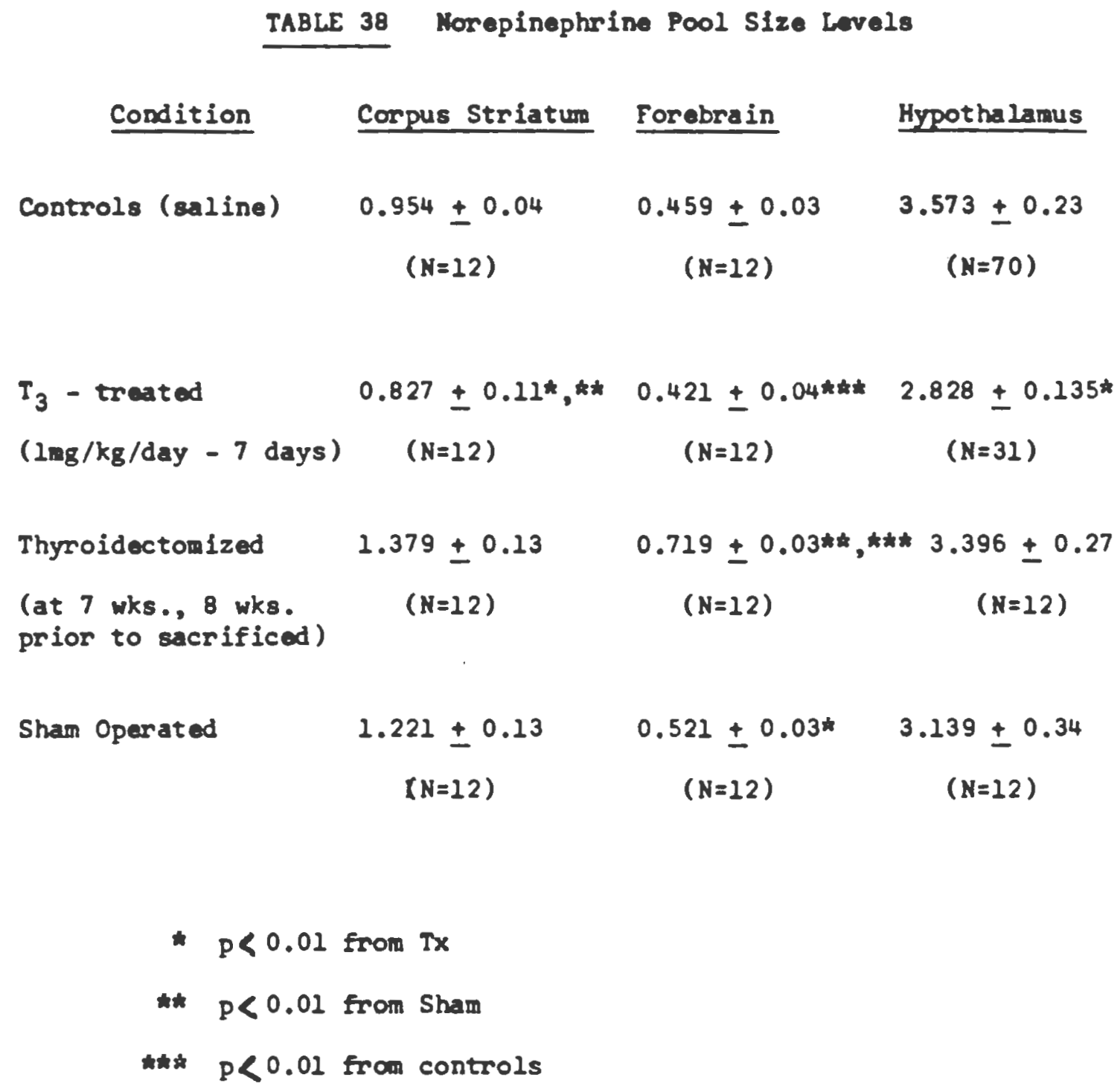


TABLE 39 Mumerical values for NE levels in hypothalamus following alpha-methyl-para-tyrosine administration and sacrificed three hours after the administration of alpha-methylpara-tryosine. Data shown graphically in Figure 9.

Dosage of MT

NE Level

Number of Aninals

No MT

$\begin{array}{ll}\text { Mean } & 3.3759 \\ \text { S.D. } & 0.4112 \\ \text { S.E.H. } & 0.2444\end{array}$

$\mathrm{N}=9$

S.E.M.

0.2444

$200 \mathrm{mg} / \mathrm{kg}$

Mean

1.9865

S.D.

0.2679

S.E.H.

0.0947

$400 \mathrm{mg} / \mathrm{kg}$

Mean

1.5639

$N=9$

S.D.

0.3326

S.E.M.

0.1109

$600 \mathrm{mg} / \mathrm{kg}$

Mean

1.1204

$N=3$

S.D.

0.3554

S.E.M.

0.2052

$800 \mathrm{mg} / \mathrm{kg}$

$\begin{array}{ll}\text { Hean } & 1.5911 \\ \text { S.D. } & 0.3798 \\ \text { S.E.M. } & 0.2193\end{array}$

$N=3$ 
TABLE 40 Alpha-nethyl-para-tyrosine dose response curve for trilodothyronine treated aninals.

Corpus Striatum Forebrain Hypothalamus

\begin{tabular}{|c|c|c|c|c|}
\hline $\begin{array}{l}0 \mathrm{~T} \text { ine } \\
\text { No } \mathrm{MT}\end{array}$ & $\begin{array}{l}\text { MEAN } \\
\text { S.D. } \\
\text { S.E.M. }\end{array}$ & $\begin{array}{c}0.5821 \\
0.1580 \\
0.0912 \\
N=3\end{array}$ & $\begin{array}{c}0.2421 \\
0.0648 \\
0.0374 \\
N=3\end{array}$ & $\begin{array}{c}2.4926 \\
0.3632 \\
0.2097 \\
N=3\end{array}$ \\
\hline $\begin{array}{l}200 \mathrm{mg} / \mathrm{kg} \\
3 \mathrm{hr} \cdot \mathrm{pt} .\end{array}$ & & $\begin{array}{c}0.3017 \\
0.1047 \\
0.0524 \\
N=4\end{array}$ & $\begin{array}{l}0.2390 \\
0.2084 \\
0.0542 \\
N=4\end{array}$ & $\begin{array}{c}1.8375 \\
0.2274 \\
0.1137 \\
N=4\end{array}$ \\
\hline $\begin{array}{l}400 \mathrm{mg} / \mathrm{kg} \\
3 \mathrm{hr} . \mathrm{pt} .\end{array}$ & & $\begin{array}{c}0.3255 \\
0.2242 \\
0.1294 \\
N=3\end{array}$ & $\begin{array}{c}0.2090 \\
0.1211 \\
0.0699 \\
N=3\end{array}$ & $\begin{array}{c}1.2367 \\
0.5095 \\
0.2942 \\
N=3\end{array}$ \\
\hline $\begin{array}{l}600 \mathrm{mg} / \mathrm{kg} \\
3 \mathrm{hr} . \mathrm{pt} .\end{array}$ & & $\begin{array}{c}0.3140 \\
0.1126 \\
0.0650 \\
k=3\end{array}$ & $\begin{array}{c}0.1668 \\
0.0768 \\
0.0443 \\
N=3\end{array}$ & $\begin{array}{c}1.4371 \\
0.8366 \\
0.4830 \\
N=3\end{array}$ \\
\hline $\begin{array}{l}800 \mathrm{mg} / \mathrm{kg} \\
3 \mathrm{hr} . \mathrm{pt} .\end{array}$ & & $\begin{array}{c}0.2405 \\
0.1811 \\
0.1102 \\
N=3\end{array}$ & $\begin{array}{c}0.3303 \\
0.1075 \\
0.0621 \\
N=3\end{array}$ & $\begin{array}{c}1.7169 \\
1.2052 \\
0.6959 \\
N=3\end{array}$ \\
\hline
\end{tabular}


TABLE 41 Turnover of Norepinephrine in the hypothalamus, corpus striatum and forebrain for control rats following administration of $400 \mathrm{mg} / \mathrm{kg}$ of alpha-methyl-para-tyrosine

TISSUE

No MT

\section{TIME (hours after MT administration)}

$\begin{array}{lllll}2.0 & 3.0 & 4.5 & 6.0 & 9.0\end{array}$

Conpus Striatum

$\begin{array}{llllllll}\text { MEAN } & 0.6978 & 0.5883 & 0.5781 & 0.4709 & 0.4292 & 0.3238 & 0.3080 \\ \text { S.D. } & 0.1767 & 0.1400 & 0.0870 & 0.2087 & 0.1086 & 0.0882 & 0.1241 \\ \text { S.E.M. } & 0.0721 & 0.0572 & 0.0389 & 0.0852 & 0.0486 & 0.0360 & 0.0439\end{array}$

Forebrain

$\begin{array}{llllllll}\text { MEAN } & 0.4536 & 0.2644 & 0.1940 & 0.1419 & 0.1780 & 0.1998 & 0.1592 \\ \text { S.D. } & 0.0747 & 0.0458 & 0.0972 & 0.0377 & 0.0482 & 0.0887 & 0.0479 \\ \text { S.E.M. } & 0.0305 & 0.0187 & 0.0436 & 0.0169 & 0.0197 & 0.0362 & 0.0169\end{array}$

Hypothalamus

$\begin{array}{llllllll}\text { MEAN } & 3.4047 & 2.9928 & 2.1869 & 1.4213 & 0.8212 & 0.8001 & 0.6264 \\ \text { S.D. } & 0.9982 & 0.6084 & 0.4625 & 0.3837 & 0.5195 & 0.2608 & 0.1573 \\ \text { S.E.H. } & 0.4075 & 0.2721 & 0.1888 & 0.1269 & 0.2121 & 0.1166 & 0.0556\end{array}$

$N=6$ for each point

slope for hypothalamus $=-0.6074$

linear regression coefficient $\left(r^{2}\right)=0.9825$

slope for corpus striatum $=-0.0587$

$=0.9680$

slope for forebrain $=-0.1298$ 
TABLE 42 Turnovar of Norepinephrine in hypothalamus, corpus striatum and forebrain for rats treated with trifodothyronine $\left(\mathrm{T}_{3}\right)$ ( $\mathrm{lmg} / \mathrm{kg} /$ day -7 days). MT $-400 \mathrm{mg} / \mathrm{kg}$

TISSUE

\section{(20)}

Corpus Striatum

MEAN

S.D.

S.E.M.
0.8971
0.0966

0.0394

No $\mathrm{MT}$

TIME (hours after MT administration)

$\begin{array}{ccccc}1.0 & 2.0 & 3.0 & 4.5 & 6.0 \\ 0.8703 & 0.6821 & 0.4447 & 0.6505 & 0.6938 \\ 0.3074 & 0.2066 & 0.1375 & 0.1440 & 0.2251 \\ 0.1375 & 0.0924 & 0.0687 & 0.0644 & 0.1007\end{array}$

Forebrain

$\begin{array}{lllllll}\text { MEAN } & 0.4408 & 0.3222 & 0.2767 & 0.2307 & 0.2086 & 0.1717 \\ \text { S.D. } & 0.1320 & 0.0606 & 0.0778 & 0.0340 & 0.0510 & 0.0742 \\ \text { S.E.M. } & 0.0539 & 0.0271 & 0.0345 & 0.0170 & 0.0255 & 0.0332\end{array}$

Hypothalamus

$\begin{array}{lllllll}\text { MEAN } & 2.8280 & 2.4068 & 2.4474 & 1.8941 & 1.6823 & 1.2003 \\ \text { S.D. } & 0.7495 & 0.5586 & 0.4825 & 1.0193 & 0.8231 & 0.7216 \\ \text { S.E.M. } & 0.1346 & 0.2793 & 0.2158 & 0.5067 & 0.3766 & 0.3227\end{array}$

$N=4$ to 6 determinations for each point

slope for hypothalamus $=-0.2615$

linear regression coefficient $\left(r^{2}\right)=0.9625$

slope for corpus striatum $=-0.1545$

$=0.9106$

slope for forebrain $=-0.0676$
$=0.9350$ 
FIGURE 23

TITLE: DNA standard curve

LEGEND

Known concentrations of deoxyribonucleic acid sodium salt

$(1.0,2.0,4.0,8.0$ and $12.0 \mathrm{ng}$ were added to assay tubes and reacted with potassium ferrous cyanide. DNA fluorescence was then read on a spectrophotofluorometric with excitation at $510 \mu$ meters and emission at $400 \mu$ meters. 
The calculations involved in determining the DNA standard Curve are listed below. A linear regression was used to determine the regression coefficient.

$$
\begin{aligned}
a_{0}= & 2.9774=\text { intercept }(\text { or blank })=2.98 \pm 0.32 \\
a_{1}= & 7.3235= \\
& \text { slope (relative fluorescence units/ug DNA }= \\
r^{2}= & 0.999803=\text { regression coefficient }
\end{aligned}
$$

Hg DNA

0
1
2
4
8
12

1

2

4

12

calculated fluorescence

$$
\begin{array}{r}
2.9774 \\
10.3010 \\
17.6245 \\
32.2716 \\
61.5657 \\
90.8598
\end{array}
$$

The standard error of $a_{0}=0.3174$

The standard arror of $a_{1}=0.0514$

\section{Actual fluorescence units plotted}

$\begin{array}{lcccccc} & \underline{0(B K)} & \underline{1} & \underline{2} & \underline{4} & \underline{8} & \underline{12} \\ \text { X } & 3.20 & 9.92 & 17.28 & 32.53 & 62.29 & 90.38 \\ \text { s.d. } & 0.995 & 1.45 & 2.12 & 2.69 & 2.98 & 2.93 \\ \text { S.E.M. } & 0.22 & 0.33 & 0.47 & 0.60 & 0.67 & 0.66\end{array}$

At least 12 determinations were performed to calculate the MEAN \pm S.E.M. $(N=12)$. 


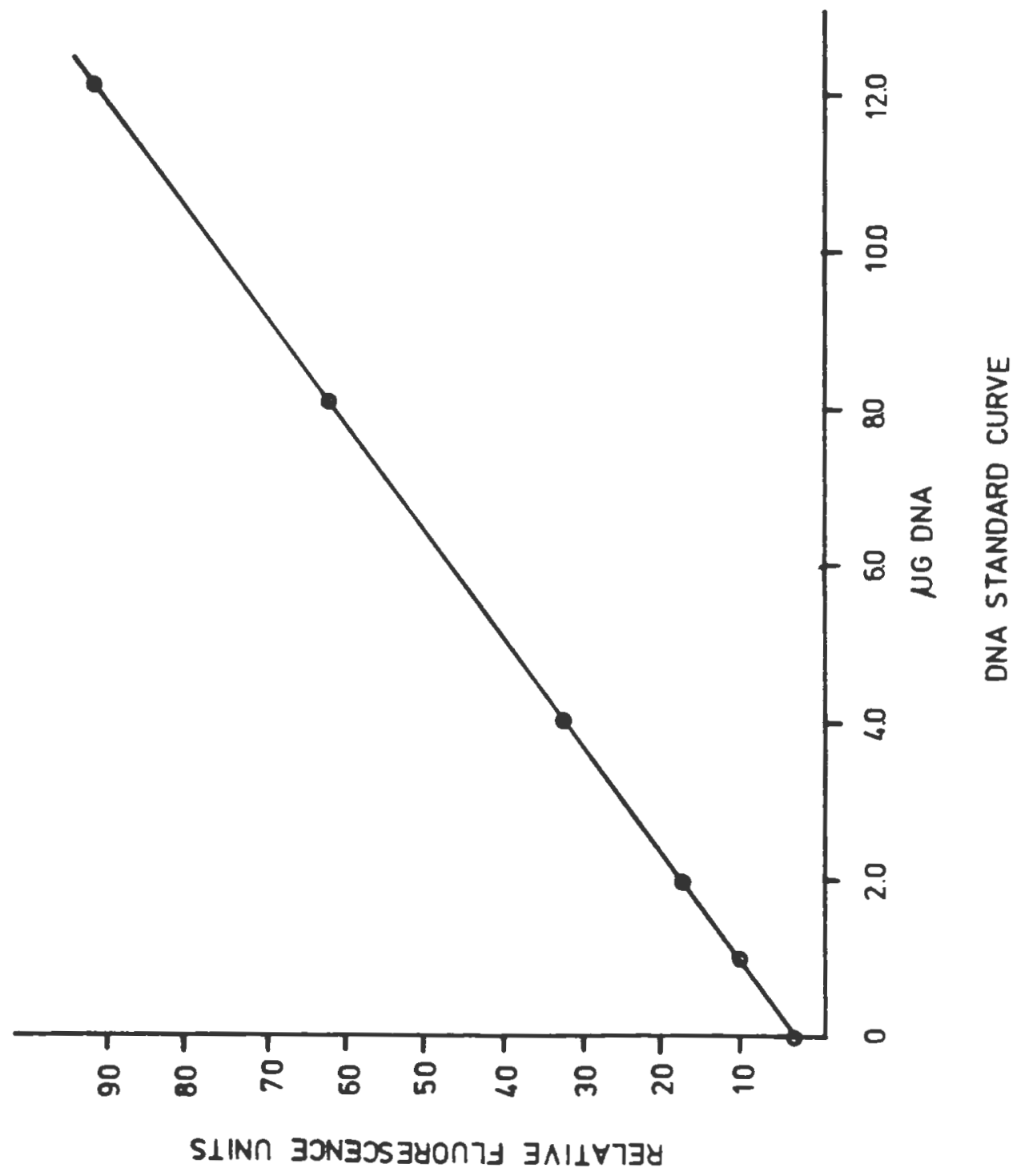


FIGURE 24

TITLE: Norepinephrine standard curve for an external norepinephrine standard

LEGEND

Varying concentrations of $\mathrm{NE}$ were added to assay tubes $(0.1,0.2$, $0.3,0.4$ and $0.5 \mathrm{mg}$ ). Fluorescence was then recorded on a spectrophotometer. Each data point represents the MEAN \pm S.E. for at least 3 experimental determinations. The linear regression coefficient was 0.9805 . 
Data used in Figure 24

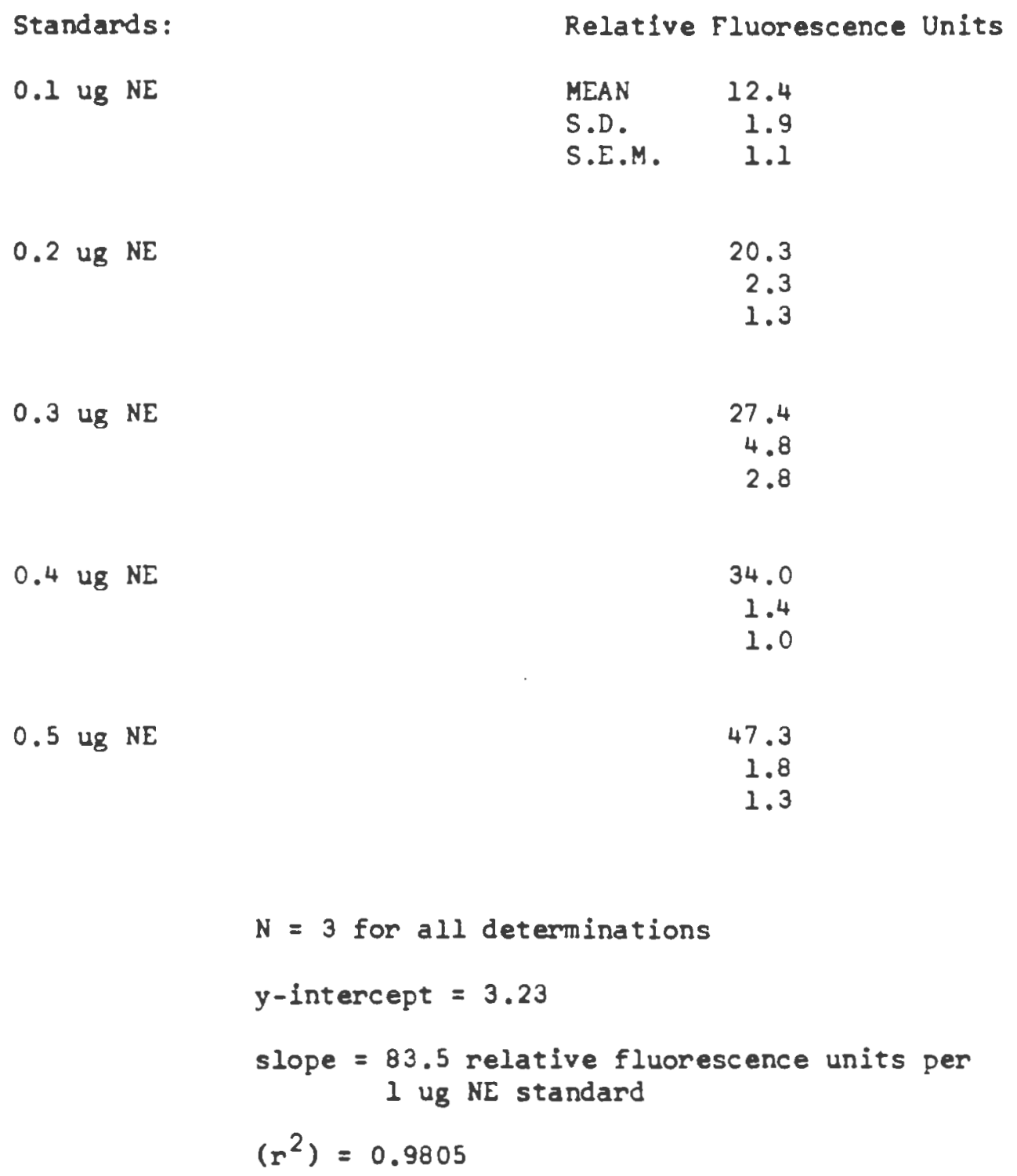




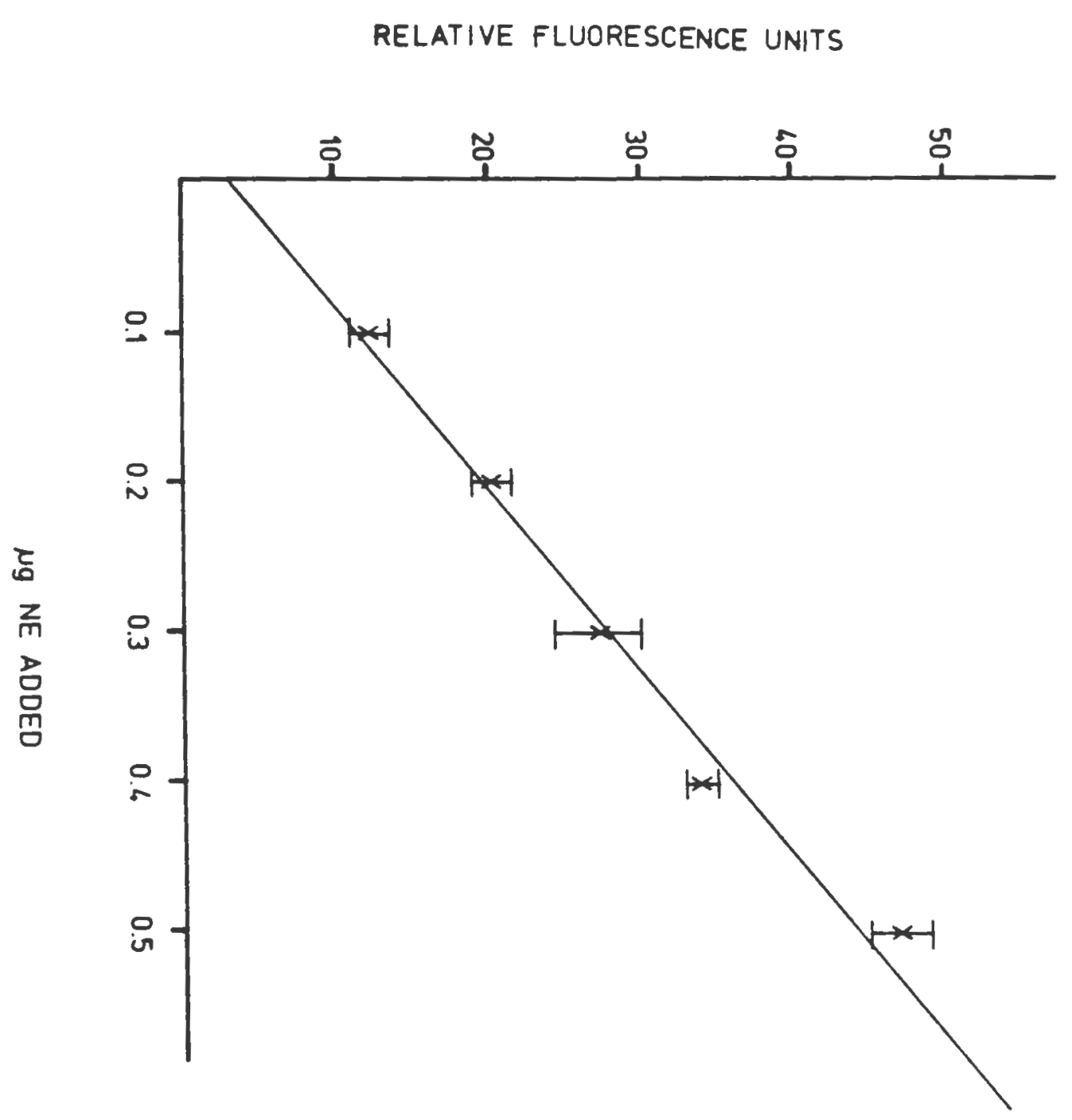


FIGURE 25

TITLE: Norepinephrine standard curve for the internal $\mathrm{H}^{3}-$ norepinephrine standard

LEGEND

Varying concentrations of labelled $\mathrm{H}^{3}-\mathrm{NE}$ were added to assay tubes and allowed to pass over prepared alumina columns and $H^{3}-N E$ recovery was recorded. Each data point represents the MEAN \pm S.E. for at least 3 experimental determinations. The linear regression coefficient is 0.9955 . 
Data used in Figure 25

Standards :

0.1 ug $\mathrm{H}^{3}-\mathrm{NE}$

0.2 ug $\mathrm{H}^{3}-\mathrm{NE}$

0.3 ug $H^{3}-N E$

0.4 ug $H^{3}-N E$

0.5 ug $H^{3}-N E$
CPM

MEAN 411.4

S.D. $\quad 52.2$

S.E.M. 30.1

739.2

99.5

57.5

979.3

126.5

73.1

1234.3

201.9

116.5

1585.0

466.1

269.1

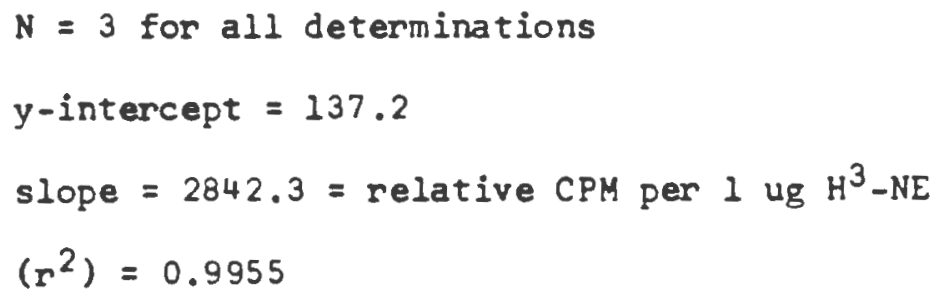




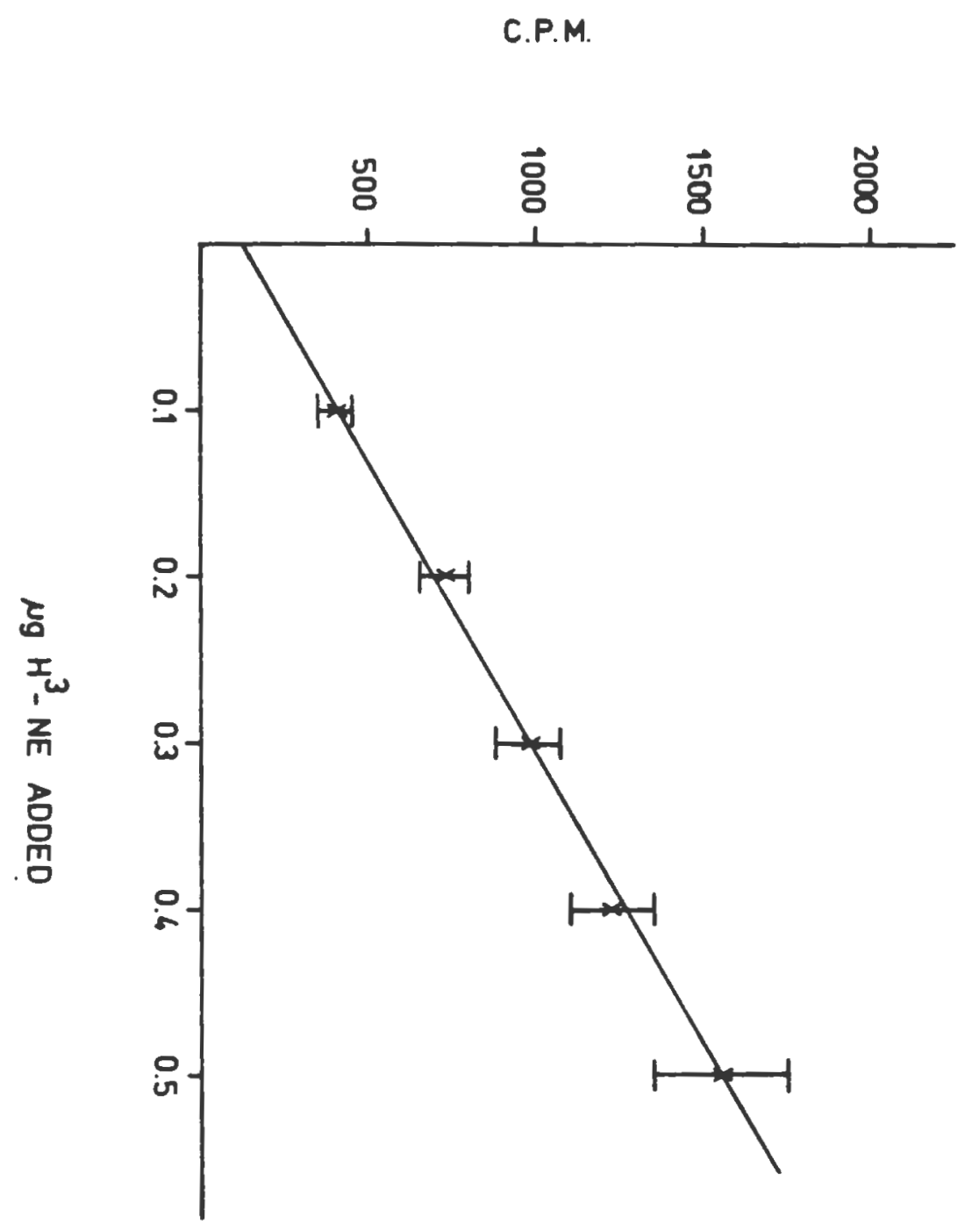


FIGURE 26

TITLE: Turnover of norepinephrine in the hypothalamus of rats treated with trilodothyronine ( $1 \mathrm{mg} / \mathrm{kg} / \mathrm{day}-7$ days) and their respective controls

LEGEND

Animals were administered alpha-methyl-para-tyrosine and were sacrificed $0,1,2,3,4.5$ and 6 hours after this MT administration. Turnover rates between these two groups, $I_{3}$ administered $(-x-)$ and saline administered $(-0-)$ were significantly different $(p<0.01)$ -

when turnover was measured between 0 time and 3 hours post MT administration. Triiodothyronine administered animals exhibitod decreased NE turnover when compared to respective saline administered animals. Each point represents the MEAN $\pm S . E$. for at least 5 experimental determinations. 


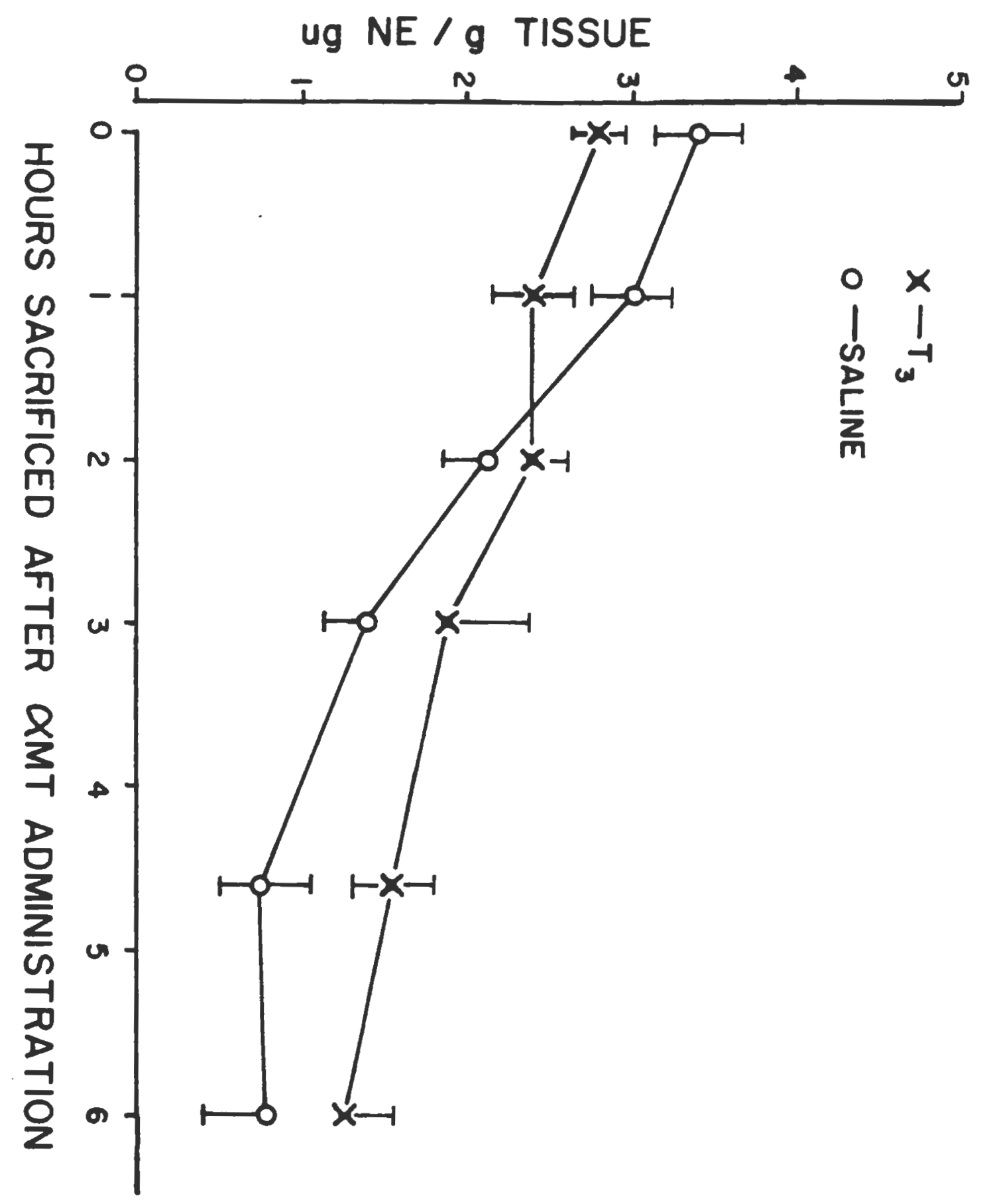


TISSUE

No MT

MEAN $\quad 1.2092$

S.D. 0.4222

S.E.M.

0.1493
Corpus Striatum

TIME (hours after MT administration)

$\begin{array}{lllll}2.0 & 3.0 & 4.5 & 6.0 & 9.0\end{array}$

$$
1.0
$$

$2.0 \quad 3.0$

4.5

9.0

0.8718

0.7349

0.3185

0.3520

0.2149

0.1574

0.1924

0.5460

0.1294

0.4164

0.1789

0.0528

0.0730

0.6189

0.2966

0.1212

Forebrain

$\begin{array}{llllllll}\text { MEAN } & 0.6734 & 0.3794 & 0.2831 & 0.2469 & 0.2310 & 0.2957 & 0.2648 \\ \text { S.D. } & 0.1123 & 0.0945 & 0.0783 & 0.0347 & 0.0562 & 0.2000 & 0.0774 \\ \text { S.E.M. } & 0.0397 & 0.0423 & 0.0350 & 0.0155 & 0.0230 & 0.0817 & 0.0316\end{array}$

Hypothalamus

$\begin{array}{llllllll}\text { MEAN } & 3.2560 & 2.5190 & 1.2864 & 1.3817 & 1.6773 & 2.0973 & 2.0818 \\ \text { S.D. } & 0.7005 & 0.5630 & 0.6429 & 0.5279 & 0.5145 & 0.6984 & 0.9936 \\ \text { S.E.H. } & 0.2477 & 0.2518 & 0.2875 & 0.2361 & 0.2100 & 0.2851 & 0.4057\end{array}$

$N=5$ to 8 animals for each detamination

8lope for hypothalamus $=-0.9848$

IInear regression coefficlent $\left(r^{2}\right)=0.9793$

- Lope for corpus striatum $=-0,2809$

$=0.9679$

slope for forebrain $=-0.1952$

$=0.9212$ 
TISSUE

No MT

Corpus Striatur

$\begin{array}{ll}\text { HEAN } & 1.0213 \\ \text { S.D } & 0.2135\end{array}$

S.E.M. $\quad 0.0755$

0.7702

0.3099

0.1265

0.5364

S.D. $\quad 0.1211$

S.E.H. 0.0428

0.3206

0.0401

0.0164

0.4189
0.0565

0.0253

0.5397
0.2082

0.0931

0.2106

0.0780

0.0318

0.2903

0.1577

0.0644

0.2442

0.1145

0.0467

\section{Hypothalamue}

$\begin{array}{llllllll}\text { HEAN } & 3.0530 & 2.2246 & 1.8903 & 1.9670 & 1.1626 & 1.0477 & 1.7161 \\ \text { S.D. } & 0.6856 & 0.8266 & 0.5722 & 0.5490 & 0.5518 & 0.7040 & 0.3216 \\ \text { S.E.H. } & 0.2424 & 0.3375 & 0.2336 & 0.2241 & 0.2253 & 0.2874 & 0.1313\end{array}$

$N=6$ for ach determination

slope for hypothalamus $=-0.3678$

IInear regression coefficient $\left(r^{2}\right)=0.8891$

- lope for corpus striatum $=-0.1875$

$=0.9631$

slope for forebrain $=-0.0728$
$=0.9909$ 
TABLE 45 Norepinephrine levels in three brain regions following a single acute administration of protriptyline or following 3 consecutive administrations of protriptyline. All animals were sacrificed 3 hours after the final protriptyline injection.

Brain Region

One Admin. (acute)

$$
\begin{aligned}
& \text { MEAN } \\
& \text { S.D. } \\
& \text { S.E.M. }
\end{aligned}
$$

Forebrain

Hypothalamus

$$
\begin{aligned}
& \text { Protriptyline Admin. } \\
& \text { animals }
\end{aligned}
$$

\begin{tabular}{|c|c|c|c|}
\hline \multirow[t]{2}{*}{ Corpus Striatum } & $\begin{array}{l}\text { MEAN } \\
\text { S.D. } \\
\text { S.E.H. }\end{array}$ & $\begin{array}{l}0.6682 \\
0.2106 \\
0.0860\end{array}$ & $\begin{array}{l}0.6862 \\
0.1803 \\
0.0901\end{array}$ \\
\hline & & $N=6$ & $N=5$ \\
\hline \multirow[t]{2}{*}{ Forebrain } & & $\begin{array}{l}0.3812 \\
0.0458 \\
0.0187\end{array}$ & $\begin{array}{l}0.3779 \\
0.1168 \\
0.0477\end{array}$ \\
\hline & & $y=6$ & $N=6$ \\
\hline \multirow[t]{2}{*}{ Hypotha lamus } & & $\begin{array}{l}2.8048 \star \\
0.0401 \\
0.0232\end{array}$ & $\begin{array}{l}2.8606 \\
0.7853 \\
0.3512\end{array}$ \\
\hline & & $N=3$ & $N=5$ \\
\hline
\end{tabular}

Saline Admin. animals

Three Adnin. (subchronic)

$\begin{array}{lcc}\text { MEAN } & 1.0008 & 0.9781 \\ \text { S.D. } & 0.3702 & 0.2845 \\ \text { S.E.M. } & 0.1511 & 0.1272 \\ & N=6 & N=5 \\ \text { Forebrain } & 0.4126 & 0.6490 \\ & 0.3056 & 0.2320 \\ & 0.1367 & 0.0947 \\ \text { Hypothalamus } & N=5 & N=6 \\ & & \\ & 3.3400 & 4.0169 \\ & 0.8197 & 1.5751 \\ & 0.3347 & 0.6430\end{array}$

- SIgnificantly lover than controls when $N=70$, however, the difference is not ignificantly lower than its paired saline control. Therefore this difference ay be due to injection stress, and may not really be a difference. 
TABLE 46 Norepinephrine levels in three brain regions following six consecutive injections of protriptyline or following 18 consecutive injections of protriptyline. All animals were acrificed 3 hours after the final protriptyline administration

Brain Region

Six Admin. (subchronic)

\section{Protriptyline Admin. animals}

Saline Admin. animals

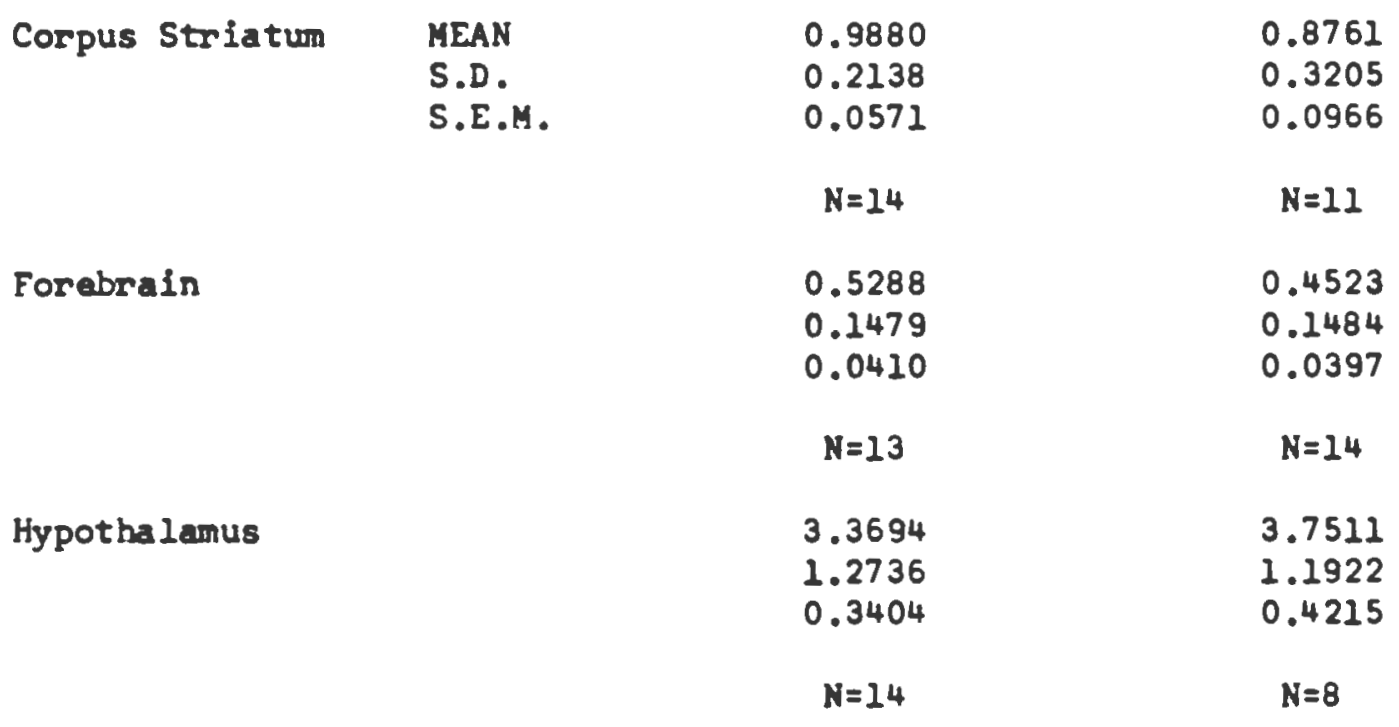

Eighteen Admin. (chronic)

\begin{tabular}{|c|c|c|c|}
\hline Corpus Striatum & $\begin{array}{l}\text { MEAN } \\
\text { S.D. } \\
\text { S.E.M. }\end{array}$ & $\begin{array}{l}0.7129 \\
0.3278 \\
0.1037\end{array}$ & $\begin{array}{l}1.0129 \\
0.4671 \\
0.1408\end{array}$ \\
\hline & & $N=10$ & $N=I I$ \\
\hline Forebrain & & $\begin{array}{l}0.3722 \\
0.1022 \\
0.0295\end{array}$ & $\begin{array}{l}0.4114 \\
0.1515 \\
0.0437\end{array}$ \\
\hline & & $N=12$ & $N=12$ \\
\hline Hypothalamus & & $\begin{array}{l}2.5661 \\
0.7011 \\
0.2124\end{array}$ & $\begin{array}{l}3.5061 * \\
1.0071 \\
0.3560\end{array}$ \\
\hline & & $N=11$ & $\mathbf{N}=8$ \\
\hline
\end{tabular}

•Difference from protriptyline adninistered $(p<0.01)$ 
TABLE 47 Norepinephrine depletion in acutely administered protriptyline aninals

HYPOTHALAMUS

No Mr Admin.

MEAN
S.D.
S.E.H.

MEAN

S.D.

S.E.M.

Howrs after MT

Administration

1.0

3.0

2.0

$N=6$

3.0440

0.5972

0.2671

$N=5$

2.3917

0.3514

0.1435

$N=6$

4.5

2.5867

0.4275

0.1745

$N=6$

6.0

2.0500

0.2868

0.1283

$N=5$ 
TABLE 48 Norepinephrine depletion in protriptyline treated animals $(10 \mathrm{mg} / \mathrm{kg} /$ day -6 days - S.C. $)$ and then administered MT 6 hours after their final protriptyline injection. These animals were then sacrificed at various time intervals after MT administration.

TIME after MT administration

No a lpha-M-P-tyrosine

1 hour

2 hours

3 hours
NE levels

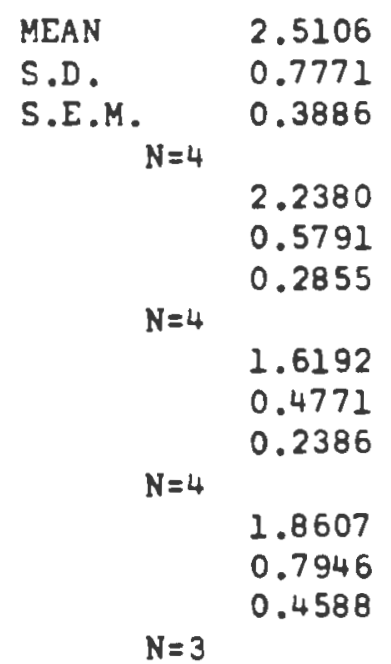

$$
\begin{aligned}
& \text { slope }=-0.2471 \\
& \left(r^{2}\right)=0.8449
\end{aligned}
$$


TABLE 49 Norepinephrine levels in three brain areas of thyroidectomized rets and Shan-operated controls following 3 and 6 consecutive days of protriptyline administration. Animaks wore eacrificed 12 hours after the final protriptyline administration

Three days of

Prot. Admin.

Thyroidectomized Rats

Shaw-operated

Controls

Six days of

Prot. Admin.

Thyroidectomized

Rats

MEAN

S.D.

S.E.M.

Sham-operated

Controls

\section{Corpus Striatum Eorebrain Hypothalamus}

$\begin{array}{lccc}\text { MEAN } & 0.8411 & 0.5842 & 3.3131 \\ \text { S.D. } & 0.5734 & 0.2318 & 0.4941 \\ \text { S.E.K. } & 0.2341 & 0.0946 & 0.2017 \\ & N=8 . & N=6 & N=6 \\ & & & \\ & 0.0659 & 0.4851 & 3.2305 \\ 0.5222 & 0.1296 & 0.7209 \\ & 0.2132 & 0.0529 & 0.2943 \\ & N=5 & N=6 & N=6\end{array}$

0.7979

0.5909

2.6163

0.6866

0.2803

0.1449

0.0456

$N=6$

$N=6$

$N=6$

0.5798

0.4740

2.8174

0.2277

0.1230

1.2590

0.1018

0.0502

0.5140

$Y=6$

$N=6$

$N=6$ 
TABLE 50 Norepinephrine levels in three brain areas of thyroldectomized rats and Shan-operated controls following 12 and 18 consecutive days of protriptyline administration. Animals were sacrificed 12 hours after the final protriptyline injection

Twelve days of Prot. Admin.

Thyroidectomized Rats

Sham-operated Controls

\section{Eighteen days} of Prot. Admin.
MEAN

S.D.

S.E.H.

Corpus Striatur Forebrain Hypothalamus

0.9537 *

0.3722

0.1520

$N=6$

1.4290

0.3715

0.1661

$N=8$

0.4887 *

0.1717

0.0701

$N=5$

0.7275

0.1988

0.0811

$N=6$
0.4708

0.1085

0.0485

$N=6$

0.4608

0.0779

0.0332

$N=6$

0.6672

0.2064

0.0843

$N=6$

0.5591

0.1538

0.0626

$N=6$
$N=6$

3.0393

0.3806

0.1702

$N=6$

3.8033

0.8986

0.3668

$N=5$

2.9943

1.1603

0.4737

$N=6$

2.9770

0.2848

0.1163

*Statistically different from Control $\mathrm{p}<0.01$ 
IABLE 51 Alpha-methyl-para-tyrosine dose response curye in animals which have received protriptyline chronically (18 days, $10 \mathrm{mg} / \mathrm{kg} /$ day) in the hypothalamus

Dose of MT

No MT

$200 \mathrm{mg} / \mathrm{kg}$

$400 \mathrm{mg} / \mathrm{kg}$

$600 \mathrm{mg} / \mathrm{kg}$

$800 \mathrm{mg} / \mathrm{kg}$
MEAN

S.D.

S.E.M.

MEAN

S.D.

S.E.M.

MEAN

S.D.

S.E.M.

MEAN

S.D.

S.E.M.

MEAN

S.D.

S.E.M.
Hypothalaimus

2.5590

1.0676

0.2387

$\mathrm{N}=\mathbf{2 0}$

2.2408

0.6440

0.2880

$N=5$

2.0801

0.9180

0.2546

$N=13$

2.1090

1.5431

0.6299

$N=6$

2.1039

0.6098

0.3049

$N=4$ 
TABLE 52 Alpha-methyl-para-tyrosine depletion curve in animals receiving 18 days chronic protriptyline administration (10 mg/kg/day)

\section{TISSUE}

0 Time

No MT

Corpus Striatum

MEAN 0.6521

S.D. $\quad 0.1699$

S.E.M. $\quad 0.0850$

0.1659

0.0742

0.7868

0.2212

0.1106

$N=5$

$N=4$

0.3351
0.0785
0.0351

0.2564

0.0606

0.0271

0.2250

0.0648

0.0324

$N=5$

$N=5$

1.9041

0.5598

2.4572

0.4616

S.D.

2.4008

0.6864

S.E.M. $\quad 0.3432$

0.2665

0.2503

$N=3$

$N=5$

1.8610
0.5120
0.2560

1.4058

0.4701

0.2102

$N=4$

$N=5$
$N=4$

$N=4$

$$
N=3
$$

$N=3$

$N=5$

*Alpha-methyl-para-tyrosine was administered 3 hours after the final protriptyline injection. Corpus Striatum slope $=-0.0464$ Forebrain slope $=-0.0113$ Hypothalanus slope $=-0.1897$ linear 
TABLE 53 Norepinephrine depletion in hypothalamus following administration of yohimbine, in control (saline administered) animals

Dosage of Yohimbine

\section{- Tina} (No Yonimbine)

$2.0 \mathrm{mg} / \mathrm{kg}$

MEAN
S.D.

S.D.

3.3099

0.5918

0.2416

$K=6$

$20.0 \mathrm{gg} / \mathrm{kg}$
TIME (hours after Yohimbine administration)

1 hour

2.5 hours

5.0 hours

2.6988

0.4708

0.2106

3.5365

0.8431

0.3770

3.8163

1.8294

0.8181

$\mathrm{N}=5$

$N=5$

$N=5$

$\begin{array}{lcc}1.6829 & 1.4616 & 2.6973 \\ 0.5312 & 0.7125 & 1.1293 \\ 0.2656 & 0.4114 & 0.5646 \\ N=4 & N=4 & N=4\end{array}$


TABLE 54 Norepinephrine tarnover in animals receiving saline, followed by yohimbine $(20 \mathrm{gg} / \mathrm{kg}$ ) followed by alpha-aethyl-para-tyrosine (400 $\mathrm{mg} / \mathrm{kg}$ )

\begin{tabular}{|c|c|c|}
\hline & & Hypothalamus \\
\hline Controls (saline only) & $\begin{array}{l}\text { MEAK } \\
\text { S.D. } \\
\text { S.E.H. }\end{array}$ & $\begin{array}{c}2.9968 \\
0.5840 \\
0.2920 \\
N=4\end{array}$ \\
\hline $\begin{array}{l}1 \text { hour after Yohimbine } \\
\text { admin. }\end{array}$ & & $\begin{array}{l}1.9212 \\
0.4589 \\
0.2294 \\
N=4\end{array}$ \\
\hline $\begin{array}{l}1 \text { hour after MT, } 2 \text { hours } \\
\text { after Yohimbine }\end{array}$ & & $\begin{array}{c}1.0348 \\
0.1929 \\
0.0965 \\
N=4\end{array}$ \\
\hline $\begin{array}{l}2 \text { hours after MT, } 3 \text { hours } \\
\text { after Yohimbine }\end{array}$ & & $\begin{array}{l}0.9750 \\
0.1249 \\
0.0559 \\
N=4\end{array}$ \\
\hline $\begin{array}{l}3 \text { hours after } M T, 4 \text { hours } \\
\text { after Yohimbine }\end{array}$ & & $\begin{array}{c}0.8724 \\
0.2391 \\
0.1069 \\
N=4\end{array}$ \\
\hline $\begin{array}{l}4.5 \text { hours after MT, } 5.5 \text { hours } \\
\text { after Yohimbine }\end{array}$ & & $\begin{array}{c}0.9404 \\
0.2593 \\
0.1297 \\
N=4\end{array}$ \\
\hline $\begin{array}{l}6 \text { hours after } \mathrm{MT}, 7 \text { hours } \\
\text { after Yohinbine }\end{array}$ & & $\begin{array}{l}1.0261 \\
0.3847 \\
0.1924 \\
N=4\end{array}$ \\
\hline
\end{tabular}


TABLE 55 Norepinephrine depletion in hypothalamus of chronically protriptyline administered animals following johinblne administration $(20 \mathrm{gg} / \mathrm{kg})$. Anluals were adninistered yohimbine 3 hours after the final protriptyline injection

Hypothalamus

18 days Prot. admin., no Yohimbine

18 days Prot., sacrificed 5 infinutes after Yohimbine

18 days Prot., sacrificed 1 hour after Yohimbine

18 days Prot., sacrificed 3 hours after Yohimbine
MEAN

S.D.

S.E.M.

2.9131

0.5240

0.2620

$N=4$

2.8602

0.4089

0.1828

$N=4$

2.6571

2.0500

1.0250

$N=4$

2.9131

0.5240

0.2620

$N=4$ 
IABLE 56 Norepinephrine turnover in hypothalamus of chronic protriptyline administered rate, followed by yohinbine administration ( $20 \mathrm{mg} /$ $\mathrm{kg}$ ) followed by alpha $\times \mathrm{M}-\mathrm{p}$-tyrosine administration $(400 \mathrm{mg} / \mathrm{kg})$. Animals recelved yohimbine 3 hours after their protriptyline infection, and received alpha-M-p-tyrosine, 1 hour after the yohimbine injection

Hypothalamus

18 days Prot. admin.

MEAN

2.9131

S.D.

0.5240

S.E.H.

0.2620

$N=4$

18 days Prot., 5 minutes

2.8602

after Yohimbine

0.4089

0.1828

$N=5$

18 days Prot., 1 hour

2.6571

after Yohimbine, 5 minutes

2.0500

after MT

1.0250

$\mathrm{N}=4$

18 days Prot., 2 hours

1.7741

efter Yohimbine, 1 hour

0.7365

after MT

0.4252

$N=4$

18 days Prot. 3 hours

1.6614

after Yohinblne, 2 hours

0.3737

after MT

0.1868

$\mathrm{N}=4$

18 dags Prot., 4 hours

1.6025

after Yohimbine, 3 hours

0.3163

after MT

0.1581

$N=4$ 
TABLE 57 Comparison of turnover rates, level of statistical significance, slope and linear regression coefficients in both saline and protriptyline treated animals.

\begin{tabular}{|c|c|c|c|c|}
\hline COHPARISON & slope & $\left(r^{2}\right)$ & Probability & $\begin{array}{l}\text { Group with } \\
\text { decreased } \\
\text { turnover }\end{array}$ \\
\hline $\begin{array}{l}\text { acute prot. }\left(6^{\prime}\right) \text { vs. } \\
6 \text { day prot. }\left(6^{\prime}\right)\end{array}$ & $\begin{array}{l}-0.1130 \\
-0.2740\end{array}$ & $\begin{array}{l}0.1183 \\
0.2003\end{array}$ & 0.6411 N.S. & -------- \\
\hline $\begin{array}{l}\text { acute prot. (6') vs. } \\
18 \text { day prot. (6') }\end{array}$ & $\begin{array}{l}-0.1130 \\
-0.2903\end{array}$ & $\begin{array}{l}0.1183 \\
0.3397\end{array}$ & 0.7363 N.S. & 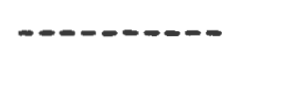 \\
\hline $\begin{array}{l}\left.6 \text { day prot. ( } 6^{\prime}\right) \text { vs. } \\
\left.18 \text { day prot. ( } 6^{\prime}\right)\end{array}$ & $\begin{array}{l}-0.2740 \\
-0.2903\end{array}$ & $\begin{array}{l}0.2003 \\
0.3397\end{array}$ & 0.0549 N.S. & $-\ldots-\ldots-\infty$ \\
\hline $\begin{array}{l}\left.\text { acute prot. ( } 24^{\prime}\right) \text { vs. } \\
\left.18 \text { day prot. ( } 24^{\prime}\right)\end{array}$ & $\begin{array}{l}-0.5423 \\
-0.1834\end{array}$ & $\begin{array}{l}0.4513 \\
0.2035\end{array}$ & $0.9234 \mathrm{~N} . \mathrm{S}$. & $-\cdots-\ldots-n$ \\
\hline $\begin{array}{c}\left.\text { acute prot. ( } 24^{\prime}\right) \text { vs. } \\
6 \text { day prot. }\left(24^{\prime}\right)\end{array}$ & $\begin{array}{l}-0.5423 \\
-0.2791\end{array}$ & $\begin{array}{l}0.4513 \\
0.8219\end{array}$ & 0.8405 N.S. & $-\cdots-\cdots$ \\
\hline $\begin{array}{l}\left.\text { acute prot. ( } 3^{\prime}\right) \text { vs. } \\
18 \text { day prot. ( } \\
\left.13^{\prime}\right)\end{array}$ & $\begin{array}{l}-0.1402 \\
-0.2344\end{array}$ & $\begin{array}{l}0.1992 \\
0.3427\end{array}$ & $0.6061 \mathrm{~N} . \mathrm{S}$. & $-\cdots+-\infty-\infty$ \\
\hline $\begin{array}{l}\text { acute saline (6') vs. } \\
\text { acute prot. (6') }\end{array}$ & $\begin{array}{l}-0.6776 \\
-0.1130\end{array}$ & $\begin{array}{l}0.6881 \\
0.1132\end{array}$ & P. $<0.01$ & Acute Prot. \\
\hline $\begin{array}{l}6 \text { day saline }\left(6^{\prime}\right) \text { vs. } \\
6 \text { day prot. }\left(6^{\prime}\right)\end{array}$ & $\begin{array}{l}-0.5324 \\
-0.2740\end{array}$ & $\begin{array}{l}0.7393 \\
0.2003\end{array}$ & 0.7219 N.S. & $\ldots \ldots \ldots$ \\
\hline $\begin{array}{l}\left.18 \text { day prot. ( } 6^{\prime}\right) \text { vs. } \\
\left.18 \text { day saline ( } 6^{\prime}\right)\end{array}$ & $\begin{array}{l}-0.2903 \\
-0.6138\end{array}$ & $\begin{array}{l}0.3397 \\
0.3163\end{array}$ & 0.6862 N.S. & $-\cdots----$ \\
\hline $\begin{array}{l}\text { acute saline }\left(3^{\prime}\right) \text { vs. } \\
\left.\text { acute prot. ( } 3^{\prime}\right)\end{array}$ & $\begin{array}{l}-0.6023 \\
-0.1402\end{array}$ & $\begin{array}{l}0.7283 \\
0.1992\end{array}$ & $P<0.005$ & Acute Prot. \\
\hline $\begin{array}{l}\left.\text { acute saline ( } 3^{\prime}\right) \text { vs. } \\
18 \text { day prot. ( }\end{array}$ & $\begin{array}{l}-0.6023 \\
-0.2344\end{array}$ & $\begin{array}{l}0.7283 \\
0.3427\end{array}$ & $P<0.05$ & Chronic Prot. \\
\hline $\begin{array}{l}18 \text { day saline }\left(24^{\prime}\right) \text { vs. } \\
18 \text { day prot. }\left(24^{\prime}\right)\end{array}$ & $\begin{array}{l}-0.6243 \\
-0.1834\end{array}$ & $\begin{array}{l}0.6699 \\
0.2035\end{array}$ & $P<0.05$ & Chronic Prot. \\
\hline $\begin{array}{l}6 \text { day prot. }\left(24^{\prime}\right) \text { vs. } \\
\left.18 \text { day prot. ( } 24^{\prime}\right)\end{array}$ & $\begin{array}{l}-0.2791 \\
-0.1834\end{array}$ & $\begin{array}{l}0.8219 \\
0.2035\end{array}$ & 0.6095 N.S. & 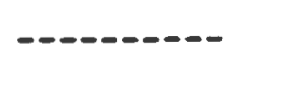 \\
\hline
\end{tabular}


TABLE 58 A statistical comparison ( $t$-test) for slope of NE depletion curves following alpha-methyl-para-tyrosine administration

Comparison

saline controls v8. acute protriptyline

saline controls vs.

$T_{3}$ admin. (7 days)

saline controls is.

chronic Prot. (18 days)

thyroidectonized $\mathbf{v 8}$. Sham-operated controls

thyroidectomized $\mathbf{8}$.

$\mathrm{T}_{3}$ admin. ( 7 days)

thysoidectomized $v 8$. acute Prot.

thyroidectomized $v 8$. chronic Prot.
Statistical Results

$p<0.005$

$p<0.025$

$p<0.005$

$p<0.05$

$p<0.01$

$P<0.005$

$p<0.005$
$I_{3}$

Prot.

These groups have decreased turnover

acute prot.

$T_{3}$

Prot.

Sham

Prot. 